154

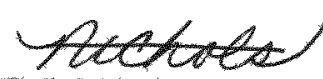

SMPO.C recordo

Subcontract NP-1

WANL - TME - 1954

September 19,1969

Westinghouse Astronuclear Laboratory

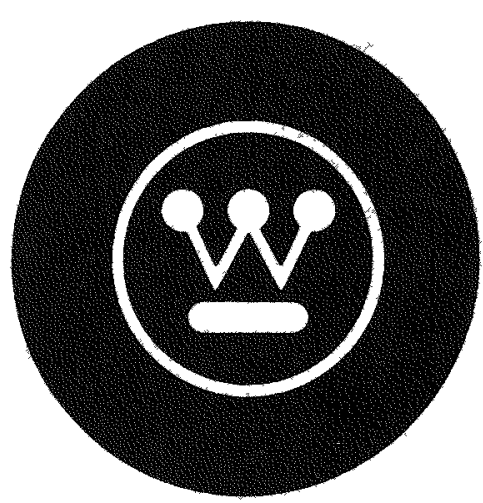

\title{
XE-1 CONTROL DRUM \\ PNEUMATIC ACTUATOR
}

QUALIFICATION TEST REPORT

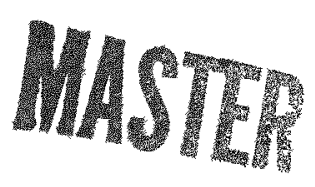




\section{DISCLAIMER}

This report was prepared as an account of work sponsored by an agency of the United States Government. Neither the United States Government nor any agency Thereof, nor any of their employees, makes any warranty, express or implied, or assumes any legal liability or responsibility for the accuracy, completeness, or usefulness of any information, apparatus, product, or process disclosed, or represents that its use would not infringe privately owned rights. Reference herein to any specific commercial product, process, or service by trade name, trademark, manufacturer, or otherwise does not necessarily constitute or imply its endorsement, recommendation, or favoring by the United States Government or any agency thereof. The views and opinions of authors expressed herein do not necessarily state or reflect those of the United States Government or any agency thereof. 


\section{DISCLAIMER}

Portions of this document may be illegible in electronic image products. Images are produced from the best available original document. 


\section{Westinghouse Astronuclear Laboratory}

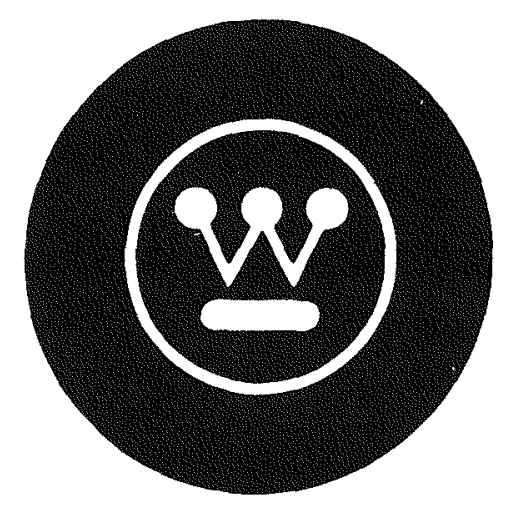

\section{XE-1 CONTROL DRUM \\ PNEUMATIC ACTUATOR}

QUALIFICATION TEST REPORT

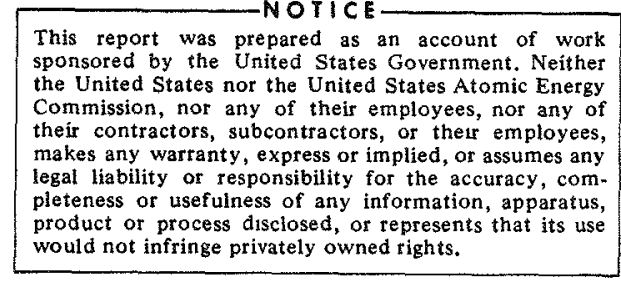

Approyed:

Norkenak

J.G. Galldgher

Manager, NERVA Design

Engineering Manager

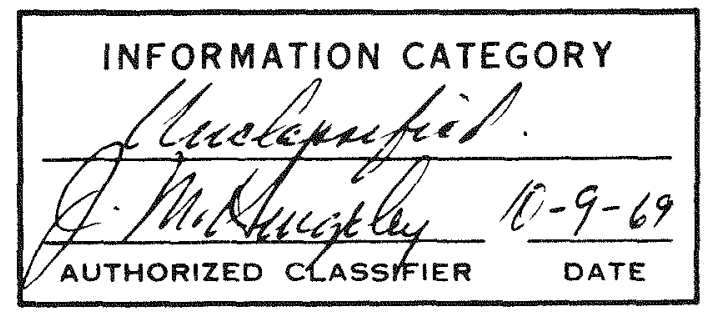




\section{ACKNOWLEDGEMENTS}

AUTHOR:

REVIEWED BY:

\author{
g. 2. Wurhe \\ J. L. Burke \\ Actuator Design
}

Rl. Clarth

R. A. Clark, Jr.

Manager

Actuator Design 


\section{(QV) Astronuclear

\section{ABSTRACT}

An XE pneumatic control drum actuator, specifically of the XE-1 build, has been subjected to a complete series of environmental tests specified in WANL-TME-1040, Revision A, "Qualification Specifications for Control Drum Pneumatic Actuators for XE Applications". The tests were performed under T-711892, "Qualification Test, Environmental, Control Drum Actuator". These tests were to determine the actuator's capability to operate in the XE environment and to provide input to future NERVA design. A series of formal dynamic and static tests was conducted in environments of vibration; mechanical shock; low temperature and thermal shock; and combined low temperature and vibration. An operating life test was also performed. At the successful conclusion of the above series of tests, a disassembly and inspection of the test actuator gave no indication of wear or damage; therefore, an extended life test to failure was conducted on the same actuator mechanism to provide further information to follow-on programs. The test results were examined and evaluated to determine potential effect on subsystem ability to meet performance requirements. The few anomalies were the result of an overambitious set of limits and in all cases performance was adequate to meet performance requirements.

In addition to the formal life test on this XE-1 unit, the results of the A-6 pneumatic actuator side-by-side radiation test are included in this report. Successful operation during this test and subsequent disassembly and inspection proved conclusively the ability of this design to function successfully in a radiation field. A secondary result of this test was to prove the adequacy of the design cooling to remove gamma generated heat. 
PAGE BLANK

iv 


\section{TABLE OF CONTENTS}

Section

1.0

2.0

3.0

4.0

5.0

6.0

7.0

8.0

9.0

10.0
Pneumatic Actuator System

Description of Actuator Preformance Test Procedure

Vibration Test

Mechanical Shock Test

Low Temperature Test

Life Test

Combined Low Temperature and Vibration Test

Actuator Disassembly and Inspection

Extended Life Test

NRX-A6 Pneumatic Actuator Side-by-Side Experiment

\section{APPENDIXES}

A. Qualification Specifications for Control Drum Pneumatic Actuators for XE-1 Application (WANL-TME-1040, Rev. A)

B. Qualification Test, Environmental XE-1 Control Drum Actuator (T-711892 A, B, C \& D)
Page

$1-1$

2-1

$3-1$

$4-1$

$5-1$

6-1

7-1

8-1

9-1

10-1 
PAGE BLANK

vi 


\section{LIST OF ILLUSTRATIONS}

Closed Loop Frequency Response - After Vibration in

3-13 Closed Loop Frequency Response - After Vibration in $a_{x}$ $a_{y}$ Direction 


\section{LIST OF ILLUSTRATIONS (Continued)}

$\underline{\text { Figure }}$

Page

4-5

Closed Loop Frequency Response - After Shocks in $a_{x}$ Direction

$4-8$

4-6

Closed Loop Frequency Response - After Shocks in $a_{y}$ Direction

4-9

4-7

Closed Loop Frequency Response - After Shocks in $a_{z}$ Direction

$4-10$

5-1

Gas Supply System for Low Temperature Test

5-3

$5-2$

Thermal Cycle No. 1 Temperature vs. Time Curve

Thermal Cycle No. 2 Temperature vs. Time Curve

Thermal Cycle No. 3 Temperature vs. Time Curve

Table of Low Temperature Test Data

Closed Loop Frequency Response - Base Line Data Thermal Cycle No. 1

5-7 Closed Loop Frequency Response - During Thermal Cycle No. 1

5-8 Closed Loop Frequency Response - Base Line Data Thermal Cycles No. 2 and 3

5-9 Closed Loop Frequency Response - During Thermal

Cylce No. 2

5-10 Closed Loop Frequency Response - During Thermal Cycle No. $3 A$

5-11 Closed Loop Frequency Response - During Thermal Cycle No. $3 B$

Life Test Command Cycle

Table of Life Test Data

Closed Loop Frequency Response - Base Line Data

Closed Loop Frequency Response - After 25 Hours 


\section{LIST OF ILLUSTRATIONS (Continued)}

Figure

$6-8$

6-9

7-1

$7-2$

$7-3$

$7-4$

$7-5$

7-6

$7-7$

$7-8$

$7-9$

$7-10$

$7-11$

8-1

8-2

$8-3$

$8-4$

8-5

8-6

$8-7$

8-8

$8-9$

8-10

8-11

$8-12$

Closed Loop Frequency Response - After 125 Hours

Low Temperature and Vibration Test Setup - Vibration Equipment

Low Temperature and Vibration Test Setup - Recording Equipment

Test Actuator and Load Stand

$7-5$

Test Actuator and Load Stand

$7-6$

Test Actuator with Heat Shield Cover Installed

Test Actuator with Heat Shield Cover Removed

Vibration Input Levels

7-9

Command Input Sequence

Table of Combined Low Temperature and Vibration Test

Data

Closed Loop Frequency Response - Base Line Data

Closed Loop Frequency Response - After Test

Drive Shaft and Pinion Gear - Lower End

Drive Shaft and Pinion Gear - Upper End

8-3

Soft Stop Spring

Rack and Piston

8-5

Piston Coupling Yoke

8-6

Lock Pin and Solenoid Valve

8-7

Lock Pin Cam

Lock Pin Cam

Cylinder Cover No. 1 


\section{LIST OF ILLUSTRATIONS (Continued)}

Figure

Page

$8-13$

Average Breakaway Friction

8-15

8-14 Servovalve $-P_{1}$ Flapper and $P_{2}$ Bellows

8-16

9-1

Extended Life Test Setup

$9-2$

9-2

Lock Pin

$9-5$

9-3

Lock Pin Cylinder

$9-6$

$9-4$

Lock Pin Cam

9-7

$9-5$

Drive Shaft and Pinion Gear

9-9

9-6

Drive Shaft - Upper End

9-10

9-7

Soft Stop Spring

9-11

9-8

Rack and Piston

$9-12$

9-9

Rack Backup Bearing

$9-13$

$9-10$

Piston Coupling Yoke

9-14

9-11

Piston and Cylinder No. 1

$9-15$

$9-12$

Cylinder Cover No. 1

$9-16$

$9-13$

Piston and Cylinder No. 2

$9-17$

$9-14$

Cylinder Cover No. 2

$9-18$

$9-15$

Actuator Housing - Internal Walls

9-19

$9-16$

Lower Drive Shaft Bearing

9-21

$9-17$

Table of Test Data

Closed Loop Frequency Response - Base Line Data

$9-23$

$9-19$

Closed Loop Frequency Response - After 1990 Hours

9-24

$9-20$

Closed Loop Frequency Response - After 2491 Hours

$9-25$

9-21

Closed Loop Frequency Response - After 3211 Hours

$9-26$

$10-1$

Block Diagram of Test Setup

$10-2$

$10-2$

Side-by-Side Actuator Test Actuator Position Diagram

$10-3$

10-3

Actuator, Pedestal and Load

$10-4$

$10-4$

Text Fixture Assembly

$10-5$ 


\section{LIST OF ILLUSTRATIONS (Continued)}

Figure

$10-5$

$10-6$

$10-7$

$10-8$

$10-9$

$10-10$

$10-11$

$10-12$

$10-13$

$10-14$

$10-15$
NRX-A6 Side-by-Side Actuator Test Fixture

Test Fixture Mounted on Test Car

NRX-A6 Side-by-Side Actuator Test Closed Frequency

Response

NRX-A6 Side-by-Side Actuator Test Full Power Run

Gamma Dose

Fast Neutron Flux

Slow Neutron Flux

Site Photo, Torque Motor

Site Photo, Lock Indicarion Switches

Three Deck Potentiometer

Site Photo, Pistons and Rack
Page

10-6

10-7

10-11

$10-12$

$10-14$

10-15

10-16

10-17

10-18

10-19

10-20 


\subsection{PNEUMATIC ACTUATOR SYSTEM}

\subsection{DESCRIPTION}

In this section the XE-1 pneumatic control drum actuator is described. This actuator is the type used throughout the tests covered by this report. Figure 1.1 is a cutaway drawing of the XE-1 actuator. The actuator can be broken into five system assemblies:

1. Servovalve Assembly.

2. Drive Train

3. Feedback Potentiometer

4. Lock Assembly

5. Housing Enclosure

\subsection{SERVOVALVE ASSEMBLY}

The servovalve assembly serves as the interface between the electrical control signal and pneumatic pressure. It consists of a torquemotor, manifold, flapper valves, and bellows. A schematic diagram is shown in Figure 1.2. The torquemotor contains a balanced permanent magnet field and wound field coils. In its de-energized state the flux from the field magnets is equally distributed through both sides of a pivoted armature. The armature is maintained in its center position by a centering spring and by the spring gradient of the bellows. An electrical current in the field coils causes an imbalance of flux in the armature and the armature pivots against the combined spring gradients.

Each end of the armature contains a flapper valve. The flapper valves act to vent the piston cylinders into the exhaust chamber and they operate in push-pull fashion so that an increased exhaust flow in one valve corresponds to a reduced exhaust flow in the other. The piston cylinders are supplied with drive gas through fixed orifices. The net effect of armature motion is a change in the relative pressures on both pistons. The bellows bear upon the armature and are pressurized by the piston pressures through porus orifices to provide a positive pressure feedback to the armature. The feedback gives the valve the low frequency characteristics of an integrator. 


\section{(18)

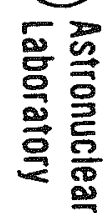

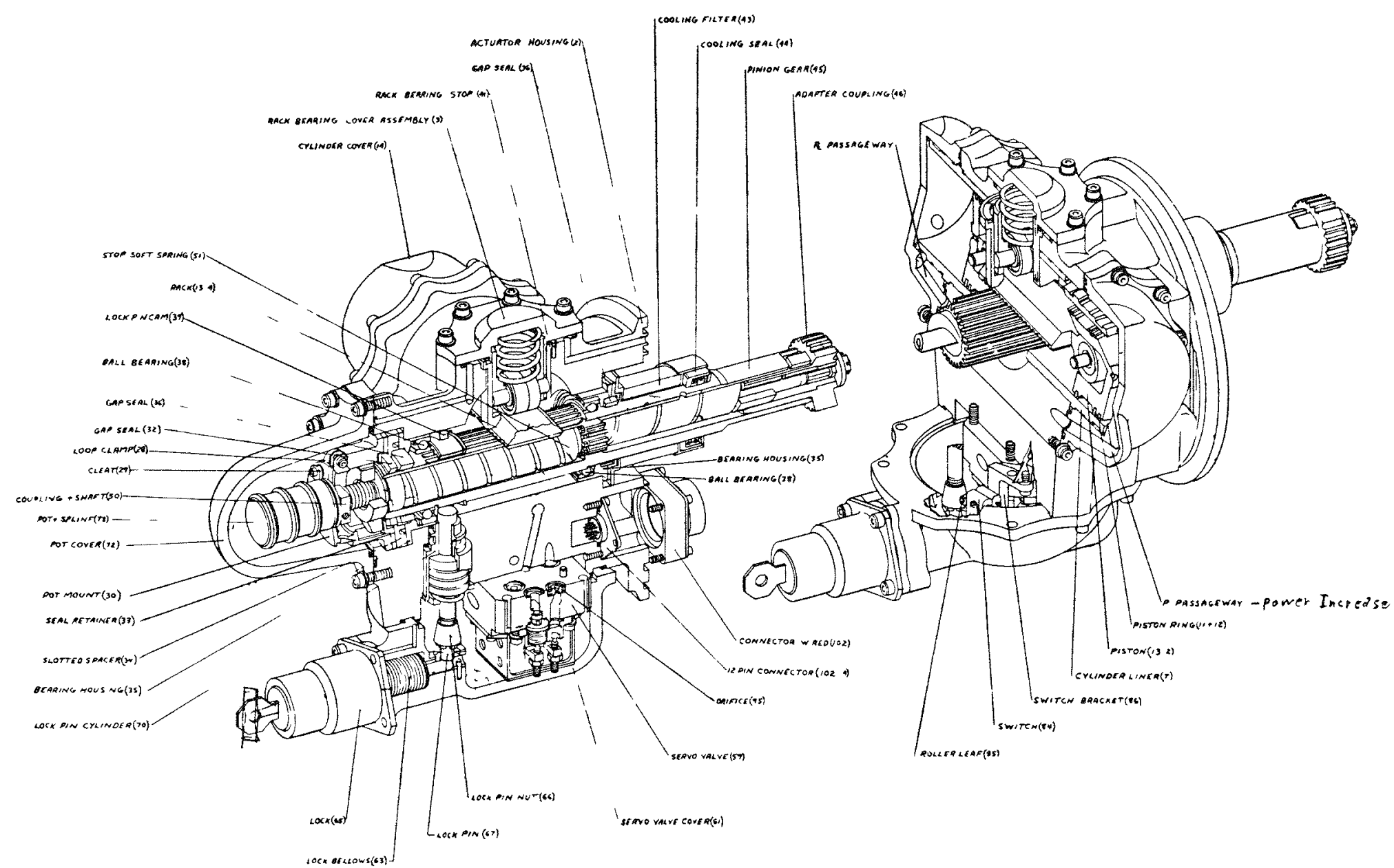

Figure 1. 1. Control Drum Pneumatic Actuator - XE Type 


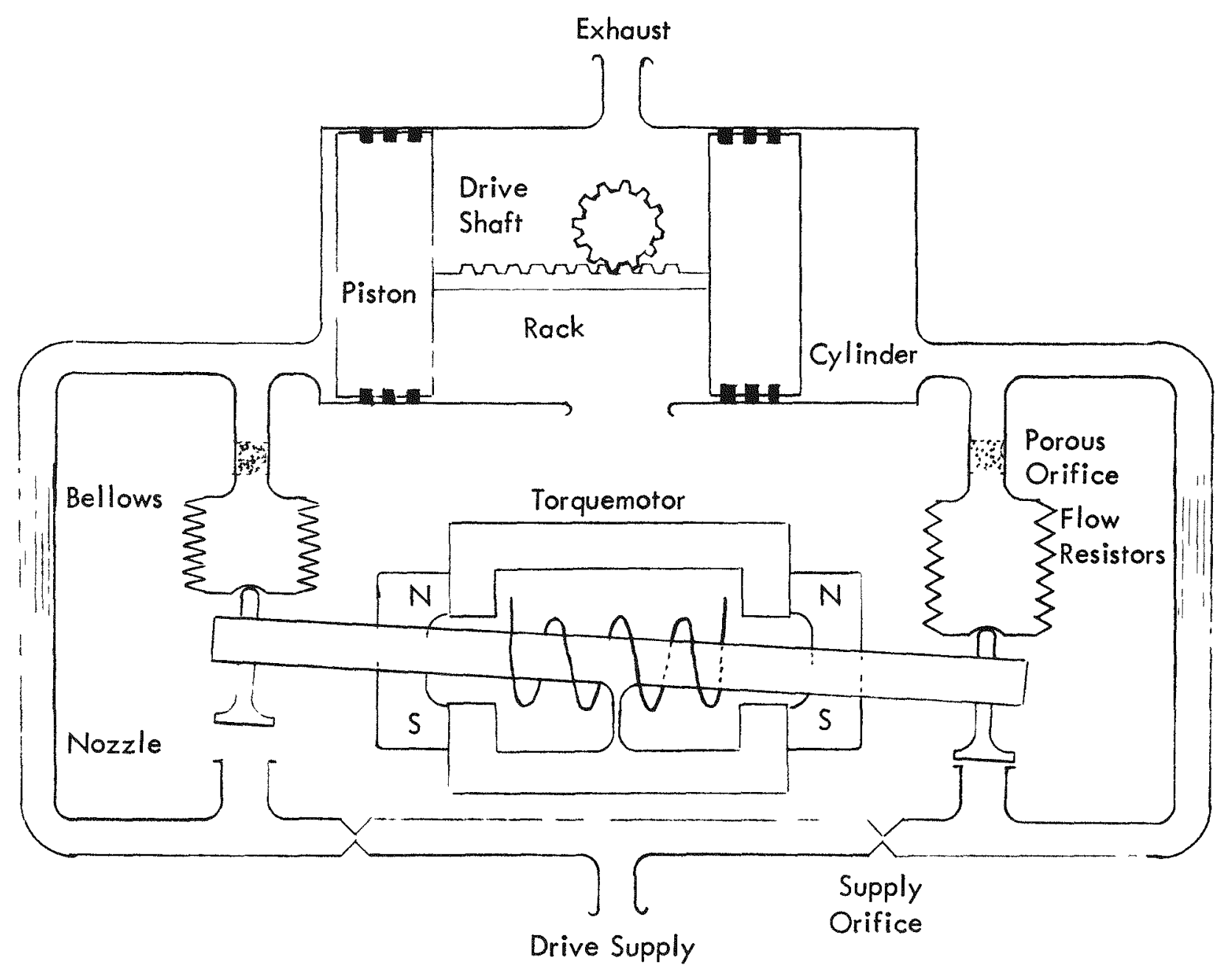

Figure 1.2 XE Actuator Schematic 


\subsection{DRIVE TRAIN}

The drive train consists of the pistons, rack, pinion gear, drive shaft, soft stop spring, rebound spring, lock cam, adapter coupling, and upper and lower drive shaft bearings. The pistons are operated in opposition and are separated by the rack. A difference in piston pressure generated by the servovalve causes a force on the rack which is transmitted to the pinion gear by the enmeshed gear teeth. The pinion gear is an integral part of the drive shaft and a torque is thus generated in the drive shaft. This torque is then transmitted to the output spline and thence to the control drum. The soft stop spring limits drive shaft travel to an angle less than $180^{\circ}$. It is disengaged for positions between $15^{\circ}$ and $165^{\circ}$ and its gradient is such that the maximum actuator forque will deflect it $\pm 7.5^{\circ}$.

\subsection{FEEDBACK POTENTIOMETER}

Located coaxially with the drive shaft is the potentiometer coupling shaft. This shaft rotates the wipers of the three-deck feedback potentiometer. The potentiometer is able to monitor drive shaft position and hence the control drum position. The three-deck provides redundancy to maintain the necessary reliability of the actuator system.

\section{5 LOCK ASSEMBLY}

In addition to the preload of the scram spring, mounted on the control drums, a lock assembly is included in the actuator to prevent inadvertent control drum roll-out. The lock assembly consists of a manual lock, lock pin, solenoid valve, and limit switches. When energized electrically the solenoid valve ports drive gas pressure to the lock pin cylinder. This pressure raises the spring loaded lock pin, provided the manual lock is disengaged. The lock pin clears the lock cam and allows the drive shaft to rotate unimpeded. The limit switches are actuated by the lock pin and give an indication when the lock pin is in either the full in or out position.

\subsection{HOUSING ENCLOSURE}

The actuator system assemblies are mounted within the housing enclosure. The base of the housing forms the interface with the actuator pedestal. Through this interface passes the coolant and drive gases, the drive shaft, the electrical connector, and $P_{1}$ and $P_{2}$ instrumentation ports. The housing is mounted on the pedestal by means of a marmon clamp and 
is sealed from gas leaks by the use of lead coated apex seals. Apex seals are used throughout the actuator. The housing provides porting for the pneumatic drive system and also allows coolant gas to circulate around the actuator components. The flow of coolant is from the pedestal, through the coolant filter, and around the potentiometer. The coolant then passes through the gap seals where it is reduced in pressure and thence around the helical slots in the cylinder liners. The flow path is then split to cool the lock assembly and the servovalve assembly. In the servovalve cover the coolant mixes with the exhausted drive gas and then both pass over the electrical connector. The electrical connector cavity in the pedestal is exhausted to the vent.

\subsection{ACTUATOR CONTROL AMPLIFIER}

The actuator control amplifier is pictured in Figure 1.3. It is constructed of modular plug-in printed circuit boards. The boards utilize NEXUS operational amplifiers and discrete passive components. A functional block diagram of the amplifier is shown in Figure 1.4. This type of amplifier was used throughout the XE qualification tests. For the extended life test, however, the amplifier was updated to conform to the XE-Prime type. The functional block diagram of the modified amplifier is shown in Figure 1.5.

For a more definitive description and analysis of the XE control drum actuator, the following references are given:

Josephson, J., "Servo-Analysis and Dynamic Testing of the Prototype NERVA XE Pneumatic Actuator-Amplifier Subsystem", WANL-TME-1537, November, 1966.

Armstrong, D., Buckley, S., "A Stability Analysis of the NERVA XE Control Drum Actuator Servovalve", WANL-TME-1625, September, 1967.

Marvin, M. D., "Final Report Control Drum Pneumatic Actuator Program for NERVA XE Series", No.67-SD-3011, General Electric, Space Power and Propulsion Section, Missile and Space Division, Cincinnati, Ohio. 
(20) Astronuclear

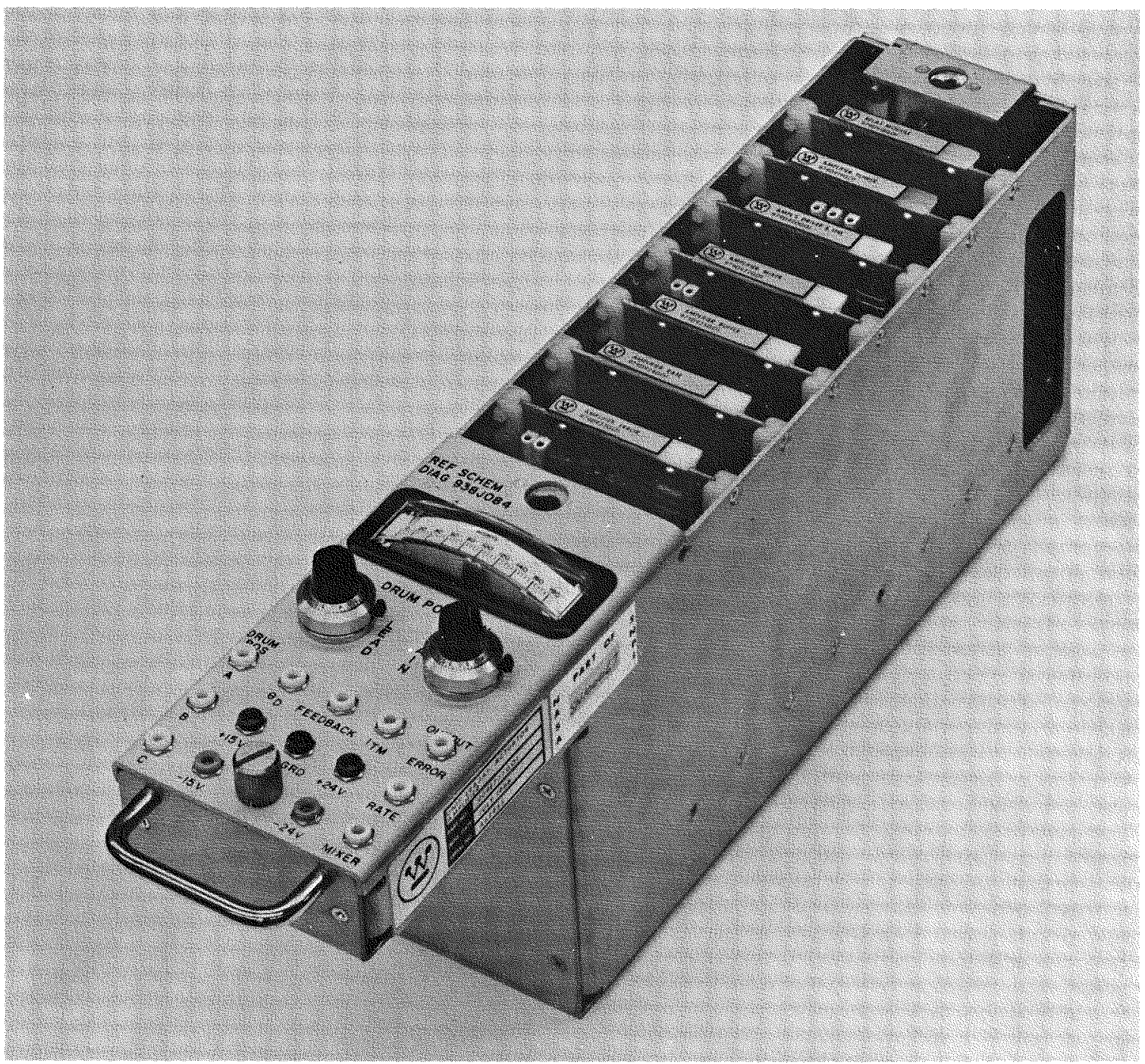

Figure 1.3. XE Actuator Control Amplifier 


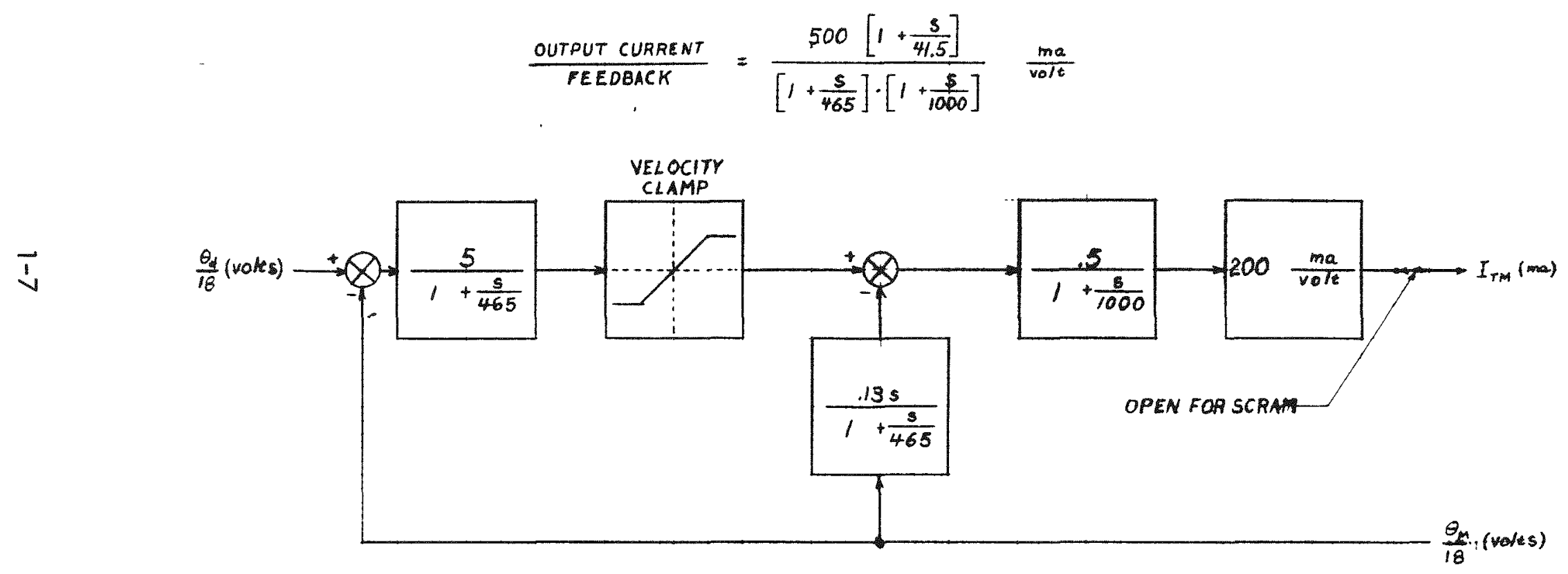

Figure 1.4. XE-1 Actuator Control Amplifier - Functional Block Diagram 


$$
\frac{\text { OUTPUT CURRENT }}{\text { FEED BACK }}=\frac{1452\left[1+\frac{s}{7.16}+\frac{s^{2}}{182}\right] \cdot\left[1+\frac{s}{513}\right] \cdot\left[1+\frac{s}{63}\right]}{\left[1+\frac{s}{6.3}\right] \cdot\left[1+\frac{5}{25}\right] \cdot\left[1+\frac{s}{333}\right] \cdot\left[1+\frac{s}{465}\right] \cdot\left[1+\frac{s}{1000}\right]}
$$

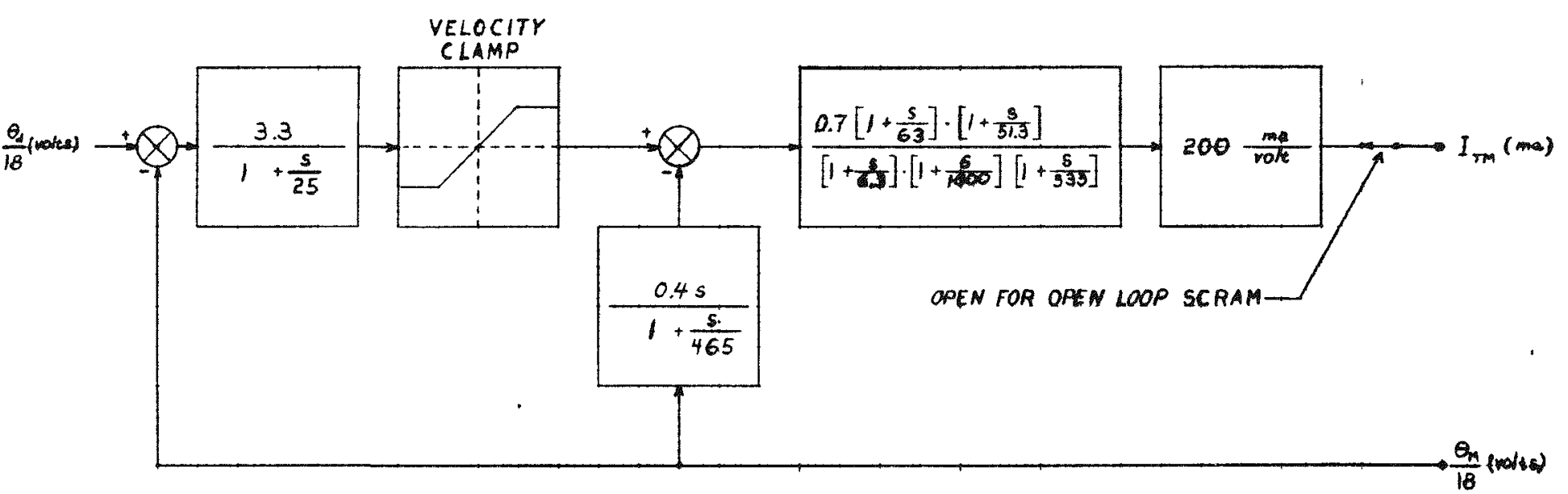

Figure 1.5. XE-2 Actuator Control Amplifier - Functional Block Diagram 


\subsection{DESCRIPTION OF ACTUATOR PERFORMANCE TEST PROCEDURE}

\subsection{INTRODUCTION}

The tests listed in this section were performed during all phases of the environmental qualification program. These tests were performed prior to the application of a specific environment to determine the Base Line Data (BLD) of the actuator for that test. Any deviations in the results of subsequent actuator performance tests from this established base line data were carefully reviewed, evaluated and finally used as a measure of the actuator's ability to perform satisfactorily during and after the specific test environments.

\subsection{PARAMETERS}

The parameters measured and/or recorded during these tests were:

2.2.1 Actuator Command (D.C. Value)

$\theta_{d}$ (degrees)

2.2.2 Actuator Dynamic Command (Time Varying Component)

$\Delta \theta_{d}$ (degrees)

2.2.3 Actuator Position (D.C. Value or Coarse Position)

$\theta_{0}$ (degrees)

2.2.4 Actuator Dynamic Position (Time Varying Component)

$\Delta \theta_{0}$ (degrees)

2.2.5 Error Signal (Command - Position)

$\theta_{e}$ (degrees)

2.2.6 Torque Motor Current

$I_{T M}(\mathrm{ma})$

2.2.7 Coolant Pressure

$P_{C}$ (psig)

2.2.8 Drive Pressure

$P_{S}$ (psig)

2.2.9 Cylinder No. 1 Pressure

$P_{1}$ (psig)

2.2.10 Cylinder No. 2 Pressure

$P_{2}$ (psig) 


\subsection{PRE-TEST SET-UP}

Two different load stands were used during the environmental tests. One load stand was used during the life tests and temperature tests, while a second stand, particularly adapted to use with the vibration table, was used during the shock vibration and cold vibration test phases.

An initial set-up and test of the actuator on each load stand was performed to establish the control amplifier settings for optimum transient response of the system. Although this adjustment was probably not required, it was performed in an attempt to eliminate differences in performance due to minor differences in load stand parameters. Consideration was given, however, to obtain control amplifier settings in the range of those to be used in the XE-1 tests in order to simulate the conditions of a reactor run.

\subsection{STATIC RESOLUTION AND LINEARITY}

The linearity and static resolution of the subsystem was determined by commanding the actuator in $9^{\circ}$ intervals over its range of travel $\left(9^{\circ}\right.$ to $171^{\circ}$ to $\left.9^{\circ}\right)$ and recording the command $\left(\theta_{d}\right)$ and the error $\left(\theta_{e}\right)$ after all transients had subsided. The difference of the $\theta_{e}$ voltage for the two directions of approaching the data points is a measure of the static resolution. Linearity is the difference between the error voltage at any point and the best straight line drawn through all the points. Refer to Figure 2.1 for a block diagram of the test set-up.

\subsection{DYNAMIC RESOLUTION}

To obtain the dynamic resolution of the subsystem, the command $\left(\theta_{d}\right)$ and position $\left(\theta_{0}\right)$ of the actuator were set at $90^{\circ}$ while the dynamic command $\left(\Delta \theta_{d}\right)$ was a $3^{\circ} / \sec$ ramp of $100^{\circ}$ magnitude. The dynamic command $\left(\Delta \theta_{d}\right)$ and error $\left(\theta_{e}\right)$ were recorded on the $X-Y$ chart recorder. The trace traversed is a hysteresis curve of error voltage. The dynamic 


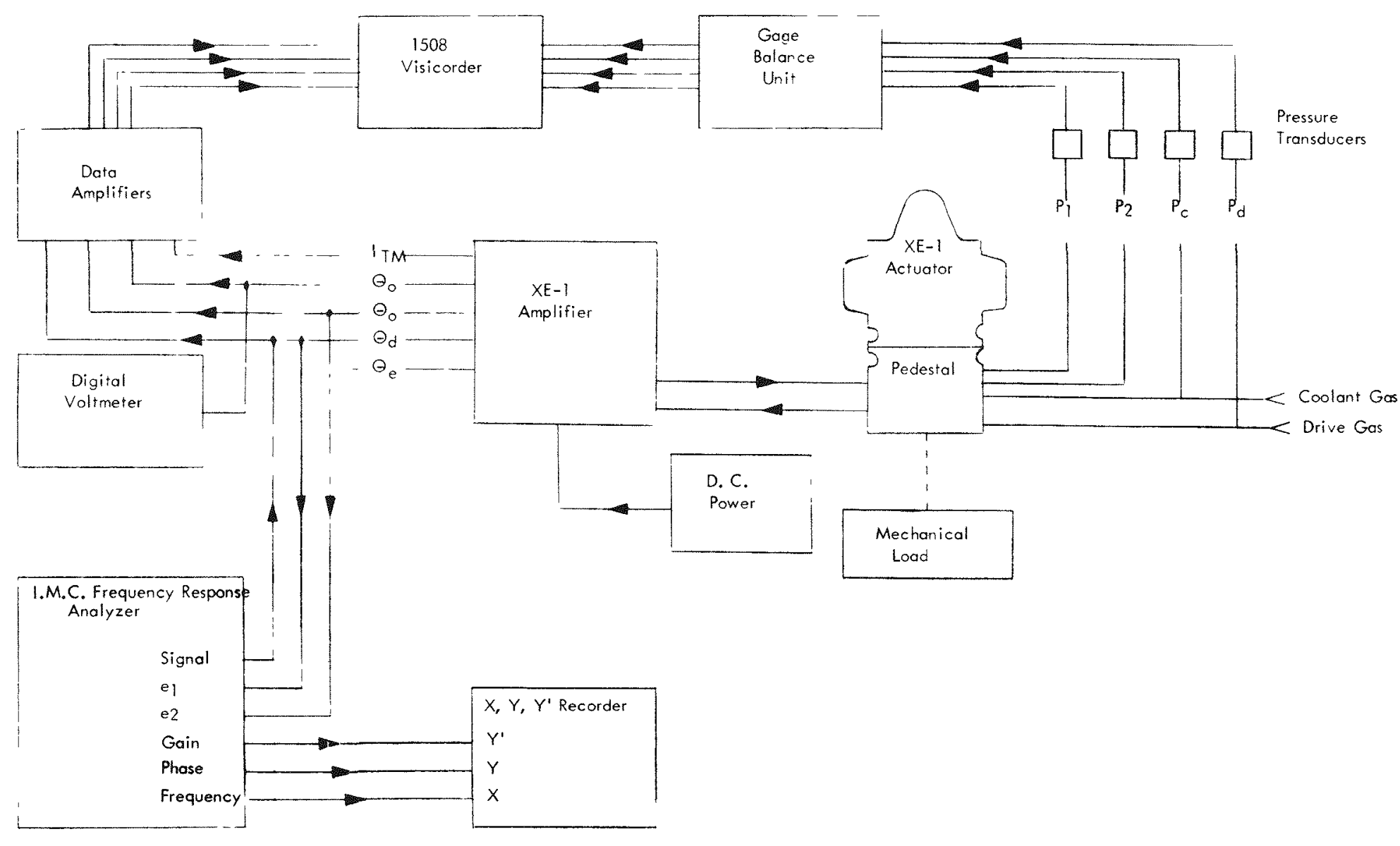

Figure 2.1. Block Diagram - Resolution Check 
resolution at any point is the width of this hysteresis curve. Refer to Figure 2.1 for a block diagram of the test set-up. Because of the close correlation existing between the static and dynamic resolutions and due to the long time required to check the static resolution, the static resolution was deleted from the tests after the first check.

\subsection{TRANSIENT RESPONSE}

The transient response of the actuator was determined by commanding $\left(\theta_{d}\right)$ the actuator output shaft to a position $\left(\theta_{0}\right)$ of $90^{\circ}$ and applying a dynamic step command $\left(\Delta \theta_{d}\right)$ with an amplitude of $18^{\circ} \mathrm{p}-\mathrm{p}$ to the control amplifier. Under the stimulus of the dynamic command, the actuator would alternate position between $81^{\circ}$ and $99^{\circ}$. The command $\left(\Delta \theta_{d}\right)$ and position $\left(\Delta \theta_{0}\right)$ were then recorded on the visicorder. Time response, overshoot and settling time can then be read from the actuator position time trace. Refer to Figure 2.2 for a block diagram of the test set-up.

\subsection{SCRAM RESPONSE}

To check the scram turnaround performance, the test set-up remained the same as for the transient response check except that the dynamic command $\left(\Delta \theta_{d}\right)$ was increased to assure that the actuator would move out to an angle greater than $120^{\circ}$. This is because a Schmidt trigger, sensitive to actuator position, was used to de-energize the scram relay when the position reached $120^{\circ}$. Actuator position $\left(\theta_{0}\right)$ and torque motor current $\left(I_{T M}\right)$ were recorded on the visicorder. The time when torque motor current was shut off was considered as the start of the scram operation. Scram turnaround was defined as the point when the position time trace reached a zero slope. Refer to Figure 2.2 for a block diagram of the test set-up.

\subsection{FREQUENCY RESPONSE}

The frequency response of the actuator was measured using an IMC Frequency Response Analyzer and recorded on an $X-Y-Y^{\prime}$ Chart Recorder. The actuator was 


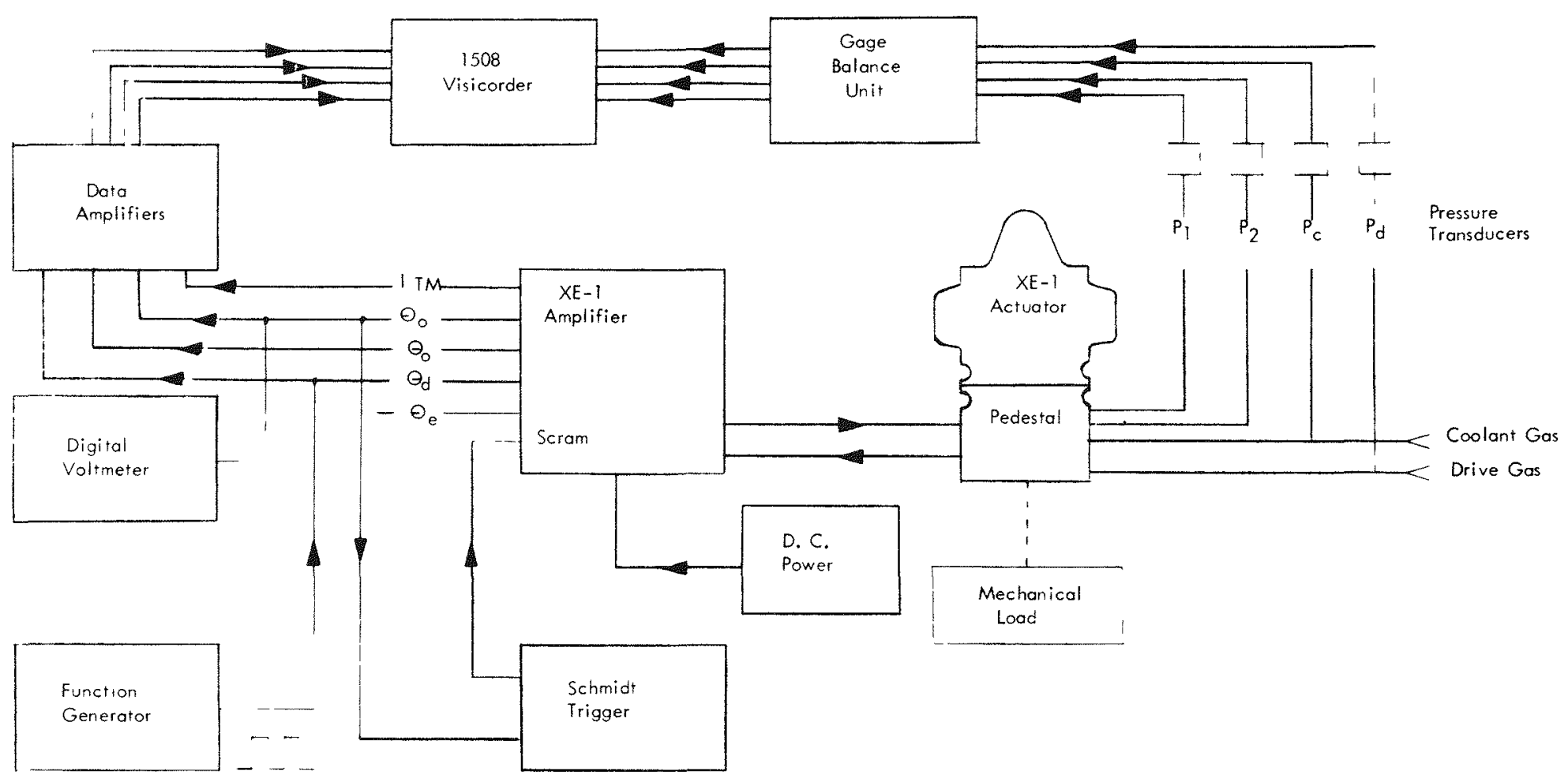

Figure 2.2. Block Diagram Transient and Scram Check 


\section{(2) Astronuclear \\ Laboratory}

commanded $\left(\theta_{d}\right)$ to a position $\left(\theta_{0}\right)$ of $90^{\circ}$ and a sinusoidal dynamic command $\left(\Delta \theta_{d}\right)$ of $4^{\circ}$ $p-p$ amplitude was applied to the control amplifier. The dynamic command $\left(\Delta \theta_{d}\right)$ and dynamic position $\left(\Delta \theta_{0}\right)$ signals were then processed by the IMC analyzer to obtain the closed loop frequency response which was plotted using the $X-Y-Y^{\prime}$ recorder. Refer to Figure 2.3 for a block diagram of the test set-up. 


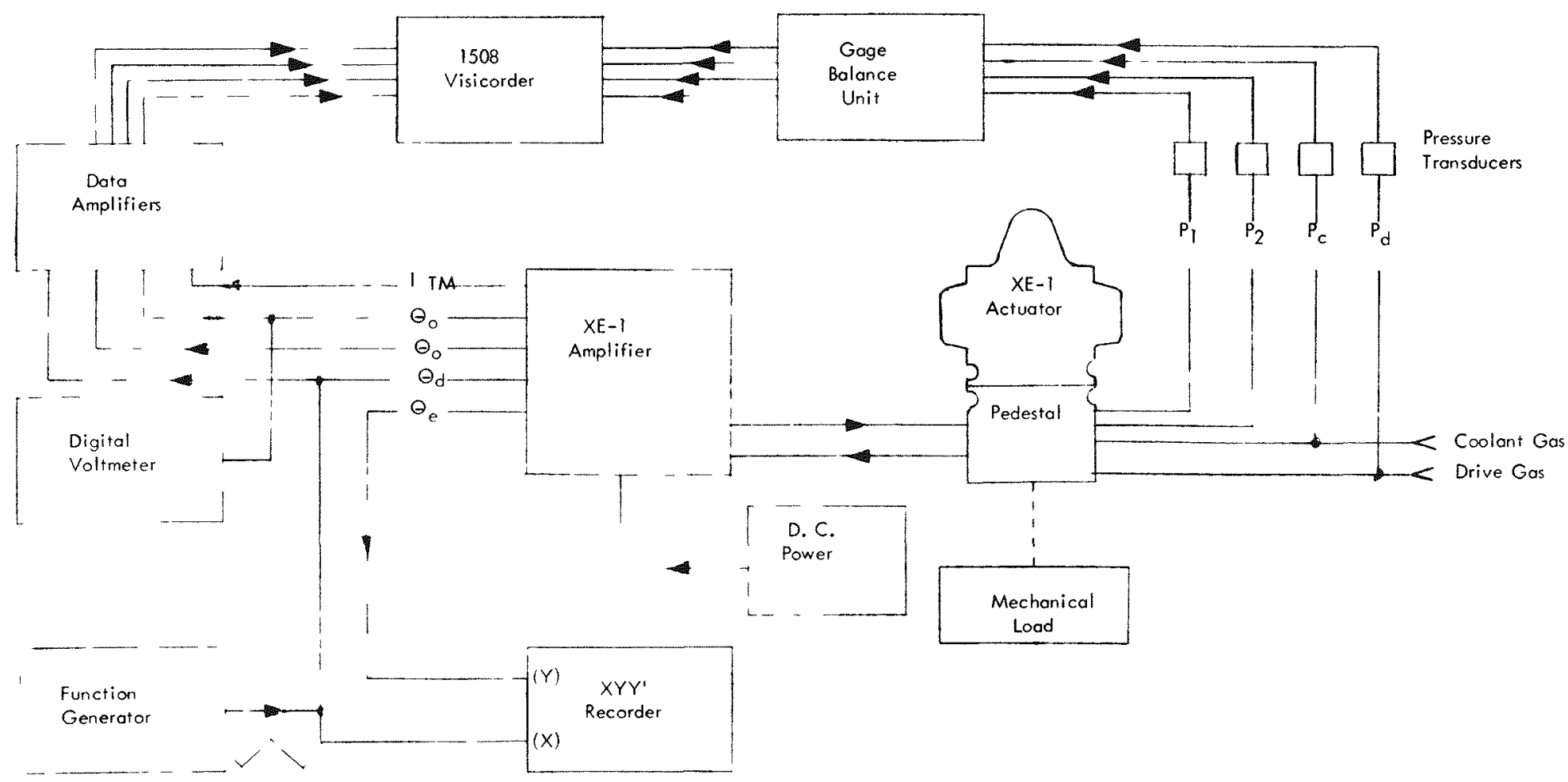

Figure 2.3. Block Diagram Closed Loop Frequency Response

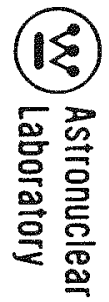


(W) Astronuclear

\subsection{VIBRATION TEST}

\subsection{INTRODUCTION}

3.1.1 The vibration qualification test was conducted within the guidelines specified in WANL-TME-1040, Revision A, Qualification Specifications for Control Drum Pneumatic Actuators for XE-1 Applications (see Appendix A), and performed under T-711892A, Qualification Test, Environmental, Control Drum Actuator (see Appendix B), with a few minor exceptions noted herein. The basis for the vibration levels was AGC Specification 90016-C. The vibration levels equaled or exceeded these specified values.

3.1.2 The purpose of the vibration test was to determine what changes in performance, if any, the XE control drum actuator would undergo when operated in a vibration environment. The vibration environment consisted of sinusoidal accelerations at levels as specified in Appendix A. The vibrations as specified were selected to closely approximate the anticipated environment to which the actuator will be subjected during both ground handling and engine operation.

3.1.3 The method of testing was to operate the actuator with various command inputs before, during and after vibrating and to record actuator performance for each condition. A comparison of the various records defines the effects of the induced environments on the performance of the actuator system.

\subsection{DESCRIPTION OF TEST SET-UP}

3.2.1 The vibration testing of the XE-1 actuator was performed in the WANL Mechanisms Laboratory between November 8, 1967 and November 15, 1967. The actuator used was an XE-1 Series, Serial Number A-58608, and the actuator control amplifier was Serial Number A-62960. The combination of actuator and amplifier comprises the closed 
loop position control system. Only the actuator was subjected to the induced environments as the amplifier is mounted in the Test Cell Building.

3.2.3 To provide vibration and to monitor acceleration, the following equipment was used:

Unholtz-Dickie Water-Cooled Shaker Table, Model 201

Philips Driver Amplifier (10 KVA), Model EL 6473-12

M-B Automatic Vibration Exciter Control, Model N572-73

Endevco Accelerometers, Model 2226 - Three accelerometers to measure tri-axial accelerations on the actuator.

Unholtz-Dickie Dial-A-Gain Signal Conditioner, Model AV604-R

Honeywell Visicorder, Model 906-C

3.2.4 The following equipment was used to determine actuator performance:

Honeywell Visicorder, Model 1508

Industrial Measurements Corp. (IMC) Frequency Response Analyzer, Model 101

Hewlett Packard Function Generator, Model 202

Honeywell $X-Y-Y^{\prime}$ Chart Recorder, Model 480

Honeywell Digital Voltmeter, Model 6305

Trygon Power Supplies, Model PS 32-2.5

CEC Pressure Transducers $-P_{s}, P_{C}$ Pressures

Statham Pressure Transducers - $P_{1}, P_{2}$ Pressures

CEC Data Amplifier, Type 155

Honeywell Gage Balance Unit

3.2.5 Helium drive gas $\left(P_{S}\right)$ and nitrogen coolant gas $\left(P_{C}\right)$ at controlled pressure and ambient temperatures were supplied to the actuator through the vibration load stand. 
(QP) Astronuclear

3.2.6 The three axes of vibration were chosen as:

Vibration parallel to actuator output shaft $\left(a_{z}\right)$.

Vibration parallel to direction of piston travel $\left(a_{y}\right)$.

Vibration perpendicular to direction of piston travel and perpendicular to actuator output shaft $\left(a_{x}\right)$.

3.2.7 The actuator is shown mounted for vibration in the $a_{z}$ direction in Figure 3.1. In Figure 3.2 , the actuator is shown mounted for vibration in the $a_{y}$ direction, and in Figure 3.3 the mounting for vibration in the $a_{x}$ direction is shown. Block diagrams of the actuator system and associated control and instrumentation components as interconnected for obtaining performance data during the vibration test series are detailed in Figures 2.1, 2.2 and 2.3 .

\subsection{DESCRIPTION OF TEST PROCEDURE}

3.3.1 The vibration test was divided into three parts corresponding to the three axes of the actuator as defined in Section 3.2.6. A schedule of vibration tests is given in Figure 3.4, wherein all the vibration tests are shown. Only selected tests from those listed in Figure 3.4 were performed in any given direction of vibration. Prior to vibration in a given axis, a test was performed to establish the base line data for use in subsequent performance evaluations.

3.3.2 The vibration tests performed on the actuator in the $a_{z}$ direction (parallel to the output shaft) were 1, 2,3,5 and 6 as listed in Figure 3.4. This series of tests was performed in the order given. Test No. 3 was a sweep of different frequencies and amplitudes as shown in Figure 3.5. While Test No. 3 was being performed, a dynamic resolution test (Section 2.5) was performed and the results recorded. Immediately after Test No. 3, dynamic resolution (Section 2.5) and transient response tests (Section 2.6) were performed and the results recorded. Test No. 6 was performed at any and all resonance frequencies 
(2) Astronuclear

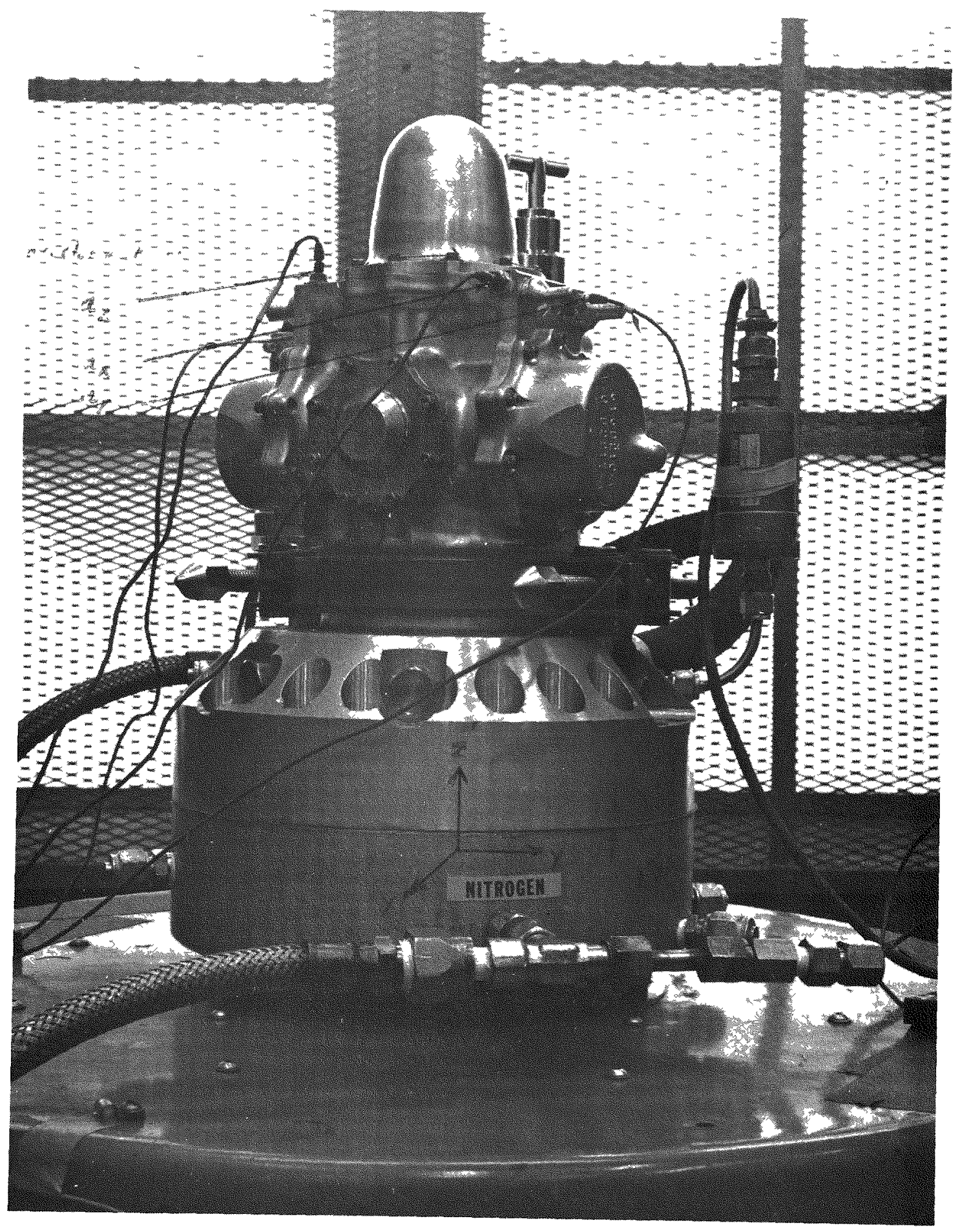

Figure 3.1. Actuator Mounted for Vibration in the $a_{z}$ Direction 
W. Astronuclear

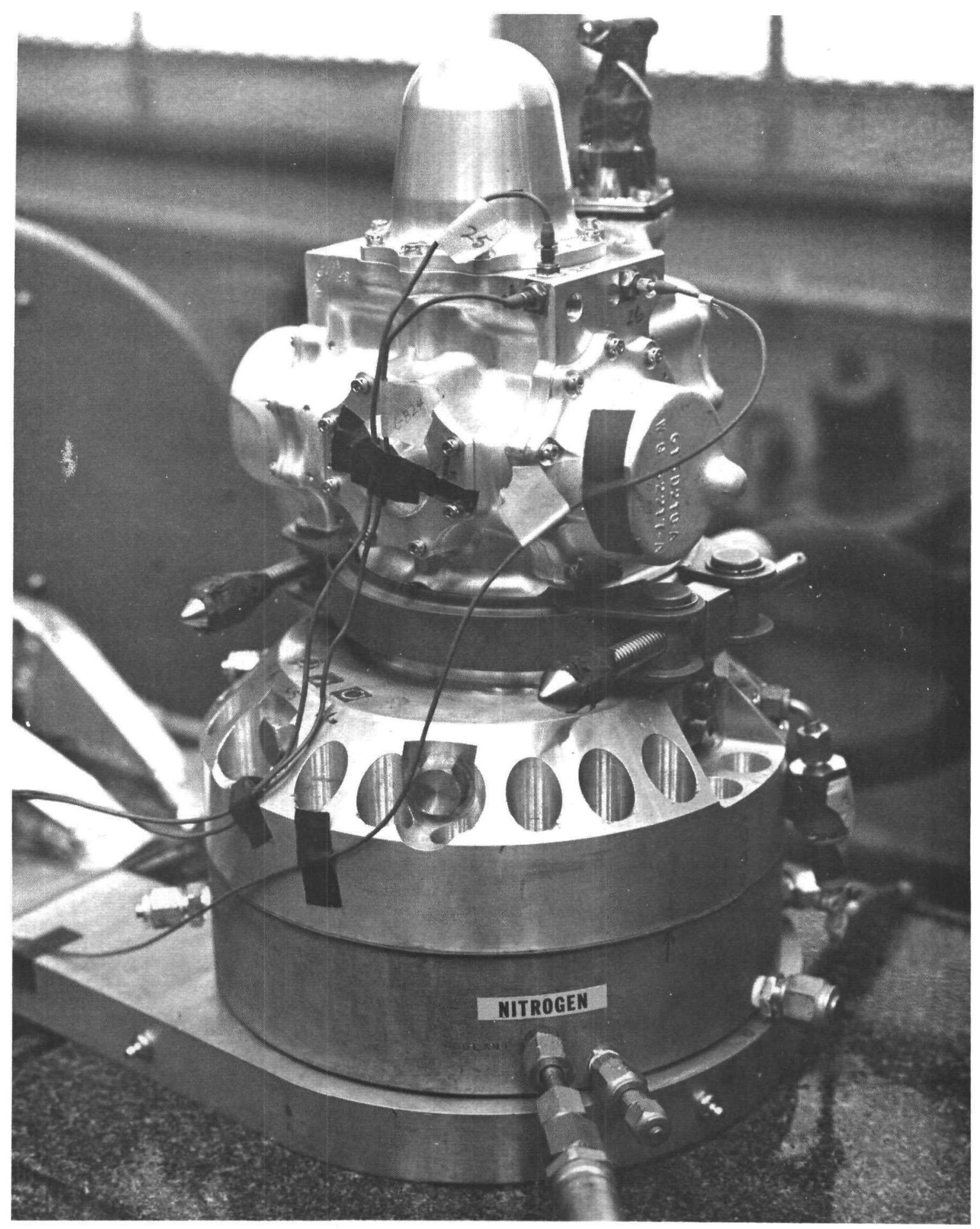

Figure 3.2. Actuator Mounted for Vibration in the $a_{y}$ Direction 


\section{(2v) Astronuclear}

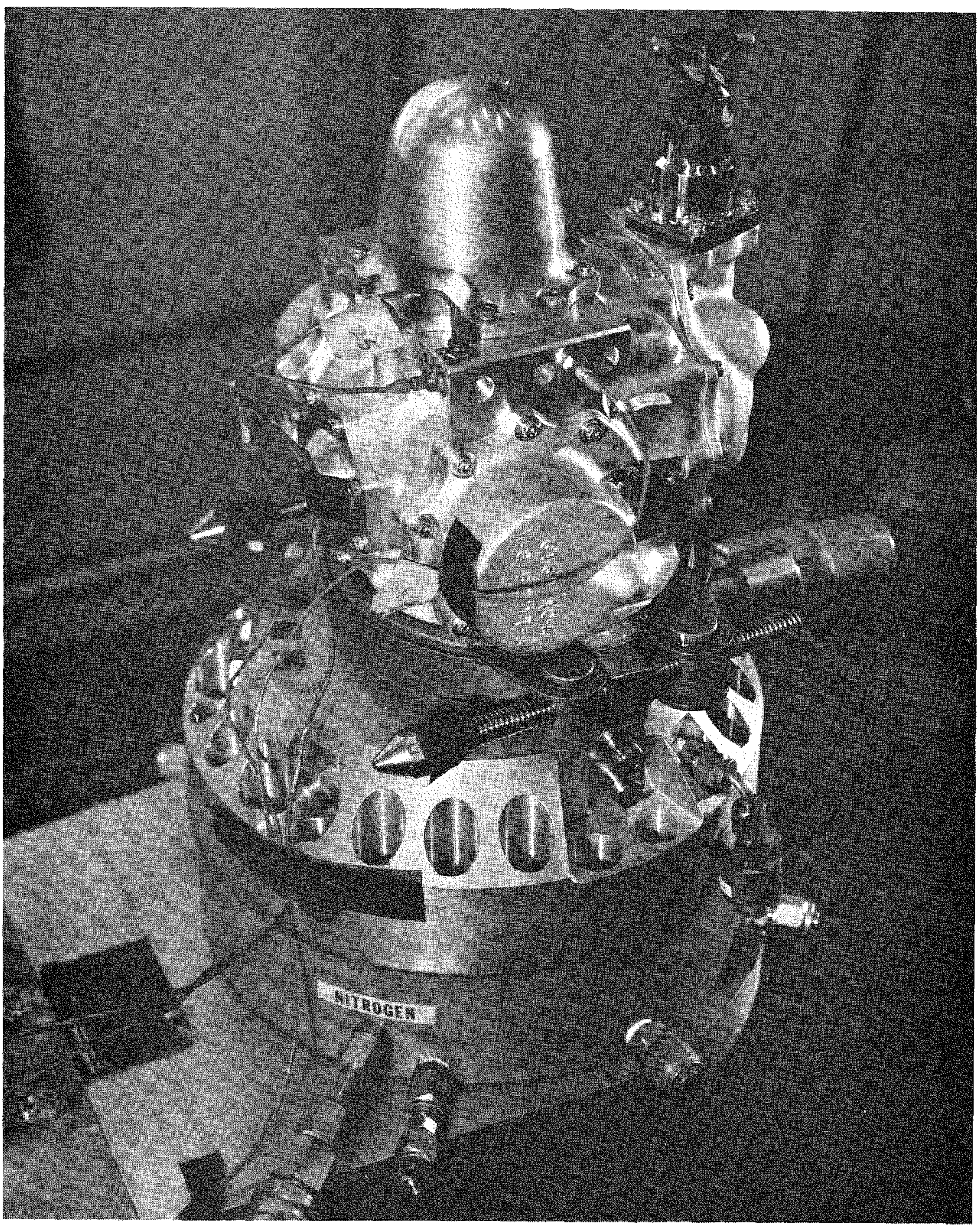

Figure 3.3. Actuator Mounted for Vibration in the a ${ }_{x}$ Direction 


\begin{tabular}{|c|c|c|c|c|c|c|c|c|c|c|}
\hline \multirow[b]{2}{*}{ Phase } & \multirow[b]{2}{*}{$\begin{array}{l}\text { Actuator } \\
\text { Condition }\end{array}$} & \multirow[b]{2}{*}{$\begin{array}{c}\begin{array}{c}\text { Vibration } \\
\text { Plane }\end{array} \\
\end{array}$} & \multicolumn{5}{|c|}{ Performance Tests } & \multicolumn{3}{|c|}{ Resonance Dwell } \\
\hline & & & $\begin{array}{l}\text { Test } \\
\text { No. }\end{array}$ & $\begin{array}{l}\text { Sweep } \\
\text { Frequency } \\
\text { (cps) }\end{array}$ & $\begin{array}{c}\text { No. } \\
\text { of } \\
\text { Sweeps }\end{array}$ & $\begin{array}{l}\text { Time/ } \\
\text { Sweep }\end{array}$ & $\begin{array}{l}\text { Applied } \\
\text { Force } \\
(\mathrm{g}) \\
\end{array}$ & $\begin{array}{l}\text { Test } \\
\text { No. }\end{array}$ & $\begin{array}{c}\text { Dwell } \\
\text { Time at } \\
\text { Resonance } \\
\end{array}$ & $\begin{array}{l}\text { Applied } \\
\text { Force (g) } \\
\text { Vector }\end{array}$ \\
\hline $\begin{array}{l}\text { Low Level } \\
\text { Vibration } \\
\text { Search }\end{array}$ & $\begin{array}{l}\text { Non-Oper- } \\
\text { ational }\end{array}$ & All 3 & 1 & $5-2000-5$ & 2 & $3 \min$ & 1.0 & -- & -- & --- \\
\hline $\begin{array}{l}\text { Shipment } \\
\text { and } \\
\text { Storage }\end{array}$ & $\begin{array}{l}\text { Non-Oper- } \\
\text { ational }\end{array}$ & All 3 & 2 & $10-30-10$ & 3 & $2 \min$ & 4.0 & 5 & $30 \mathrm{~min}$ & 4.0 \\
\hline $\begin{array}{l}\text { Ground } \\
\text { Firing }\end{array}$ & Operating & Vertical & 3 & $5-2000-5$ & 1 & $30 \mathrm{~min}$ & $\begin{array}{c}\text { See } \\
\text { Figure } 3.5\end{array}$ & 6 & $10 \mathrm{~min}$ & $\begin{array}{c}\text { See } \\
\text { Figure } 3.5\end{array}$ \\
\hline $\begin{array}{l}\text { Ground } \\
\text { Firing }\end{array}$ & Operating & Horizontal & 4 & $5-500-5$ & 2 & $15 \mathrm{~min}$ & $\begin{array}{c}\text { See } \\
\text { Figure 3.6 }\end{array}$ & 7 & $10 \mathrm{~min}$ & $\begin{array}{c}\text { See } \\
\text { Figure } 3.6\end{array}$ \\
\hline
\end{tabular}

Figure 3.4. Test Sequence and Specifications 


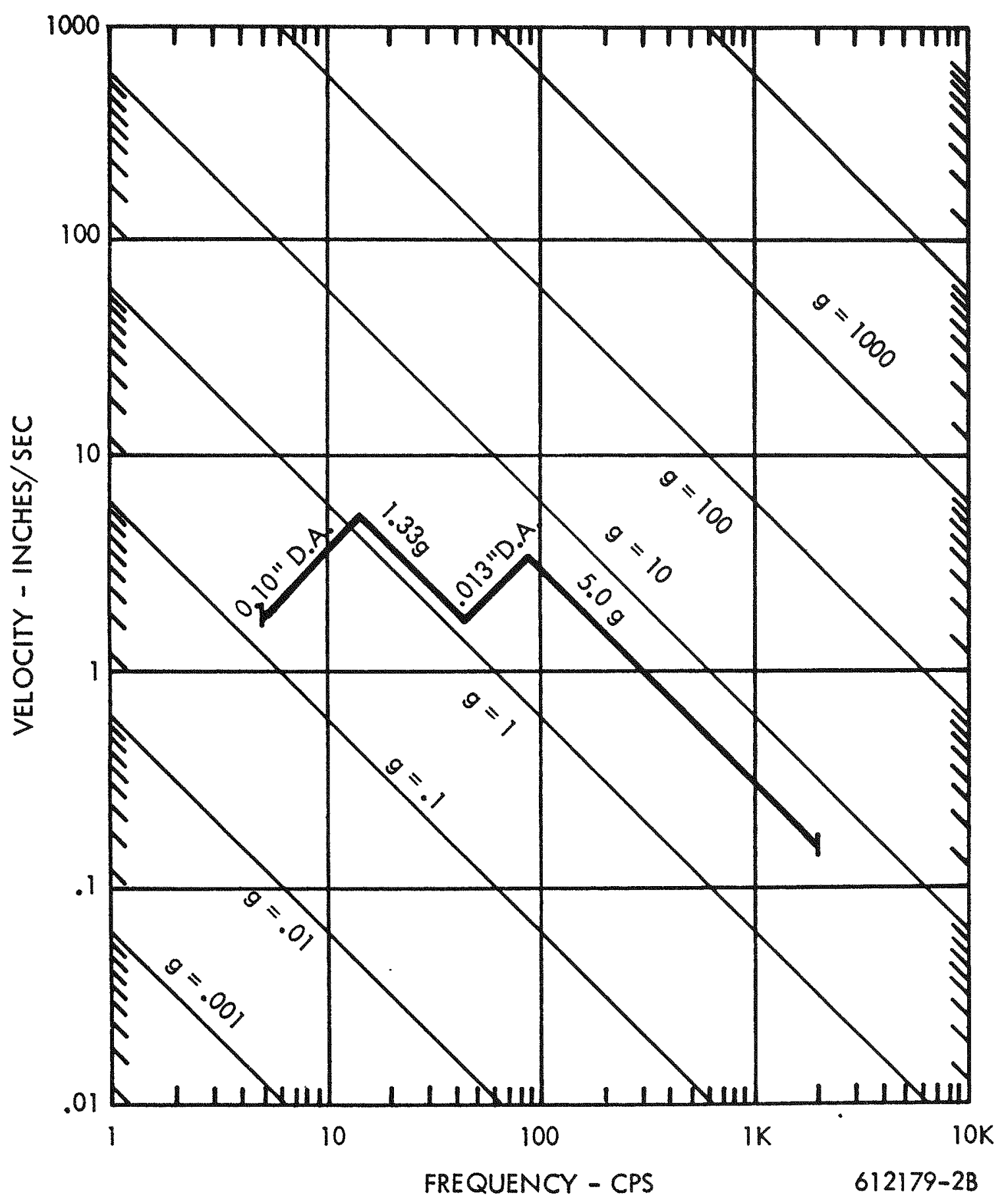

Figure 3.5. Vibration Environment, Sinusoidal Vibration in $a_{z}$ Direction 
(W) Astronuclear

observed during Test No. 3. While Test No. 6 was being performed, a dynamic resolution test (Section 2.5) was performed and the results recorded. After Test No. 6, which was the last test in the $a_{z}$ direction, a complete actuator performance test was conducted and recorded (Sections 2.5, 2.6, 2.7 and 2.8)。

3.3.3 The vibration tests performed on the actuator in the $a_{y}$ direction (parallel to piston travel) were $1,2,4,5$ and 7 as listed in Figure 3.4. This series of tests was performed in the order given. Test No. 4 was a sweep of different frequencies and amplitudes as shown in Figure 3.6. A dynamic resolution (Section 2.5) was recorded both during and after Test No. 4 and a transient response (Section 2.6) was recorded after Test No. 4. Test No. 7 was performed at any and all resonance frequencies observed during Test No. 4. A dynamic resolution (Section 2.5) was recorded during Test No. 7 and a complete actuator performance test was conducted and recorded (Sections 2.5, 2.6, 2.7, 2.8) after Test No. 7.

3.3.4 For vibration in the $a_{x}$ direction (perpendicular to piston travel) the same tests were performed as in the $a_{y}$ direction $(1,2,4,5$ and 7$)$ and the same actuator performance tests were conducted as specified in 3.3.3.

\subsection{DISCUSSION OF TEST RESULTS}

3.4.1 The results of the scram turnaround, transient response, and dynamic response tests were reduced from visicorder and $X-Y$ plots and tabulated in Figure 3.7, and a typical scram response is shown in Figure 3.8.

3.4.1.1 Scram turnaround time was determined as the period between torque motor current shut-off (opening of scram relay) and the point where the actuator ceased its outward motion (zero angular velocity). The scram turnaround times did not change appreciably throughout the vibration tests. Changes in scram turnaround and scram velocity 
(2) Astronuclear

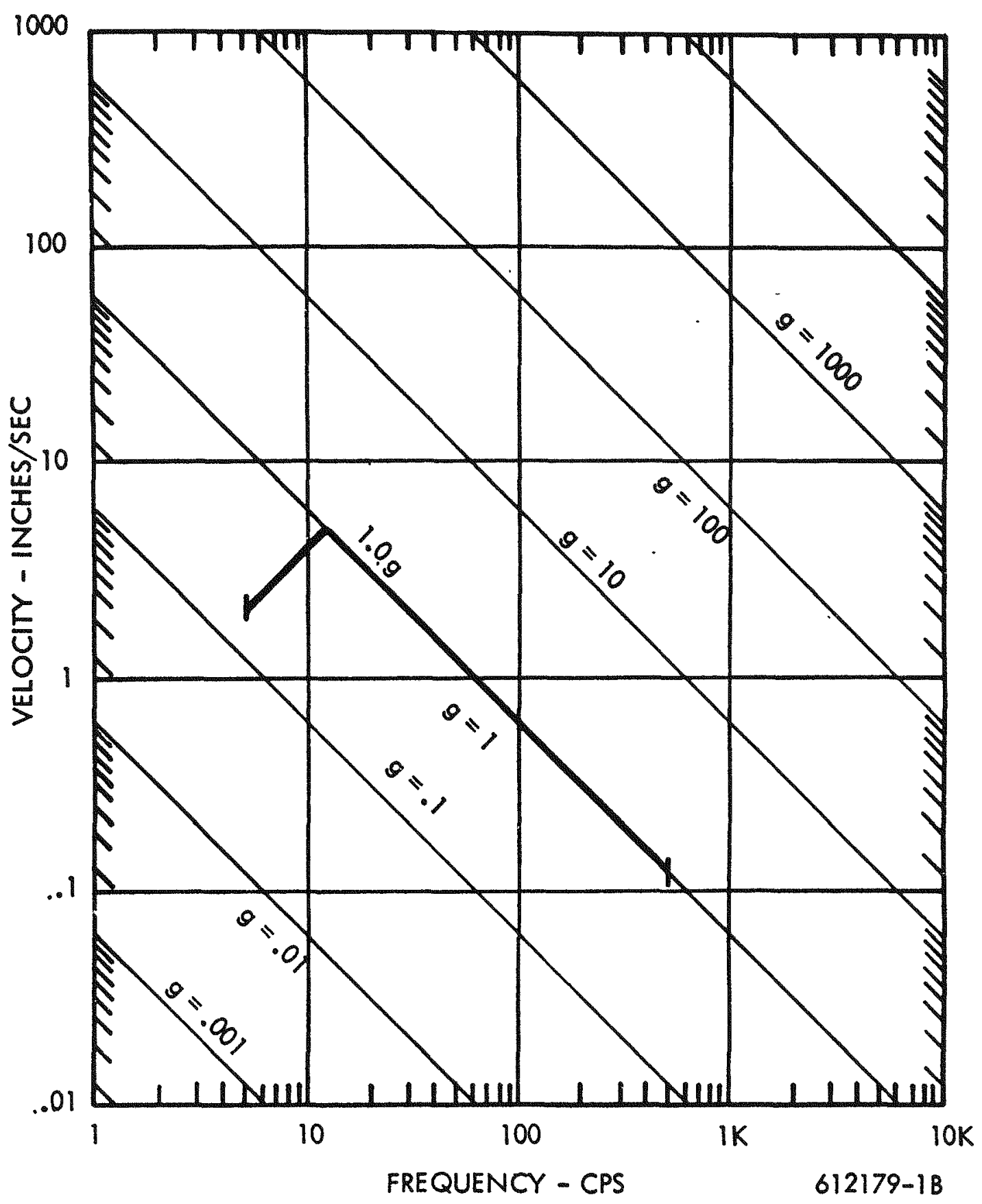

Figure 3.6. Vibration Environment, Sinusoidal Vibration in $a_{x}$ and $a_{y}$ Direction 
Vibration Vertical $\left(a_{z}\right)$ Vertical $\left(a_{z}\right)$ Horiz. $\left(a_{y}\right)$ Horiz, (ay) Horiz. $\left(a_{y}\right)$ Horiz. $\left(a_{y}\right)$ BLD Test No.3 Test No.6 Test No. 4 Test No.7 Test No. 4 Test No.7

Scram Turnaround Time (sec)

$\%$ BLD

0.034

0.033

0.033

0.032

$-2.96$

$-2.96$

$-5.88$

Rise Time (in) Time (sec) $\triangle \%$ BLD
0.149
0.114
-23.5

0.119
-20.2

0.114
-23.5

0.117
-21.5

0.109

0.116

Rise Time (out) Time (sec) $\triangle \% B L D$

0.149

0.122

$-18.1$

0.174
+16.8

. 0.129

0.134

$-26.9$

$-22.2$

Overshoot (in)

\section{Degrees}

$\% 18^{\circ}$

$\stackrel{w}{\underline{1}}$
Overshoot (out)
Degrees
$\% 18^{\circ}$

0.4

2.22

0.6

3.33

0.7

3.88

0.3

1.67

$-10.1$

0.129
-13.4

0.135

$-9.4$

$0.2 \quad 0.6$

1.11

3.33

0.3

1.67

0.2

0.5

0.5

0.6

Settling Time (in)

Time (sec)

$\triangle \%$ BLD

0.208

0.171

$-17.8$

0.177

0.177
-14.9

0.184

$$
2.78
$$

2.78

3.33

Settling Time (out)

Time (sec)

$\triangle \% B L D$

0.224

0.189
-14.4

$\begin{aligned} & 0.258 \\ &+13.9\end{aligned}$

0.200

0.5

0.3

0.3

Dynamic Resolution

During

Vibration (o)

After

0.22

0.16

0.11

0.09

0.27

0.41

0.22

0.40

0.56

0.16

0.23

0.34

0.20

Figure 3.7

Table of Vibration Test Data 


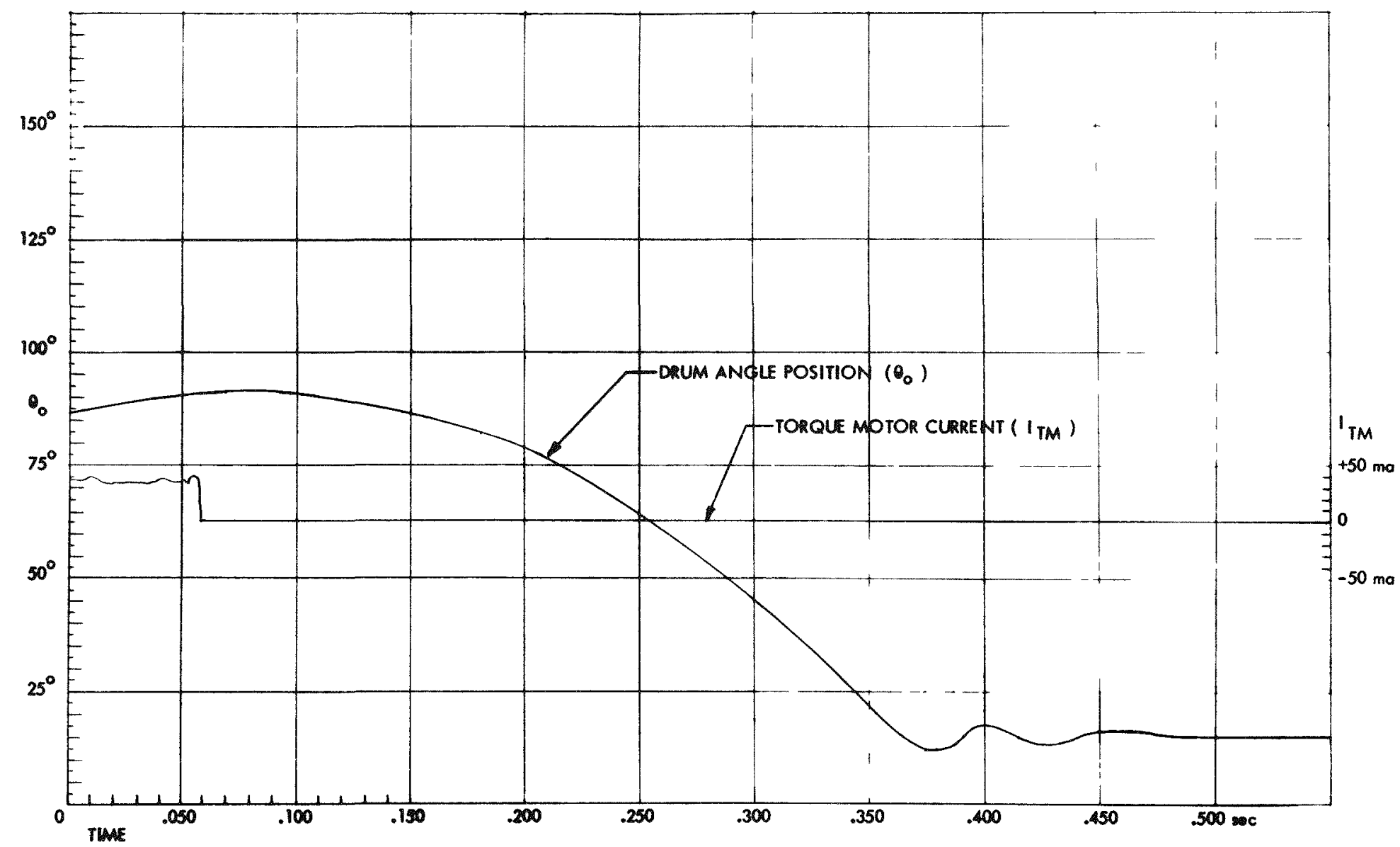

Figure 3.8. Typical Scram Response 
would not have been surprising since scrams are open loop measurements. Open loop performances are very sensitive to small changes in system parameters. Later modifications to the XE actuator systems incorporated a closed loop scram to reduce the effects of parameter variations on performance results.

3.4.1.2 Transient response rise time was defined and measured as the period between an $18^{\circ}$ step command signal and the time when the actuator position reached $63 \%$ of its final value. After the first sweep of vibration, some of the data changes to what appeared to be new base line points. This change was felt to be due to a settling of the load stand and coupling into its point of lowest friction as a result of the vibration. The observed rise times and settling times are indicative of lower values of system friction.

In general, the values changed from base line data more than anticipated, but after a careful evaluation the difference was not felt to be of significant consequence. Part of the difference can be attributed to the selection of the parameters to be measured. For all step commands the actuator travels to its commanded position at a velocity determined by its velocity clamp which is a subsystem setting. This velocity limit is a subsystem specification and is used as a measured parameter in all actuator subsystem performance evaluations. In order to more closely define the shape of the step response for the environmental test series, the rise time, settling time and overshoot parameters were specified instead of the single velocity parameter. The more detailed parameter specification appears to have been an over ambitious attempt to tighten a design specification, whereas the real parameter, that is, velocity at clamp, is not intended to be a precise specification value, but only a backup safety to the reactor control system clamps which are of lower value. In any event, the average velocity of the actuator during these rise times, settling times and overshoot measurements is within acceptable limits; therefore, it was decided to continue the test series pending anymore serious anomalias. 


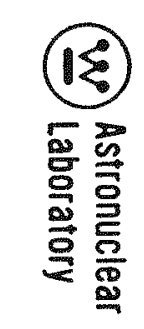

$\frac{\omega}{A}$

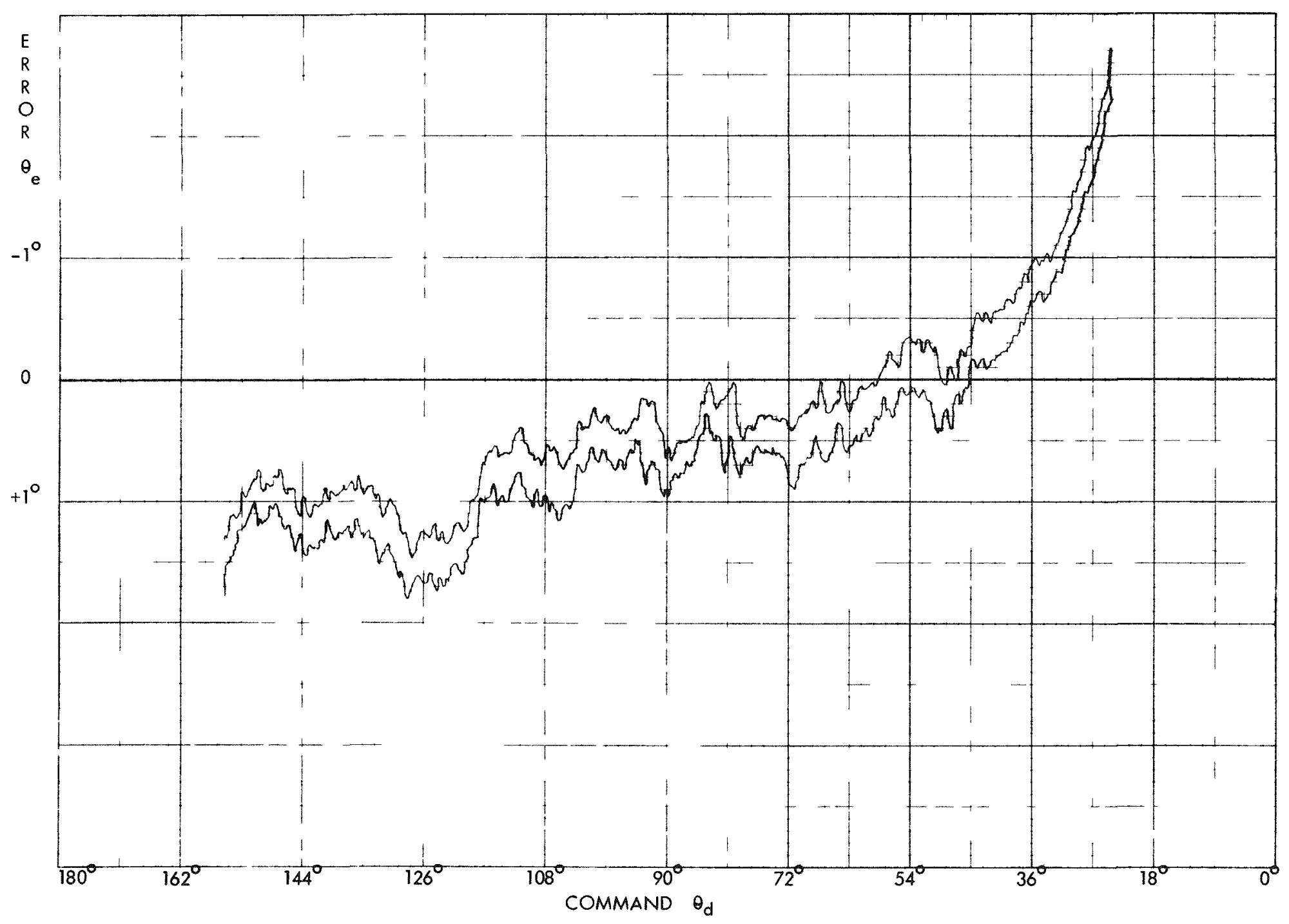

Figure 3.9. Typical Dynamic Response 


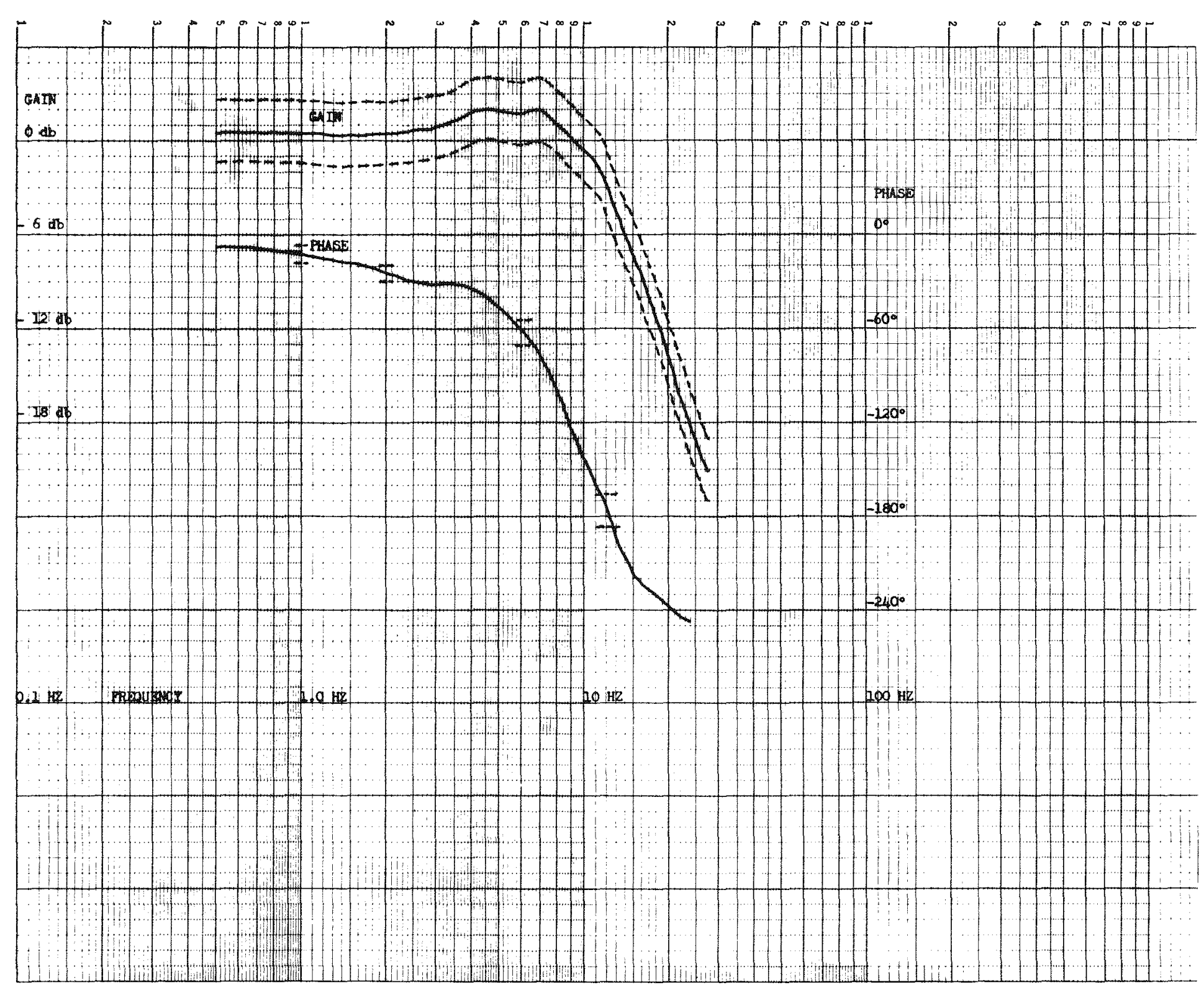

Figure 3. 10. Closed Loop Frequency Response Base Line Data 
$\frac{\omega}{a}$

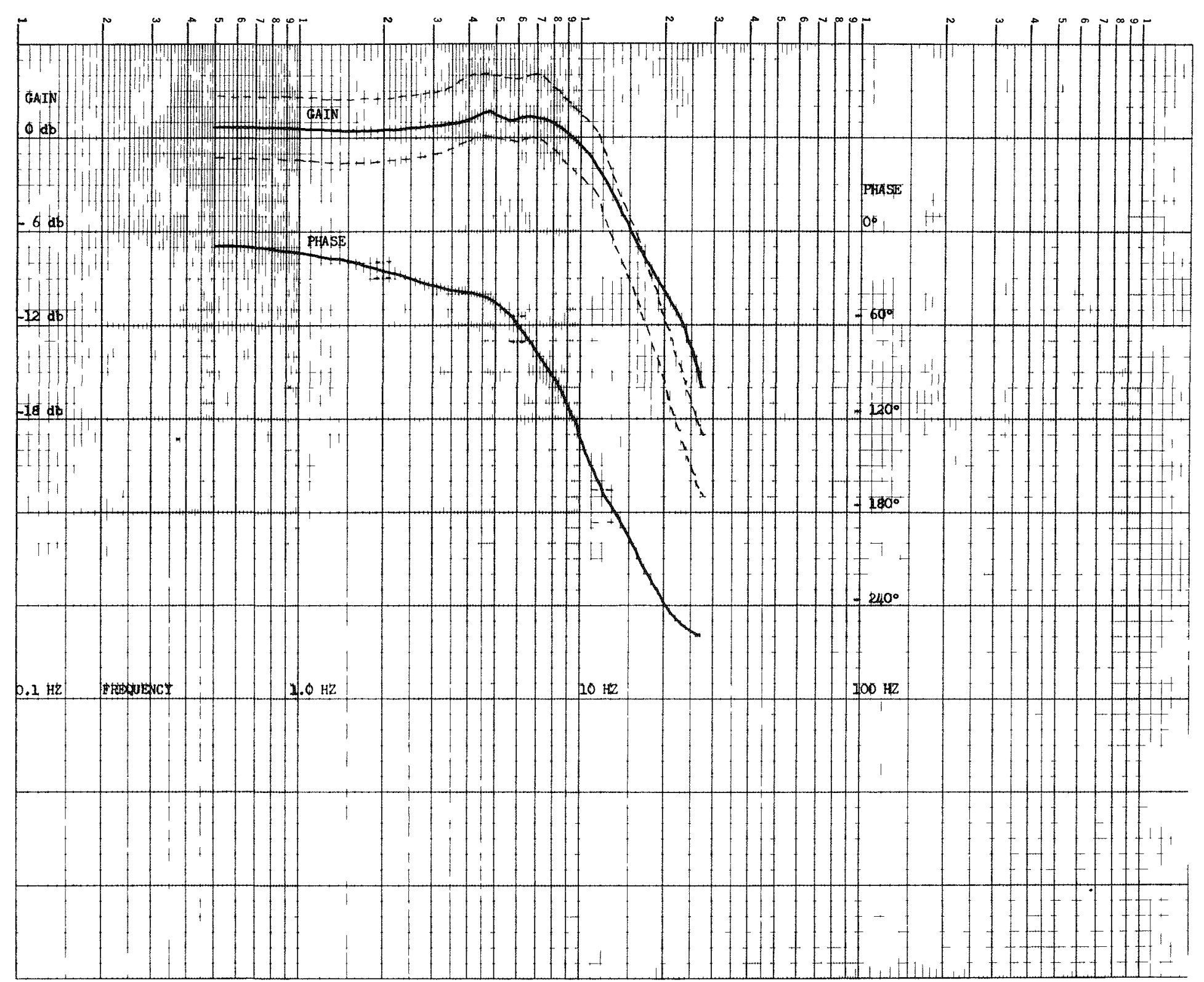

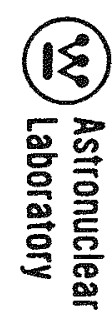

Figure 3.11. Closed Loop Frequency Response - after Vibration in $a_{z}$ Direction 


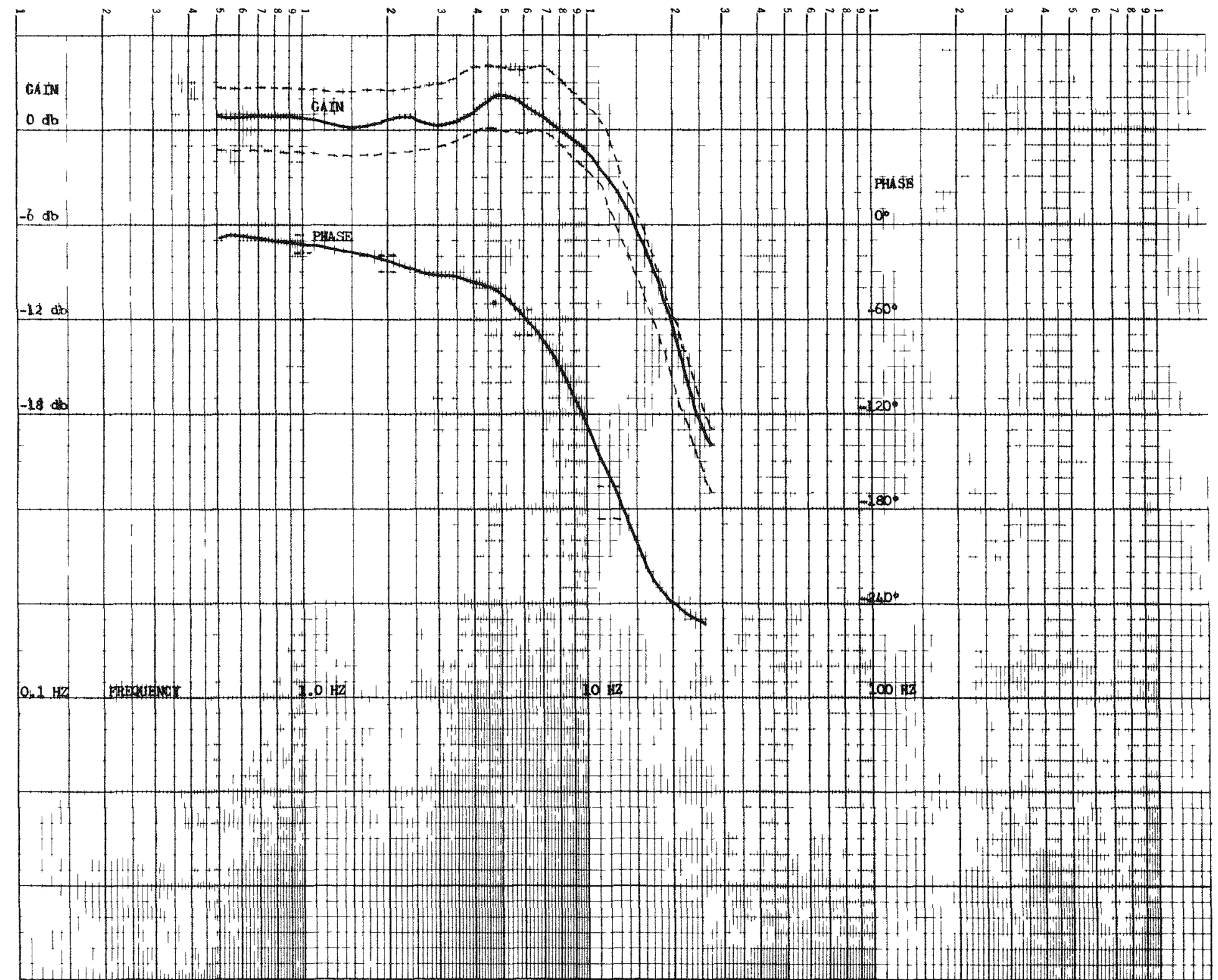

Figure 3.12. Closed Loop Frequency Response - after Vibration in $a_{y}$ Direction 


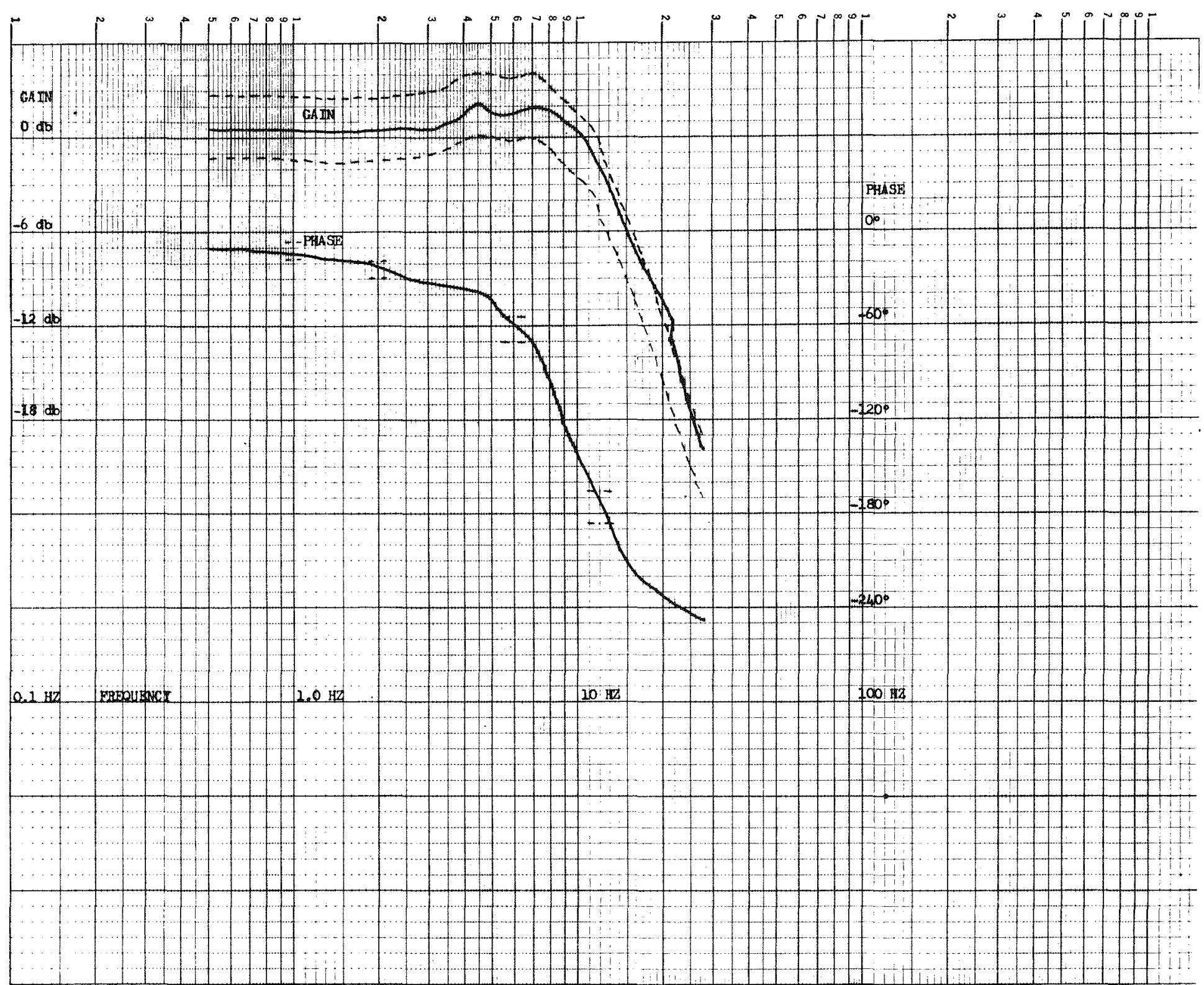

Figure 3. 13. Closed Loop Frequency Response - after Vibration in a Direction 
3.4.1.3 The values for overshoot listed in Figure 3.7 were less than $5 \%$ of the total $18^{\circ}$ travel throughout the test. The change in overshoot is the difference between the percent overshoot of the base line data and the percent overshoot for the subsequent tests. No ringing was observed but a period of approximately 0.5 seconds was required for the actuator drive shaft to reach its final value. This subsiding time was due to the extremely low frequency component of the transfer function contributed by the servovalve bellows feedback.

3.4.1.4 The settling time of the transient response was the period between the time the actuator was commanded to $\left(+18^{\circ}\right)$ and the time when the actuator position remained within $5 \%$ of its final value. Since no overshoot was greater than $5 \%$ of $18^{\circ}$, the time of first approach determined settling time.

3.4.1.5 The dynamic response of the actuator listed in Figure 3.7 was obtained from the curve of command $\left(\theta_{d}\right)$ versus error $\left(\theta_{e}\right)$. A typical dynamic response curve is shown in Figure 3.9. Each curve was compared with the base line data and the greatest deviation was measured. The two values listed for Test No. 6 were for actuator resonances of $1050 \mathrm{~Hz}\left(0.16^{\circ}\right)$ and $1350 \mathrm{~Hz}\left(0.11^{\circ}\right)$. Because no low frequency, non-operational resonances were experienced, Test No. 5 was not performed. The resonant frequency for the horizontal $\left(a_{z}\right)$ Test No. 7 was $125 \mathrm{~Hz}$ and that for the horizontal $\left(a_{x}\right)$ Test No. 7 was $130 \mathrm{hz}$.

3.4.2 Curves for the closed loop frequency response of the actuator are shown in Figures $3.10,3.11,3.12$ and 3.13. Figure 3.10 is the base line data curve. The limits for qualification, derived from the base line data curve, are superimposed on the three other frequency response curves. All three curves were within the limits set except for frequencies above $10 \mathrm{~Hz}$ where some values went beyond the limits. Because of the low closed loop gain at these frequencies, there would appear to be no problem with slight variations outside the limits. 
(2) Astronuclear

\subsection{MECHANICAL SHOCK TEST}

\subsection{INTRODUCTION}

4.1.1 The mechanical shock test was conducted within the guidelines specified in WANL-TME-1040, Revision A, Qualification Specifications for Control Drum Pneumatic Actuators for XE-1 Applications (see Appendix A), and performed under T-711892B, Qualification Tests, Environmental, Control Drum Actuator (see Appendix B), with a few minor exceptions noted herein. The basis for the shock levels was AGC Specification 90016-C. The shock levels of this test equaled or exceeded these specified values.

4.1.2 The purpose of the shock test was to determine what changes, if any, would occur in the actuator performance when the actuator was subjected to a mechanical shock. The mechanical shock as specified in Appendix A was selected to closely approximate the maximum anticipated environment to which the actuator will be subjected during both ground handling and engine operation.

4.1.3 The method of testing was to operate the actuator with various input commands before, during and after the application of controlled shocks in all three planes and to record actuator performance for each condition. A comparison of the various records defines the effects of the induced environment on the performance of the actuator system.

\subsection{DESCRIPTION OF TEST SET-UP}

4.2.1 The mechanical shock testing of the XE-1 actuator was performed in the WANL Mechanisms Laboratory between November 16, 1967 and November 21, 1967. The actuator used was an XE-1 Series, Serial Number A-58608, and the actuator control amplifier was Serial Number A-62960. The combination of actuator and amplifier comprises the closed loop position control system. Only the actuator was subjected to the induced environments as the amplifier is mounted in the Test Cell Building. 


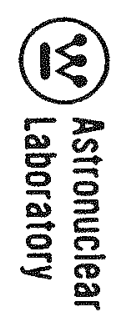

\begin{tabular}{|c|c|c|c|c|c|}
\hline Plane & $\begin{array}{c}\text { Actuator } \\
\text { Condition }\end{array}$ & $\begin{array}{c}\text { Load } \\
\left(g^{\prime} s\right)\end{array}$ & $\begin{array}{c}\text { Dwell Time } \\
(\mathrm{sec})\end{array}$ & $\begin{array}{c}\text { Shocks in } \\
\text { Each Direction }\end{array}$ & $\begin{array}{c}\text { Shocks in } \\
\text { Each Plane }\end{array}$ \\
\hline Vertical $\left(a_{z}\right)$ & Operating & \pm 2.0 & 0.01 & 3 & 6 \\
Horizontal $\left(a_{y}\right)$ & Operating & \pm 1.0 & 0.01 & 3 & 3 \\
Horizontal $\left(a_{x}\right)$ & Operating & \pm 1.0 & 0.01 & 6 \\
\hline
\end{tabular}

Figure 4. 1. Shock Schedule 


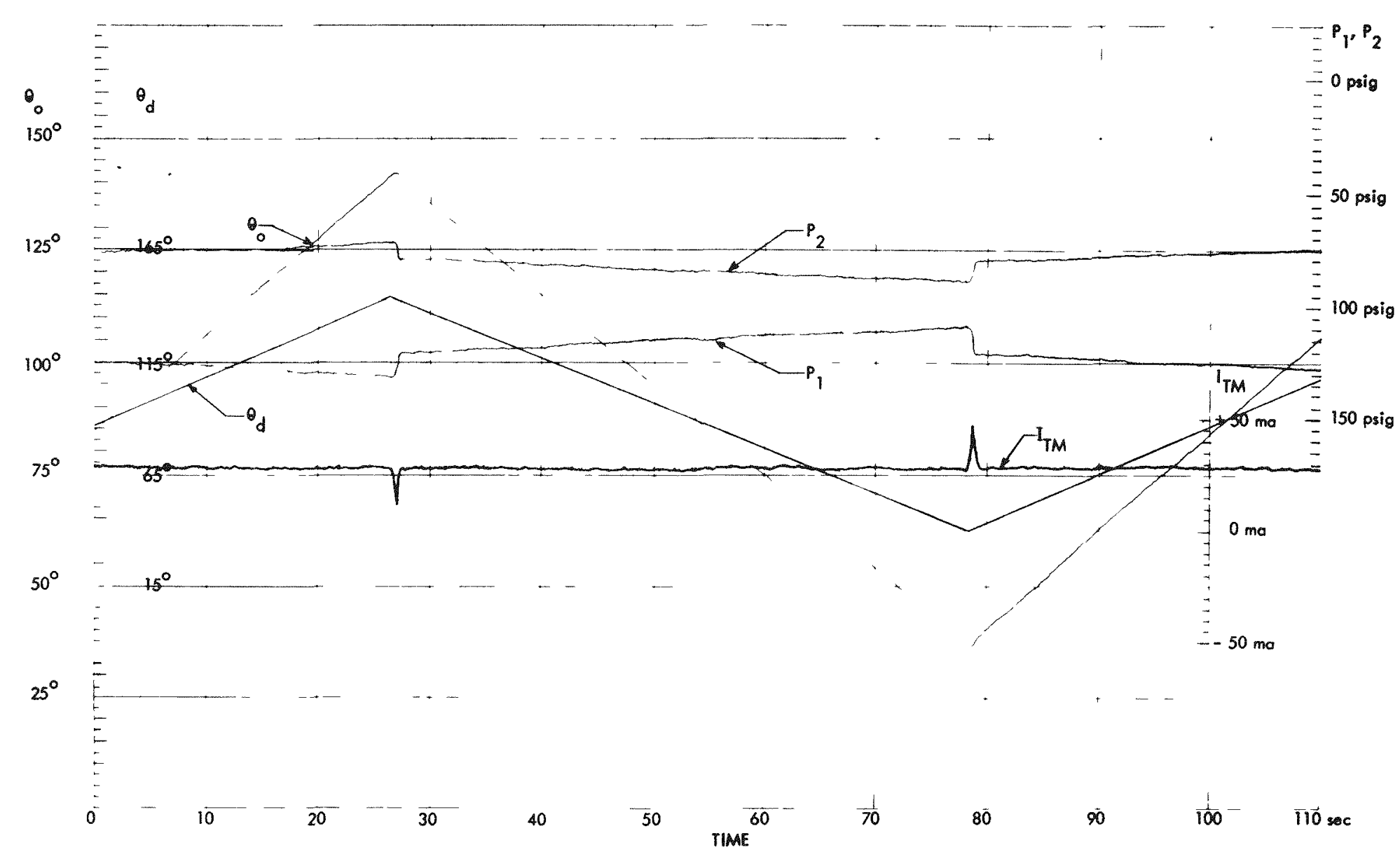

Figure 4.2. Typical $3^{\circ} / \mathrm{Sec}$ Ramp During Mechanical Shock 
Scram Turnaround

Time (sec)

$\%$ BLD

Rise Time (in)

Time (sec)

$\triangle \% B L D$

Rise Time (out)

Time (sec)

$\triangle \%$ BLD

Overshoot (in)

Degrees

$\%$ of $18^{\circ}$

Overshoot (out)

Degrees

$\%$ of $18^{\circ}$

Settling Time (in)

Time (sec)

$\triangle \%$ BLD

Settling Time (out)

Time (sec)

$\triangle \%$ BLD

Dynamic Resolution

Max. Deviation

from BLD after

Shock (Degrees)

\begin{tabular}{cccc}
$\begin{array}{c}\text { Shock } \\
B L D\end{array}$ & $\begin{array}{c}\text { Horizontal } \\
\left(a_{x}\right)\end{array}$ & $\begin{array}{c}\text { Horizontal } \\
\left(a_{y}\right)\end{array}$ & $\begin{array}{c}\text { Vertical } \\
\left(a_{z}\right)\end{array}$ \\
\hline
\end{tabular}

0.032

0.026

0.025

0.021

$-18.75$

$-21.9$

$-28.1$

0.116

0.118

0.124

0.117

$+1.72$

$+6.89$

$+0.86$

0.135

0.139

0.145

0.128

$+2.96$

$+7.41$

$-5.18$

0.6

3.33

0.3

1.67

0.3

1.67

0.5

2.78

\section{3}

1.67

0.2

1.11

0.2

0.5

1.11

2.78

0.178

0.172

0.190

0.186

$-3.38$

$+6.74$

$+4.50$

0.208

0.212

0.220

0.213

$+1.92$

$+5.77$

$+2.41$

0.18

0.33

0.20

Figure 4.3. Table of Shock Test Data 
4.2.2 The test set-up used in the mechanical shock tests was the same as that used for vibration testing. The only exception was that a step input voltage was used to produce the shock pulses. For a detailed description of the equipment used and the test set-up, refer to Sections 3.2 .3 through 3.2 .7 , inclusive.

\subsection{DESCRIPTION OF TEST PROCEDURE}

4.3.1 The schedule for shock testing is given in Figure 4.1. The actual sequence for the test was: horizontal $\left(a_{x}\right)$, horizontal $\left(a_{y}\right)$, and vertical $\left(a_{z}\right)$. The sequence of testing was changed because the actuator was in the horizontal $\left(a_{x}\right)$ position after completion of the vibration test series. To maintain continuity of the overall environmental testing and to avoid needless repetition of the test set-up, this position was chosen to be first in the shock test plan. The base line data for the shock test was that obtained at the end of the vibration test.

4.3.2 During each series of shocks, the actuator was operated with a $3^{\circ} /$ sec ramp over a range of $100^{\circ}$. The shocks were applied at some point during the ramp. The actuator parameters were measured and recorded. A typical plot of positions versus time for the $3^{\circ} /$ sec ramp is shown in Figure 4.2. No disturbance can be identified with the applied shocks.

4.3.3 After six (6) shocks in each plane, the actuator performance was measured and recorded. The results of these tests were compared with the base line data to detect any deviation and to determine the actuator ability to function properly under conditions of mechanical shock.

\subsection{DISCUSSION OF TEST RESULTS}

4.4.1 The results of the scram turnaround, transient response and dynamic response tests were reduced from visicorder and $X-Y$ plots and tabulated in Figure 4.3. A typical scram response curve was shown previously in Figure 3.8 . 
4.4.1.1 After the initial series of six shocks in the $a_{x}$ direction, the scram turnaround time was reduced by $18.75 \%$ of its base line data value and continued to be reduced for each subsequent series of shocks. This reduction of scram turnaround time was probably due to a reduction of internal static friction. These changes are not surprising since the scram measurements are open loop measurements. Later modifications to the XE actuator amplifiers incorporated a closed loop scram circuit to reduce the effects of parameter variations on performance results.

4.4.1.2 The transient response rise times and settling times are tabulated in Figure 4.3. The rise and settling times changed little throughout the test.

4.4.1.3 The overshoot to an $18^{\circ}$ step input is also given in Figure 4.3. The percent overshoot was less than $3.33 \%$ of the $18^{\circ}$ command value while the greatest change in percent overshoot was $2.22 \%$.

4.4.1.4 From Figure 4.3, the greatest deviation from the base line data for the dynamic resolution curves was $0.33^{\circ}$.

4.4.1.5 The closed loop frequency response curves are shown as Figures 4.4, 4.5 and 4.6. The base line data curve is shown as Figure 3.13 of the vibration test. The qualification limits, taken from the base line data curve, are superimposed on the other three curves. The curves for the $a_{x}$ and $a_{y}$ direction are within the limits. The curve for the $a_{z}$ direction shows a decrease in gain and phase for frequencies above $4 \mathrm{~Hz}$. The decrease in gain and phase and the absence of peaking is indicative of a reduction in static friction which agrees with the scram and transient response. The reduction of peaking also suggests an increase in stability of the closed loop system. 


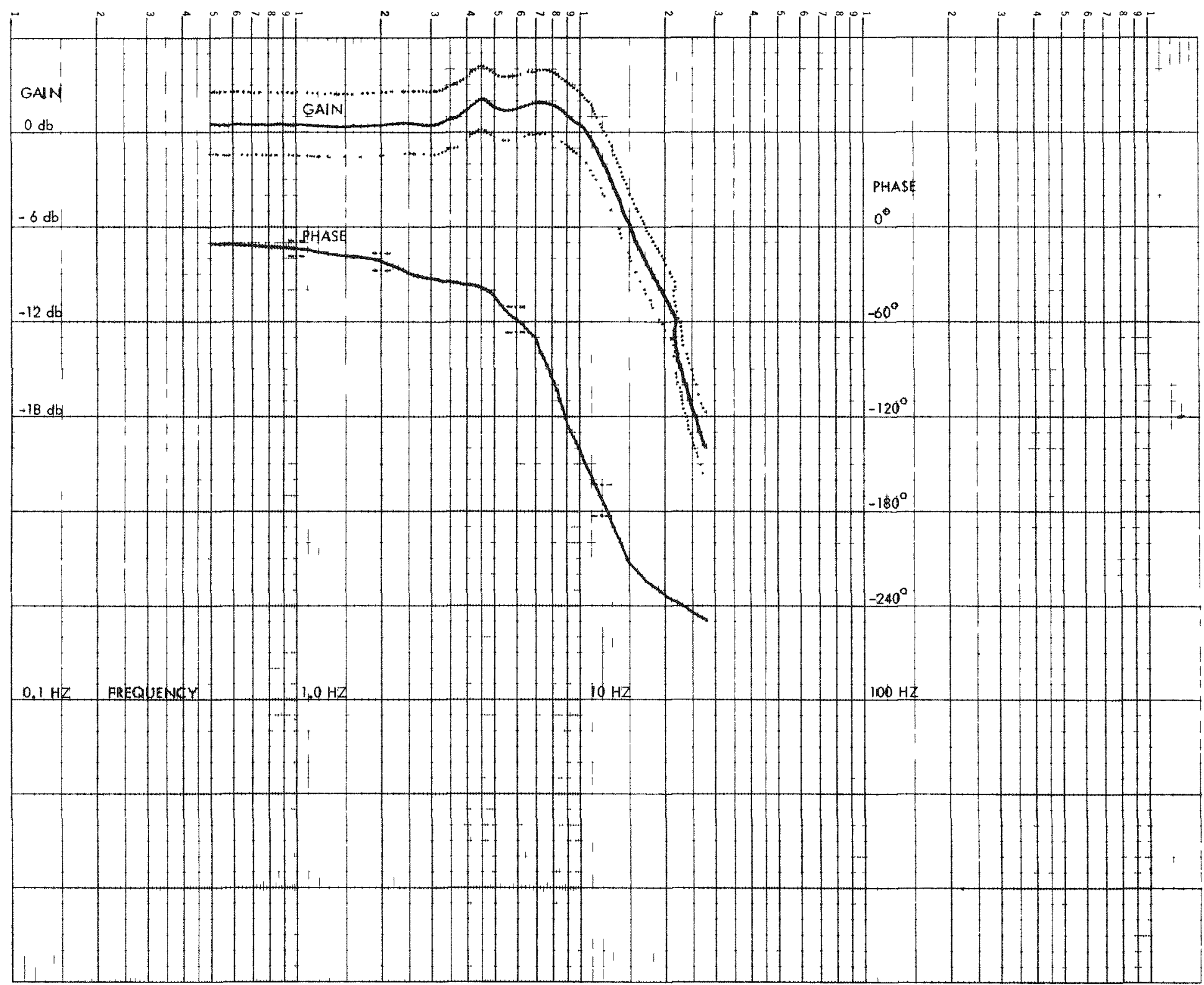

Figure 4.4. Closed Loop Frequency Response - Base Line Data

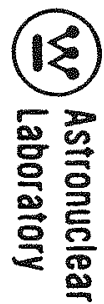




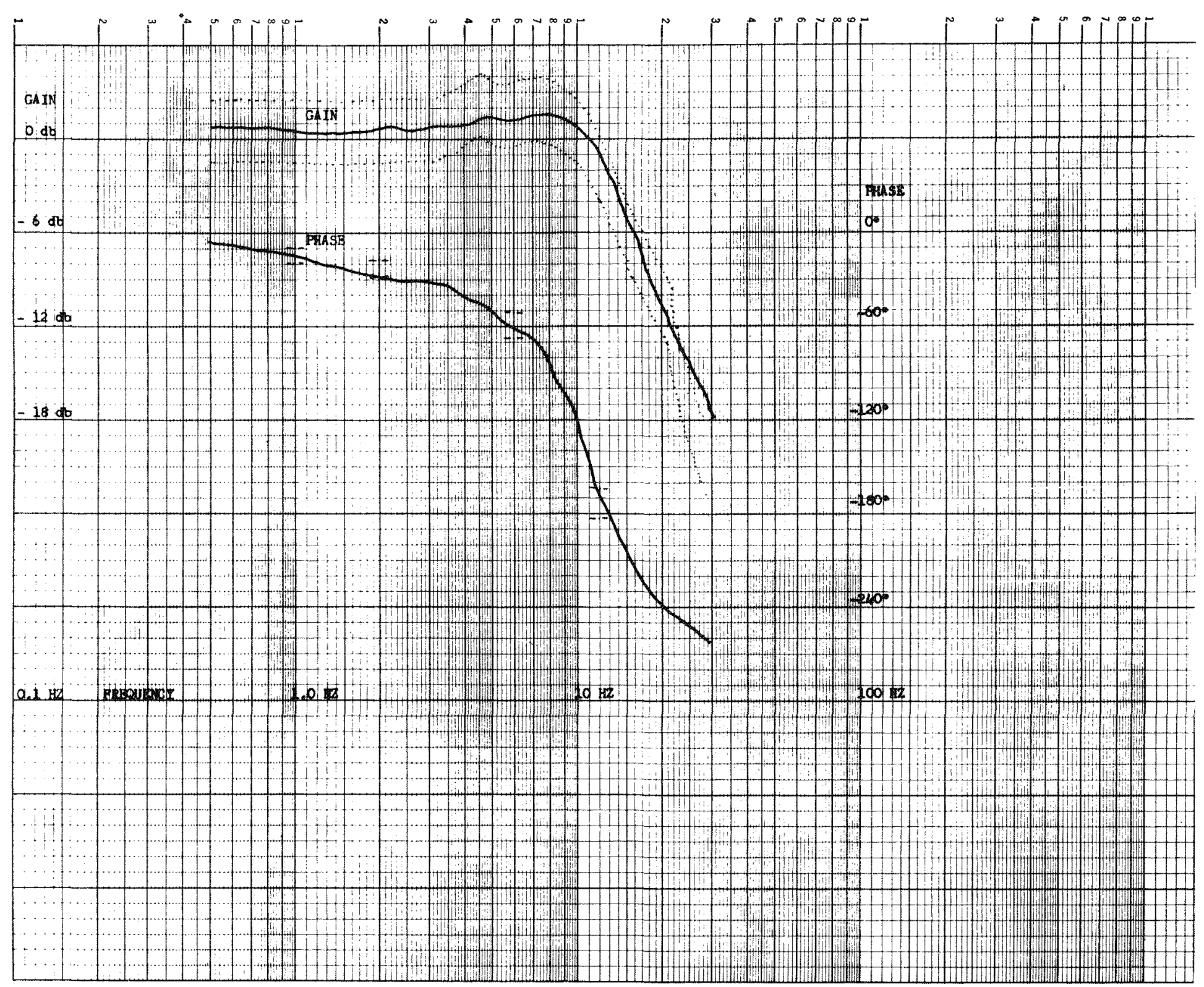

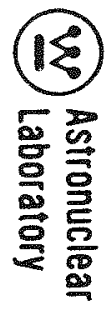

Figure 4.5. Closed Loop Frequency Response - After Shocks in $a_{x}$ Direction 


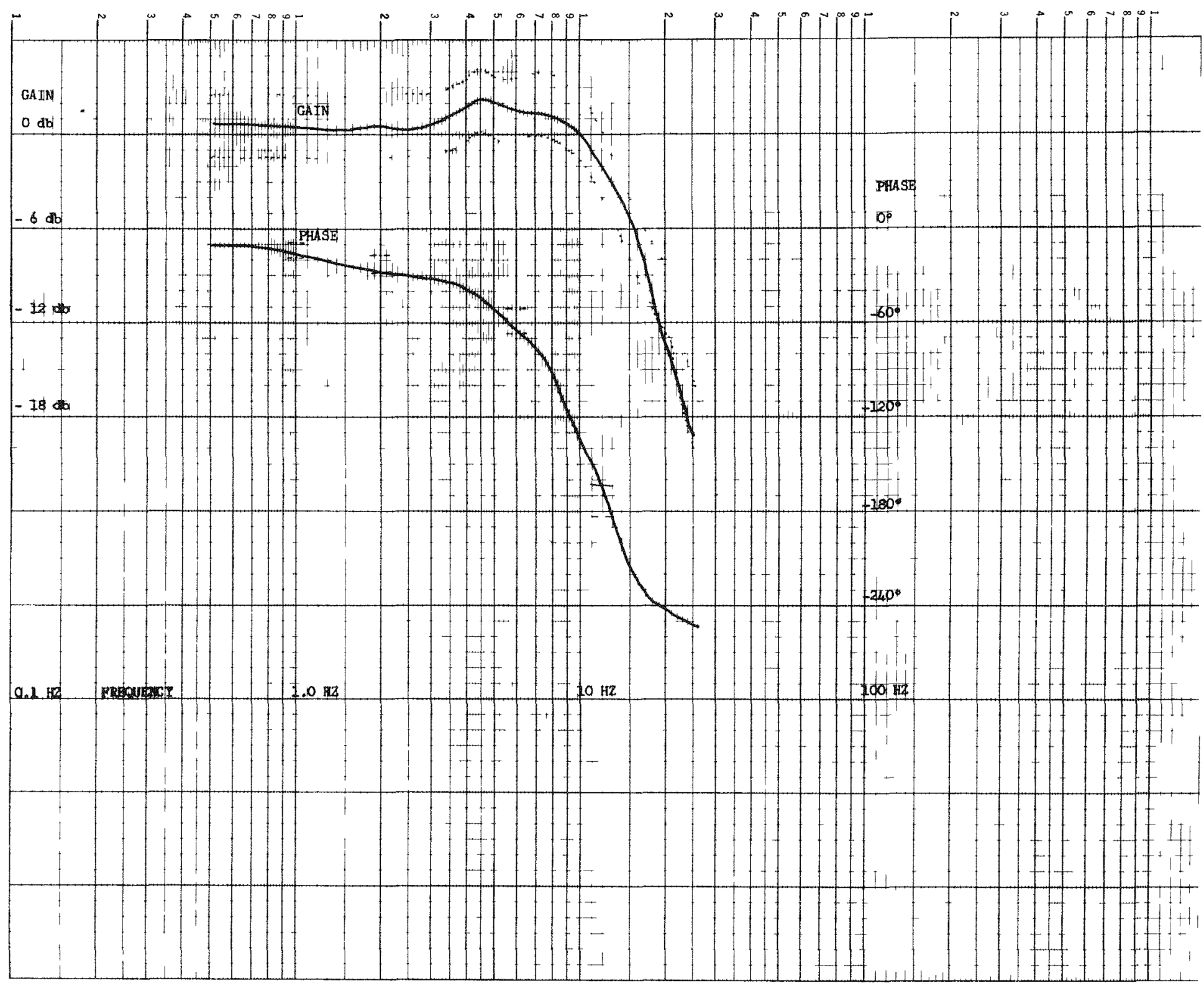

Figure 4.6. Closed Loop Frequency Response -After Shocks in $a_{y}$ Direction

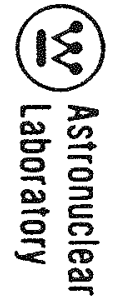




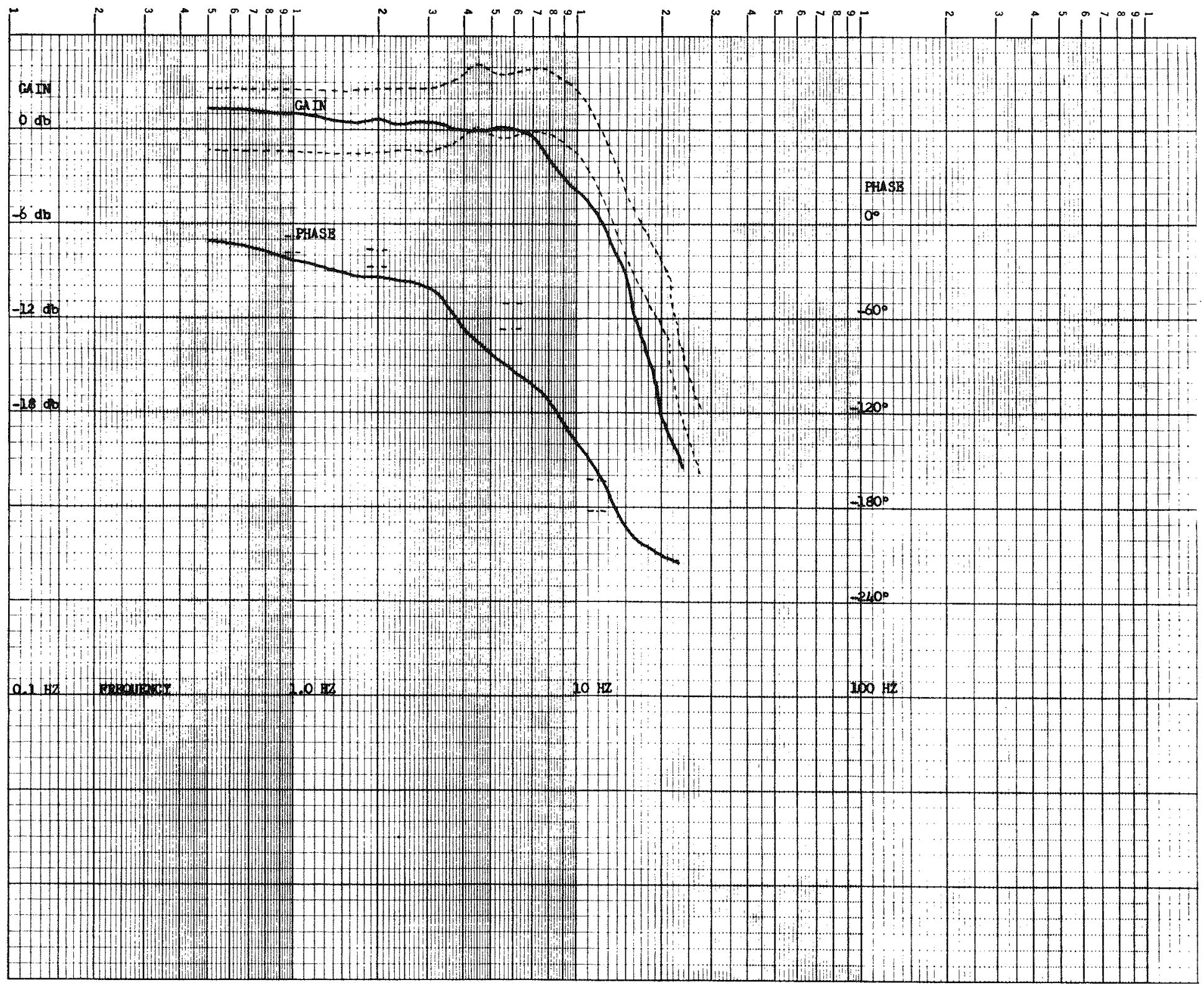

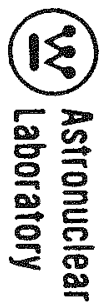

Figure 4. 7. Closed Loop Frequency Response - After Shocks in $a_{z}$ Direction 


\subsection{LOW TEMPERATURE TEST}

\section{$5.1 \quad$ INTRODUCTION}

5.1.1 The low temperature qualification test was conducted within the guidelines specified in WANL-TME-1040, Revision A, Qualification Specifications for Control Drum Pneumatic Actuators for XE-1 Applications (see Appendix A), and performed under T-711892C, Qualification Test, Environmental, Control Drum Actuator (see Appendix B), with a few minor exceptions noted herein.

5.1.2 The purpose of the low temperature test was to determine what changes in performance, if any, the XE control drum actuator would undergo when operated in a cryogenic environment. An additional objective was to determine the actuator sensitivity to condensible contamination. For this purpose, a cryotrap and counterflow heat exchanger was installed in the drive gas supply line. A bypass around the heat exchanger permitted it to be inserted into or taken out of the flow path as desired. The cryogenic environment was specified to be equal to or lower than that expected during NERVA engine operation.

The basis for the low temperature extreme was originally established by review of appropriate station data from the NRX series full power reactor tests. This review resulted in an actuator design temperature of about $250^{\circ} \mathrm{R}$. Subsequent issue of AGC Specification 90016-C reduced the low temperatures limit to about $212^{\circ} \mathrm{R}$. All actuator low temperature testing was conducted at the most convenient test point below this limit, that is, the temperature of $L N_{2}\left(140^{\circ} \mathrm{R}\right)$. This test temperature was felt to provide a large safety margin below the expected low temperature extreme. Further updating of available analyses predicted low reactor power hold, dome temperatures as low as $60^{\circ} \mathrm{R}$. Actuator coolant is supplied directly from the reactor dome. Therefore, although pressure at this hold point (and therefore actuator coolant flow) was only about $10 \%$ of design, the possibility existed 
that actuator temperature could conceivably be below design and below the lowest test temperature. An additional objective of the low temperature test was inserted into the test program to determine the lowest acceptable actuator temperature allowable and still maintain acceptable stability margins of performance.

5.1.3 The method of testing was to operate the actuator at ambient temperature with various position commands to defermine the ambient performance characteristics. The actuator temperature was then to be lowered using cryogenic coolant gas and either ambient or cryogenic drive gas. During the cooldown transient, the actuator was operated in various modes. Once a constant temperature was reached, the cryogenic performance characteristics were to be determined.

\subsection{DESCRIPTION OF TEST SET-UP}

5.2.1 The low temperature testing of the XE-1 actuator was performed at the NASA Lewis Research Center, Cleveland, Ohio, on October 14, 1967 and December 2, 1967. The actuator used for the test was an XE-1 Series, Serial No. A-58608, and the actuator control amplifier was Serial No. A-62960.

5.2.2 The gas system is shown in Figure 5.1. Hydrogen gas was used for both drive and coolant during the actual test while helium gas was used for initial set-up of the actuator and also to purge the system of hydrogen when required. The working fluid, obtained from hydrogen or helium storage trucks, was first reduced in pressure and then cooled as required. The cooling was accomplished by pre-cooling the gas in a liquid nitrogen heat exchanger and then cooling to $50^{\circ} \mathrm{R}$ in a liquid hydrogen heat exchanger.

The desired temperature gas was then obtained by means of two separate pairs of temperature mixing valves: one pair for coolant and one pair for drive. The required coolant and drive pressures were then set by regulators. 


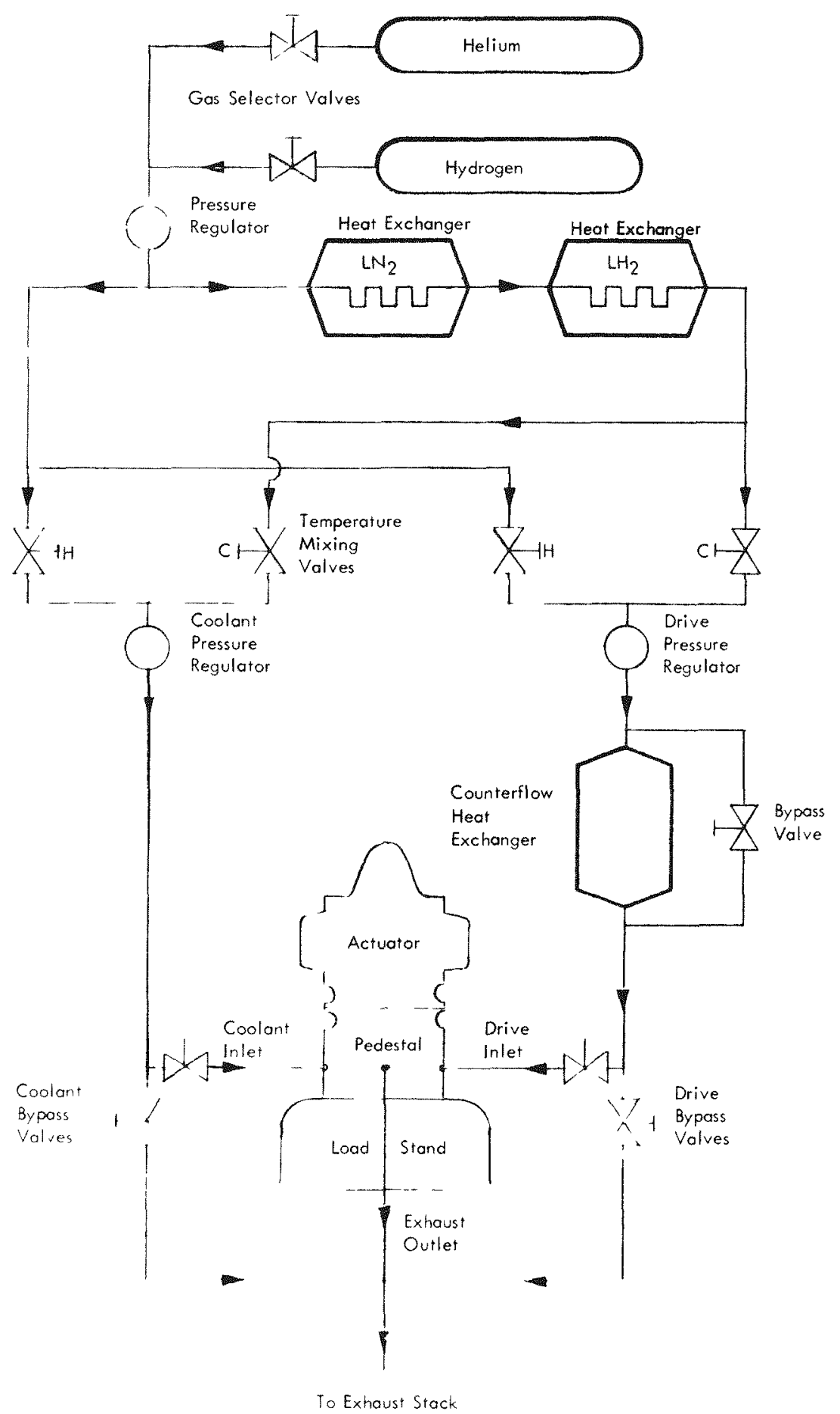

Figure 5. 1. Gas Supply System for Low Temperature Test 
A counterflow heat exchanger was used in the drive gas supply line. Its purpose was to trap any impurities in the drive gas whenever warm drive gas was delivered to a cold actuator. When not in use, it was bypassed.

To achieve rapid cooldown and warmup of the lines, bypass valves were placed in the coolant and drive lines in close proximity to the actuator. When the bypass lines were opened, the flow of gas in the system was increased and exhausted to the exhaust stack, thus affording the desired piping system rapid cooldown.

Thermocouples were provided at the coolant and drive inputs, the actuator exhaust outlet, the actuator housing and the counterflow heat exchanger inlet.

In order to ensure adequate ventilation in case of hydrogen leakage, the actuator was open to the atmosphere. The load stand was thermally insulated at its base by being mounted on a plywood platform.

5.2.3 The following equipment was used to determine actuator performance:

Boonshaft Transfer Function Analyzer

Brush 8 Channel Strip Chart Pen Recorder

Honeywell $X-Y$ Chart Recorder

Hewlett Package Function Generator

Bristol 24-Channel Temperature Recorder

\subsection{DESCRIPTION OF TEST PROCEDURE}

5.3.1 Prior to cryogenic operation, the actuator was operated on ambient $\left(520^{\circ} R-540^{\circ} R\right)$ hydrogen in order to obtain base line data. After ambient operation, the actuator was shut down and the drive and coolant gas was diverted by way of the bypass valves. The reason for this was to cool the drive and coolant gas lines to cryogenic temperature and then apply the cold gas to the actuator to obtain the fastest possible cooldown transient. 
5.3.2 The following series of tests was developed to simulate maximum effected temperature transients under various operating and non-operating conditions.

5.3.2.1 Thermal Test No. 1 - No cryogenic trap is operating for this test.

5.3.2.1.1 Start at $530^{\circ} \mathrm{R}$, precool facility lines to actuator.

5.3.2.1.2 Introduce $60^{\circ} \mathrm{R}$ drive gas and coolant gas.

5.3.2.1.3 During thermal transient command actuator on a $100^{\circ}$ ramp at $3^{\circ} / \mathrm{sec}$.

5.3.2.1.4 When temperatures stabilize (approximately $60^{\circ} \mathrm{R}$ ) run actuator base line data tests.

5.3.2.1.5 Introduce $530^{\circ} \mathrm{R}$ drive gas and coolant gas.

5.3.2.1.6 During thermal transient command actuator on a $100^{\circ}$ ramp at $3^{\circ} / \mathrm{sec}$.

5.3.2.2 Thermal Test No. 4 - No cryogenic trap during this test unless freezeup is noticed; then switch to cryogenically trapped drive gas.

5.3.2.2.1 Start at $530^{\circ} \mathrm{R}$, precool facility lines to actuator.

5.3.2.2.2 Introduce $60^{\circ} \mathrm{R}$ coolant gas and $530^{\circ} \mathrm{R}$ drive gas.

5.3.2.2.3 During thermal transient command actuator on a $100^{\circ}$ ramp at $3^{\circ} / \mathrm{sec}$.

5.3.2.2.4 When temperatures stabilize rerun base line data tests.

5.3.2.2.5 During thermal transient command actuator on a $100^{\circ}$ ramp at $3^{\circ} / \mathrm{sec}$.

5.3.2.3 Thermal Test No. 2 - No cryogenic trap during this test.

5.3.2.3.1 Repeat 5.3.2.1 except keep actuator locked during 5.3.2.1.3 and

\subsubsection{6.}


5.3.2.4 Thermal Test No. 3 - No cryogenic trap during this test unless freezeup is noticed; then switch to cryogenically trapped drive gas.

5.3.2.4.1 Start at $530^{\circ} \mathrm{R}$, precool facility lines to actuator.

5.3.2.4.2 Introduce $60^{\circ} \mathrm{R}$ drive and coolant gas.

5.3.2.4.3 During thermal transient command actuator on a $100^{\circ}$ ramp at $3^{\circ} / \mathrm{sec}$.

5.3.2.4.4 When temperatures stabilize rerun base line data tests.

5.3.2.4.5 Switch to $530^{\circ} \mathrm{R}$ drive gas.

5.3.2.4.6 During thermal transient command actuator on a $100^{\circ}$ ramp at $3^{\circ} / \mathrm{sec}$.

5.3.2.4.7 When temperatures stabilize rerun base line data tests.

\subsection{Switch to $530^{\circ} \mathrm{R}$ coolant gas.}

5.3.3 Only three of the planned thermal cycles were performed on the actuator because of available time. Thermal Cycle No. I was performed on October 14, 1967. It consisted of applying a $3^{\circ} / \mathrm{sec}$ ramp command of $100^{\circ}$ amplitude to the actuator as it was cooling down with both cryogenic coolant and drive gas. Thermal Cycle No. 2 was performed on December 2, 1967. It consisted of applying a $3^{\circ} / \mathrm{sec}$ ramp command of $100^{\circ}$ amplitude to the actuator as it was cooling down with cryogenic coolant. The drive gas was maintained at ambient temperature. Thermal Cycle No. 3 was also performed on December 2, 1967. it consisted of locking the actuator and leaving it de-energized during cooldown. Thermal Test No. 4 was not performed due to lack of facility time. The first three (3) tests adequately simulated operating conditions.

\subsubsection{Once a cryogenic equilibrium temperature was reached, the actuator was} subjected to a series of functional tests. The results of these cryogenic tests were compared with the ambient base line data and the comparison was used to evaluate the performance of the XE-1 actuator under cryogenic temperature conditions. 
(2) Astronuclear

Laboratory

\subsection{DISCUSSION OF TEST RESULTS}

5.4.1 The graph of temperature excursion versus time for Thermal Cycle No. 1 is presented in Figure 5.2. The three temperature curves are drive gas, coolant gas, and the actuator skin temperature. During the cryogenic part of Thermal Cycle No. 1, it was noted that the lock indicating light failed to come on. However, the actuator was in a locked condition. Upon completion of the cryogenic test, the actuator was warmed up with the lock energized. Time "A" shows the temperatures where the lock began to function normally. A subsequent evaluation indicated that the lock failure was due to a shifting of the lock indicator switch cam and not due to binding or galling of the lock pin. After Thermal Cycle No. 1, the lock mechanism was disassembled and inspected for any evidence of galling. No evidence was found; therefore, the lock was reassembled in the actuator and recalibrated. This malfunction did not repeat on subsequent tests.

\subsubsection{Temperatures for Thermal Cycle No. 2 are represented in Figure 5.3. No} anomalies were noted during Thermal Cycle No. 2.

5.4.3 The temperature curves for Thermal Cycle No. 3 are shown in Figure 5.4. From the start of cooldown to time " $A$ ", the actuator was locked at the $15^{\circ}$ position. At time "A", the actuator was unlocked and commanded to the $90^{\circ}$ position in preparation for obtaining actuator performance data. The actuator responded very slowly to the applied commands. This slow response characteristic persisted and gradually resulted in an inability to control the actuator position. This anomaly was attributed to frozen gaseous drive gas contamination collecting in the servovalve flapper nozzles. At time "B", the temperature of the drive gas was increased with the coolant gas left at the same low temperature. This rise in drive gas temperature from about $80^{\circ} R$ to about $130^{\circ} R$ was enough to free the valve of contamination. Control of the actuator was regained at time " $\mathrm{C}$ " and the drive gas temperature was again lowered to see if the contamination freezing 
(W) Astronuclear

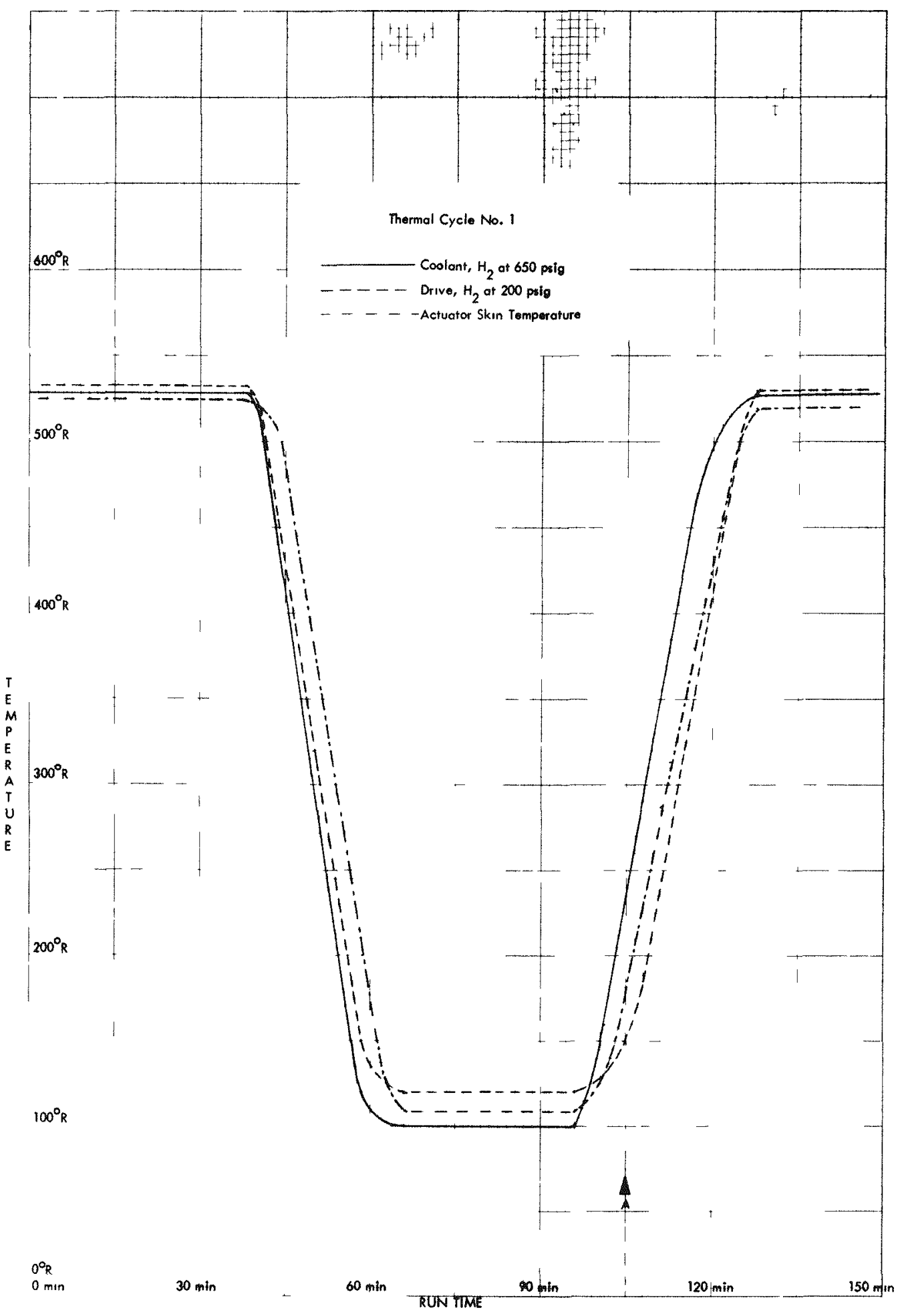

Figure 5.2. Thermal Cycle No. I Temperature vs. Time Curve 
(2) Astronuclear
Laboratory

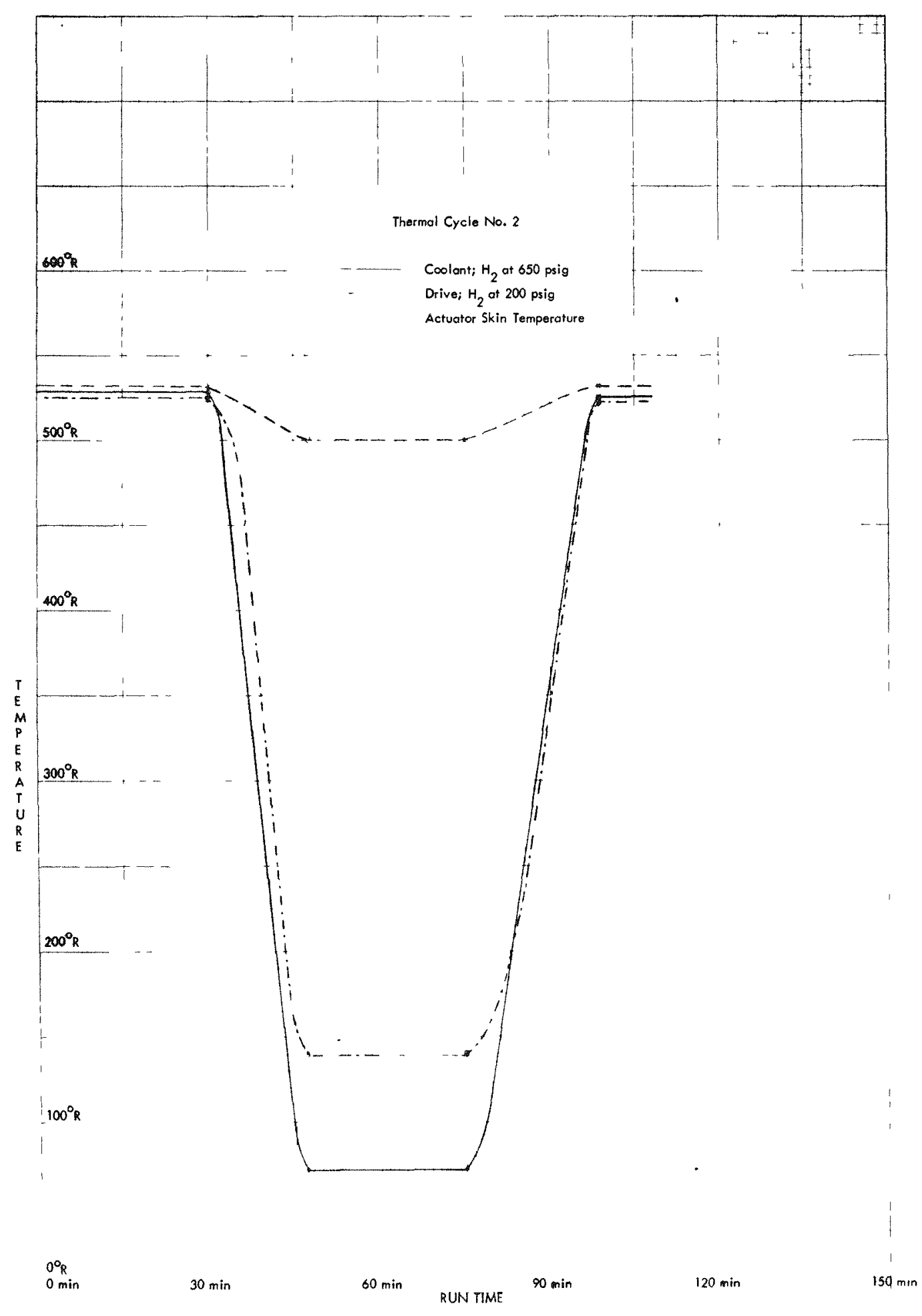

Figure 5.3. Thermal Cycle No. 2 Temperature vs. Time Curve 


\section{(W) Astronuclear \\ Laboratory}
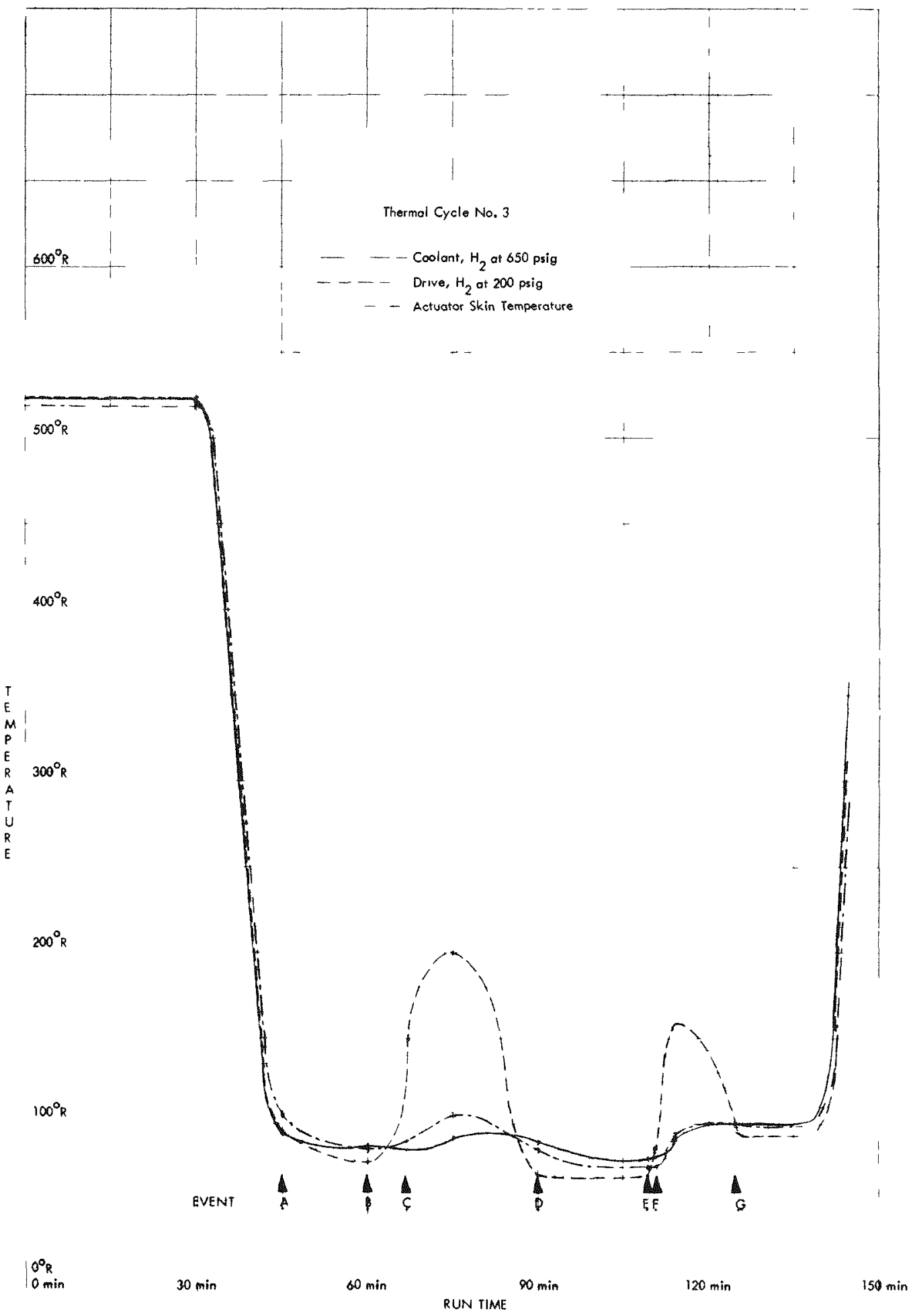

Figure 5.4. Thermal Cycle No. 3 Temperature vs. Time Curve 
reoccurred. The drive gas temperature stabilized at time " $D$ " and, since no evidence of contamination freezing was present and the actuator was under control, the actuator was subjected to the standard performance tests.

After obtaining the actuator performance data, the actuator was locked and the torque motor current turned off for five minutes. The actuator was then unlocked, commanded to $90^{\circ}$, and scrammed several times. After the scrams and just before time "E", an oscillation of the actuator servovalve appeared. The frequency of oscillation was in the audio range (approximately $800 \mathrm{~Hz}$ ) and was a servovalve instability induced by the low temperature of the actuator. At time "E", the drive gas was again warmed up and the oscillation stopped at time "F".

Once the oscillation stopped, the drive gas was cooled and at time " $G$ " the actuator was again subjected to performance tests and the test concluded, as was predicted, margins of stability are inadequate when the actuator is operated near $\mathrm{LH}_{2}$ temperature which is far below its design limit. From these tests, it appears that operating the actuator below about $100^{\circ} \mathrm{R}$ results in operation in a region where reliable valve control cannot be guaranteed. Therefore, $100^{\circ} \mathrm{R}$ must be considered the lowest operating temperature with $140^{\circ} \mathrm{R}$ a more conservative lower limit.

5.4.4 The results of the dynamic resolution, transient response and scram turnaround tests are tabulated in Figure 5.5. Because of the different dates of the tests, Thermal Cycle No. 1 (October 14, 1967) has its own base line data while Thermal Cycles No. 2 and No. 3 (December 2, 1967) have a different base line data. With the exception of Thermal Cycle No. 2, the scram turnaround times tended to decrease while the actuator was at cryogenic temperatures. The drive gas for Thermal Cycle No. 2 was at ambient with a higher viscosity than cryogenic drive gas, which results in the longer turnaround times. Thermal Cycle No. 3 was divided into No. 3A and No. 3B taken before and after the servovalve oscillation. Data for Thermal Cycle No. 3A was taken between times "D" 


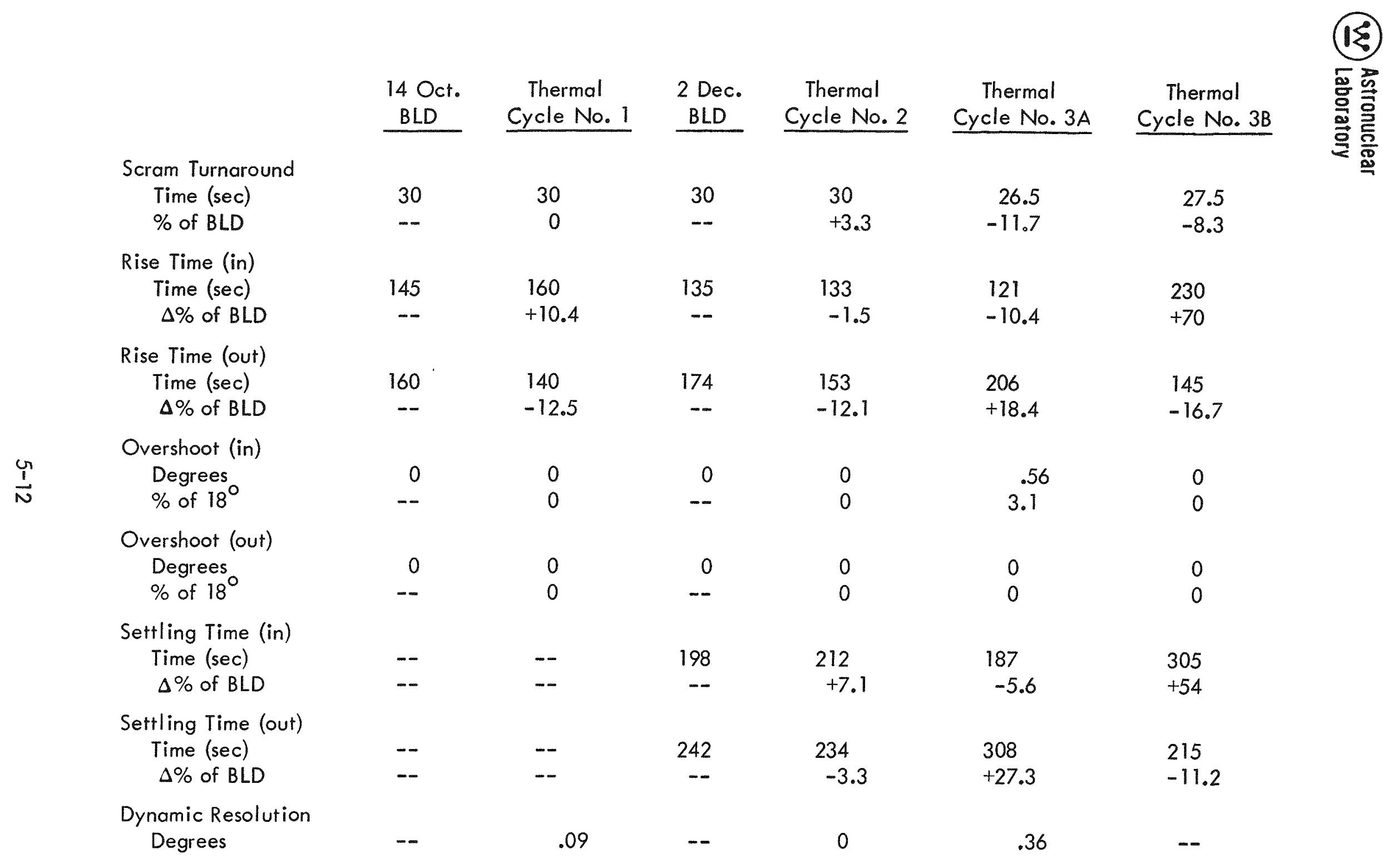

Figure 5. 5. Table of Low Temperature Test Data 
and "E" while Thermal Cycle No. 3B was between time " $G$ " and the end of the test. The overshoot noted for Thermal Cycle No. 3A is within specification values, but relatively larger than other data, and is indicative of a decrease in actuator friction.

5.4.5 The results of the frequency response tests are presented in Figures 5.6 to 5.11. The corresponding line data curves are superimposed on the cryogenic data curves. The increase in peaking and the rapid drop in phase angle of Thermal Cycle No. 3A indicates a reduction in friction and a decrease in stability. 


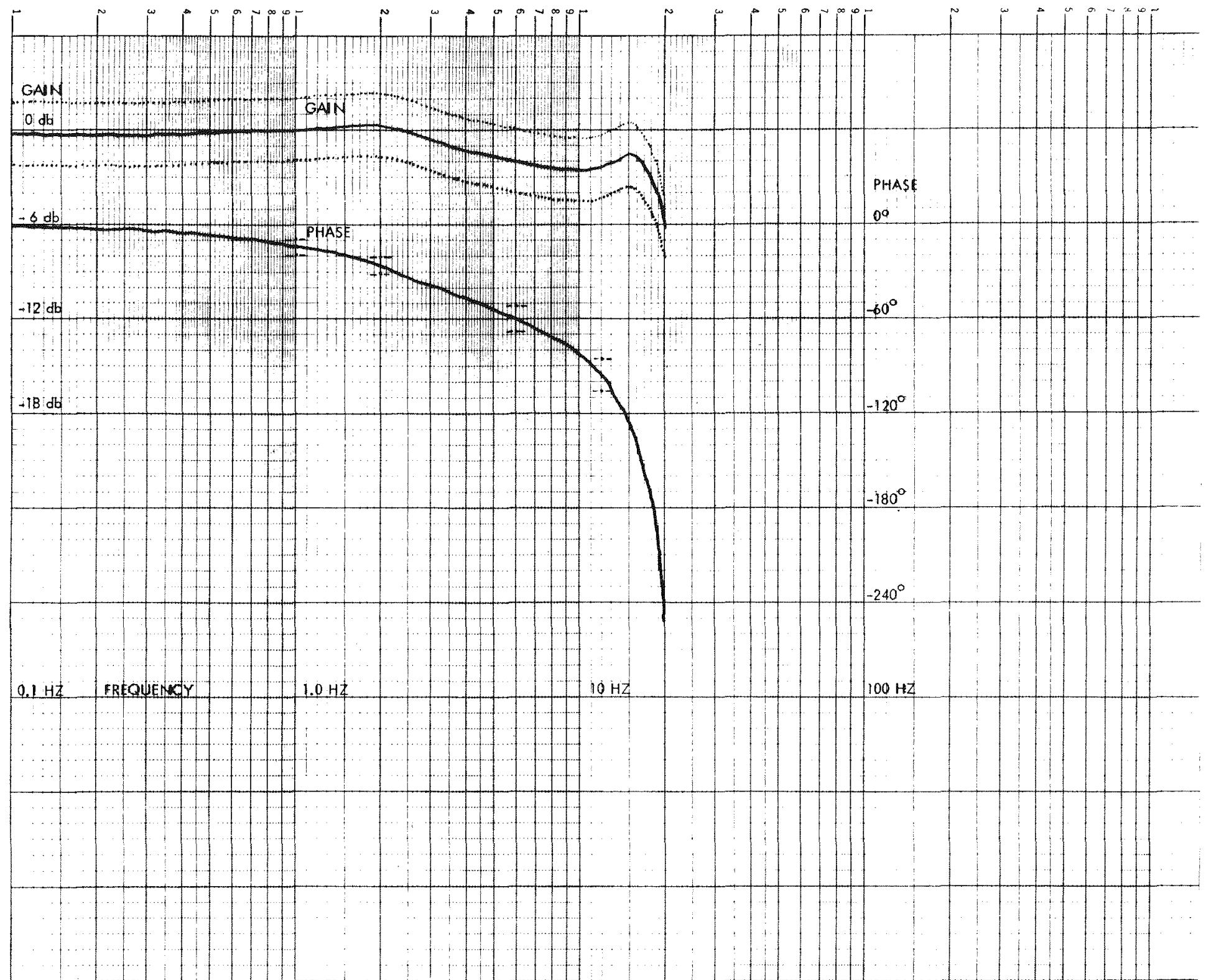

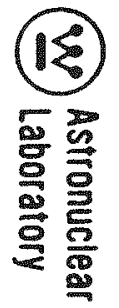

Figure 5.6. Closed Loop Frequency Response Base Line Data Thermal Cycle No. 1 


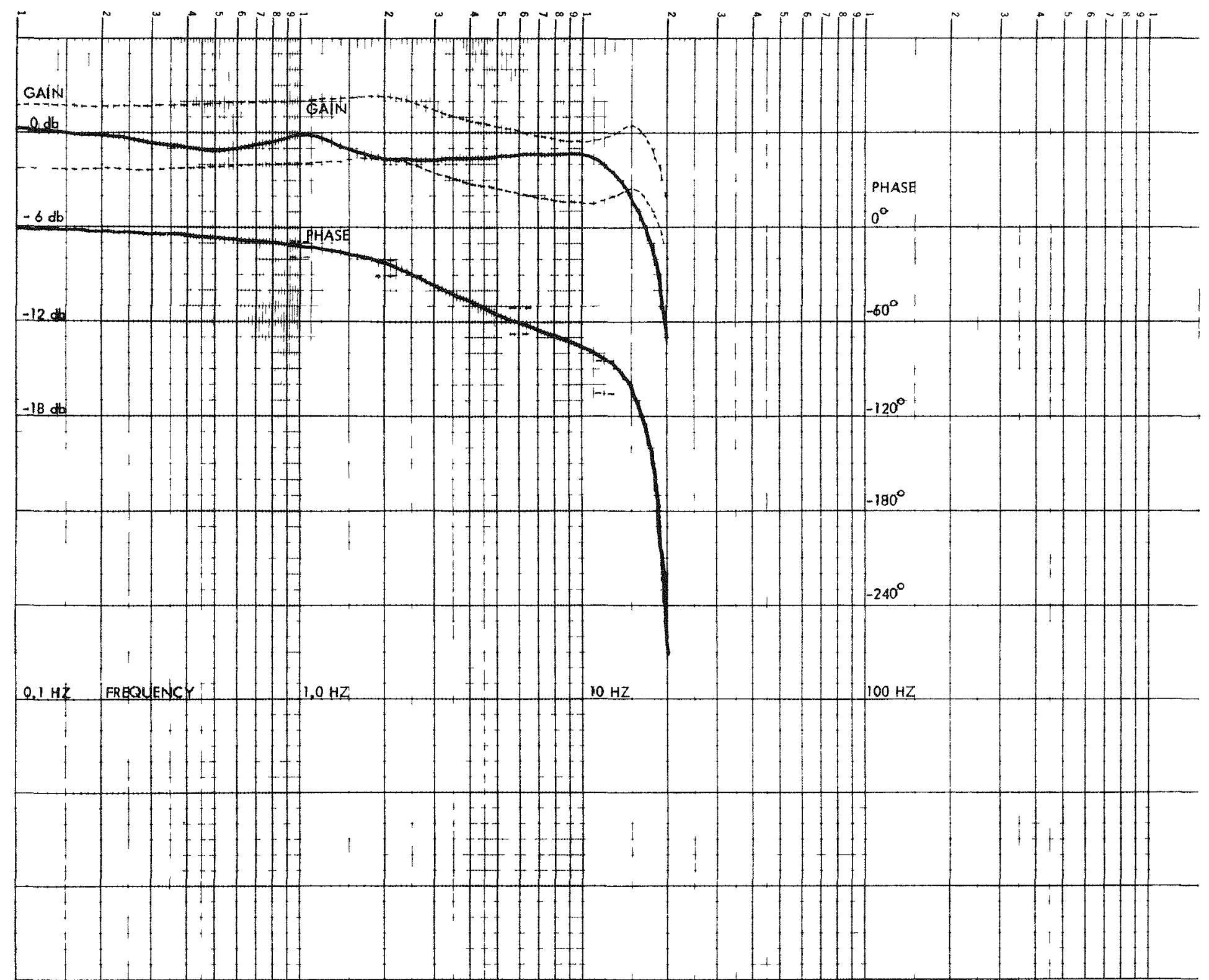

Figure 5.7. Closed Loop Frequency Response during Thermal Cycle No. 1 


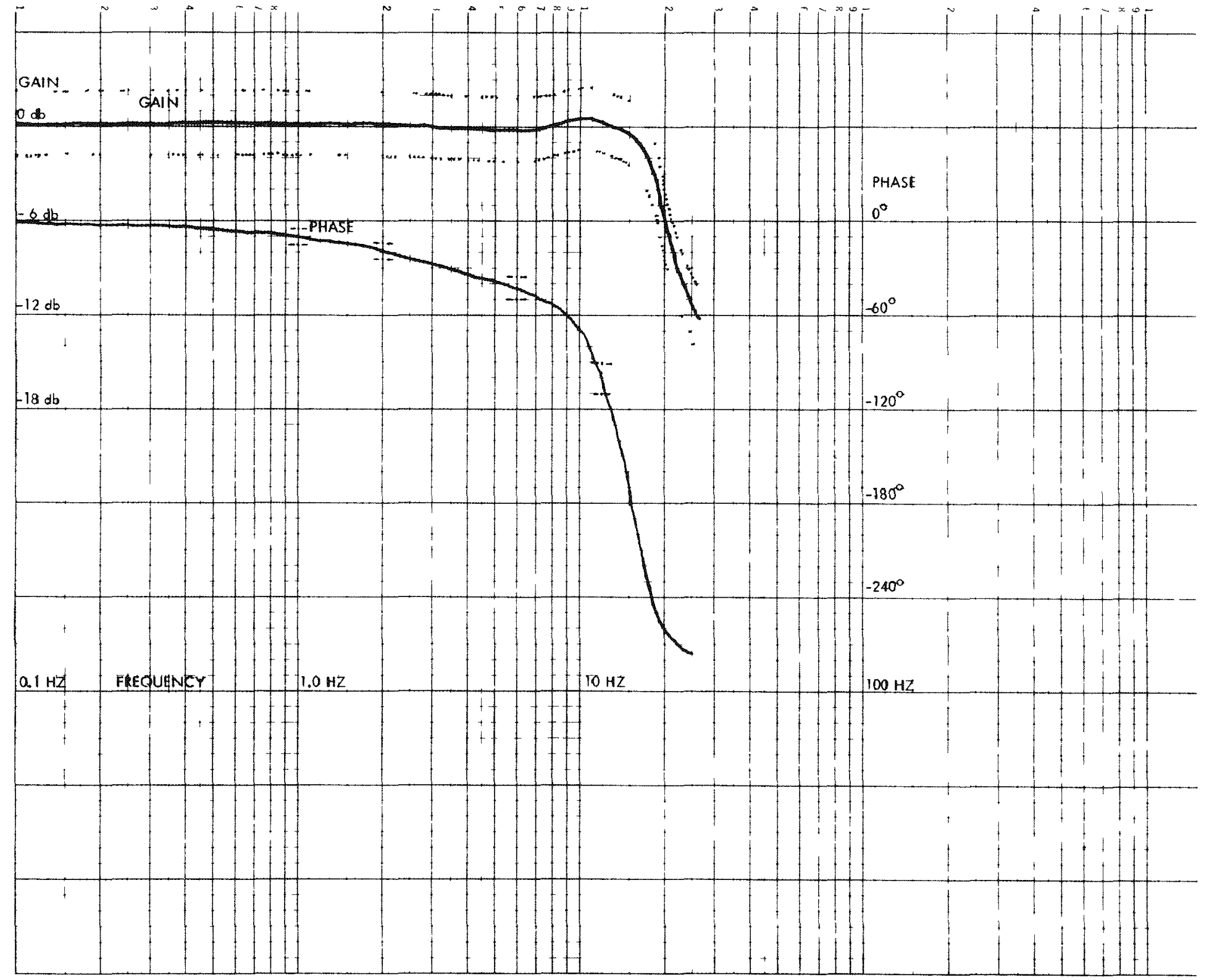

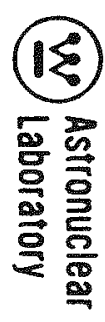

Figure 5.8. Closed Loop Frequency Response Base Line Data Thermal Cycles No. 2 \& No. 3 


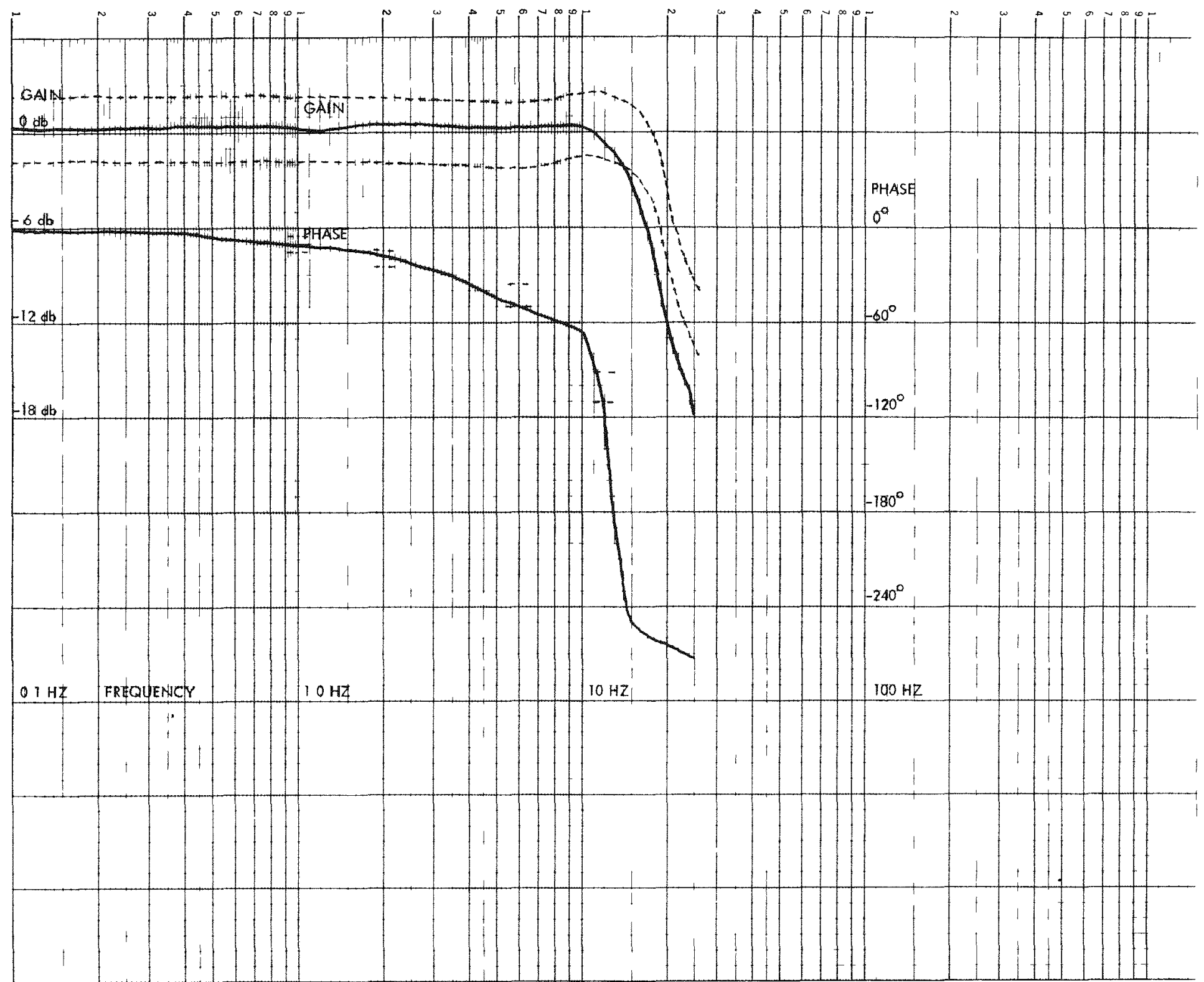

Figure 5.9. Closed Loop Frequency Response during Thermal Cycle No. 2 


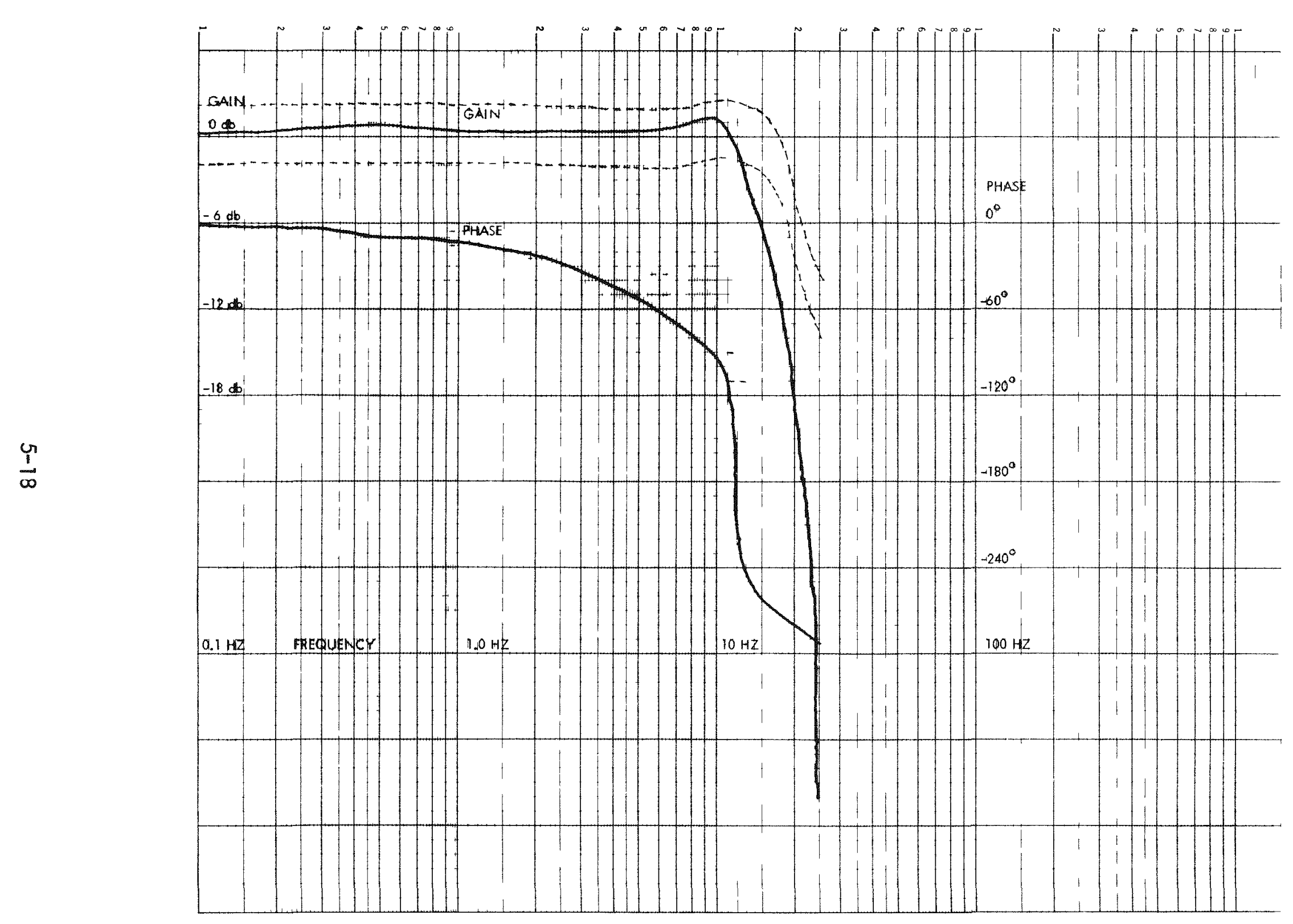

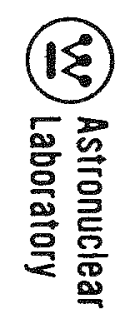

Figure 5. 10. Closed Loop Frequency Response during Thermal Cycle No. 3A 


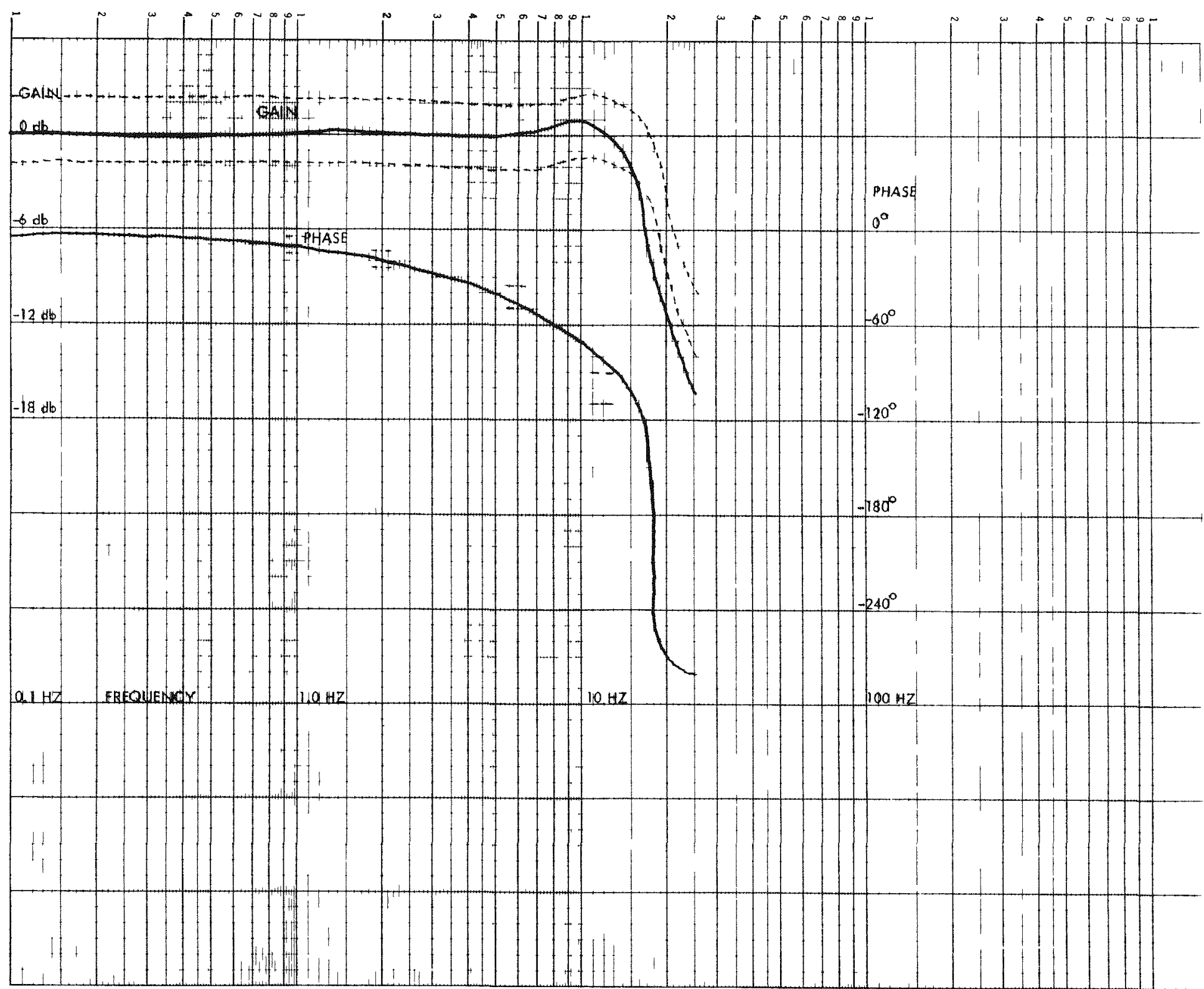

Figure 5.11. Closed Loop Frequency Response during Thermal Cycle No. 3D 


\subsection{LIFE TEST}

\subsection{INTRODUCTION}

6.1.1 The life qualification test was conducted within the guidelines specified in WANL-TME-1040, Revision A, Qualification Specifications for Control Drum Pneumatic Actuators for XE-1 Application (see Appendix A), and performed under T-711892-D, Qualification Test, Environmental, Control Drum Actuator (see Appendix B), with a few minor exceptions noted herein.

6.1.2 The purpose of the testing was to determine what changes in performance would result in the actuator when operated for long periods of time. An additional purpose of the test was to determine what effects a simulated liquid nitrogen rain would cause when applied to a localized area of the actuator.

6.1.3 The method of testing consisted of operating the actuator with a repeating sequence of command inputs and recording the actuator performance at specified intervals. Also during the test, the actuator performance was monitored while liquid nitrogen was spilled on selected locations of the actuator to simulate possible operating environment on the engine.

\subsection{DESCRIPTION OF TEST SET-UP}

6.2.1 The life test of the XE-1 actuator was performed in the WANL Mechanisms Laboratory between January 8, 1968 and January 26, 1968. The actuator used was an XE-1 Series, Serial No. A-58608, and the actuator control amplifier was Serial No. A-62960. The combination of actuator and amplifier comprises the closed loop position control system.

6.2.2 For mechanical support, the actuator was mounted on a load stand. This load stand was designed to simulate the inertia, friction, and spring gradient of a control drum. 
A modified actuator pedestal provided the interface between the load stand and the actuator and between the actuator and the gas system. The gas system provided nitrogen gas at a regulated pressure for coolant. Although not needed to cool the actuator, the coolant gas was used to simulate bearing loads and lock pressures that are expected during a reactor run. To reduce the expense that would be incurred by using large quantities of helium, the drive gas supply was selectable between helium and nitrogen. Helium drive gas was used for all performance testing and nitrogen was used while accumulating the specified running time.

6.2.3 A cam switch timer was used to automatically cycle the actuator through the predetermined sequence of various command input signals. The timer had a cycle time of one hour. Four function generators were used to provide the input signals. The appropriate function generator was switched in and out of the mount by the timer at required times in the test sequence.

The following equipment was used to determine the actuator performance:

Honeywell Visicorder, Model 1508

Industrial Measurements Frequency Response Analyzer, Model 101

Hewlett Packard Function Generator, Model 202 (3)

Hewlett Packard Low Frequency Oscillator, Model 202CR

Honeywell $X-Y-Y^{\prime}$ Chart Recorder, Model 480

Honeywell Digital Voltmeter, Model 6305

Trygon Power Supplies, Model PS 32-2.5

CEC Data Amplifiers, Type 155

CEC Pressure Transducers

Statham Pressure Transducers

Honeywell Gage Balance Units 


\subsection{DESCRIPTION OF TEST PROCEDURE}

6.3.1 Prior to running the life test, a complete set of actuator performance tests were run to determine the base line data. For this portion of the test, the actuator was operated on nitrogen coolant gas at $540^{\circ} \mathrm{R}$ and 650 psig. The drive gas was helium at $540^{\circ} \mathrm{R}$ and 200 psig. Any impurities in the helium supply were cryogenically trapped and filtered out of the drive gas supply line before its entry into the actuator.

6.3.2 After obtaining the base line data, the drive gas supply was changed to nitrogen and the actuator was operated for 150 hours. The total accumulated hours for each command signal input are shown in Figure 6.1. Also given in Figure 6.1 is the time for each cycle of the cam switch timer.

6.3.3 At the end of each 25-hour interval, the drive gas was changed to helium and a closed loop frequency response to a $4^{\circ} p-p$ sine wave command was recorded. During the test, one liter of liquid nitrogen was poured on each of the following: $P_{1}$ cylinder cover, $\mathrm{P}_{2}$ cylinder cover, servovalve cover, feedback potentiometer cover, and rack back-up bearing cover.

6.3.4 After 150 hours of accumulated operating time, the actuator performance was recorded using helium drive gas and nitrogen coolant.

\subsection{DISCUSSION OF TEST RESULTS}

6.4.1 The results of scram turnaround, transient response, and dynamic resolution are tabulated in Figure 6.2. The actuator experienced a change in friction as evidenced by the reduced scram turnaround time, the decrease in overshoot and the increase in settling time. The slight changes in measured values did not adversely affect the system performance. Subsequent disassembly and examination did not show any wear which might explain the changes. 
Command Input

Sine; $6 \mathrm{~Hz}, 4^{\circ} \mathrm{p}-\mathrm{p}$

Scram, Lock and Reset

Sine; $0.5 \mathrm{~Hz}, 40^{\circ} \mathrm{p}-\mathrm{p}$

Scram, Lock and Reset

Ramp; $0.01 \mathrm{~Hz}, 3^{\circ} / \mathrm{sec}$

Scram, Lock and Reset

Step; $0.1 \mathrm{~Hz}, 18^{\circ} \mathrm{p}-\mathrm{p}$

Scram, Lock and Reset

Dwell at $90^{\circ}$

Scram, Lock and Reset

Total Scram, Lock and Reset

Total Time
Total Time

$12.5 \mathrm{hr}$

--

$20.0 \mathrm{hr}$

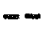

$45.0 \mathrm{hr}$

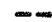

$25.0 \mathrm{hr}$

$--$

$25.0 \mathrm{hr}$

$-$

$22.5 \mathrm{hr}$

$150.0 \mathrm{hr}$
Time Per Cycle

$5.0 \mathrm{~min}$

$1.8 \mathrm{~min}$

$6.0 \mathrm{~min}$

$1.8 \mathrm{~min}$

$20.0 \mathrm{~min}$

$1.8 \mathrm{~min}$

$10.0 \mathrm{~min}$

$1.8 \mathrm{~min}$

$10.0 \mathrm{~min}$

$1.8 \mathrm{~min}$

$-$

$1.0 \mathrm{hr}$

Figure 6.1. Life Test Command Cycle 


\section{(2) Astronuclear}

Base Line Data

Scram Turnaround

$$
\text { Time (sec) }
$$

$\%$ BLD

Rise Time (in)

Time (sec)

$\triangle \% B L D$

Rise Time (out)

Time (sec)

$\triangle \% B L D$

Overshoot (in)

Degrees

$\% 18^{\circ}$

Overshoot (out)

Degrees

$\% 18^{\circ}$

Settling Time (in)

Time (sec)

$\triangle \%$ BLD

Settling Time (out)

Time (sec)

$\triangle \% B L D$

Dynamic Resolution

Deviation from

BLD Degrees
0.028

0.024

$-1.4$

0.117

0.109

$-6.8$

0.120

0.126

$+5.0$

0.2

0

1.11

0

0.25

0.4

1.39

$+2.22$

0.175

0.159

$-9.1$

0.177

0.195

$+10.2$

$--$

0.49

Figure 6.2. Table of Life Test Data 
(Q) Astronuclear

6.4.2 Figures 6.3 to 6.9 show the closed loop frequency responses obtained for each 25-hour interval. Except for minor variations in phase angle and in the response to frequencies over $10 \mathrm{~Hz}$, the curves were all within the envelope of the base line data. The increase in friction noted in the scram turnaround and transient response data above was not noticeable in the frequency response data. The peaking of the gain curve remained at a nearly constant level throughout the test.

6.4.3 No change in actuator performance was detected while pouring liquid nitrogen on various parts of the actuator housing. The high thermal conductivity of the aluminum housing in conjunction with the flow of coolant gas throughout the actuator appears adequate in eliminating any localized cooling. 


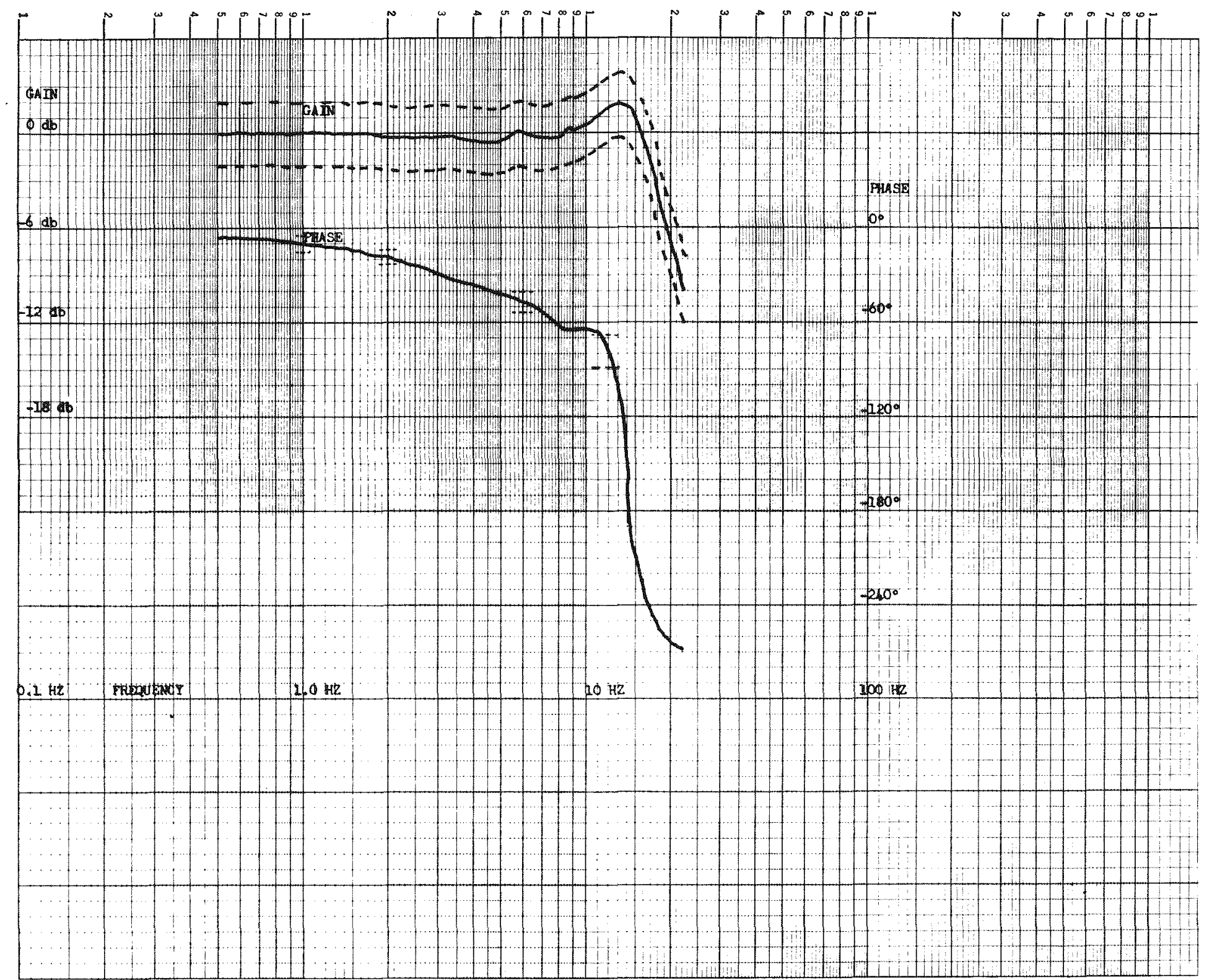

Figure 6.3. Closed Loop Frequency Response Base Line Data

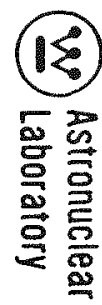




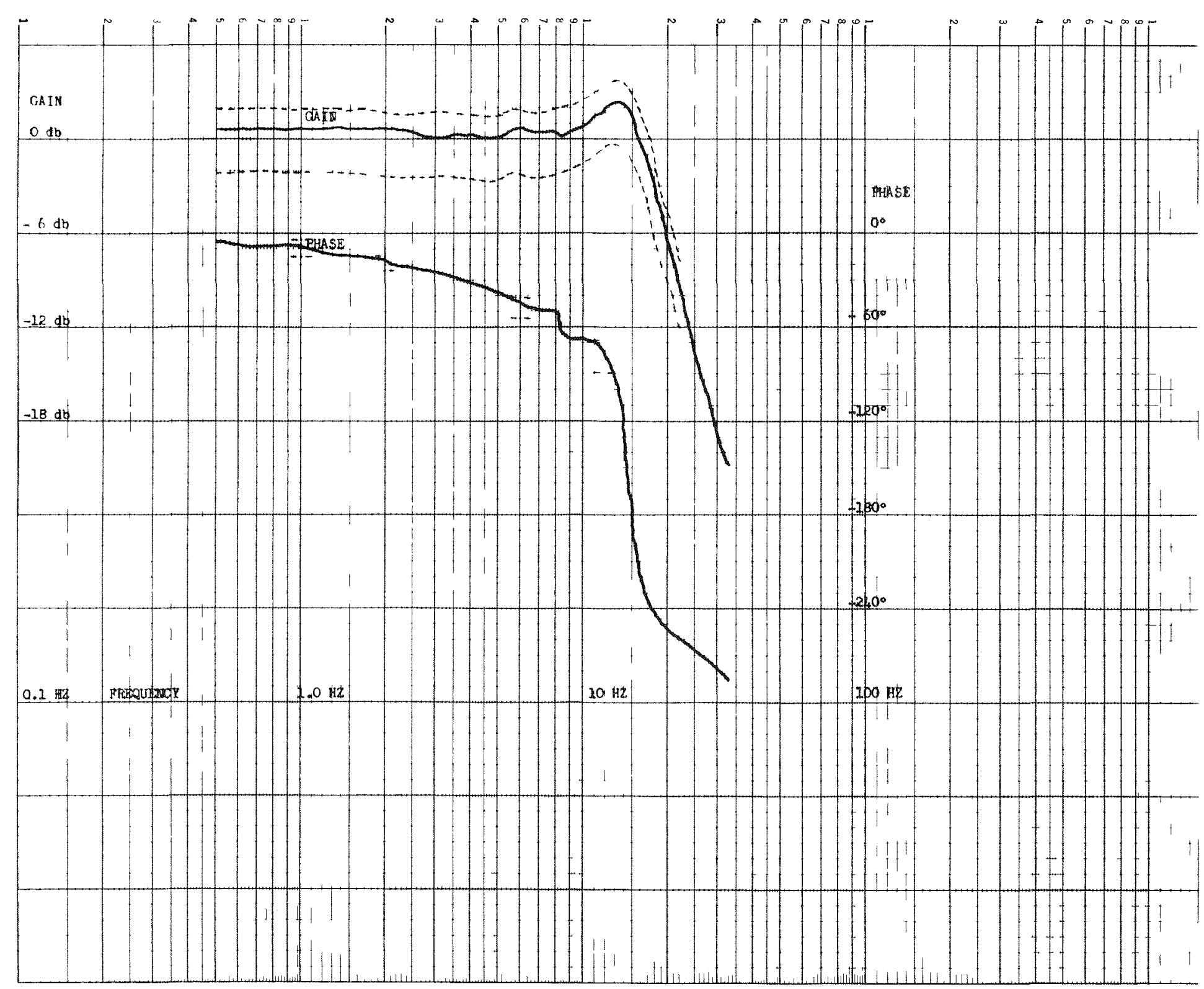

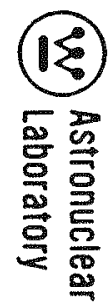

Figure 6.4. Closed Loop Frequency Response after 25 Hours 


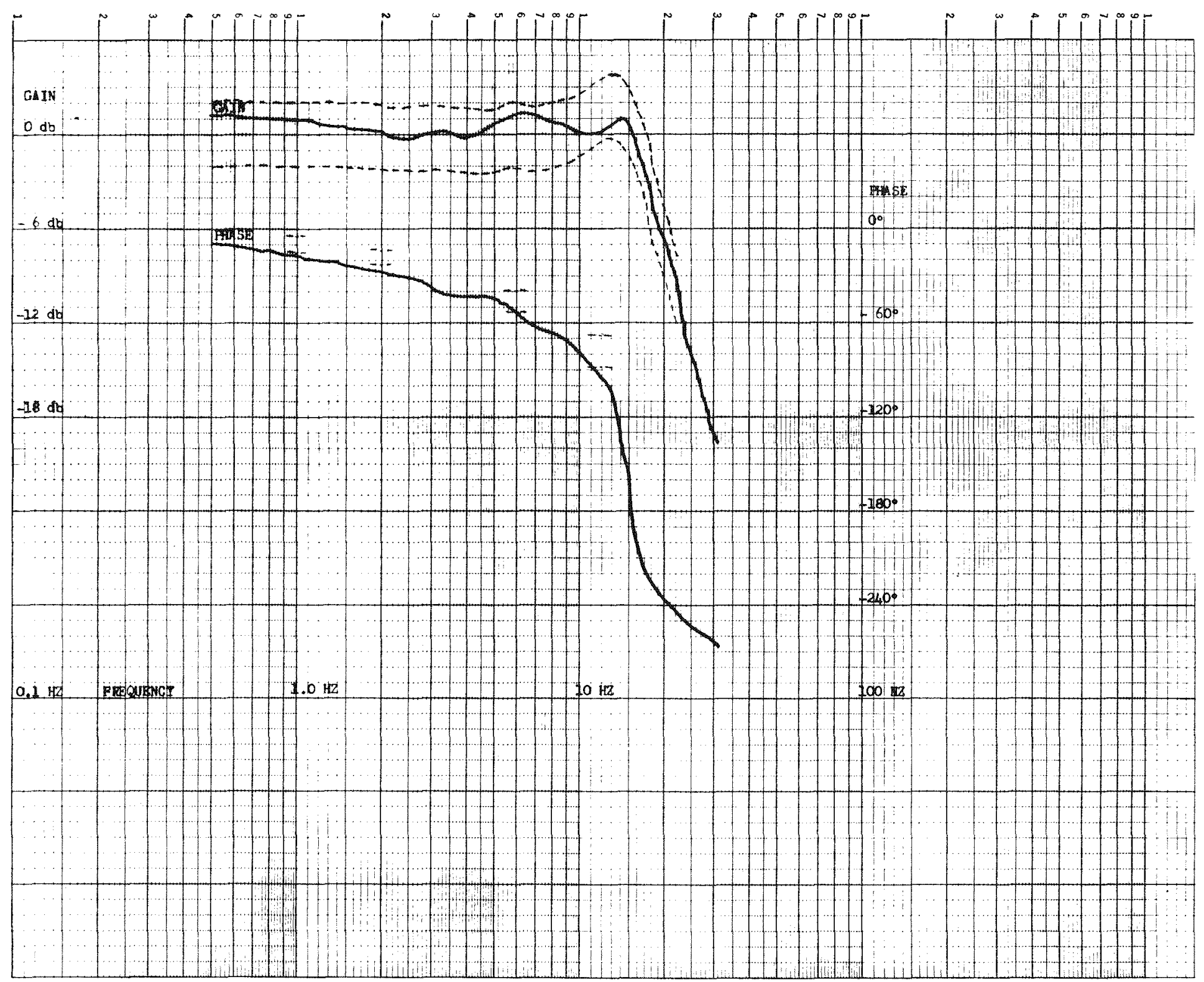

Figure 6.5. Closed Loop Frequency Response after 50 Hours

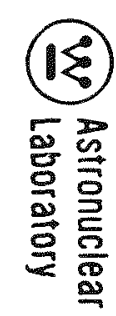




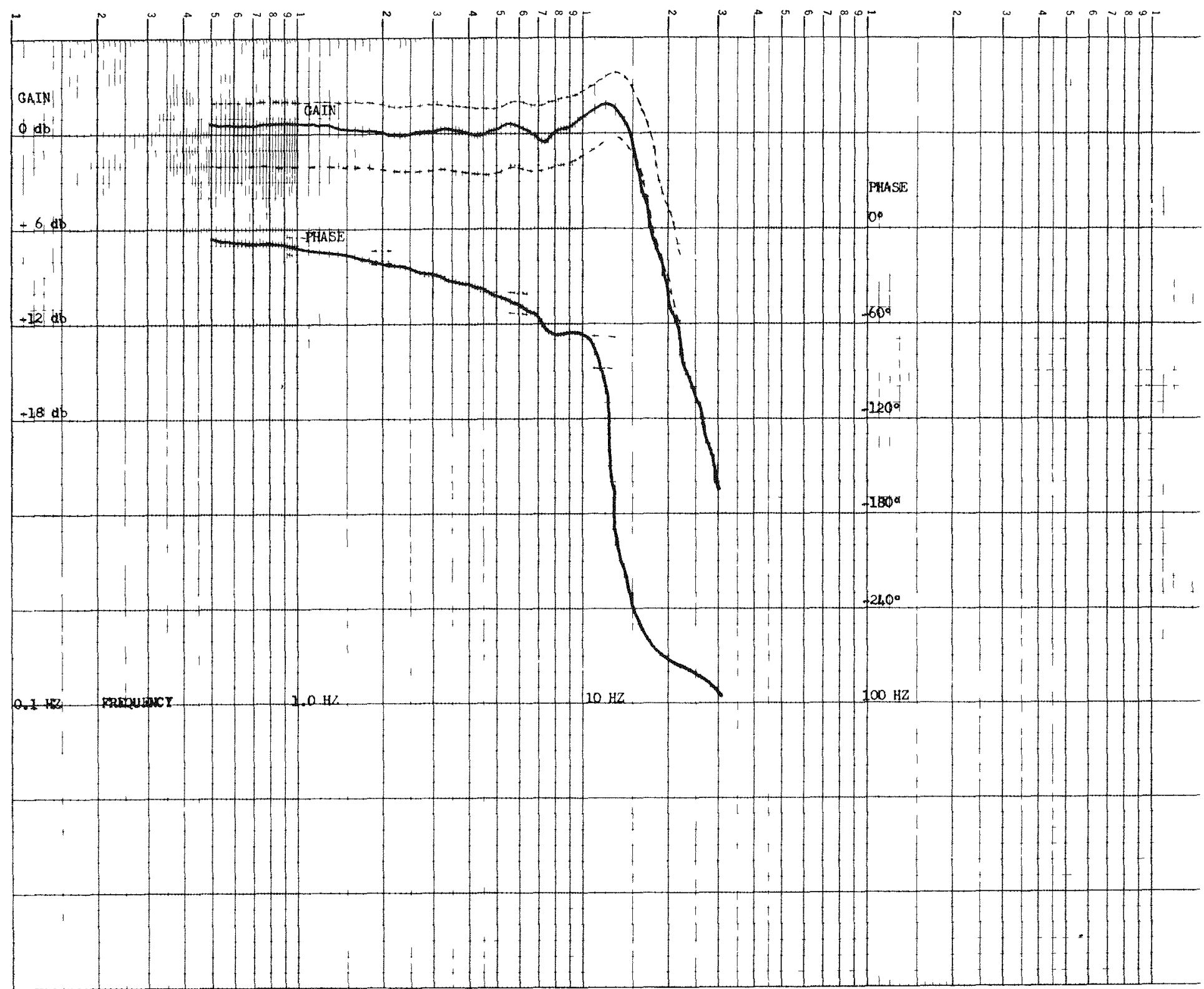

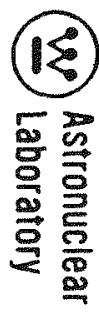

Figure 6.6. Closed Loop Frequency Response after 75 Hours 


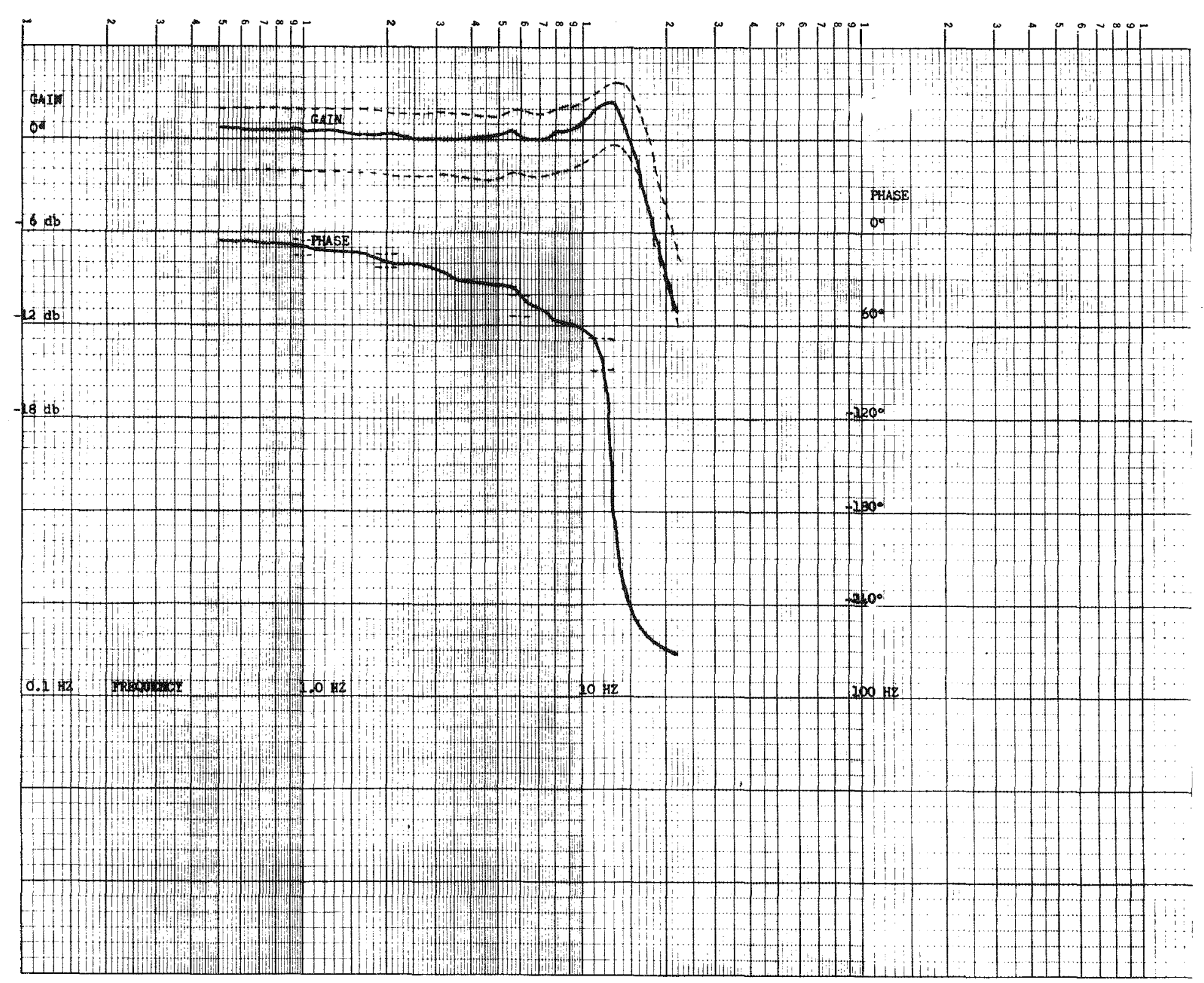

Figure 6.7. Closed Loop Frequency Response after 100 Hours

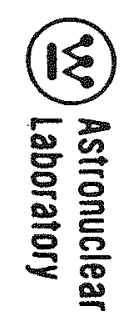




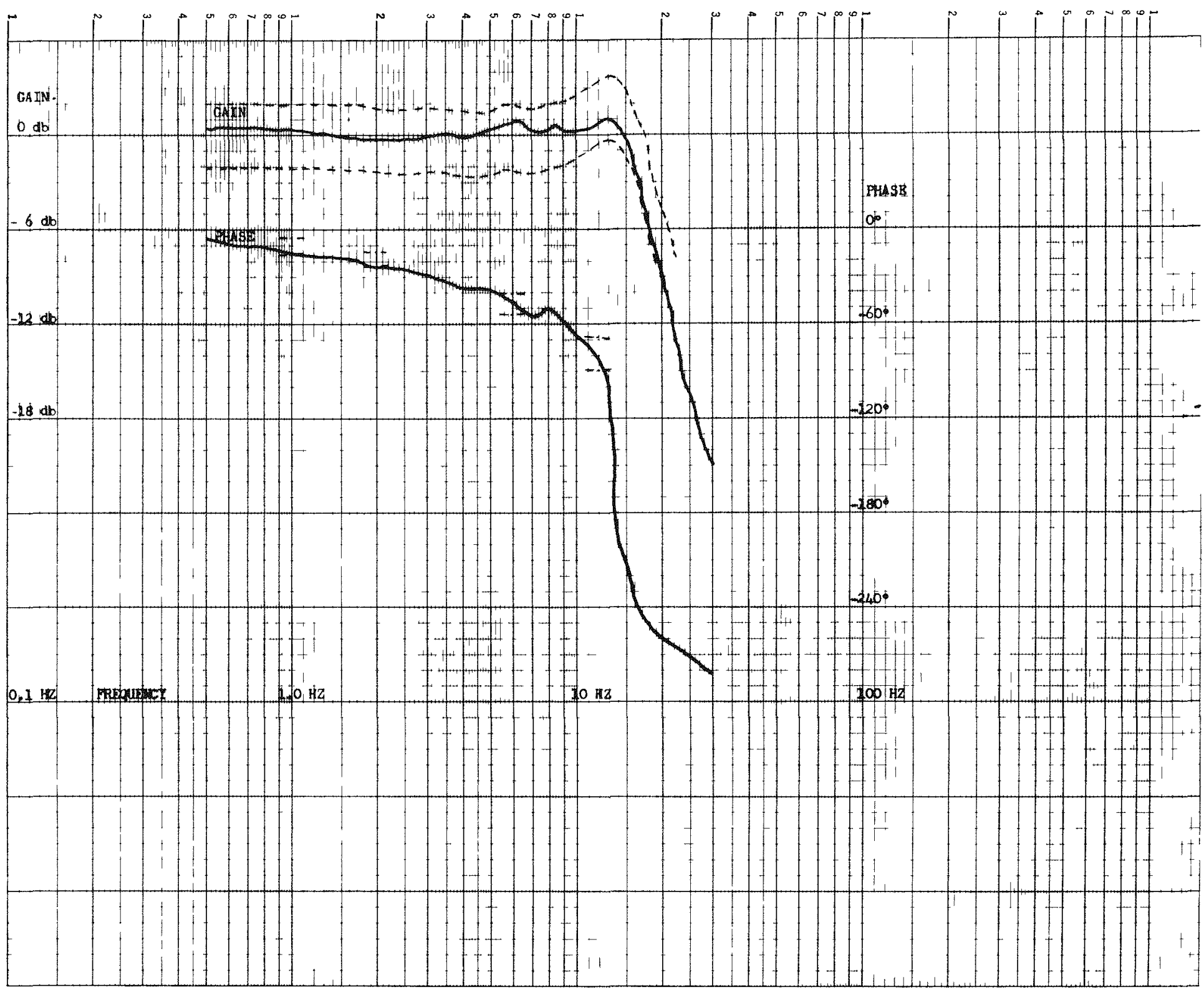

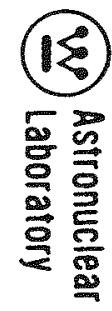

Figure 6.8. Closed Loop Frequency Response after 125 Hours 


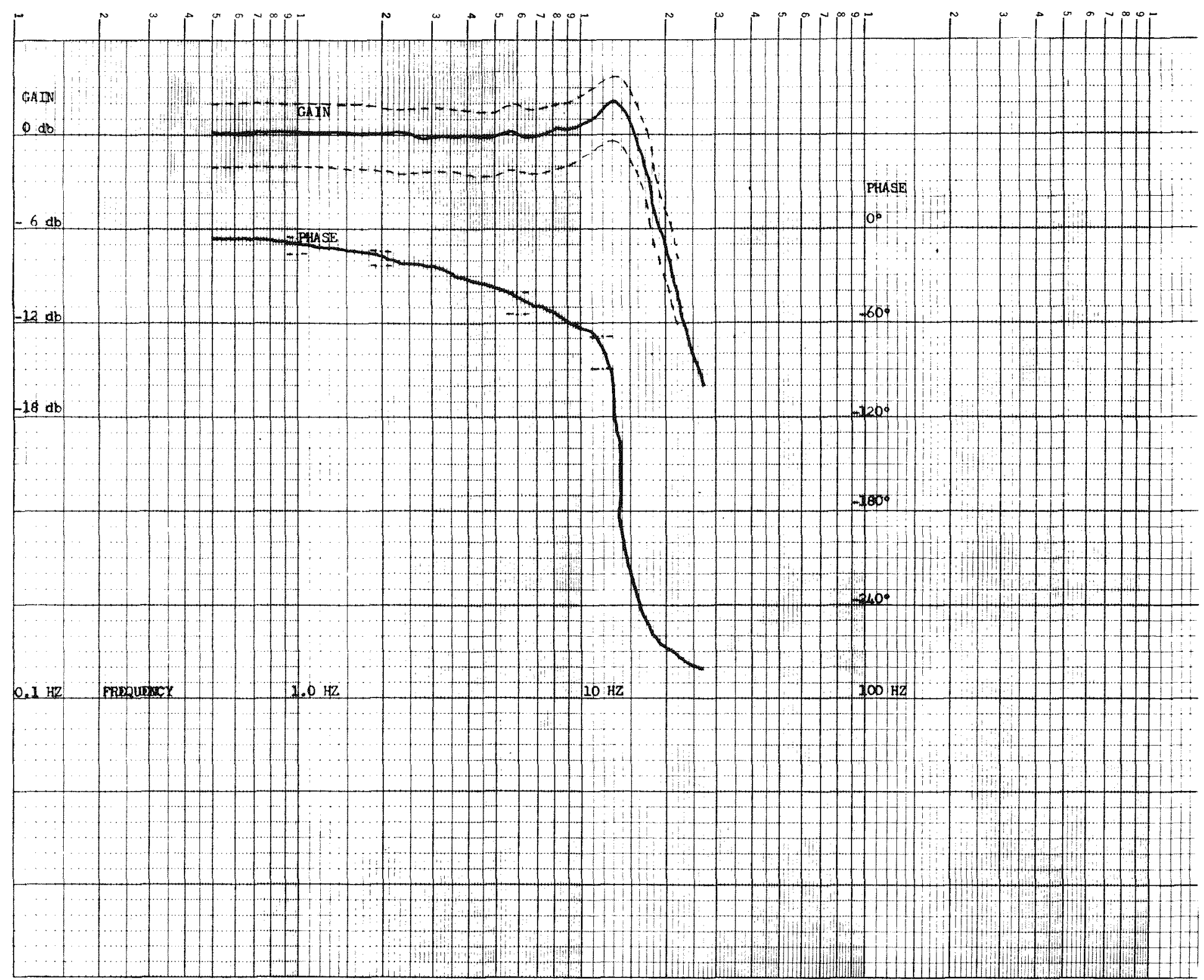

Figure 6.9. Closed Loop Frequency Response after 150 Hours

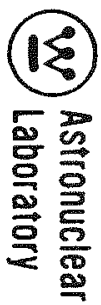




\subsection{COMBINED LOW TEMPERATURE AND VIBRATION TEST}

\section{$7.1 \quad$ INTRODUCTION}

7.1.1 The combined low temperature and vibration test was conducted within the guidelines specified in WANL-TME-1040, Revision A, Qualification Specifications for Control Drum Pneumatic Actuators for XE-1 Applications (see Appendix A), and performed under T-711892D, Qualification Test, Environmental, Control Drum Actuator (see Appendix B), with exceptions noted herein.

7.1.2 The purpose of the test was to determine what changes in performance the actuator would undergo when cooled to cryogenic temperatures and then subjected to vibration.

7.1.3 The method of testing was to operate the actuator with various position command signals before, during, and after vibration and cooling, and to record the actuator performance. By comparing this performance data, any changes could be determined.

\subsection{DESCRIPTION OF TEST SET-UP}

7.2.1 The combined low temperature and vibration of the XE-1 actuator was performed in the WANL Mechanisms Laboratory between April 5, 1968 and April 10, 1968. The actuator used was an XE-1 Series, Serial No. A-58608, and the actuator control amplifier was Serial No. A-62960.

7.2.2 The equipment used in the vibration qualification test was also used in this combined low temperature and vibration test. For a complete listing of this equipment, see the vibration test section of this report (Section 3.0).

In addition to the vibration equipment mentioned above, the following was also used: 
(W) Astronuclear

Laboratory

Bristol Strip Chart Recorder, Model 24P12H-590-51-B 14-E51B-TIII-T82K

Pace Thermocouple Reference Junction $\left(150^{\circ} \mathrm{F}\right)$, Model BRJ14-18TP- 1182

7.2.3 The gas supply system was equipped with heat exchanger in a liquid nitrogen dewar to cool the gas to cryogenic temperatures for the test. The drive gas used was helium at 200 psig and the coolant was nitrogen of 650 psig.

7.2.4 Photographs of the test set-up are shown in Figures 7.1 and 7.2. Close-up photographs of the actuator mounted on the load stand with pressure transducers and accelerometers installed are shown in Figures 7.3 and 7.4. A large path for thermal conduction exists between the load stand and the shaker table which was due to the rigid coupling required to transmit vibration. In view of this large heat gain to the actuator, other paths of heat transfer had to be reduced to achieve the low actuator temperatures required for the test. To reduce heat flow by convection and radiation, the actuator was enclosed in a metallized mylar cover. The actuator is shown with this cover in place in Figure 7.5 and after the removal in Figure 7.6.

\subsection{DESCRIPTION OF TEST PROCEDURE}

7.3.1 The actuator was first placed on its load stand and tuned for optimum transient response. After this tune-up, a complete set of actuator performance data was recorded. This data was used to establish the base line data.

7.3.2 Having recorded the pre-test actuator performance data, the actuator was given a $3 \%$ sec ramp command of $100^{\circ}$ peak-to-peak span about the $90^{\circ}$ position. With the actuator undergoing a ramp position change, the drive and coolant gas supplies were diverted through the heat exchangers and the actuator cooled to its equilibrium temperature. Once at equilibrium temperature, the actuator was vibrated at the levels shown in Figure 7.7. Four complete cycles of vibration, from low frequency to high frequency and back to low frequency, were performed and the period of each cycle was 15 minutes. During each 


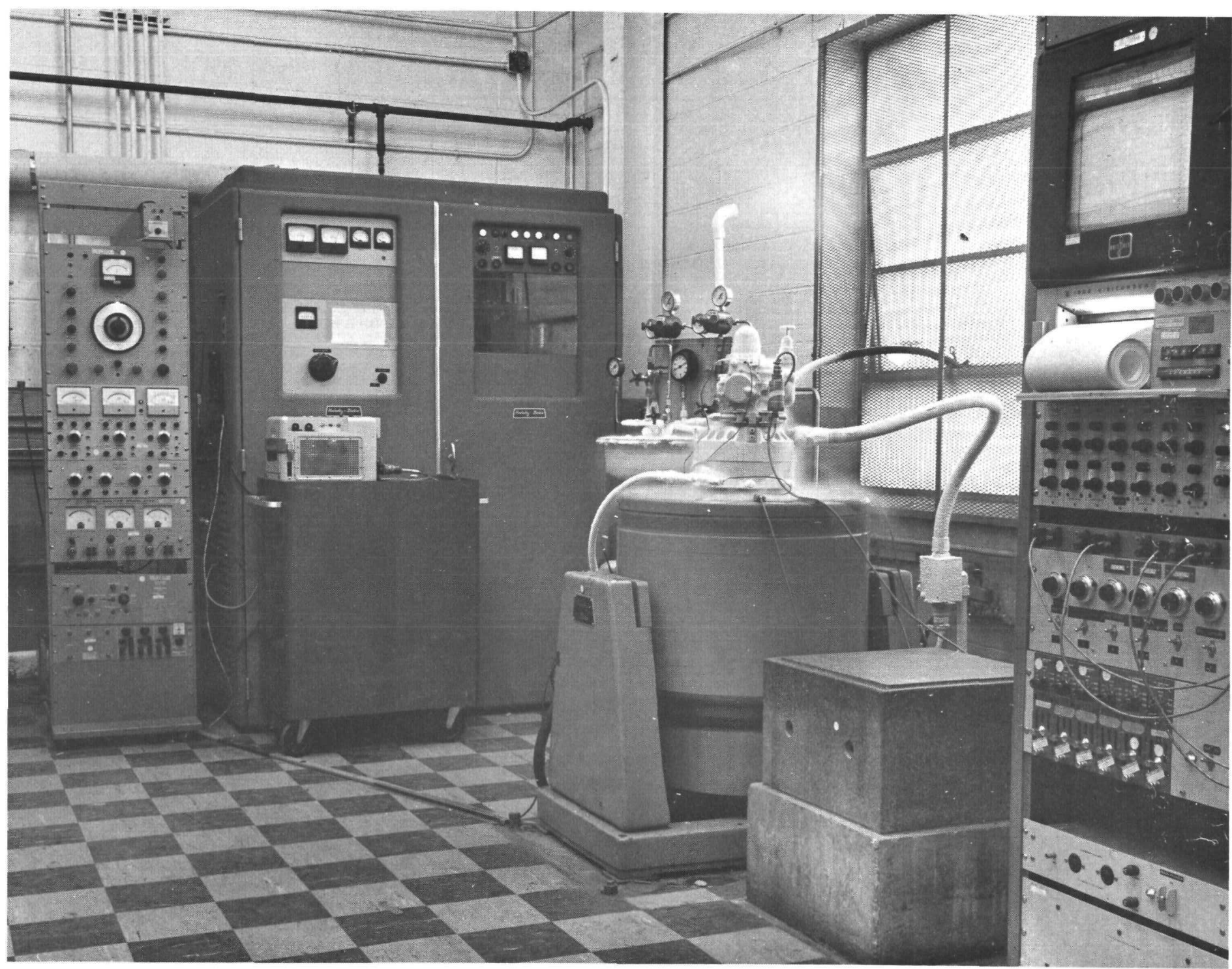

Figure 7. 1. Low Temperature and Vibration Test Setup-Vibration Equipment 


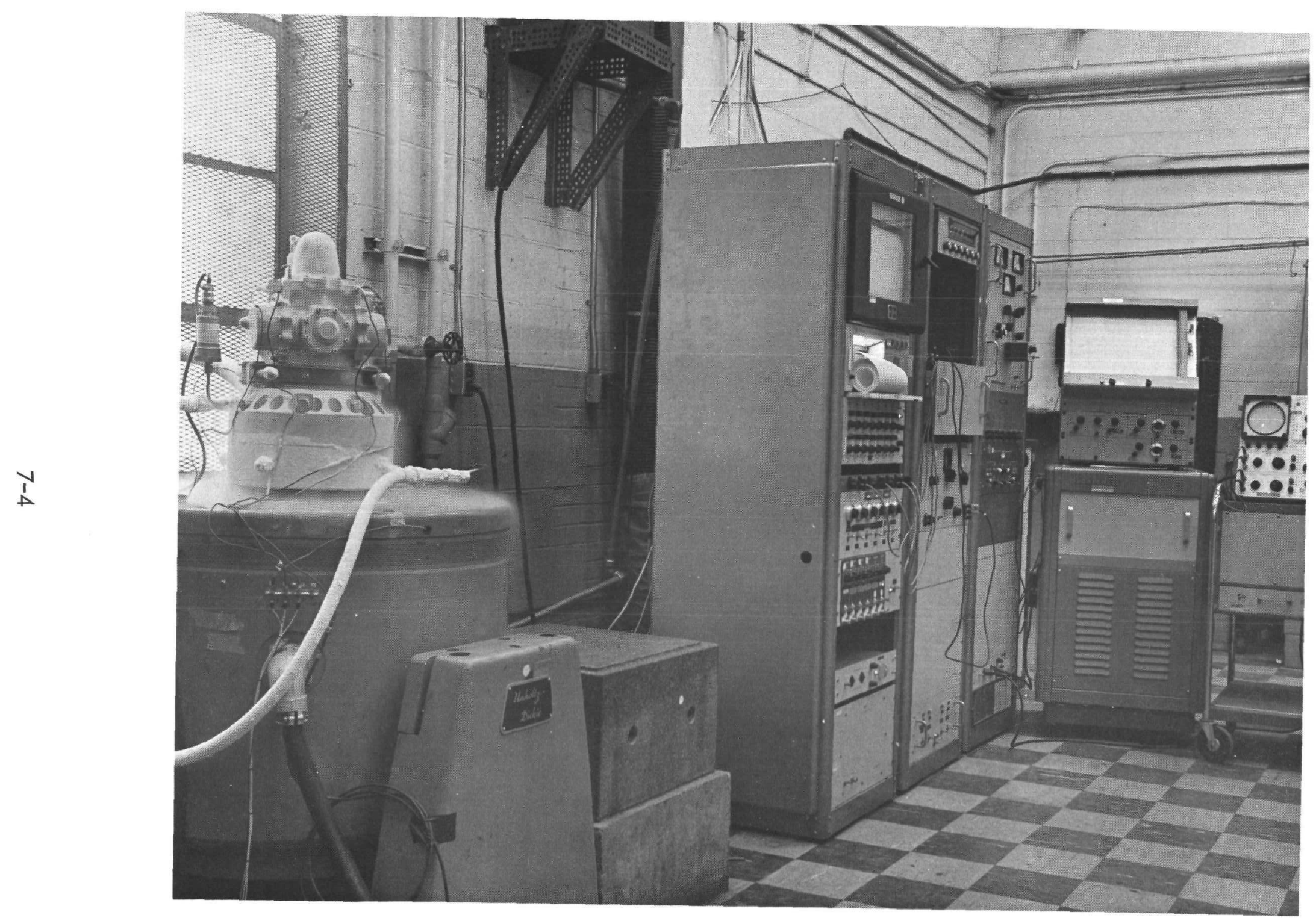

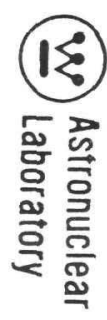

Figure 7.2. Low Temperature and-Vibration Test Setup-Recording Equipment 
We Astronuclear

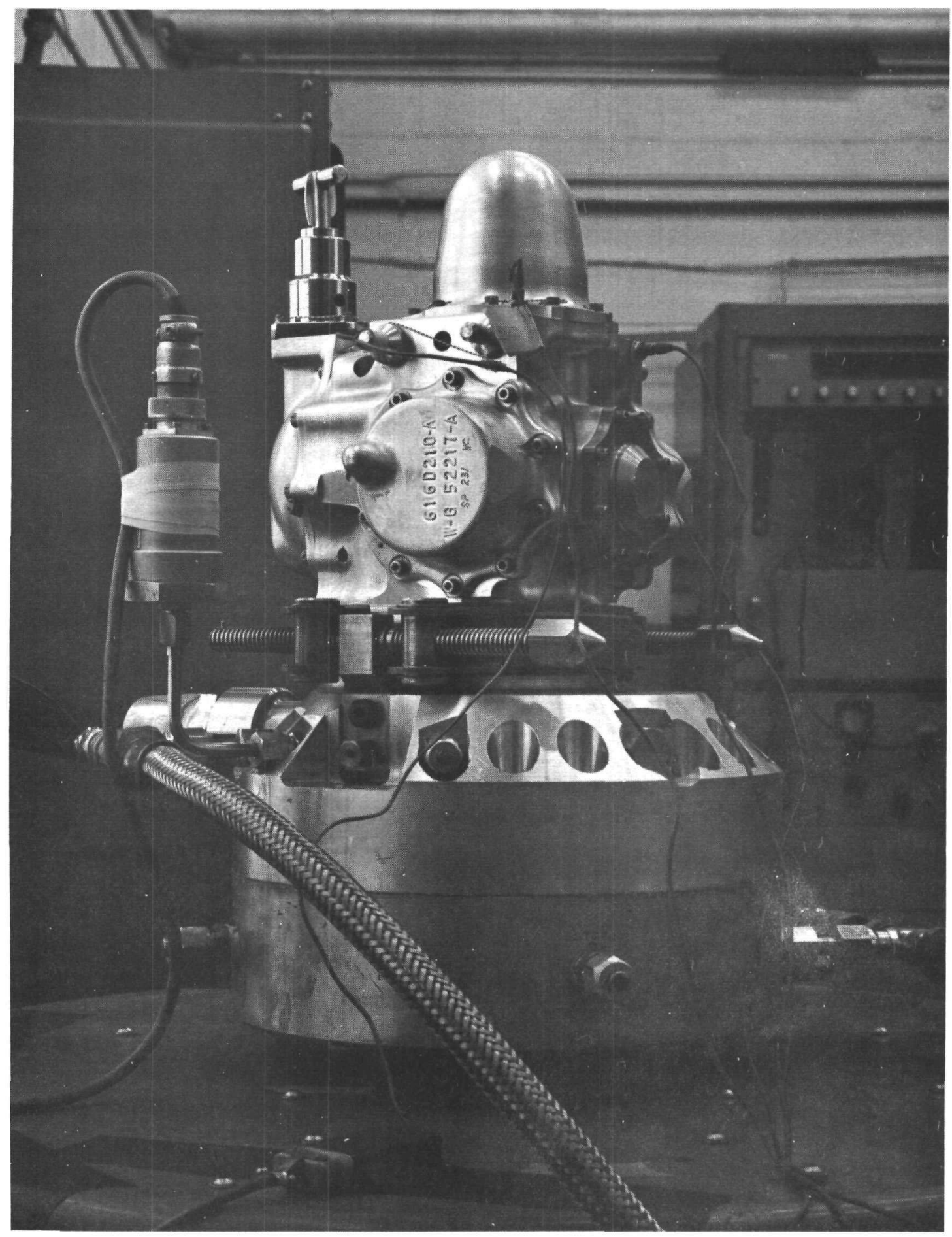

Figure 7.3. Test Actuator and Load Stand 
(W) Astronuclear

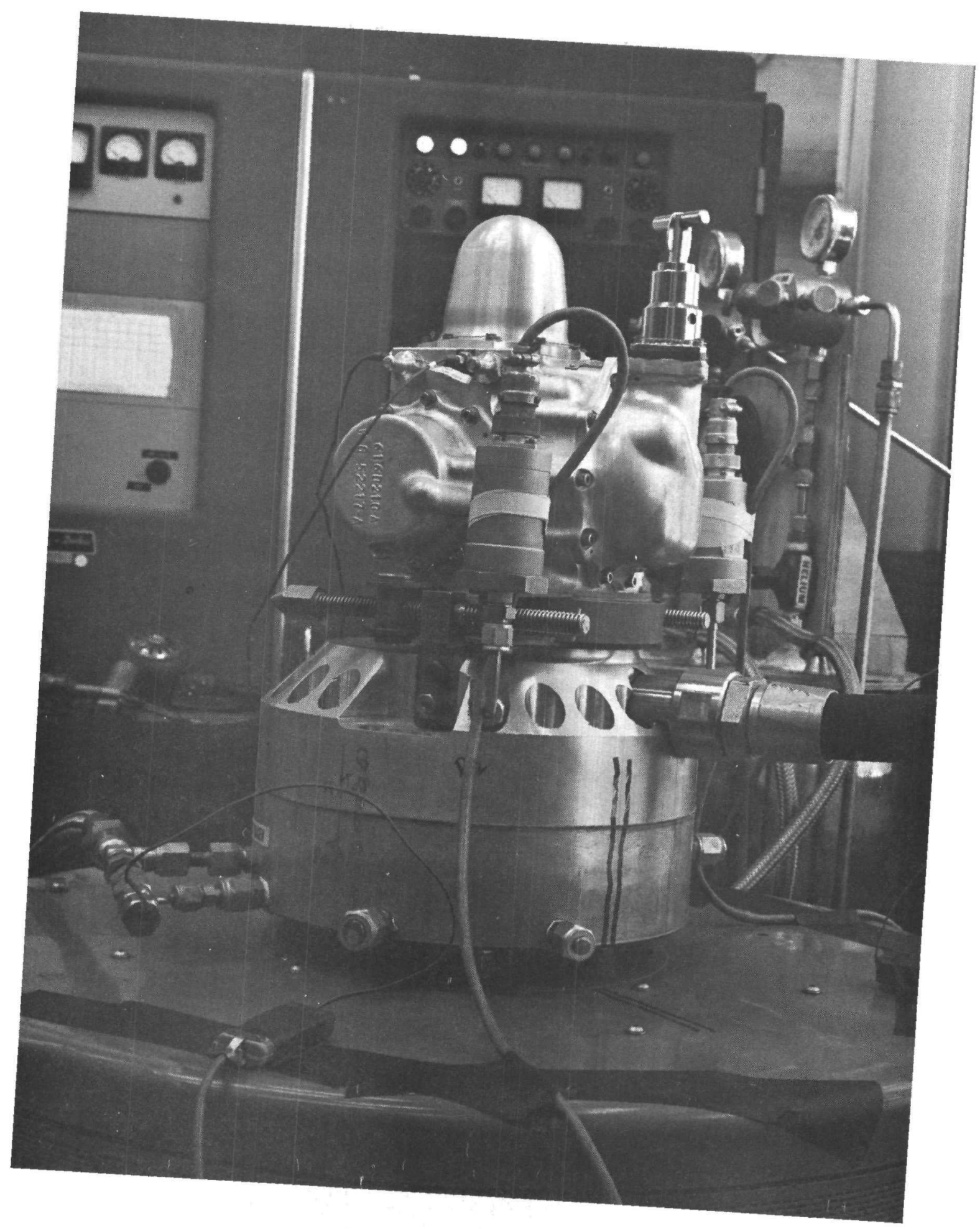

Figure 7.4. Test Actuator and Load Stand 


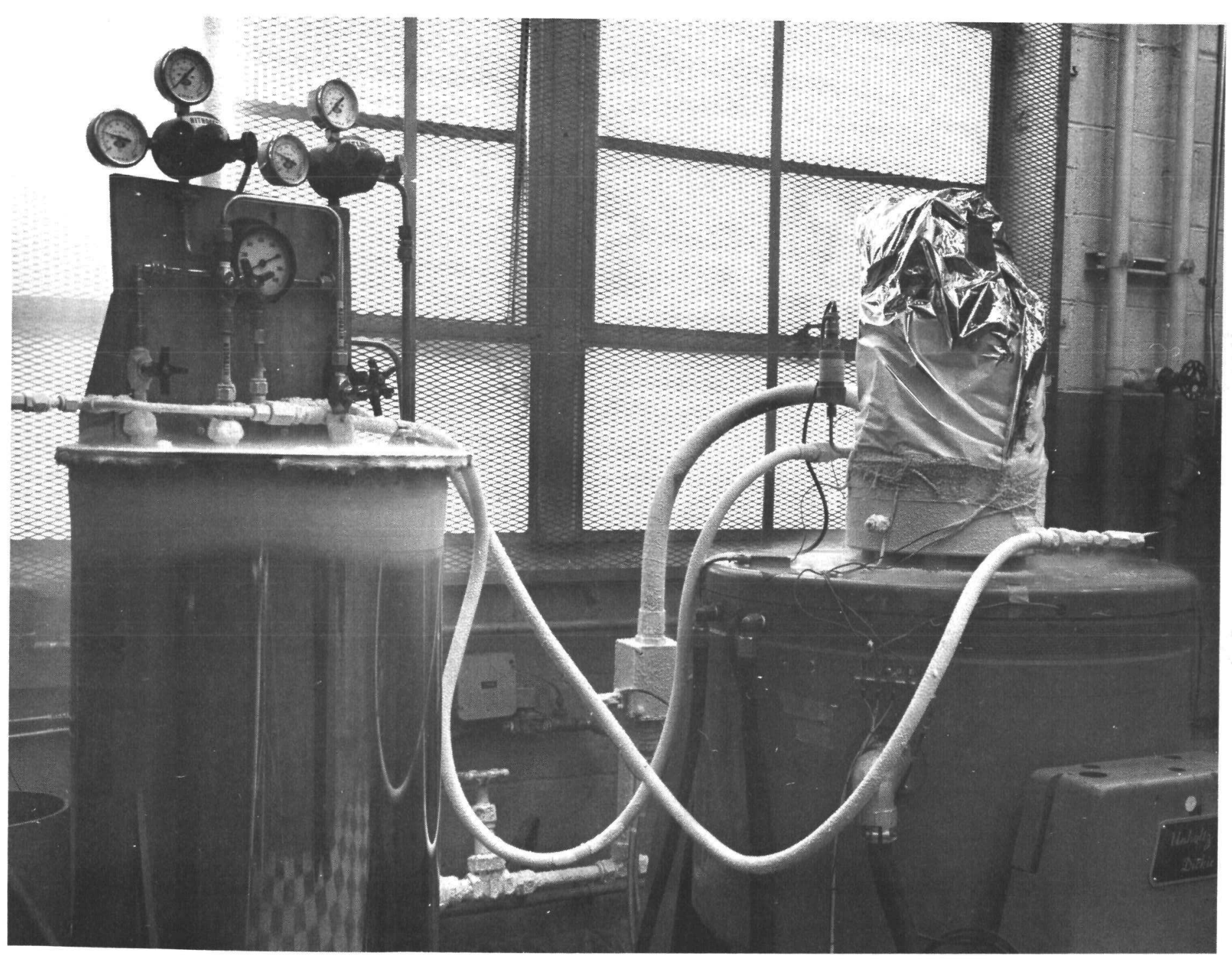

Figure 7.5. Test Actuator with Heat Shield Cover Installed 


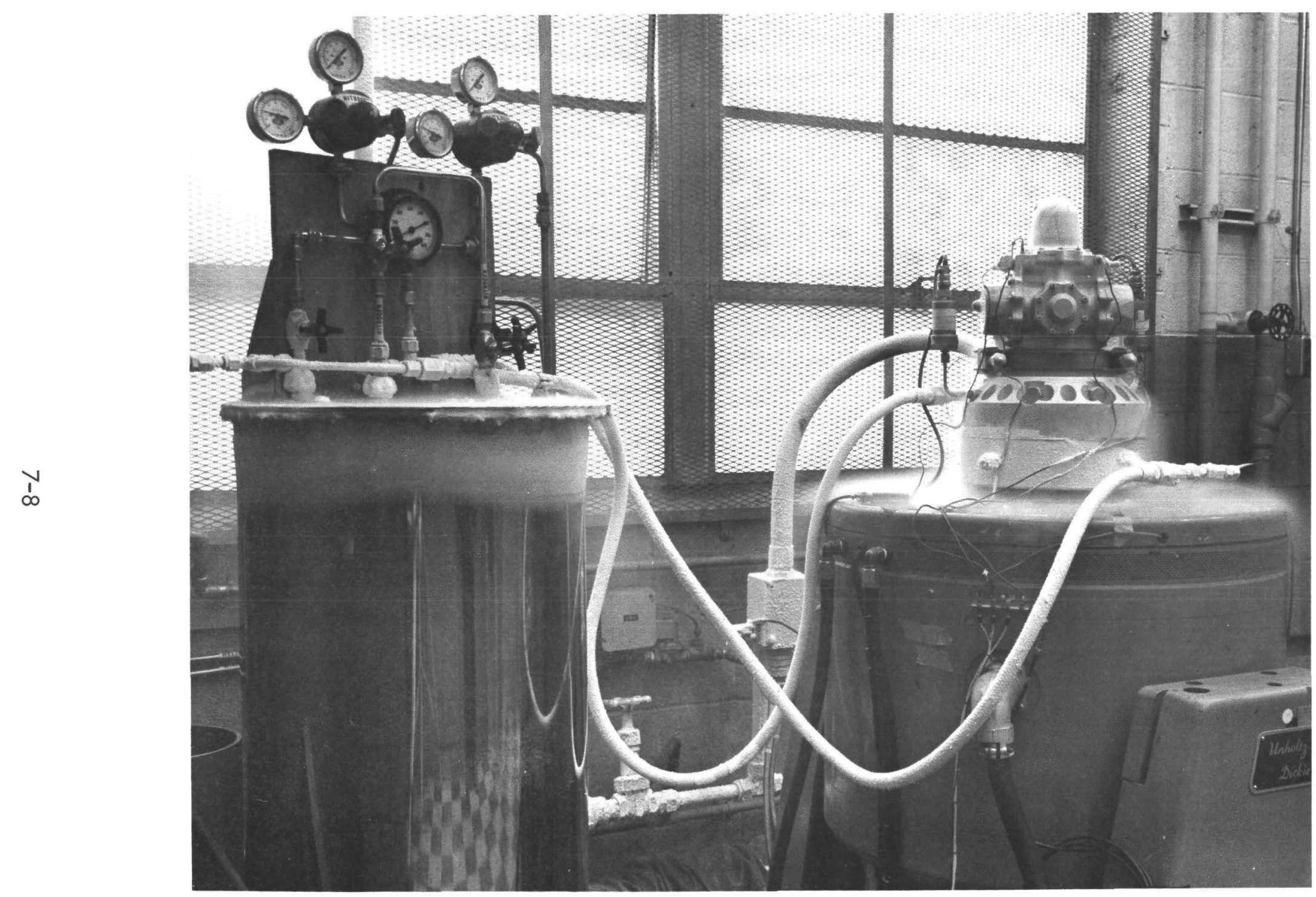

Figure 7.6. Test Actuator with Heat Shield Cover Removed 
(W) Astronuclear

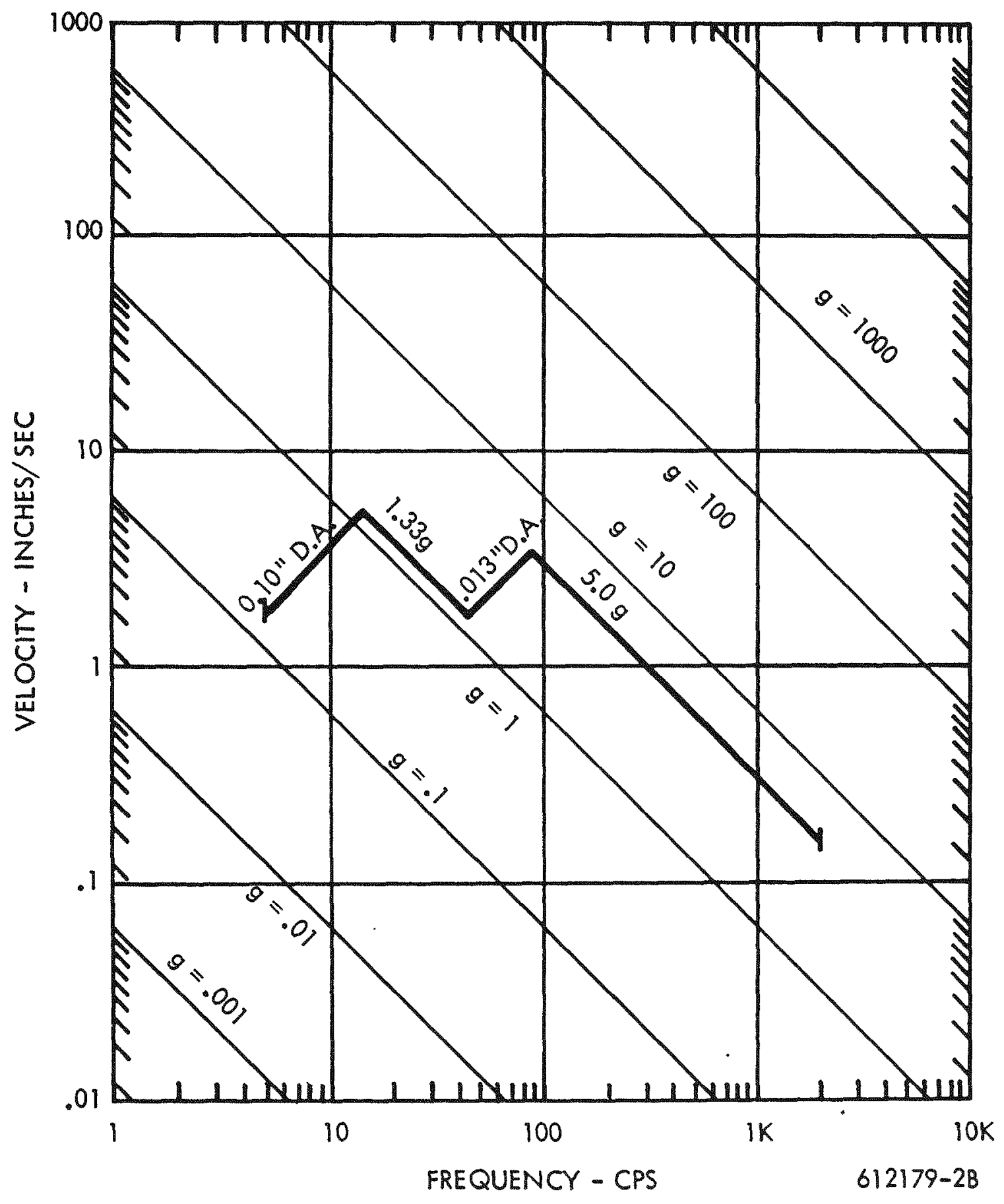

Figure 7.7. Vibration Input Levels 
successive cycle the actuator was given the command inputs shown in Figure 7.8. When the four vibration cycles were completed, the actuator was warmed to ambient temperature and a complete set of performance data was obtained.

7.3.3 A predicted natural frequency of vibration of the engine nozzle is $250 \mathrm{~Hz}$. The resonant frequency of the actuator torque motor armature is also about $250 \mathrm{~Hz}$. To check the actuator performance at this frequency of vibration and to determine if any adverse effects would be caused by engine induced frequencies, the actuator was again lowered to cryogenic temperature and vibrated at $240 \mathrm{~Hz}, 250 \mathrm{~Hz}$ and $260 \mathrm{~Hz}$. The vibration level at each frequency was $5 \mathrm{~g}$ and the vibration time was 10 minutes. At each frequency, the actuator was given a static dwell at $90^{\circ}$ for 5 minutes and a $3^{\circ} / \sec$ ramp command of $100^{\circ}$ amplitude for 5 minutes. During the $90^{\circ}$ dwell, the actuator position, torque motor current, and cylinder pressures were recorded. During the $3 \%$ sec ramp, a dynamic resolution of command versus error was recorded.

\subsection{DISCUSSION OF TEST RESULTS}

7.4.1 During the cryogenic part of this test, the following equilibrium temperatures were attained:

$\begin{array}{ll}\text { Drive Gas } & 175^{\circ} \mathrm{R} \\ \text { Coolant Gas } & 167^{\circ} \mathrm{R} \\ \text { Exhaust Gas } & 140^{\circ} \mathrm{R} \\ \text { Actuator Housing } & 174^{\circ} \mathrm{R}\end{array}$

A large leakage flow at the base of the load stand was noted while at cryogenic temperatures. This was due to the use of a rubber " $O$ " ring seal on the load stand. The highest coolant pressure attainable under this high flow condition was 400 psig. This pressure was considered adequate to achieve the desired effects within the actuator. 


\section{INPUT FUNCTION}

RAMP, $3^{\circ} /$ SEC, $100^{\circ} p-p$

STEP, $0.1 \mathrm{~Hz}, 18^{\circ} \mathrm{p}-\mathrm{p}$

DWELL AT $90^{\circ}$ POSITION

SINE, $6 \mathrm{~Hz}, 4^{\circ} \mathrm{p}-\mathrm{p}$

\section{VIBRATION TIME}

MINUTES

15

15

15

TOTAL $\quad \frac{15}{60}$ 
7.4.2 The results of the scram turnaround, transient response, and dynamic resolution tests are given in Figure 7.9. The actuator appeared to have changed its friction level as evidenced by small increases in scram turnaround, rise and settling times. An overall shift in the dynamic resolution curve of $0.55^{\circ}$ after the one hour vibration test was noted. Because the shape of the curve remained the same, this shift in dynamic resolution was attributed to a change in the $+10 \mathrm{~V},+15 \mathrm{~V}$, and the $-15 \mathrm{~V}$ power supplies. The dynamic resolution curve moved closer to the base line data while the actuator was being vibrated in the $250 \mathrm{~Hz}$ range. During the 240,250 and $260 \mathrm{~Hz}$ vibration and while at $90^{\circ} \mathrm{dwell}$, the actuator showed no signs of induced oscillation or position potentiometer noise. No hunting greater than $+0.01^{\circ}$ was detected.

7.4.3 The frequency response curves for the base line data and after the cryogenic vibration are shown in Figures 7.10 and 7.11 . The post-vibration curve did not deviate from the base line data by any appreciable amount. 
(W) Astronuclear

Laboratory

Base Line Data After Vibration $\begin{gathered}\text { During } 10 \mathrm{Min} \text {. Dwell at } 5 \mathrm{~g} \\ 240 \mathrm{~Hz} \quad 250 \mathrm{~Hz} \quad \underline{260 \mathrm{~Hz}}\end{gathered}$

\begin{tabular}{|c|c|c|c|c|c|}
\hline \multicolumn{6}{|l|}{ Scram Turnaround } \\
\hline Time (sec) & .025 & .029 & -- & -- & -- \\
\hline$\%$ BLD & $=-$ & 16 & -- & -- & -- \\
\hline Rise Time (sec) & .149 & .155 & -- & -- & -- \\
\hline$\Delta \% B L D$ & -- & 4.0 & -- & -- & -- \\
\hline Overshoot (degrees) & 0 & 0 & -- & -- & -- \\
\hline$\% 18^{\circ}$ & - & -- & -- & - & -- \\
\hline Settling Time (sec) & .214 & .224 & -- & -- & -- \\
\hline$\triangle \% B L D$ & -- & 4.7 & -- & -- & $=-$ \\
\hline Dynamic Resolution & & & & & \\
\hline $\begin{array}{l}\text { Deviation from } \\
\text { BLD Degrees }\end{array}$ & -- & .55 & .13 & .11 & .10 \\
\hline
\end{tabular}

Figure 7.9. Table of Combined Low Temperature and Vibration Test Data 


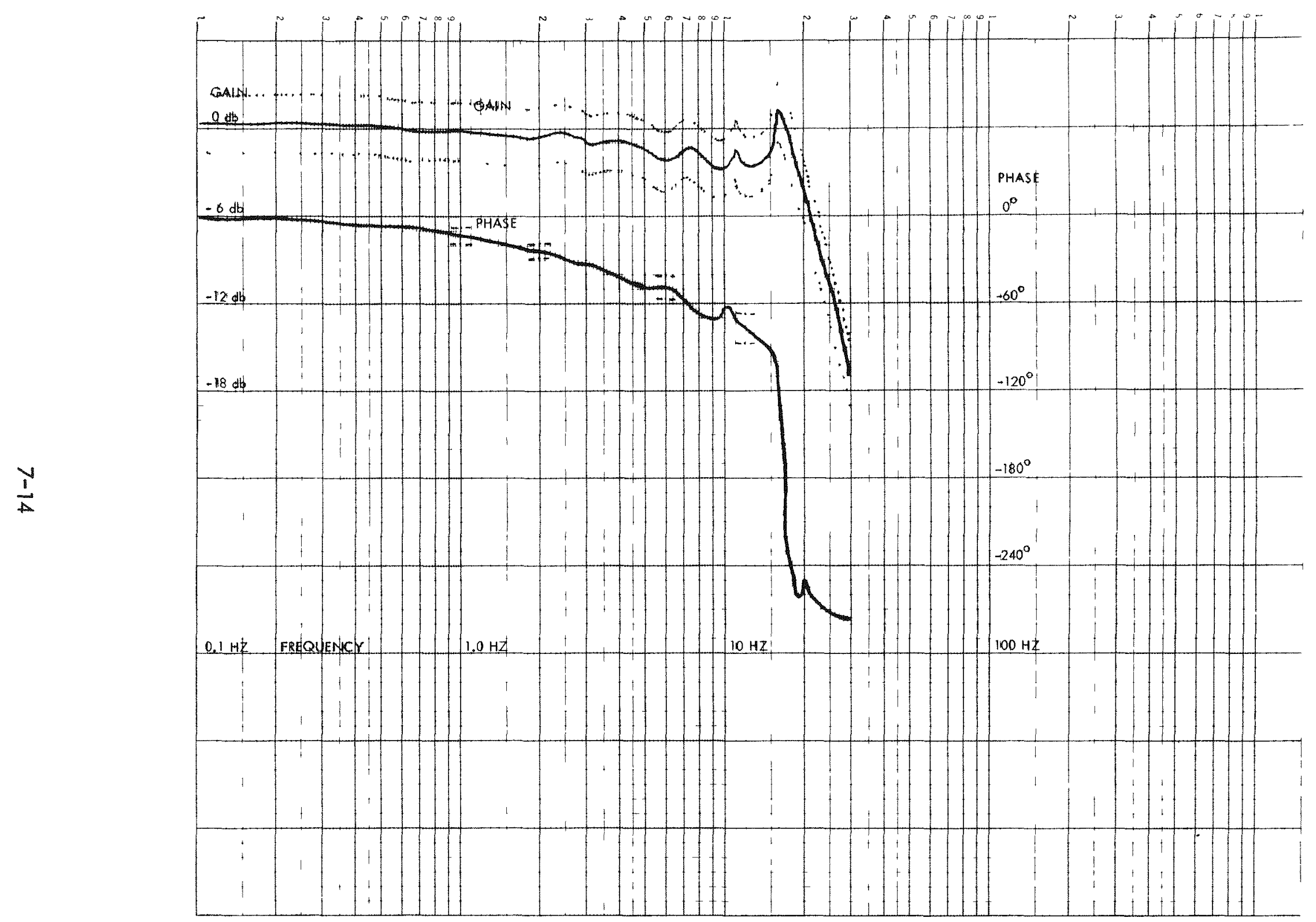

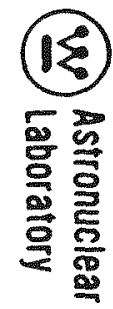

Figure 7.10. Closed Loop Frequency Response Base Line Data 


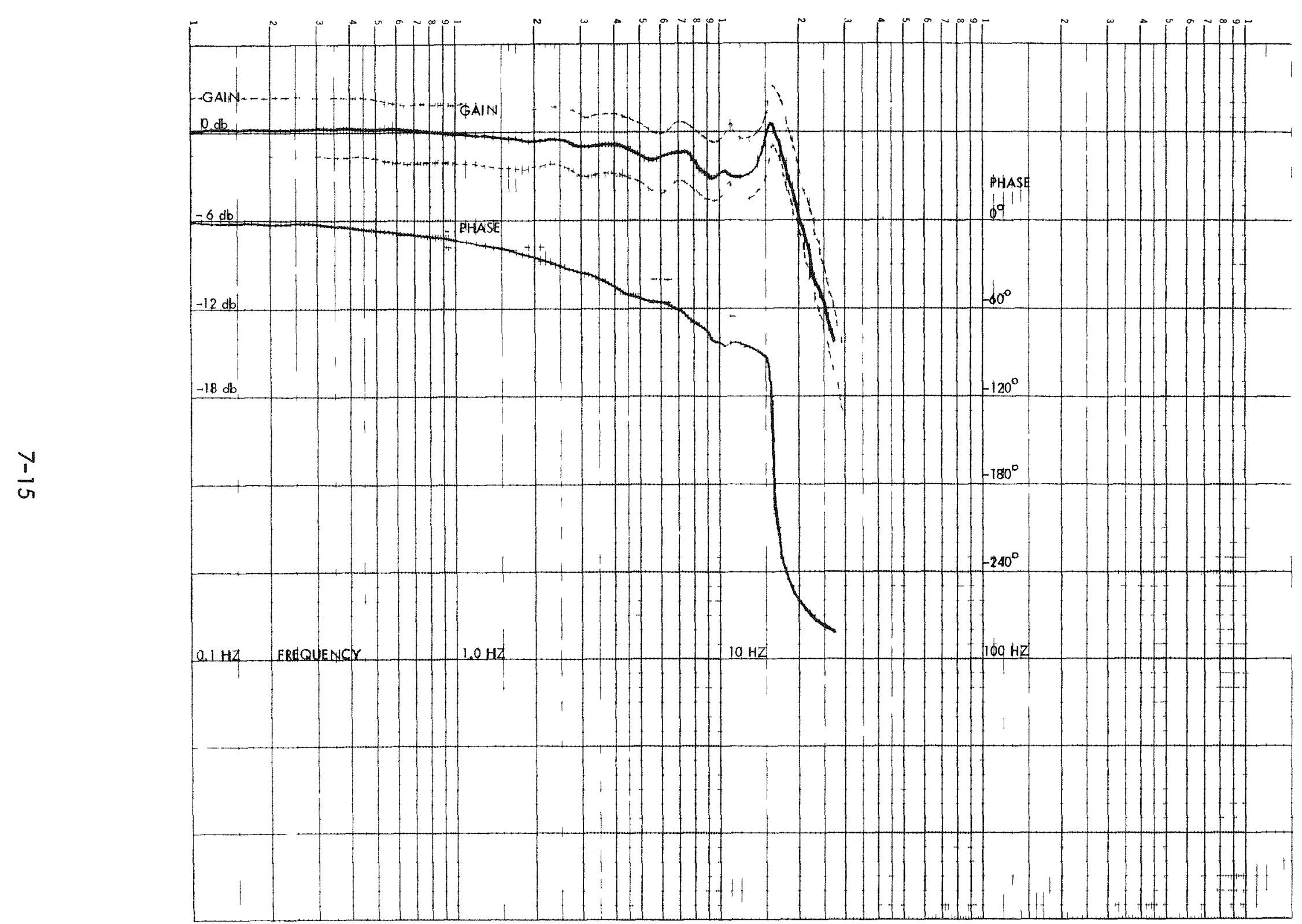

Figure 7.11. Closed Loop Frequency Response After Test

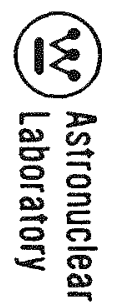




\subsection{ACTUATOR DISASSEMBLY AND INSPECTION}

\subsection{Upon completion of the XE-1 environmental qualification tests of vibration,} mechanical shock, cryogenic, life and combined vibration/cryogenic, the test actuator was disassembled and inspected for wear or mechanical failure.

\subsection{DRIVE SHAFT PINION AND RACK ASSEMBLY}

The drive shaft pinion gear is shown in Figure 8.1. Some evidence of use was noted on that part of the gear which mates with the rack. The black oxide finish in this area appeared to be worn. No signs of chips or fractures were evident. Shown in Figure 8.1 and also in Figure 8.2 are six rings at each end of the drive shaft. These were caused by the silver-plating of the gap seals rubbing onto the drive shaft. This silver coating was not enough to cause a dimensional change. The soft stop spring bearing surface appeared to be worn where it comes in contact with the internal diameter of the drive shaft. This area is shown in Figure 8.3. Under normal operating conditions, the soft stop spring moves with the drive shaft and the increase in friction goes unnoticed. The increased friction appears during a scram when the actuator approaches the $15^{\circ}$ position and its effect is to reduce penetration into the soft stop. The rack is shown in Figure 8.4. As on the pinion gear, the black oxide coating shows signs of use. No chips, flaking or fractures were noted on the gear teeth. The rack yoke is shown in Figure 8.5. No change in the yoke width was noted. Also, no sign of fracture or strain appeared near the yoke fillets.

\subsection{LOCK PIN AND LOCK CAM}

The lock pin is shown in Figure 8.6. No sign of wear was noted on the cylindrical surface but the end of the pin did show signs of chipping. This wear is caused by dropping the lock pin down on the lock cam surface during the scram operation. The 


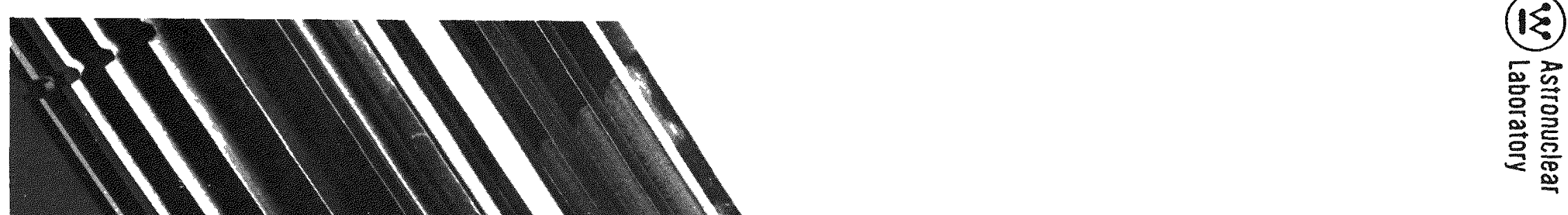

$\stackrel{\infty}{\sim}$

Figure 8-1. Drive Shaft and Pinion Gear - Lower End 


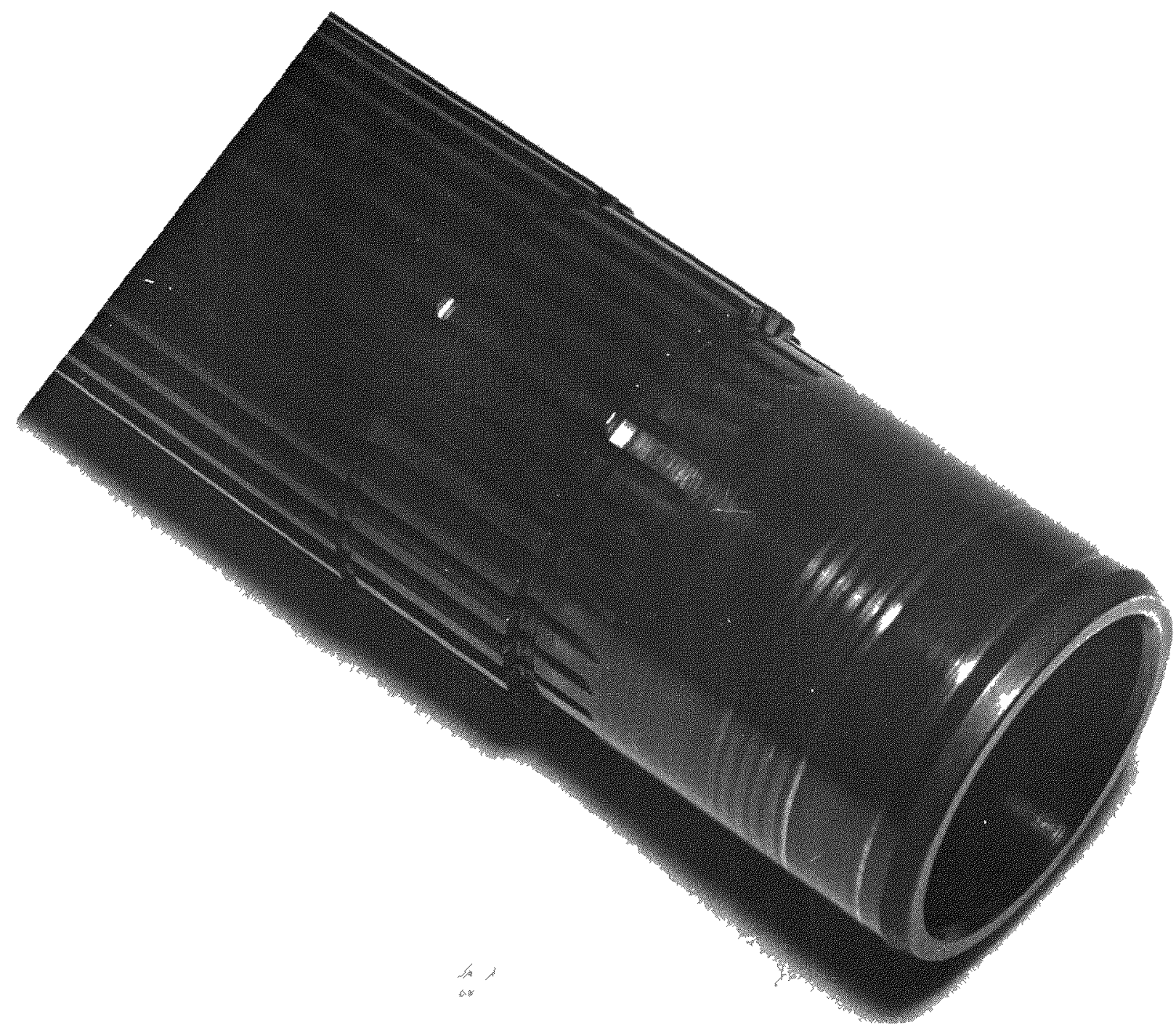




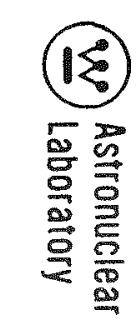

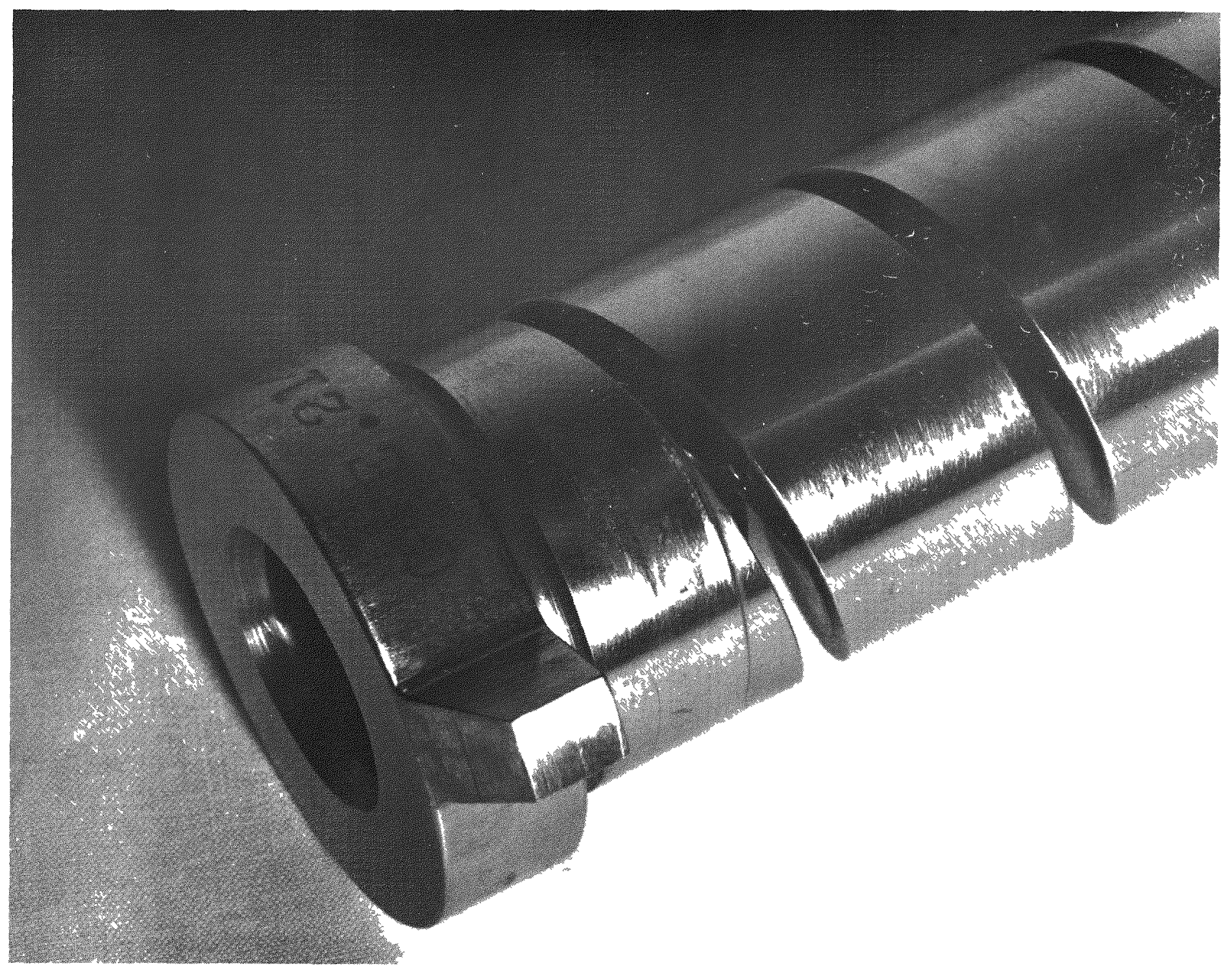

Figure 8.3. Soft Stop Spring 


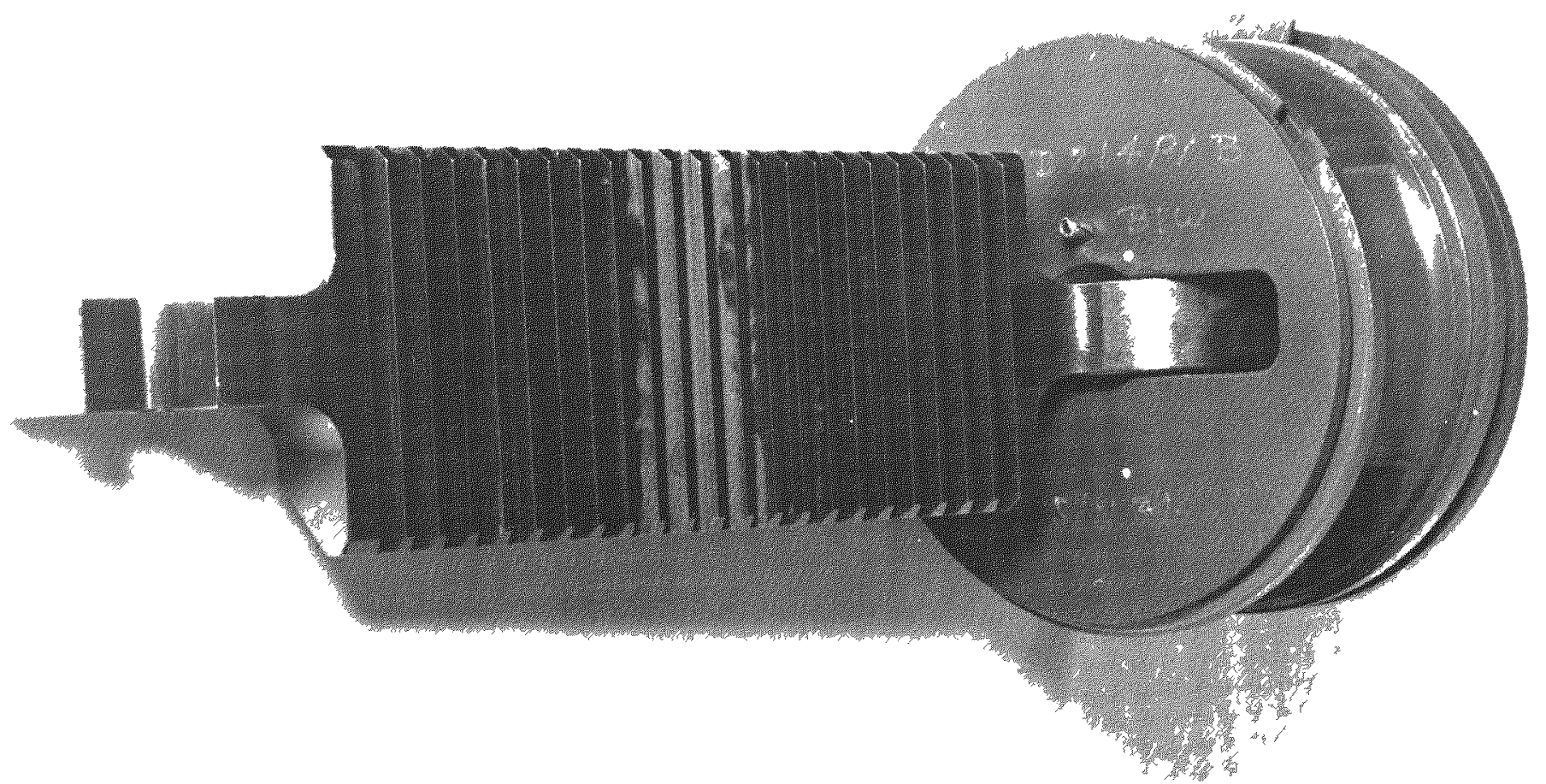

产

옹 亭

Figure 8,4. Rack and Piston 


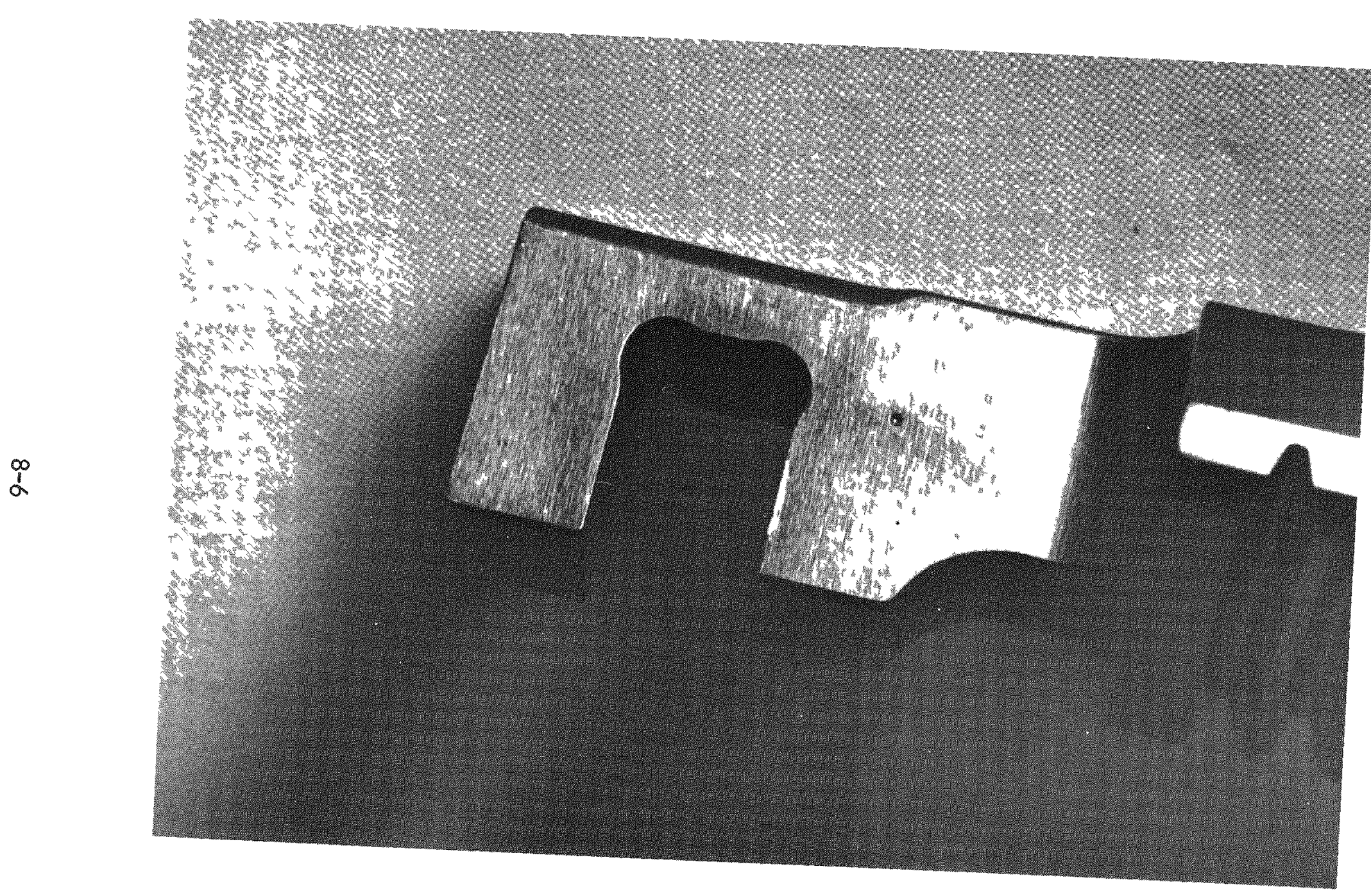

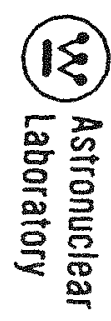

Figure 8.5. Piston Coupling Yoke 


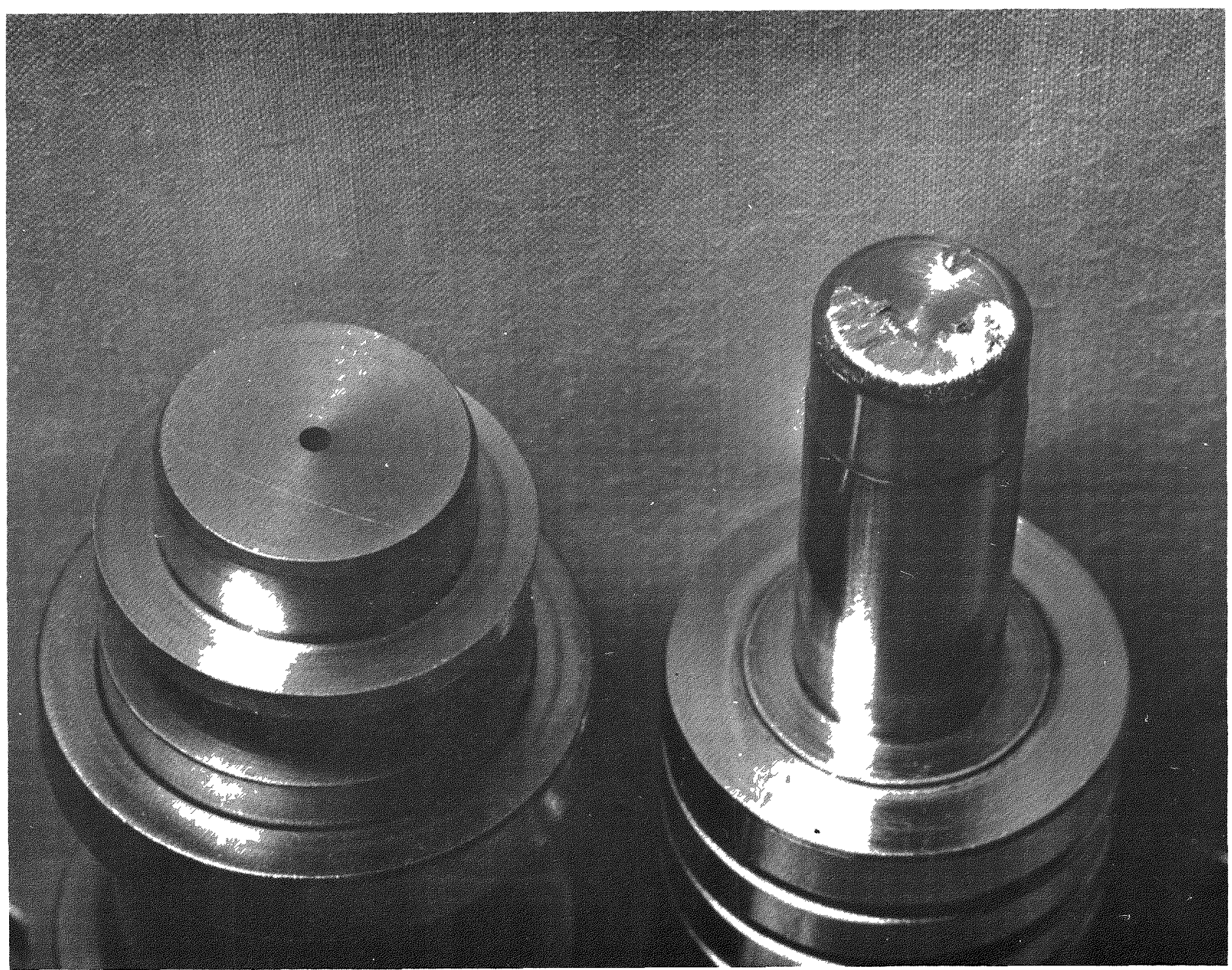

Figure 8.6. Lock Pin and Solenoid Valve 
increased friction has little effect on the dynamic operation performance of the actuator. The chips generated from the lock pin could cause increased friction in the drive shaft bearings if the actuator is operated without coolant gas flow. The lock cam upon which the lock pin rides is shown in Figure 8.7. The wear is apparent on the surface as it was on the lock pin tip. Figure 8.8 shows the lock cam riser surface at the $15^{\circ}$ position. The edge has been rounded by wear although the flat surface still provides adequate area for the lock pin to hold the actuator locked securely at the $15^{\circ}$ position.

\subsection{CYLINDER LINER, CYLINDER COVER AND PISTON ASSEMBLY}

Cylinder Cover No. 1 is shown in Figure 8.9 and Cylinder Cover No. 2 in Figure 8.10. A darkened spiral can be seen on both cylinder covers. This is a coating of the molybdenum diselenide used as a lubricant on the rack and which collected in the grooves between the cylinder liners and the cylinder covers. This black dust was also noted in the cylinder. These particles collected in the apex seals at the ends of the cylinder liners. The pneumatic flow resistors are shown inserted in the cylinder covers in Figures 8.9 and 8.10. Piston No. 1 and its cylinder liner is shown in Figure 8.11. Piston No. 2 and its cylinder liner is shown in Figure 8.12. Some wear was noted on the cylinder liners at the full stroke position of the pistons. This wear was more apparent in the cylinder liner of Piston No. 1 which corresponds to the $15^{\circ}$ position of the drive shaft. The remainder of the cylinder bore was relatively free of scratches. The piston rings were also free of nicks and scratches and no increase in friction was noted. A comparison of the breakaway friction torque is compared with the original assembly data in Figure 8.13.

\subsection{SERVOVALVE ASSEMBLY}

The servovalve was removed from the actuator and inspected. The Glyptal on Bellows No. 2 adjustment screw was cracked and is shown in Figure 8.14. The purpose of 
(Q Astronuclear

(E) Laboratory

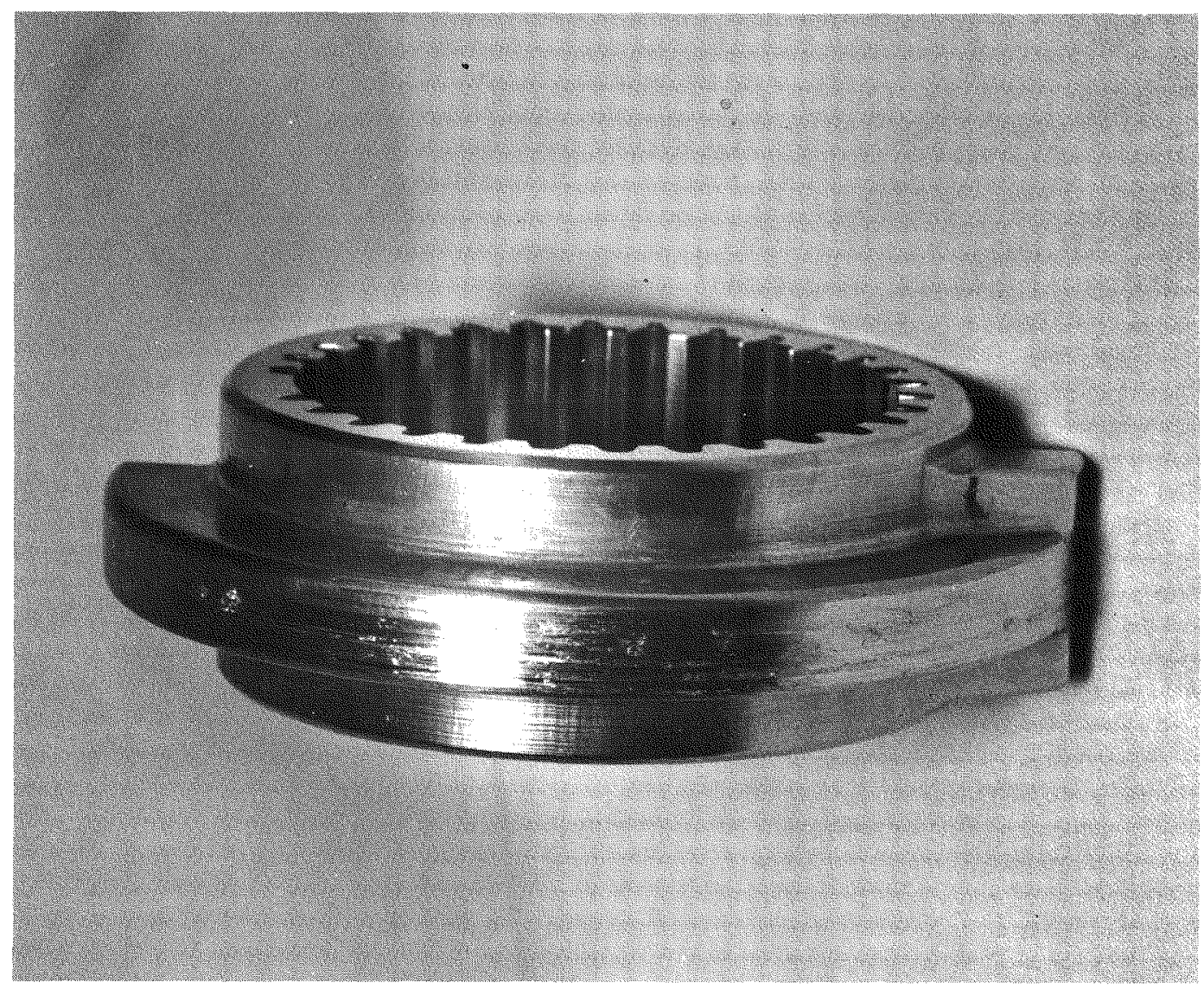

Figure 8.7. Lock Pin Cam 


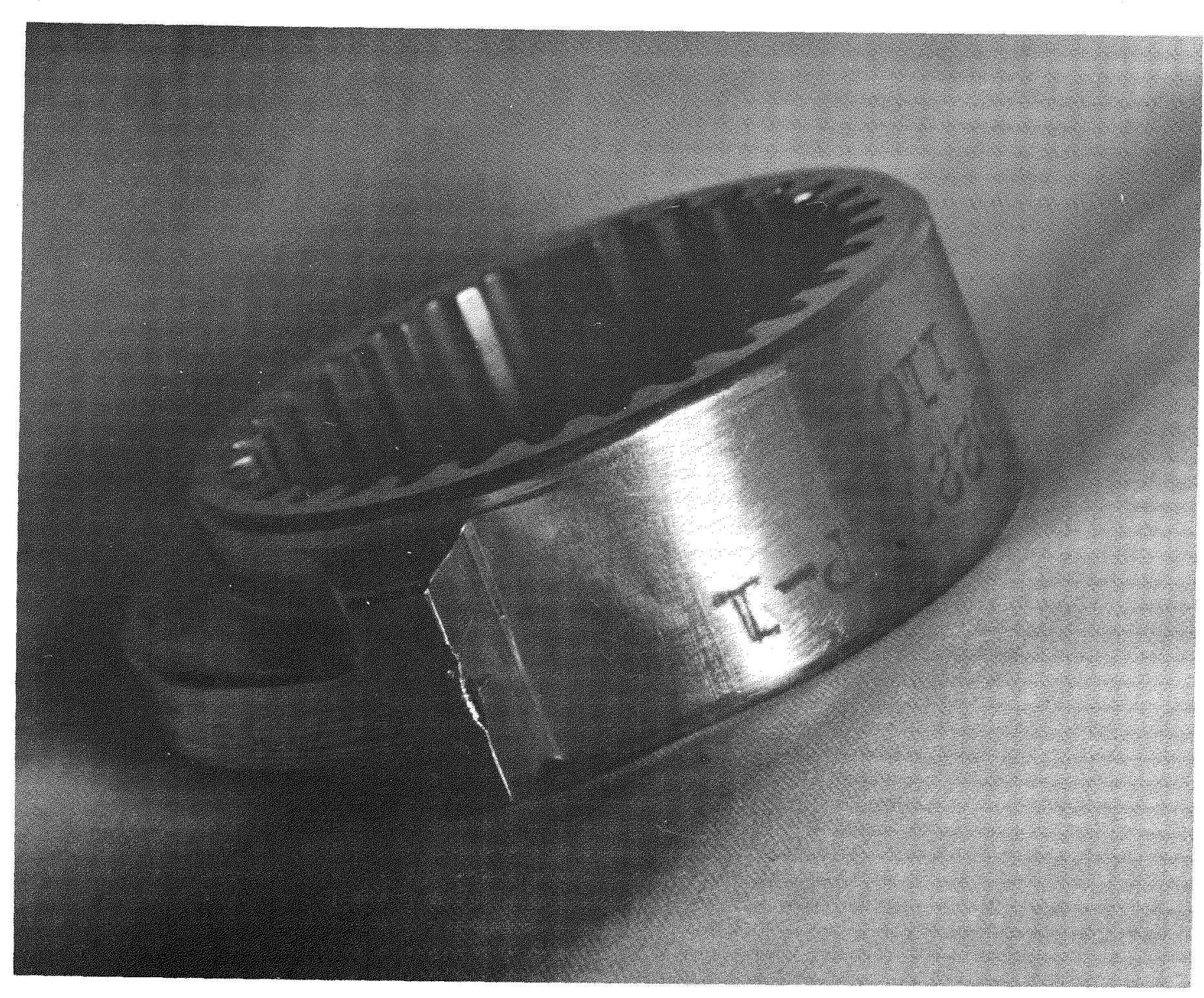

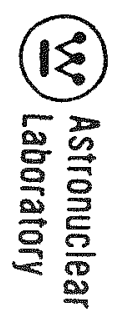

Figure 8.8. Lock Pin Cam 
(v) Astronuclear Laboratory

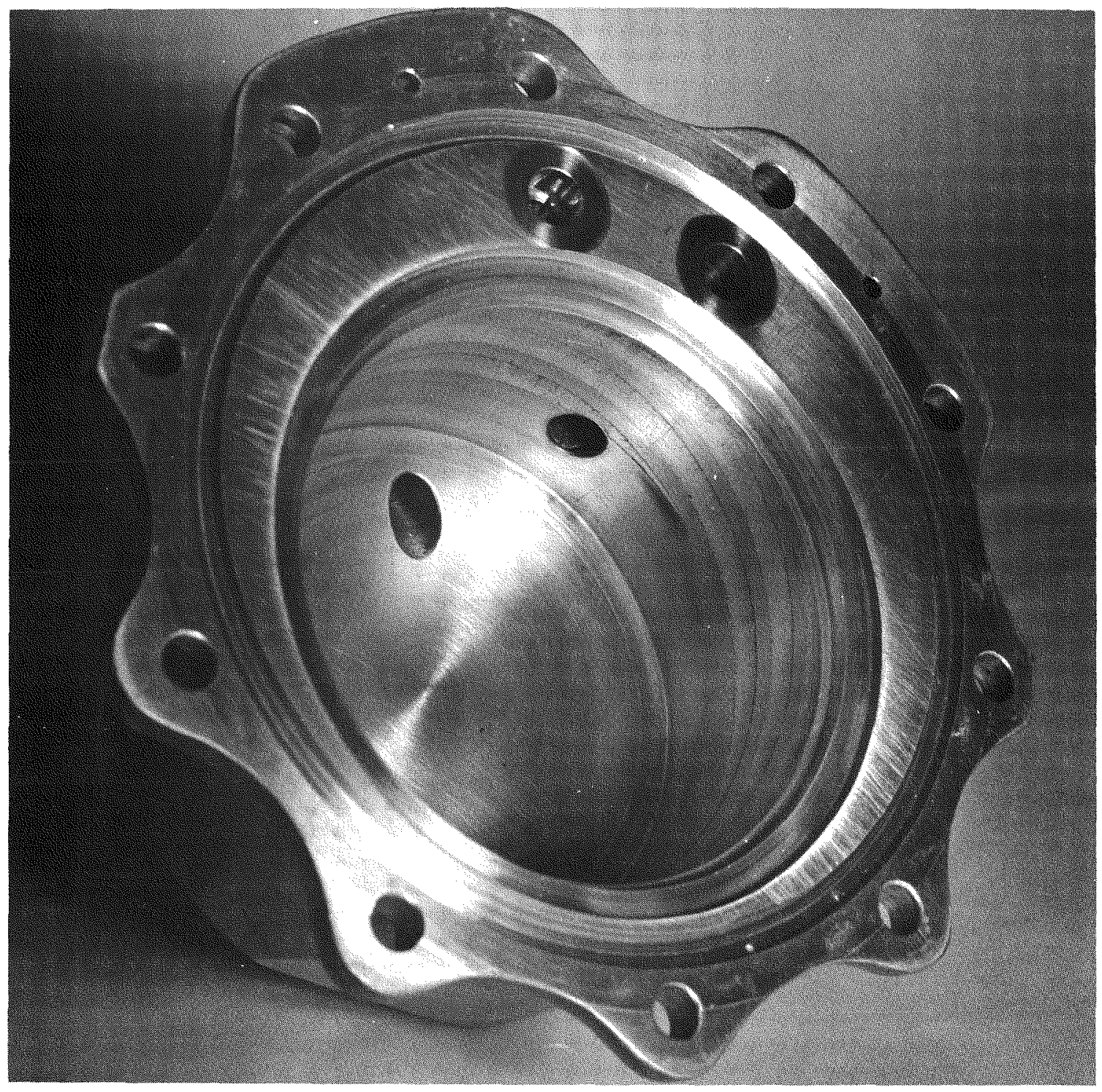

Figure 8.9. Cylinder Cover No. 1 


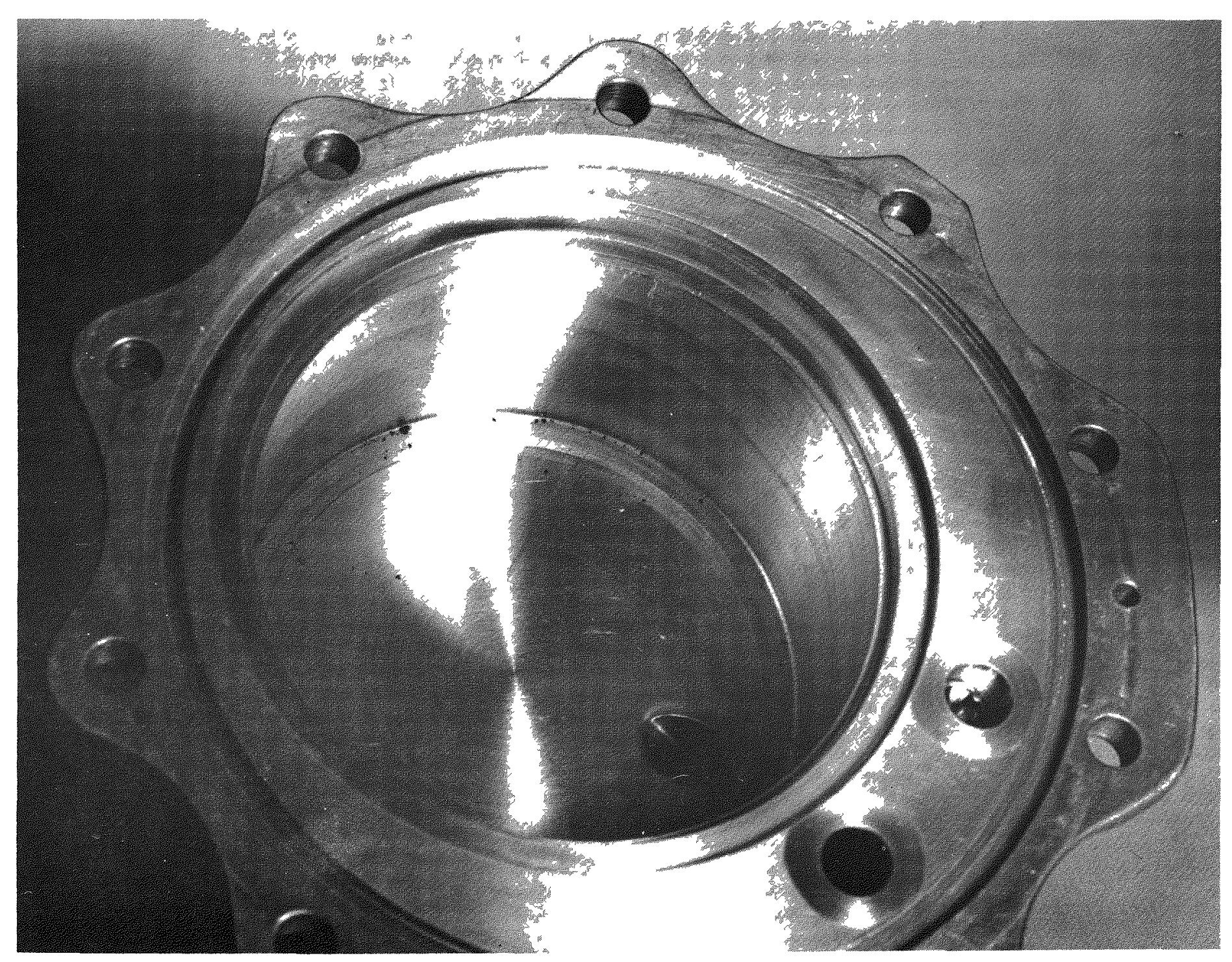

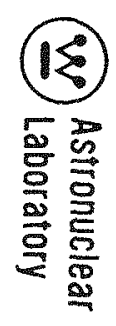

Figure 8.10. Cylinder Cover No. 2 


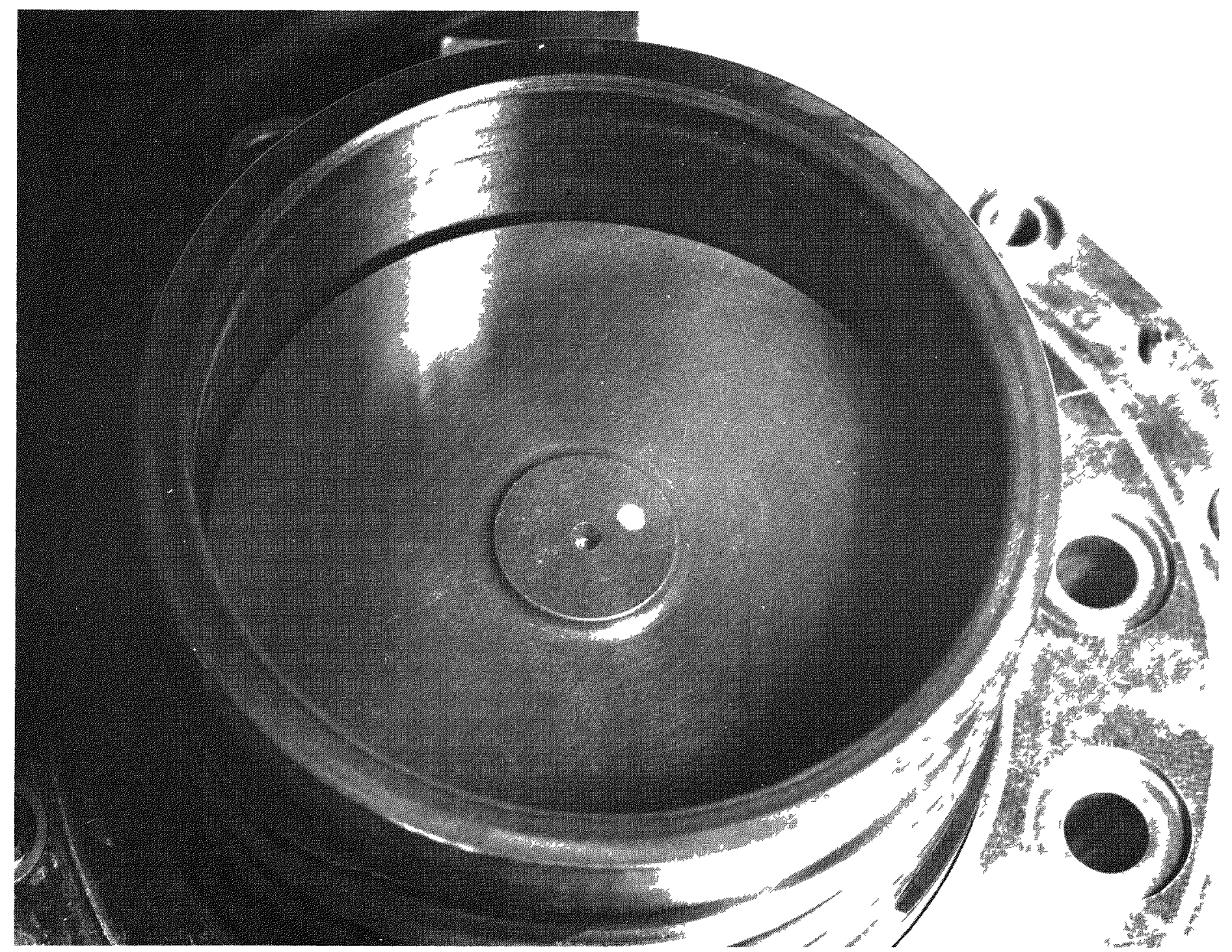

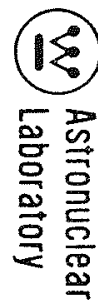

Figure 8.11. Piston and Cylinder No. 1 


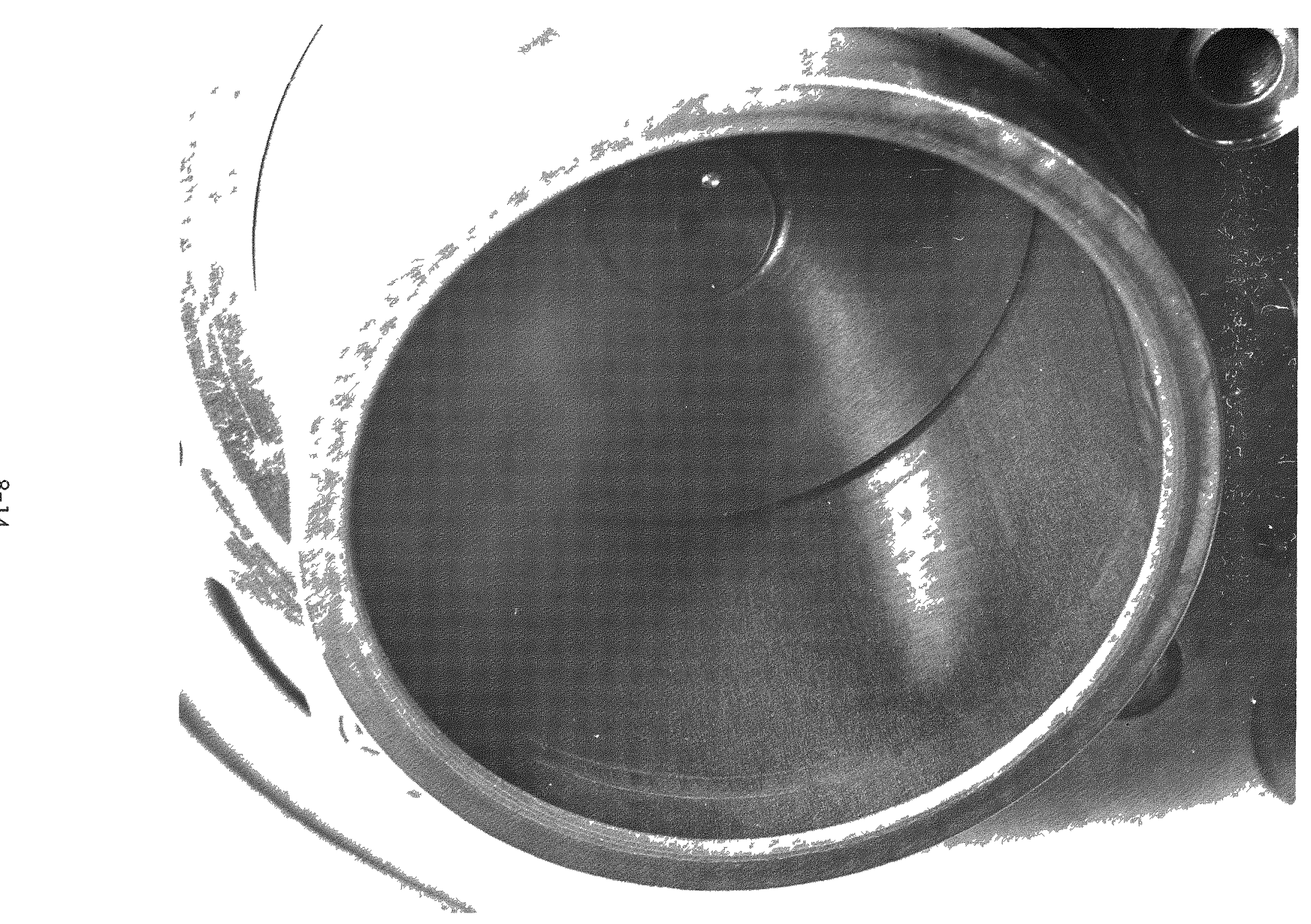

(18)

호을

$\infty$
$\frac{1}{1}$

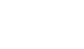

Figure 8. 12. Piston and Cylinder No. 2 


$\begin{array}{lll}\text { AVERAGE BREAKAWAY TORQUE: } & \begin{array}{l}\text { ASSEMBLY TEST BY } \\ \text { VENDOR }\end{array} & \begin{array}{l}\text { TEST DURING DISASSEMBLY } \\ \text { OF ACTUATOR }\end{array} \\ \text { INCREASING SHAFT ANGLE - } & 33.6 \mathrm{OZ} \mathrm{IN} & 40 \mathrm{OZ} \text { IN } \\ \text { DECREASING SHAFT ANGLE - } & 38.3 \mathrm{OZ} \mathrm{IN} & 35 \mathrm{OZ} \text { IN }\end{array}$




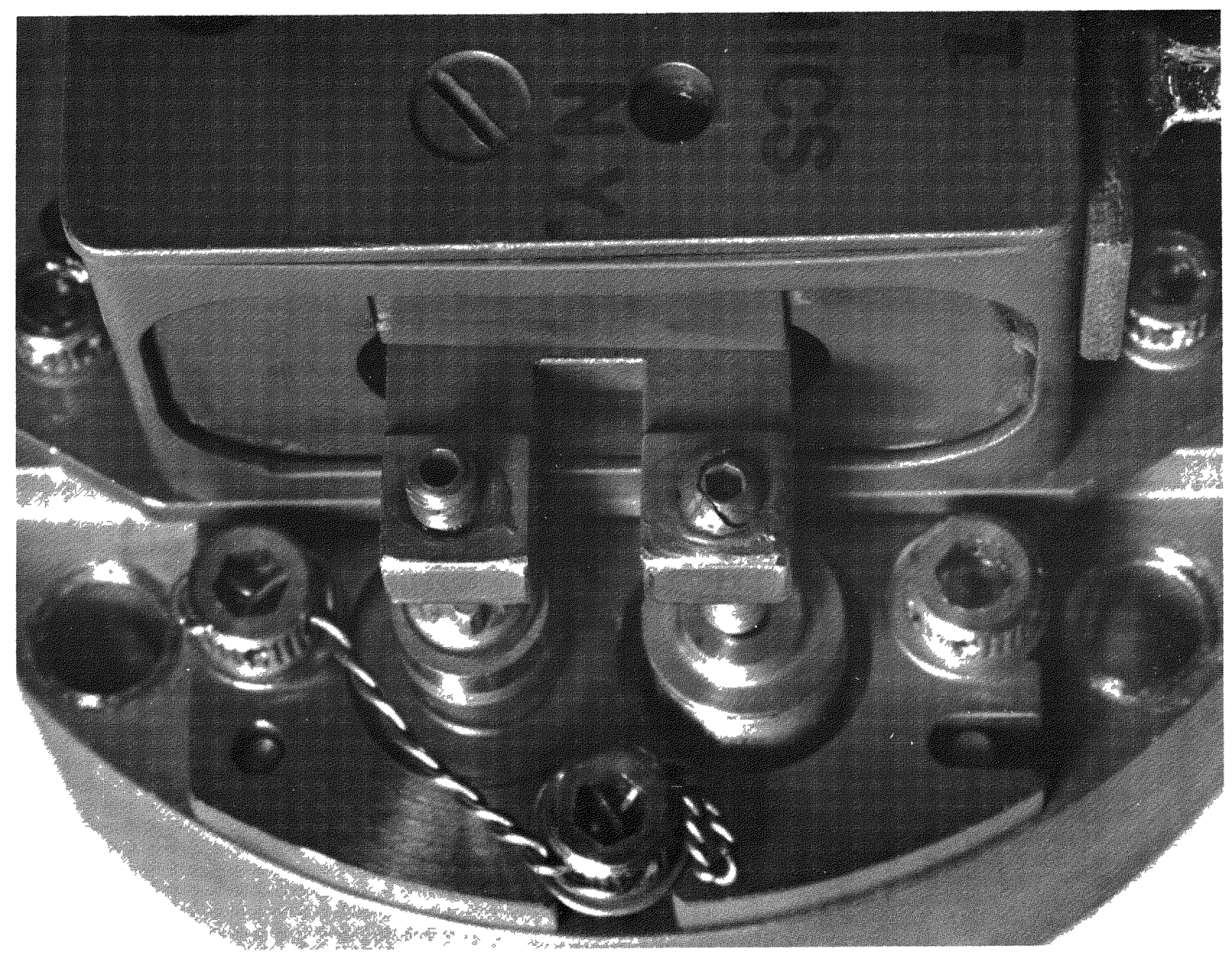

产

产

Figure 8. 14. Servovalve $-P_{1}$ Flapper and $P_{2}$ Bellows 
the Glyptal is to indicate that the screw has been set to its final adjustment and is not intended to serve as a screw locking device. A measurement of the locking torque of this screw indicated that it was above the 5 in-oz minimum. The most probable time for the Glyptal to crack was during a thermal cycle due to the difference in thermal contractions between the metal screw and the Glyptal. The Glyptal is downstream of the servovalve gas porting and therefore cannot enter the nozzle flapper valve. When operated after the environmental tests, the servovalve exhibited a bias current of 29 ma as opposed to 31 ma before the tests. This shift in bias current is considered normal. The crossover pressure, the value of $P_{1}$ and $P_{2}$ when they are equal, was 67 psig after the tests as opposed to 87 psig before the tests. This reduction in crossover pressure was the result of increased seal leakage and a shift of the flapper valve bullets and it appeared to have little or no effect on actuator performance. 
(W) Astronuclear

Laboratory

\subsection{EXTENDED LIFE TEST}

9.1 As a supplement to the XE-1 qualification tests, an extended life test was performed on the XE-1 pneumatic control drum actuator. The purpose of the test was to gain further insight into the reliability and durability of the XE actuator design and to aid in future development of control drum actuator concepts. The extended life test was performed between January and May, 1969 in the WANL Mechanisms Laboratory.

9.2 The test set-up is shown in Figure 9.1. The actuator is mounted on a load stand which simulates a control drum and a scram spring. A modified pedestal serves as the actuator mounting support and provides the electrical, pneumatic, and mechanical interface to the actuator. The actuator control amplifier is mounted in a cabinet which provides lock and scram logic for the system. The visicorder, frequency respone analyzer, and chart recorder are used to measure actuator performance. A timing cam system is used for periodic scram commands. The function generator generates the actuator position command.

9.3 The actuator used in this test was the same used throughout the qualification tests (Serial No. A58608). Following the post-qualification test actuator disassembly, the actuator parts were cleaned and the actuator reassembled and adjusted. The actuator control amplifier was of the modified XE-2 type (Serial No. 80823), which reduces the overall system closed loop bandwidth and also incorporates the selectable open or closed loop scram modes.

9.4 The assembled actuator was placed on the load stand and operated with helium drive gas $\left(200 \mathrm{psig}, 540^{\circ} \mathrm{R}\right)$ and nitrogen coolant gas (600 psig, $\left.540^{\circ} \mathrm{R}\right)$. After initial alignment, the actuator performance was recorded to establish the base line data. Having established the base line data, the actuator was given a command signal as listed in the table below: 


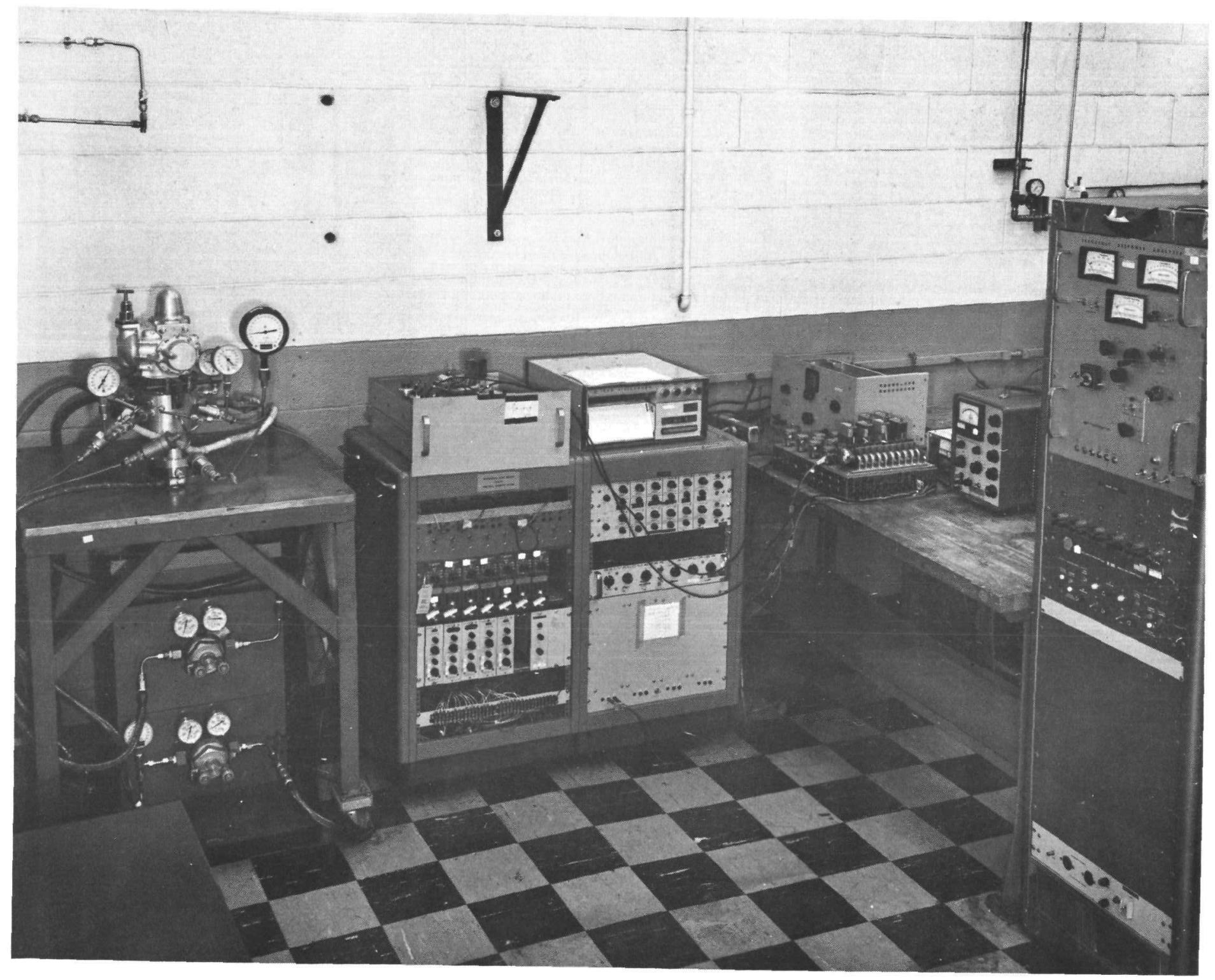

(18)

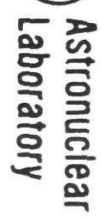

Figure 9.1. Extend Life Test Setup

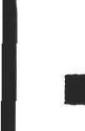




$$
\begin{array}{ll}
100^{\circ} \text { ramps } & 3^{\circ} / \mathrm{sec} \\
100^{\circ} \text { steps } & 0.1 \mathrm{~Hz} \\
18^{\circ} \text { steps } & 0.5 \mathrm{~Hz} \\
40^{\circ} \text { p-p sine } & 0.1 \mathrm{~Hz} \\
4^{\circ} \text { p-p sine } & 1.0 \mathrm{~Hz}
\end{array}
$$

Each input signal was applied for 24 hours with the exception that inputs scheduled for Saturdays were also continued on Sundays for a total of 48 hours. Equal time distribution was given to the inputs throughout the test. An additional scram input command was given to the actuator. The actuator was scrammed every 30 minutes alternately in the open loop mode and the closed loop mode. The net effect was an open loop and a closed loop scram for each hour of operation. To conserve helium gas the drive gas supply was changed to nitrogen ( $200 \mathrm{psig}, 540^{\circ} \mathrm{R}$ ). The nitrogen used for coolant was reduced from 650 to 250 psig.

9.5 At several time intervals, the life test was suspended and the actuator performance was checked. The first performance check was taken after 1990 hours (2000 hour check). The actuator drive gas was changed to helium $\left(200 \mathrm{psig}, 540^{\circ} \mathrm{R}\right)$ and the nitrogen coolant pressure was raised $\left(650 \mathrm{psig}, 540^{\circ} \mathrm{R}\right)$ for the performance check in order to repeat the conditions of the base line data check. No serious changes in actuator performance were noted. There was, however, a change in torque motor current from the nominal $30 \mathrm{ma}$ to $21 \mathrm{ma}$. After the 2000 hour performance check, the extended life test was resumed.

9.6 It was noted that the feedback potentiometer developed noise when the actuator was given a continuous input signal, especially an $18^{\circ}$ or a $100^{\circ}$ step. This noise would develop in as little as one hour of operation but would disappear when the input signal was changed or the actuator was scrammed. The noise did not appear during the 2000 hour performance check but it did return afterwards in increasing intensity. At 2491 hours 
(2500 hour check) the actuator performance was again checked. The potentiometer noise did not affect performance and the torque motor current remained at 21 ma. To further investigate the potentiometer noise, the potentiometer was removed and replaced by a new one. The potentiometer was disassembled and examined for track wear. "C" track showed wear over about a $20^{\circ}$ segment near to $90^{\circ}$ position. The wiper arm also appeared to be worn. It is believed that the rough worn areas, when operated for extensive periods at low coolant flows, allow the buildup of track particles which cause the wiper arm to skip and cause noise when traveling at high velocities. After the 2500 hour check, the extended life test was resumed.

9.7 With the new potentiometer installed, the test continued until 3213 hours of the extended life test. During this time, the new potentiometer developed no significant noise problems. At 3213 hours, however, the lock pin failed to engage when the actuator was given its periodic scram command. Further testing of the lock showed it incapable of achieving either the fully locked or the fully unlocked positions. Although the lock was inoperable, it was retracted enough not to interfere with the drive shaft rotation. The actuator performance was checked and it did not change significantly from the base line data. The extended life test was terminated and the actuator removed to the Clean Room for disassembly.

9.8 Upon disassembly, it was noted that the lock pin was jammed in the lock pin cylinder. The lock pin and cylinder showed score marks and signs of galling. The tip of the pin was also worn and chipped. The lock pin and cylinder had been coated with molybdenum diselenide at assembly but this had worn off due to the high stresses imposed during the scram operations. The lock pin is shown in Figure 9.2 and the lock pin cylinder is shown in Figure 9.3. The worn tip of the lock pin was caused by the lock pin falling on the lock pin cam during the scram operations. The lock pin cam also showed signs of wear as can be seen in Figure 9.4. The pre-test condition of the lock pin and 


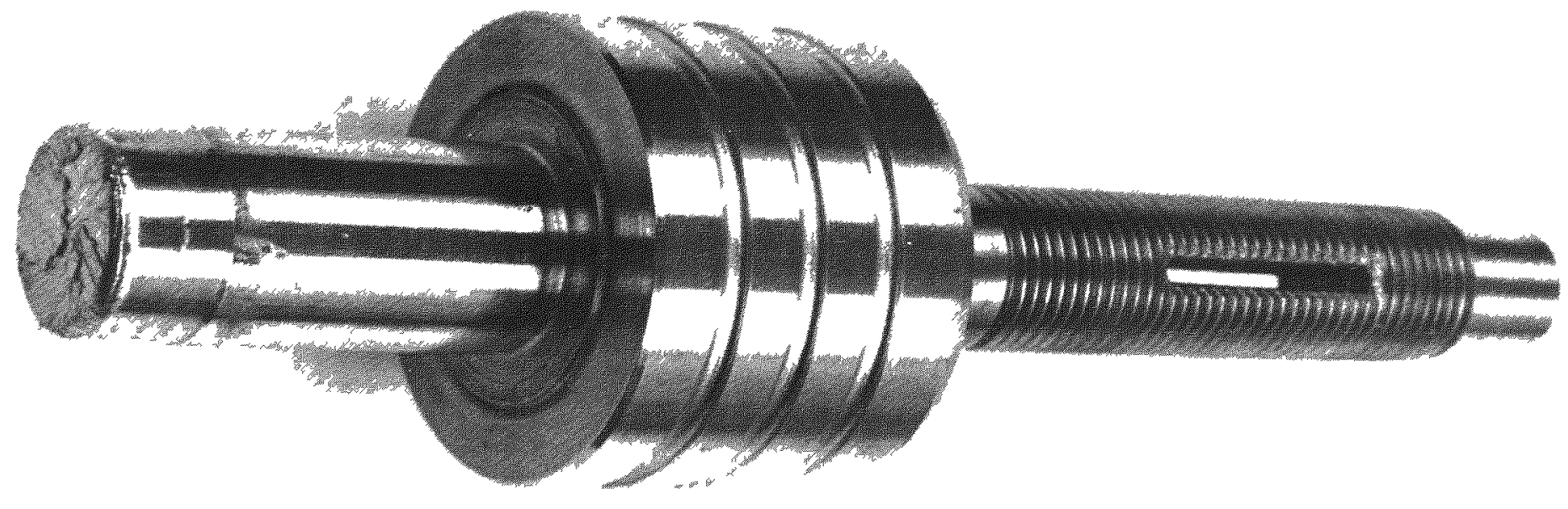

(18)

Figure 9.2. Lock Pin

总言 


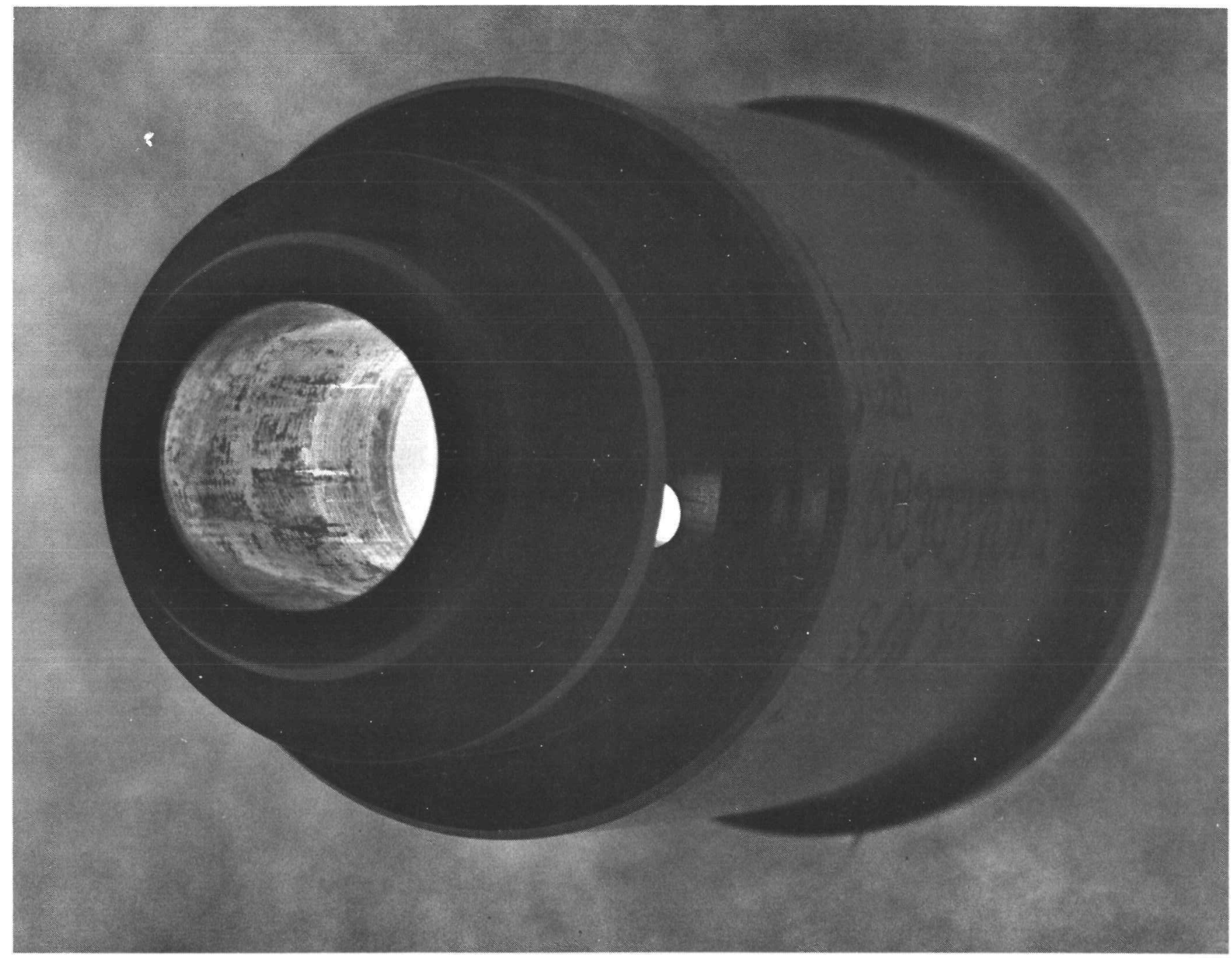

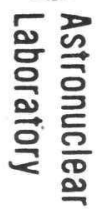

$\stackrel{1}{\alpha}$

Figure 9.3. Lock Pin Cylinder

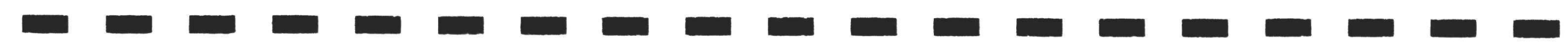




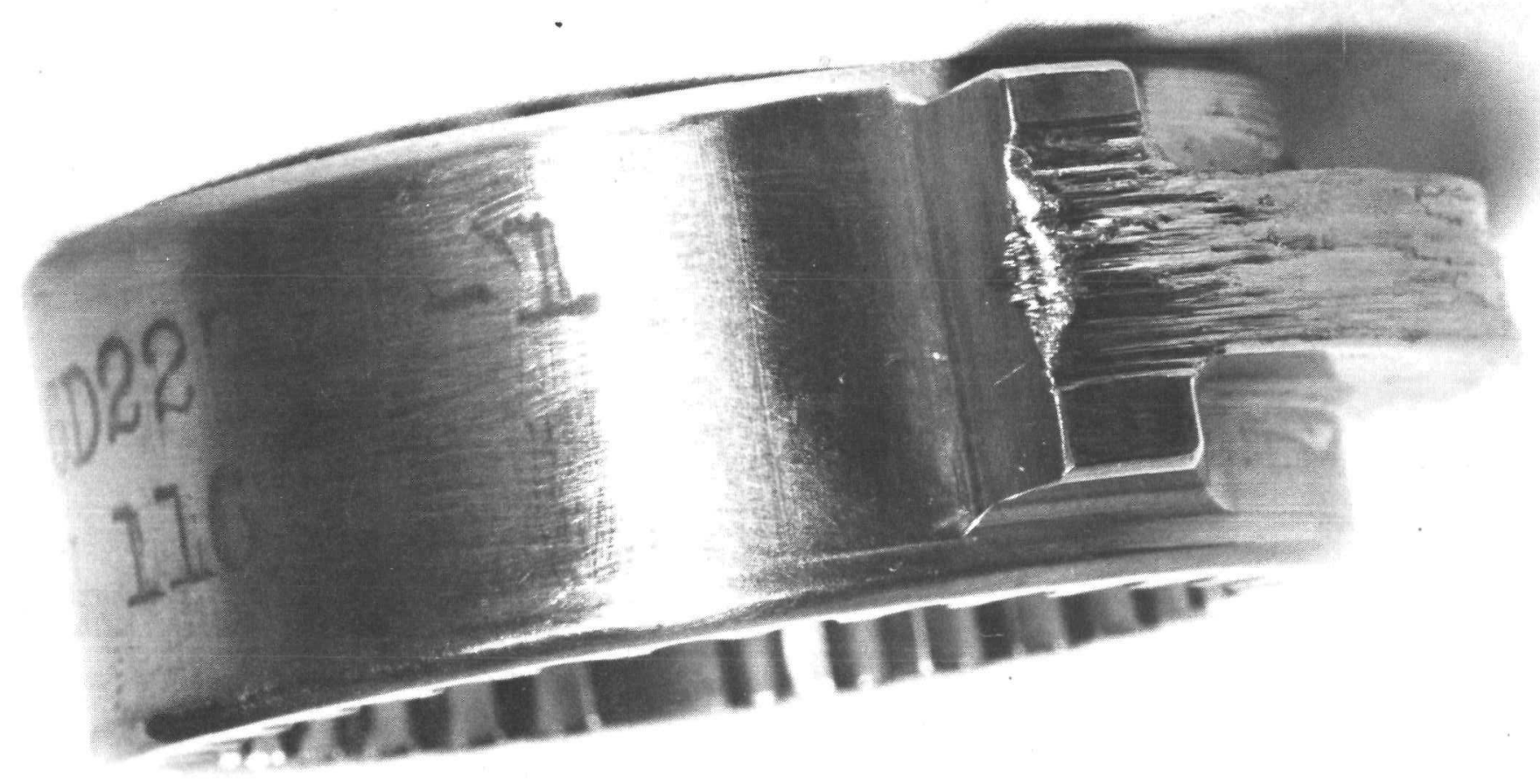

Figure 9.4. Lock Pin Cam 몸

웅

㤩 $\frac{5}{\$ 刃}$ 
cam can be seen in Figures $8.6,8.7$ and 8.8 in the preceding section of this report. 9.9 The drive shaft pinion gear is shown in Figure 9.5. There appears to be more wear in the area of rack contact in comparison with Figure 8.1 , but there is no sign of chipped gear teeth. The upper end of the drive shaft is shown in Figure 9.6 and the corresponding contact area of the soft stop spring is shown in Figure 9.7. The contact areas appear to be worn but this wear occurs only when the actuator is locked and has no effect on actuator performance. The actuator rack and piston is shown in Figure 9.8. As on the pinion, the rack gear teeth show a wearing away of the oxide coating. On the rack, however, there are signs of flaking of the gear teeth. The flaking is a small percentage of the gear teeth and not enough to cause disengagement of the rack and pinion. An accumulation of residue was noted in the space between the two piston rings. This residue was a combination of dust from piston ring wear, rack and pinion oxide, and dry film lubricant. The space between the piston rings is not washed by either the coolant or drive gas and any particles in this area accumulate to form a residue. Figure 9.9 is of the rack back-up bearing. A spalling of the gold-plate can be seen. Performance of the bearing was not affected by this spalling of the gold-plate. In Figure 9.10, the piston coupling yoke is shown in good condition. There are no signs of bending, fracture or wear.

9.10 The cylinder liner and piston of the $P_{1}$ side is shown in Figure 9.11 and the corresponding cylinder cover is in Figure 9.12. Figure 9.13 shows the $\mathrm{P}_{2}$ liner and piston and Figure 9.14 is the cylinder cover for the $P_{2}$ side. The cylinder liners show very little wear but an accumulation of dust can be seen at the limit of the piston stroke. Metallic chips from the lock pin and cam can be seen inside the cylinder covers. These chips were trapped in the seal areas of the coolant flow passages and did not enter the piston areas. The dry film lubricant appears to have adhered to the internal surfaces of the actuator as a black coating and is shown in Figure 9.15. 
(W. Astronuclear

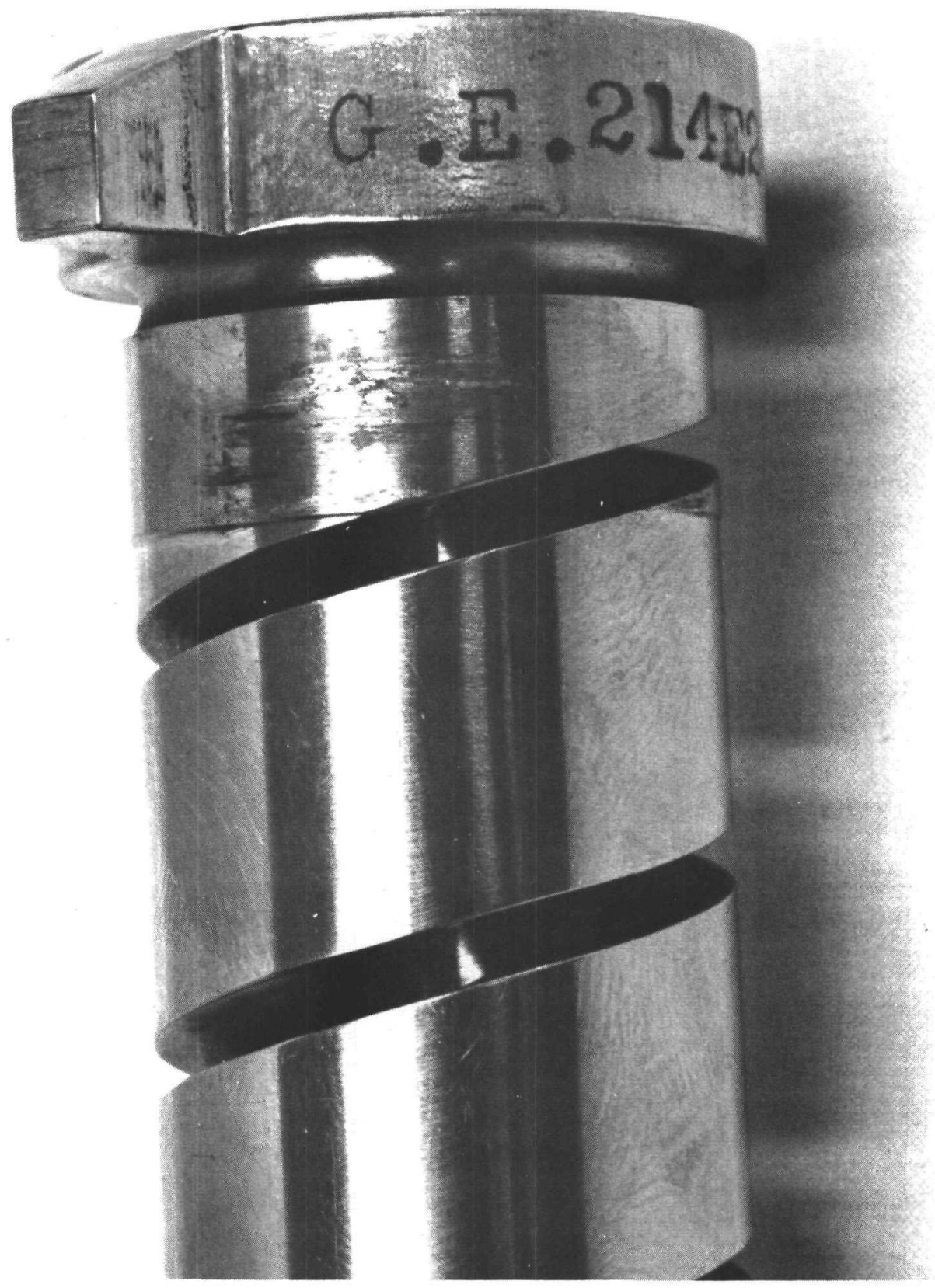

Figure 9.7. Soft Stop Spring 


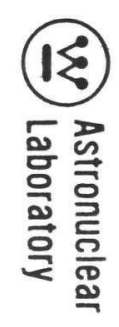

Figure 9.8. Rack and Piston 


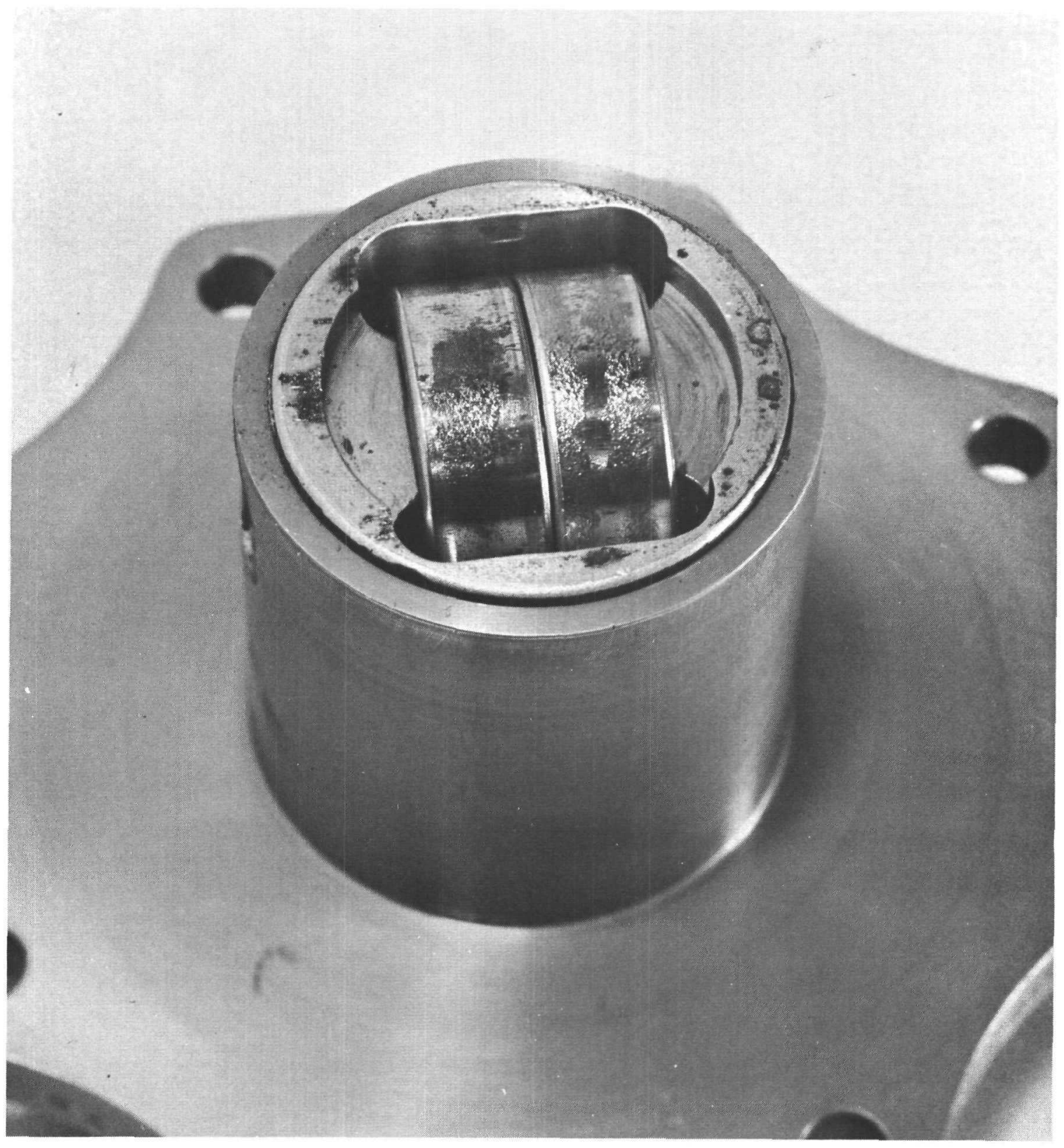

Figure 9.9. Rack Back Up Bearing 
(W. Astronuclear

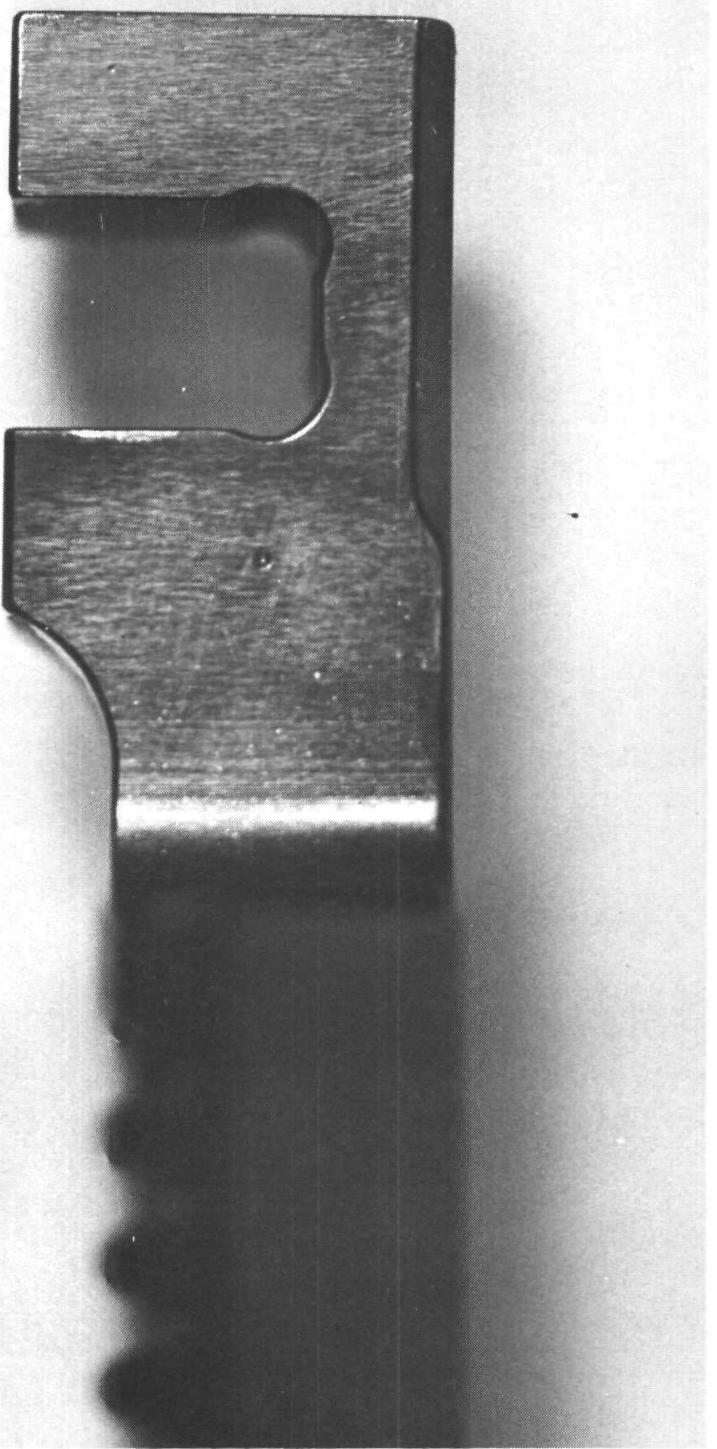

Figure 9. 10. Piston Coupling Yoke 
W Astronuclear

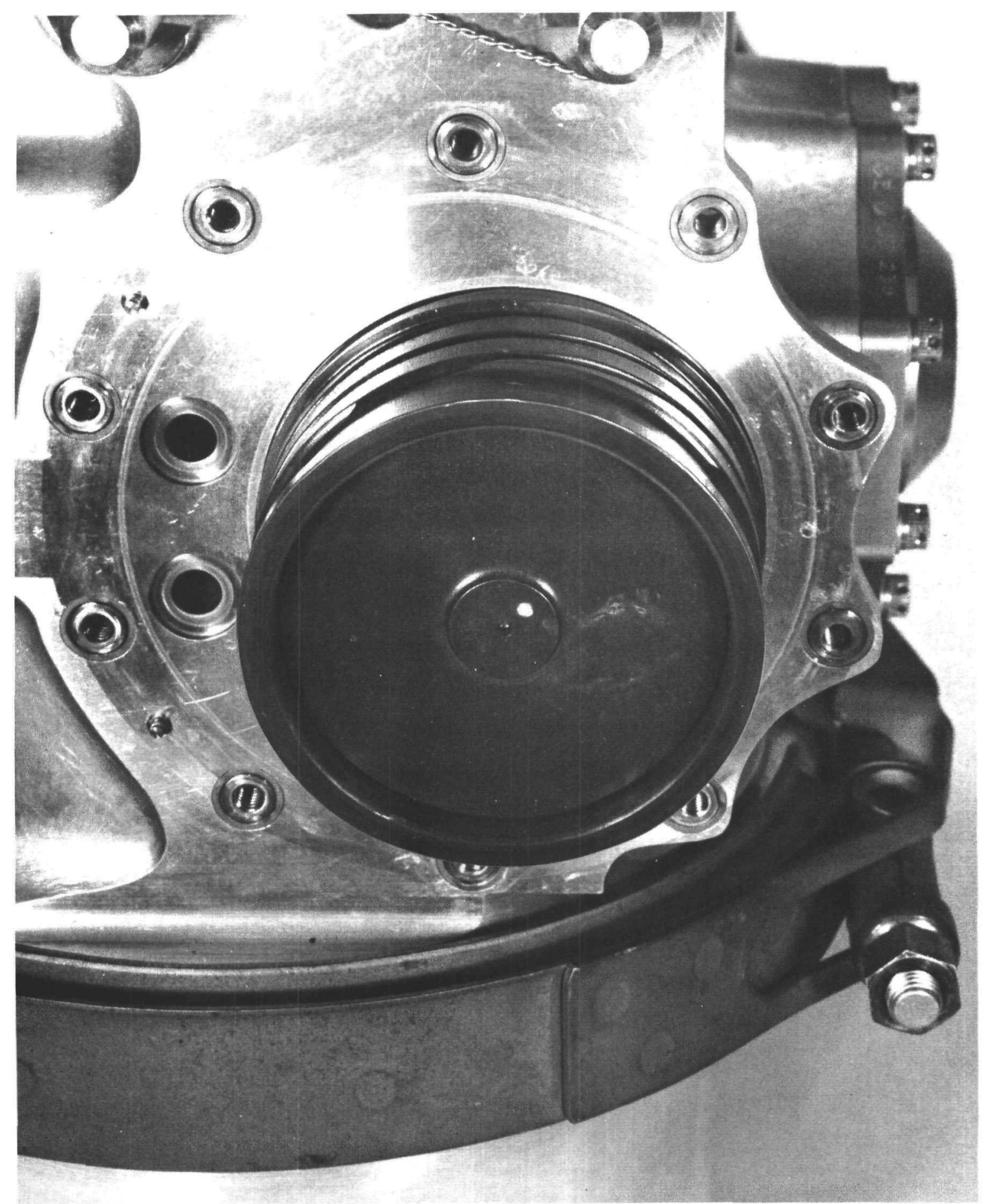

Figure 9.11. Piston and Cylinder No. 1 
We Astronuclear

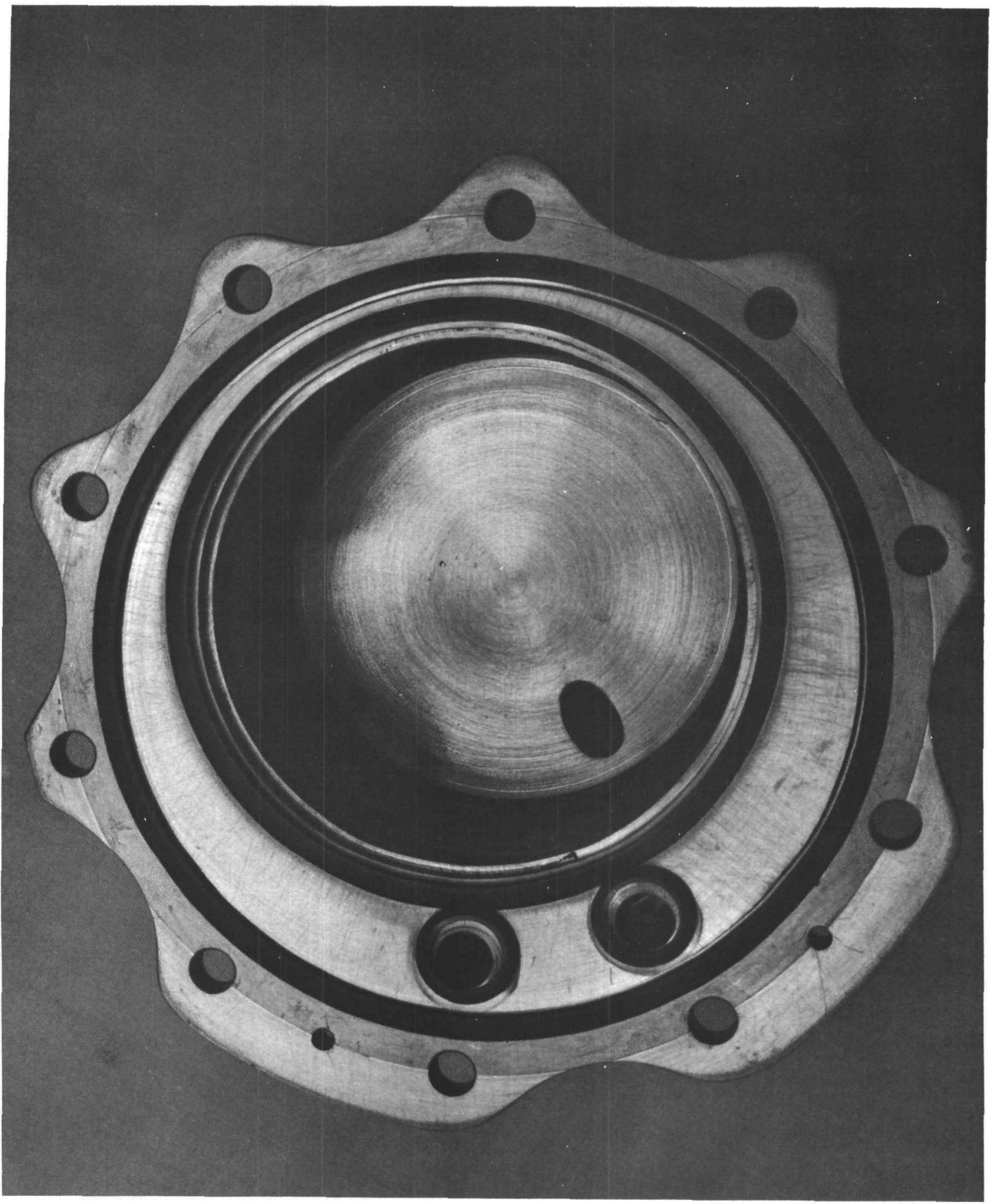

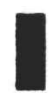

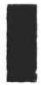

$\square$

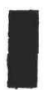

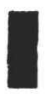

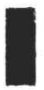

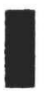

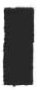

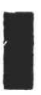

I

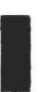

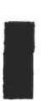

,

1

I

Figure 9. 12. Cylinder Cover No. 1

$$
9-16
$$


Astronuclear
Laboratory

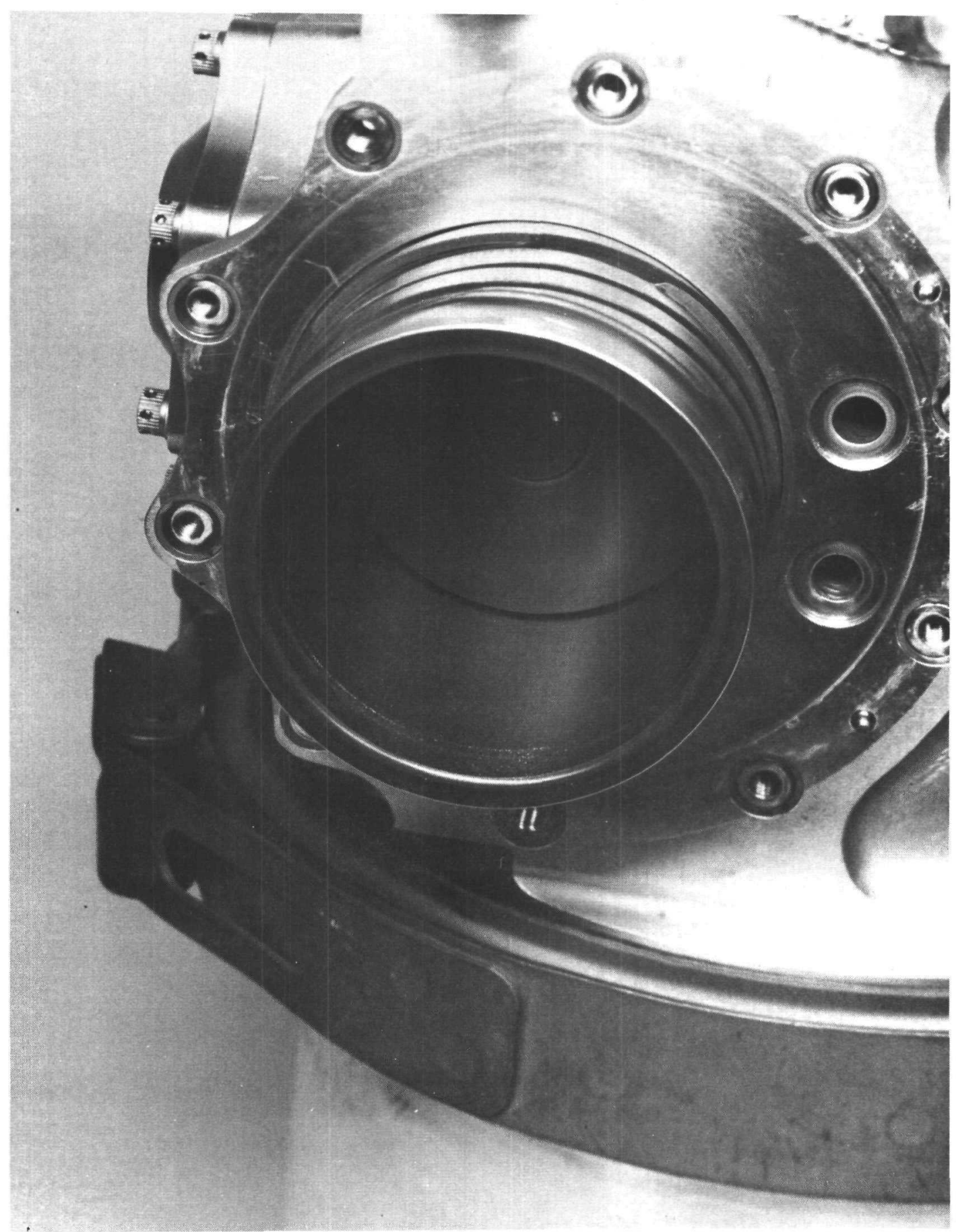

Figure 9.13. Piston and Cylinder No. 2 
(2) Astronuclear

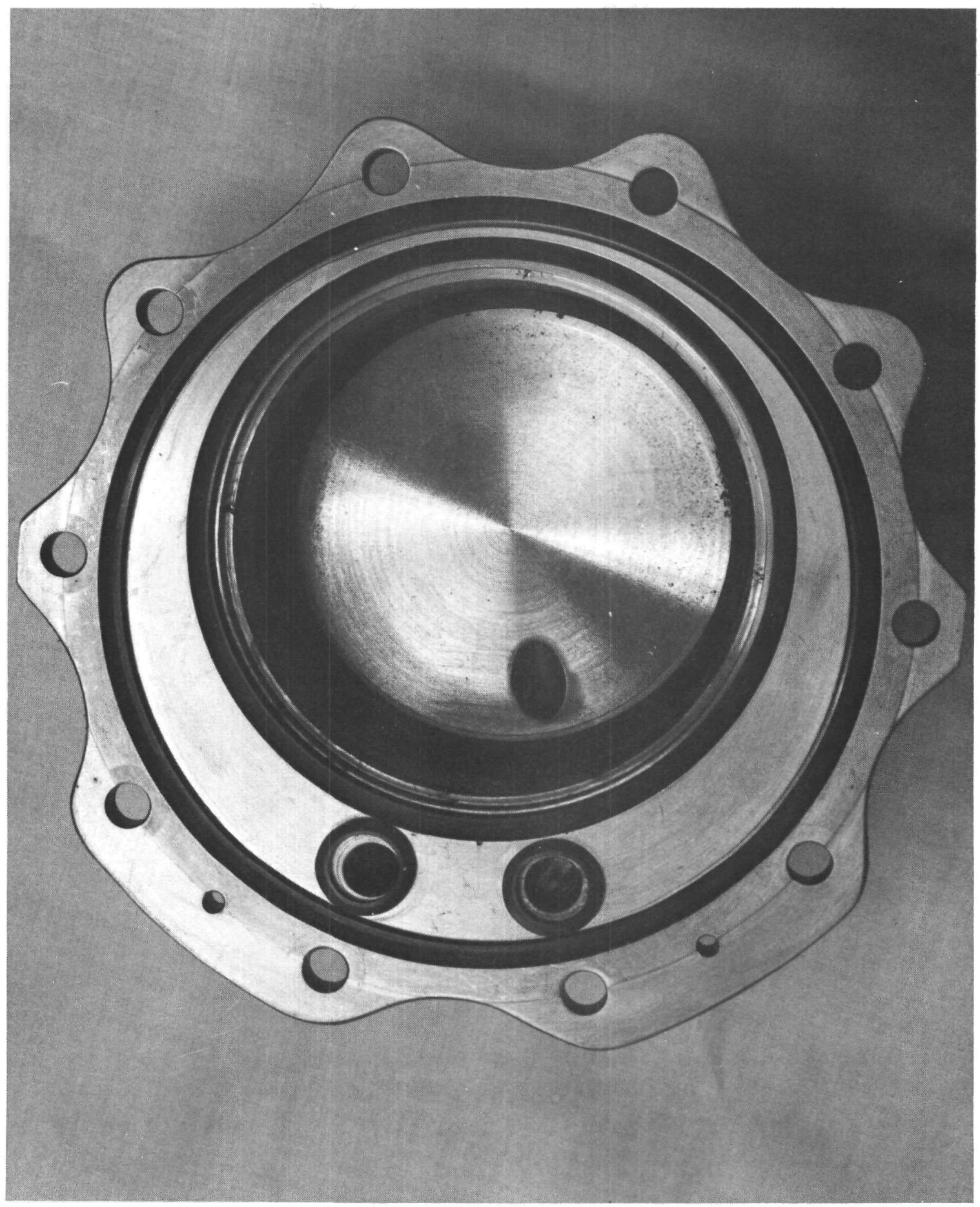

Figure 9. 14. Cylinder Cover No. 2 
(2) Astronuclear

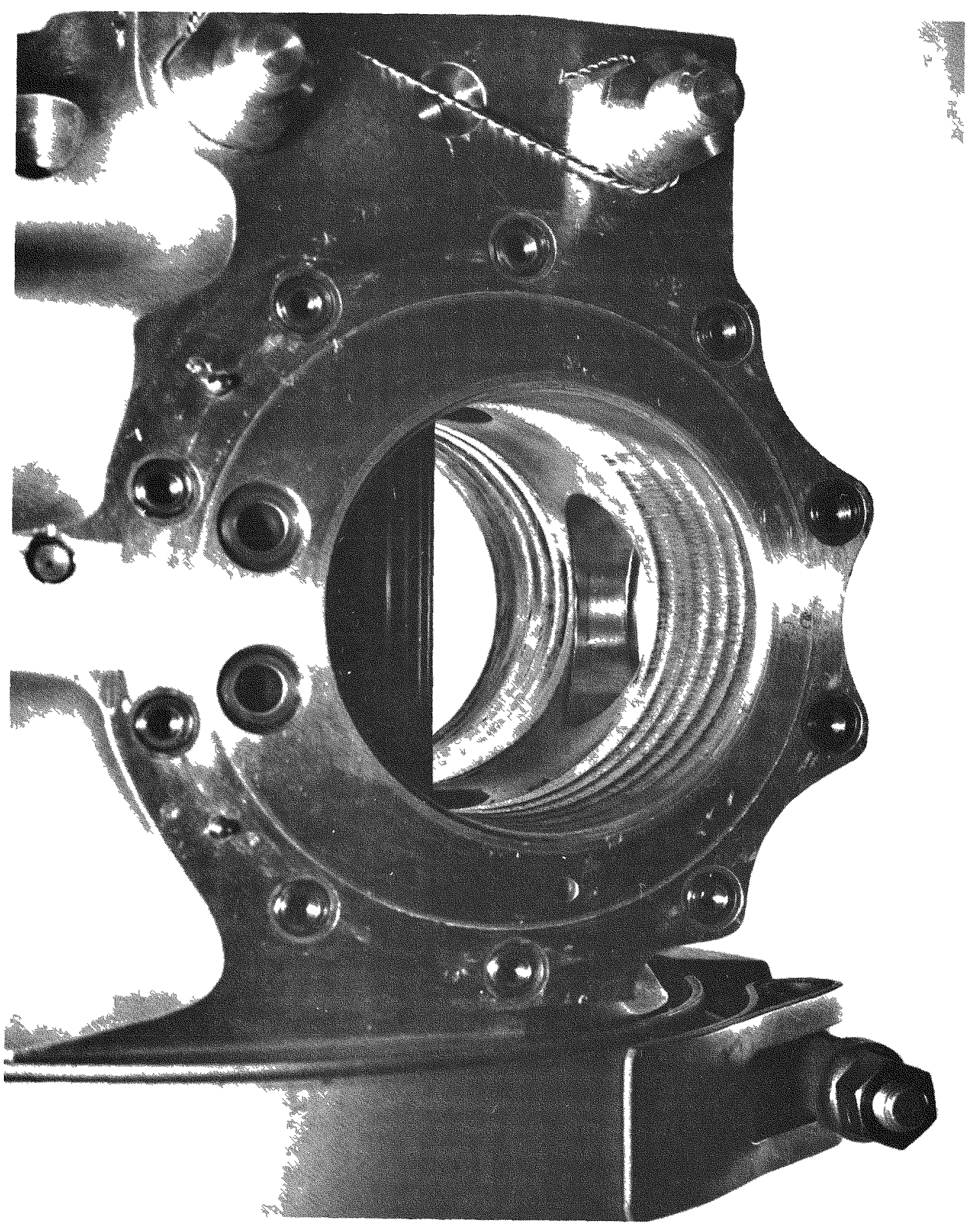

Figure 9.15. Actuator Housing - Internal Walls 
(Q) Astronuclear

9.11 The lower drive shaft bearing is shown in Figure 9.16. The gold-plate is gone from the balls and metallic chips can be seen in the recesses of the bearing holder. The bearing rotation appeared to be rough and uneven. Before disassembly, the breakaway friction of the drive train was measured. The maximum breakaway friction was 6 in-lbs. Maximum specified friction for the XE actuator is 1.875 in-lbs. The increase in friction is attributed to bearing wear caused by metallic chips from the lock pin and cam and a loss of the gold-plate on the bearings. The increased friction, however, did not appear to seriously affect actuator performance.

9.12 The servovalve was removed as a unit and placed on the servovalve test stand. The bias current remained at 20 ma as it had throughout the test. The frequency response of the valve did not change from its initial setpoint. It appears that the change in bias current from the setpoint value of 30 ma to 20 ma was the result of a shift in the bellows on the valve at the onset of the test.

9.13 Figure 9.17 lists the results of the transient response, scram turnaround, and resolution tests obtained during the performance checks. The most noticeable change was in the resolution. This deviation occurred as a shift of the entire resolution curve which was caused by a difference in shift between the +10 VDC and the -15 VDC power supplies. In conjunction with the change in resolution was also the maximum change in outward rise and settling times. The frequency response curves are shown in Figures 9.18, 9.19, 9.20 and 9.21. The change in frequency response from the base line data appears as a low frequency peaking and a more rapid roll-off which is indicative of increased actuator friction.

9.14 The following table lists the total operating time of the XE test actuator No. 58608: 


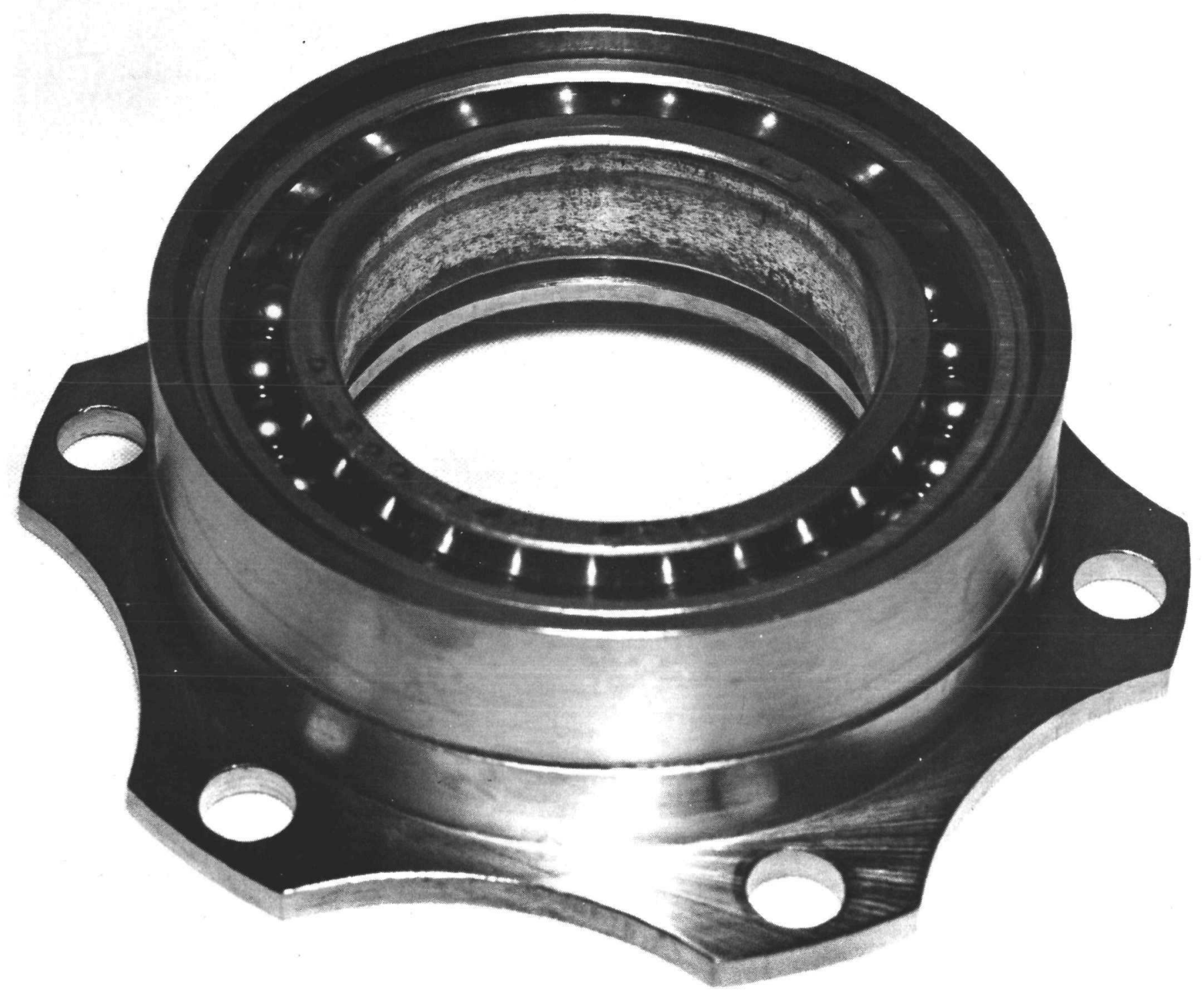

Figure 9. 16. Lower Drive Shaft Bearing

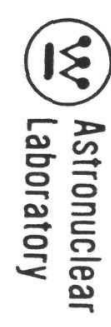




\begin{tabular}{|c|c|c|c|c|}
\hline & $B L D$ & $1990 \mathrm{hr}$ & $2491 \mathrm{hr}$ & $3211 \mathrm{hr}$ \\
\hline $\begin{array}{l}\text { Scram Turnaround } \\
\text { Closed Loop (sec) } \\
\% \text { of BLD }\end{array}$ & $\begin{array}{c}0.019 \\
-\end{array}$ & $\begin{array}{l}0.021 \\
+10.5\end{array}$ & $\begin{array}{l}0.021 \\
+10.5\end{array}$ & $\begin{array}{l}0.018 \\
-5.3\end{array}$ \\
\hline $\begin{array}{l}\text { Open Loop (sec) } \\
\% \text { of BLD }\end{array}$ & $\begin{array}{c}0.057 \\
\ldots\end{array}$ & $\begin{array}{l}0.040 \\
-30.0\end{array}$ & $\begin{array}{l}0.048 \\
-16.0\end{array}$ & $\begin{array}{l}0.062 \\
+8.8\end{array}$ \\
\hline $\begin{array}{c}\text { Rise Time (in) } \\
\text { Time (sec) } \\
\Delta \% B L D\end{array}$ & $\begin{array}{c}0.259 \\
--\end{array}$ & $\begin{array}{l}0.277 \\
+7.0\end{array}$ & $\begin{array}{l}0.250 \\
-3.5\end{array}$ & $\begin{array}{l}0.246 \\
-5.0\end{array}$ \\
\hline $\begin{array}{c}\text { Rise Time (out) } \\
\text { Time (sec) } \\
\Delta \% \text { BLD }\end{array}$ & $\begin{array}{c}0.294 \\
--\end{array}$ & $\begin{array}{l}0.333 \\
+13.3\end{array}$ & $\begin{array}{l}0.327 \\
+11.3\end{array}$ & $\begin{array}{l}0.332 \\
+12.9\end{array}$ \\
\hline $\begin{array}{c}\text { Settling Time (in) } \\
\text { Time (sec) } \\
\triangle \% B L D\end{array}$ & $\begin{array}{c}0.460 \\
--\end{array}$ & $\begin{array}{c}0.460 \\
0\end{array}$ & $\begin{array}{l}0.494 \\
+7.4\end{array}$ & $\begin{aligned} & 0.455 \\
- & 1.1\end{aligned}$ \\
\hline $\begin{array}{c}\text { Settling Time (out) } \\
\text { Time (sec) } \\
\triangle \% \text { BLD }\end{array}$ & $\begin{array}{c}0.507 \\
--\end{array}$ & $\begin{array}{l}0.623 \\
+23.0\end{array}$ & $\begin{array}{l}0.546 \\
+7.7\end{array}$ & $\begin{array}{r}0.545 \\
+7.5\end{array}$ \\
\hline $\begin{array}{l}\text { Maximum Resolution } \\
\text { Deviation (degrees) }\end{array}$ & -- & 1.07 & 0.7 & 0.99 \\
\hline
\end{tabular}

Figure 9.17. Table of Test Data 


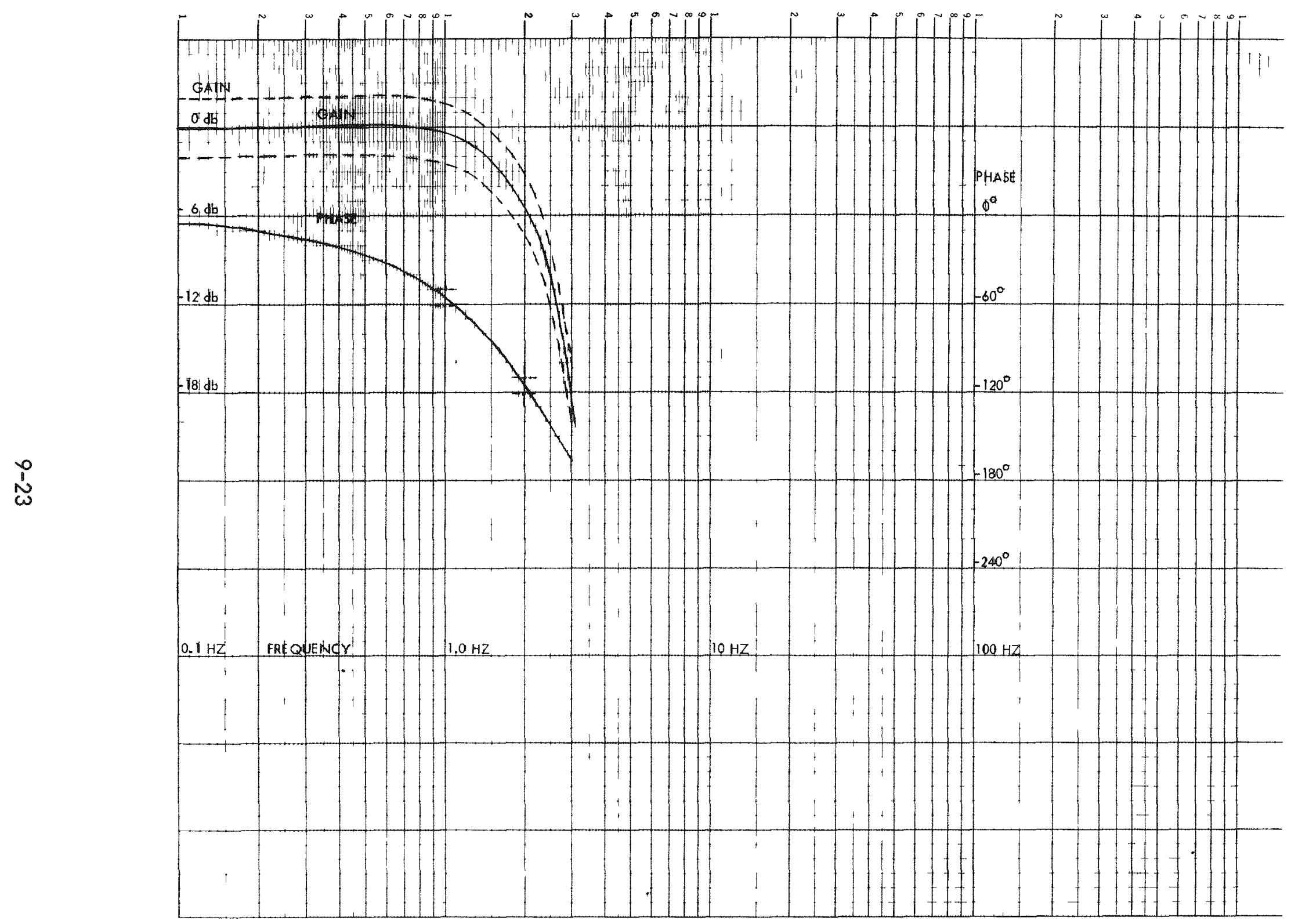

Figure 9. 18. Extended Life Test Base Line Data

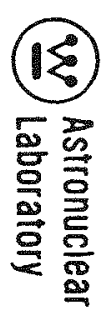




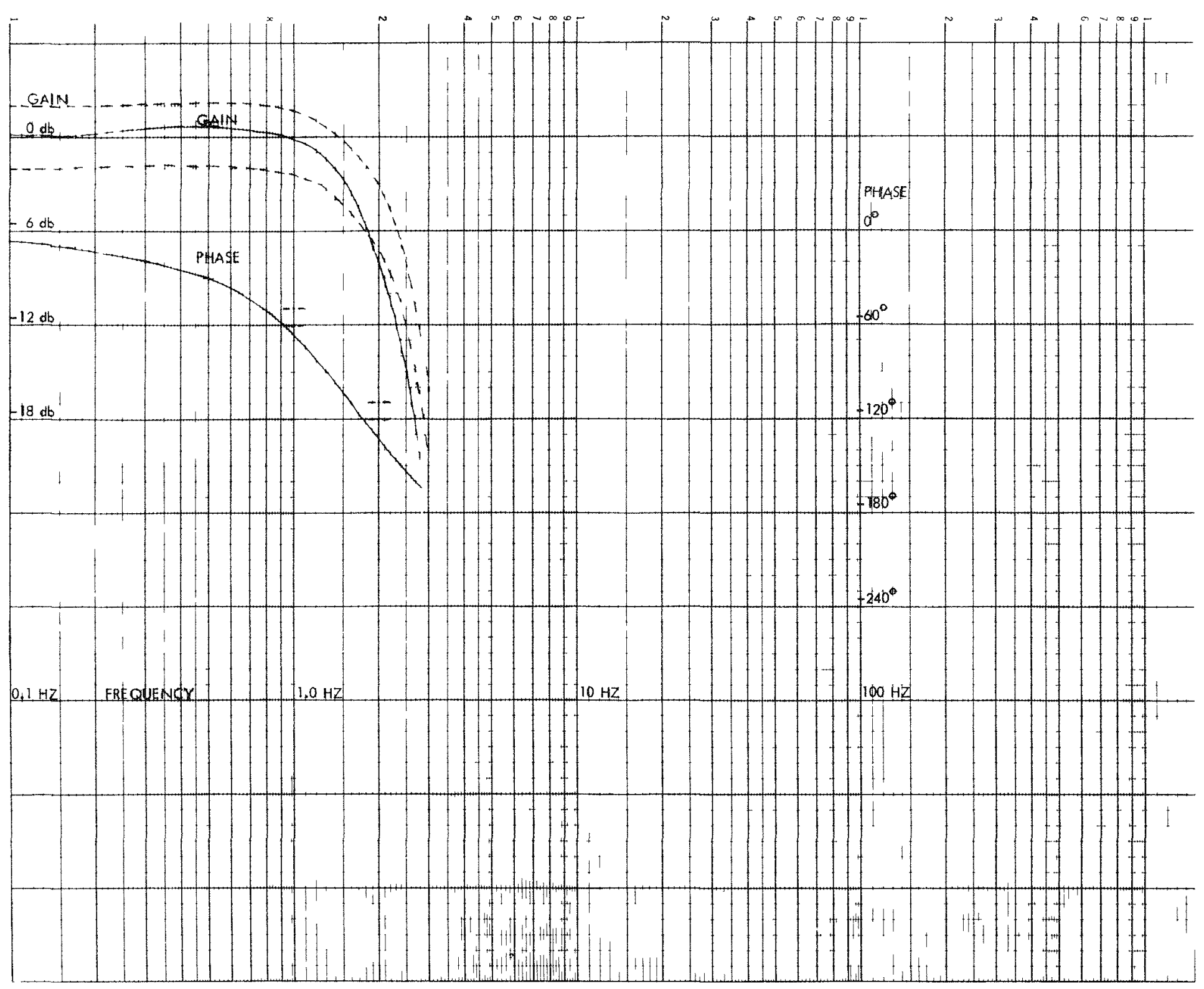

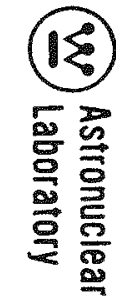

Figure 9.19. Extended Life Test 1990 Hours 


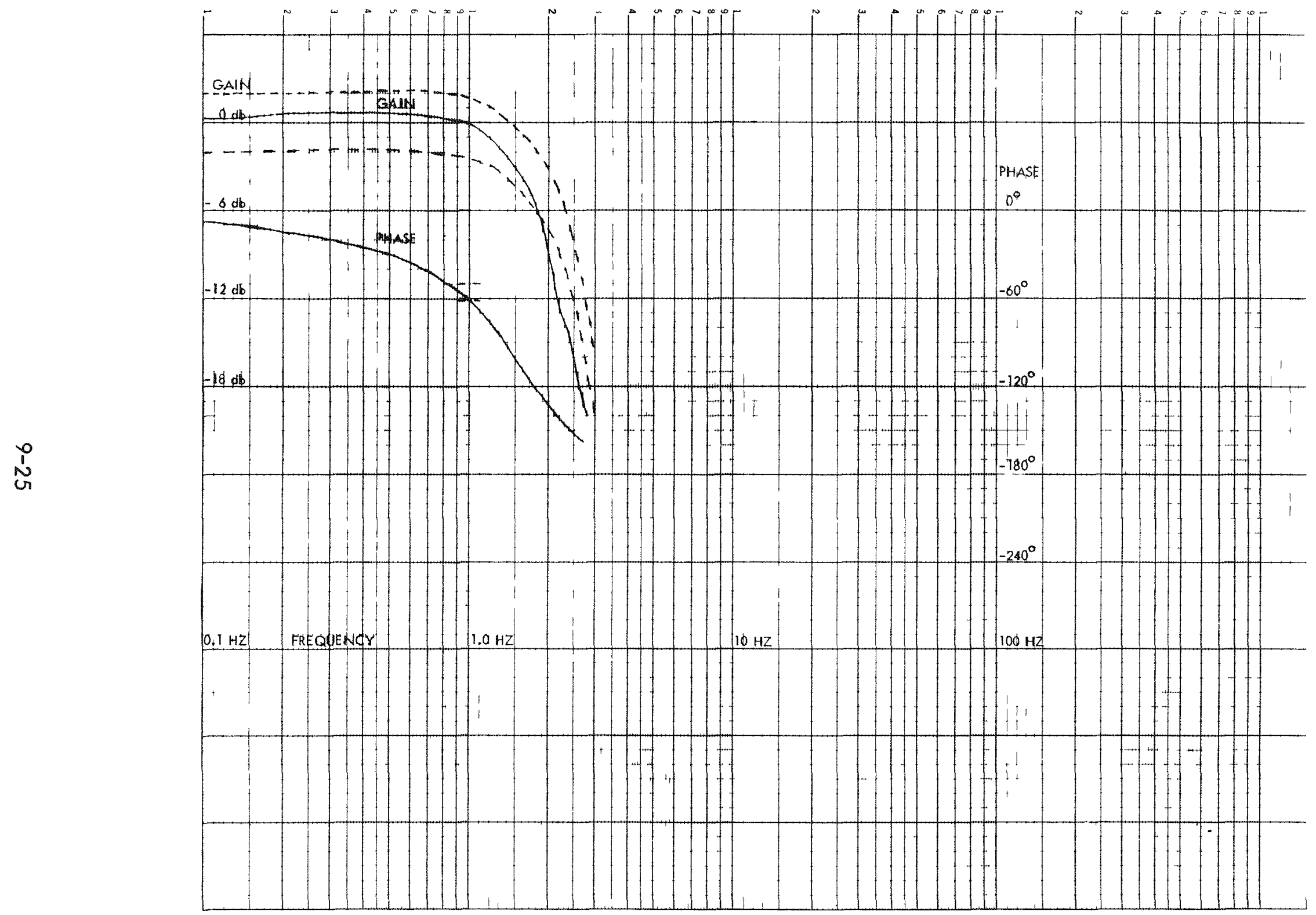

Figure 9.20. Extended Life Test 2491 Hours

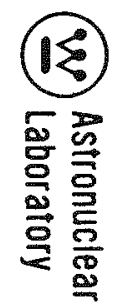




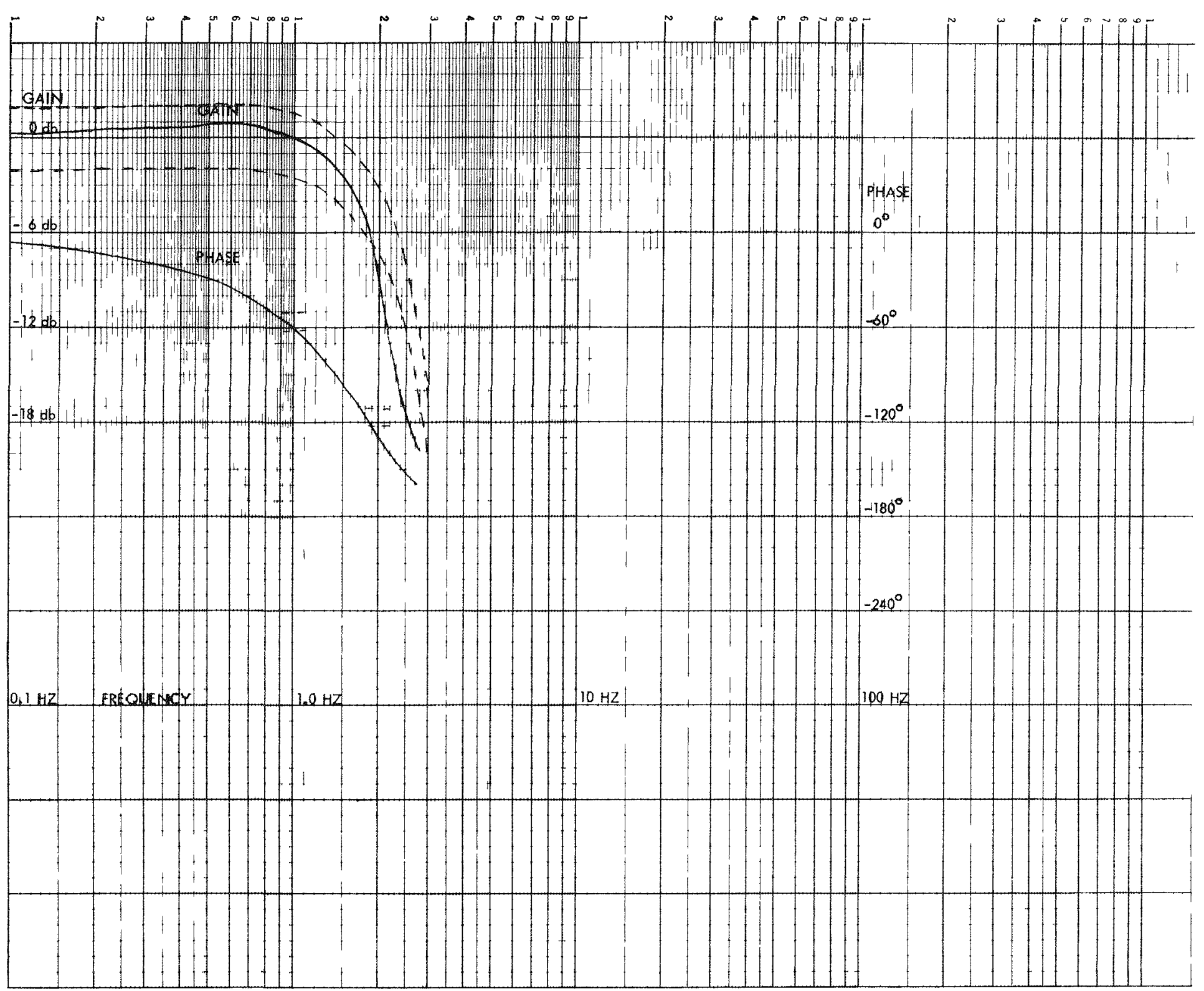

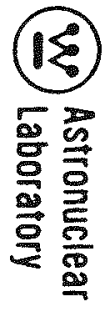

Figure 9.21. Extended Life Test 3211 Hours End of Test 
(20) Astronuclear

Acceptance Test

Subsystems Test

Vibration Test

Mechanical Shock Test

Thermal Test

Life Test

Combined Environment Test

Extended Life Test

TOTAL
$8.35 \mathrm{hr}$

$21.50 \mathrm{hr}$

$17.75 \mathrm{hr}$

$17.78 \mathrm{hr}$

$4.95 \mathrm{hr}$

$157.00 \mathrm{hr}$

$15.00 \mathrm{hr}$

$3211.00 \mathrm{hr}$

$3453.30 \mathrm{hr}$

During the above total accumulated hours of operation, the actuator performed the following number of scram operations.

Open Loop Scrams

3985

Closed Loop Scrams

Total Full Load Scrams
3215

7200 
(2v) Astronuclear

\subsection{NRX-A6 PNEUMATIC ACTUATOR SIDE-BY-SIDE EXPERIMENT}

The side-by-side actuator test was performed to obtain data on the effects of a radiation environment on the components and on the operation of the pneumatic control drum actuator.

One objective of the test was to determine component, subassembly and/or assembly degradation due to the infegrated neutron flux and gamma radiation. A second objective was to determine the effectiveness of the coolant gas flow and its ability to remove radiation induced heating.

\section{1 DESCRIPTION OF TEST SETUP}

A block diagram of the test setup is shown in Figure 10.1. The drive supply gas was regulated to a constant pressure of 215 psia and maintained at this constant pressure throughout the test. Coolant was supplied to the actuator through a regulating valve controllable from the control room. Both the He drive and coolant passed through an $\mathrm{LN}_{2}$ heat exchanger. The temperature at the exit of this heat exchanger was about $140^{\circ} \mathrm{R}$. The coolant gas pressure and the electrical input and output signals to the actuator originated in the control room and were varied during the test by the side-by-side Test Operator. The actuator experiment was mounted on the test car inside the 360 degree shield next to the reactor at the 180 degree $\theta$ position. The position of the pneumatic actuator side-by-side experiment with respect to the NRX-A6 reactor is shown in Figure 10.2. Figure 10.3 is a drawing of the actuator, pedestal and a simulated drum load enclosed in its housing. This drawing shows external details of the actuator, pedestal and simulated drum load as well as showing instrumentation impulse lines, instruments and thermocouples. A photograph of the instrumented actuator system is shown in Figure 10.4 prior to installation of the enclosure. In this photograph, the actuator, pedestal, electrical control wires and many of the instrumentation cables and impulse lines are visible. The marmon clamp, one pressure transducer and several accelerometers are also visible. This photograph is oriented approximately the same as the drawing of Figure 10.3 and can be used for comparative purposes. The completely assembled pneumatic actuator side-by-side test fixture is shown in Figure 10.5. The clamp that mounts the side-by-side experiment to the test car adapter can be seen in this picture. Also, the electrical leads, thermocouples and plumbing lines are shown. In Figure 10,6 the test fixture is shown mounted on the test car. The dosimeter packets 


\section{(18) \\ 흥응}

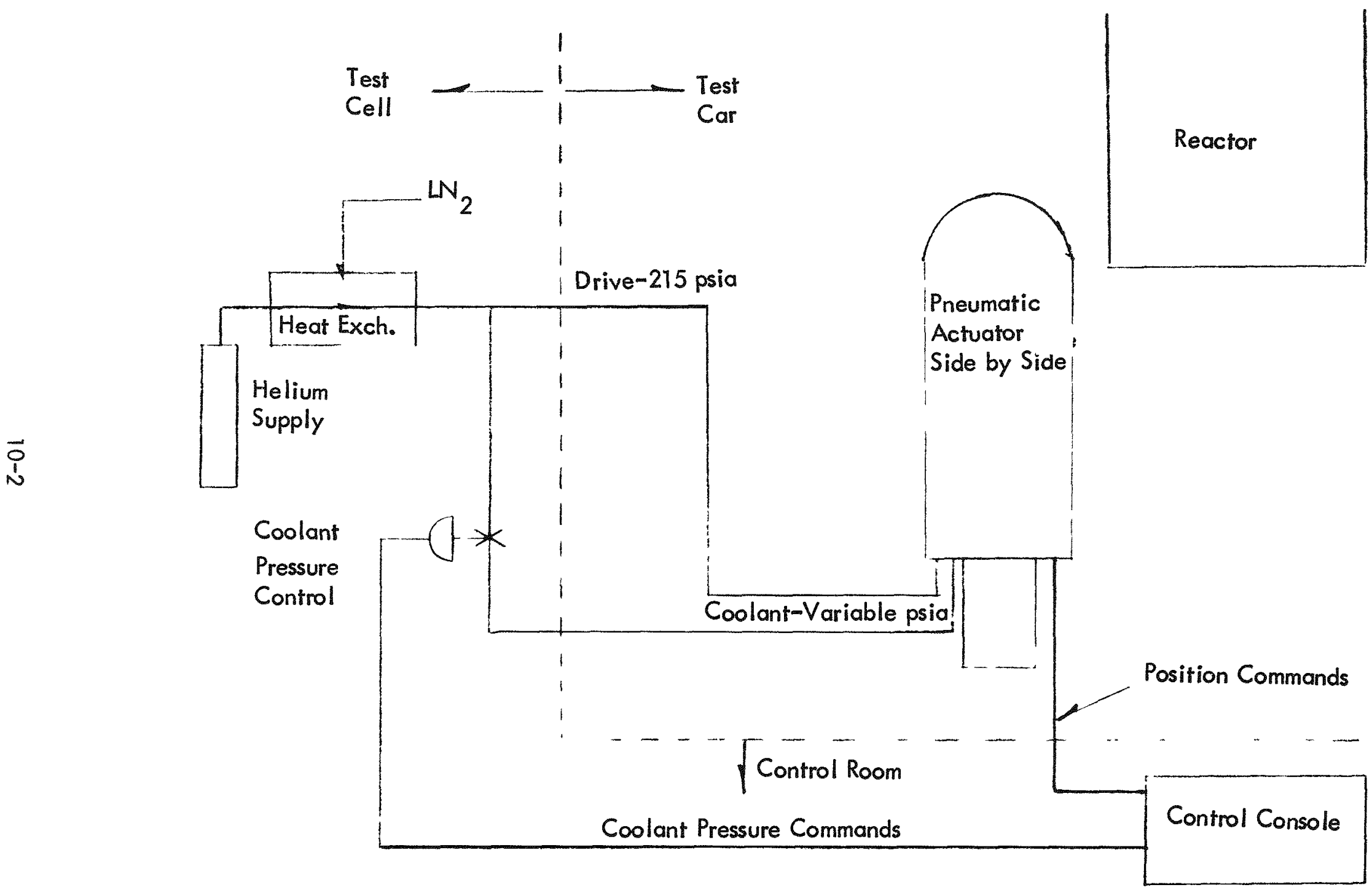

Figure 10.1. Block Diagram of Test Setup 


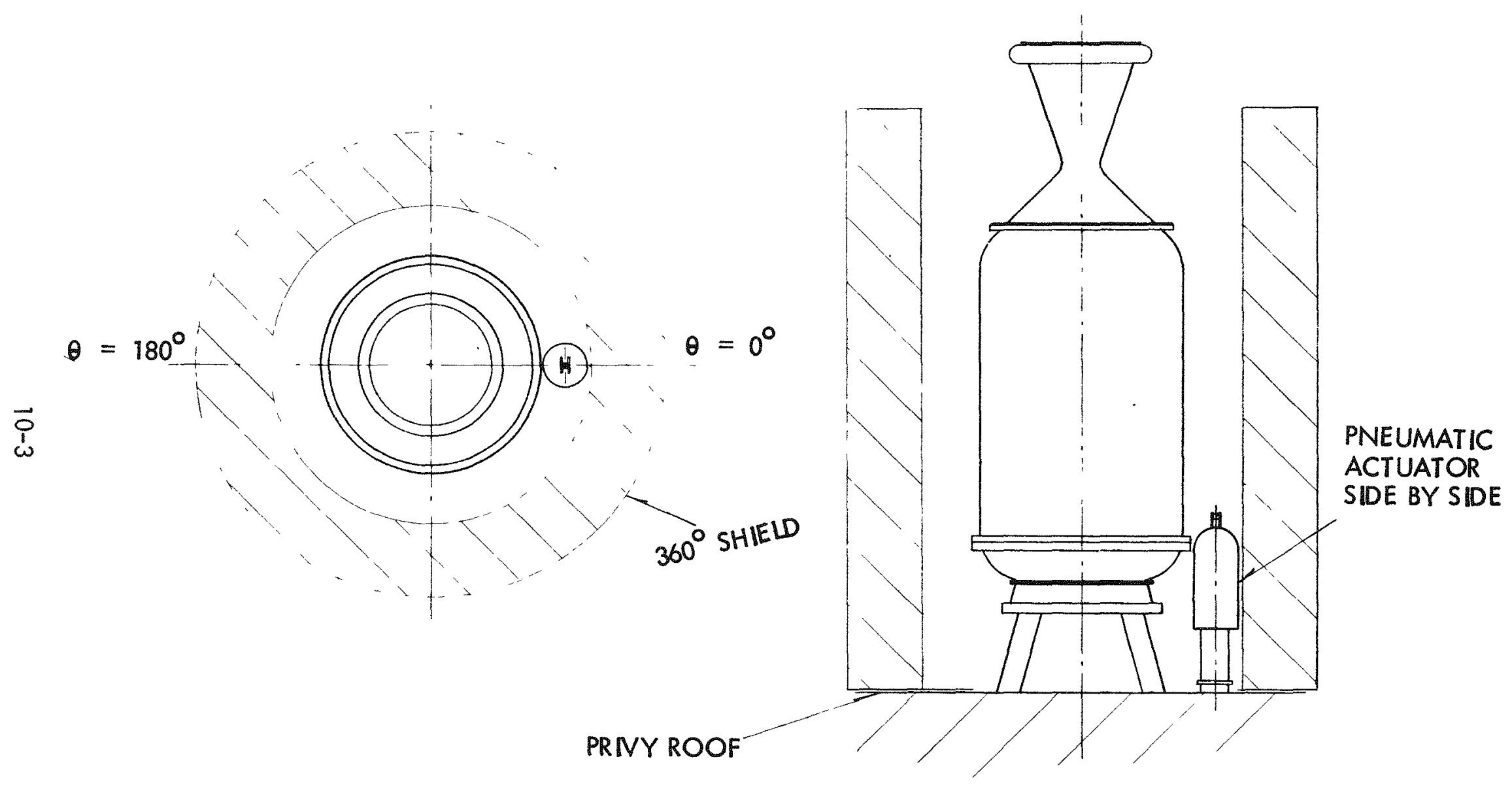

Figure 10.2. Side-by-Side Actuator Test Actuator Position Diagram 


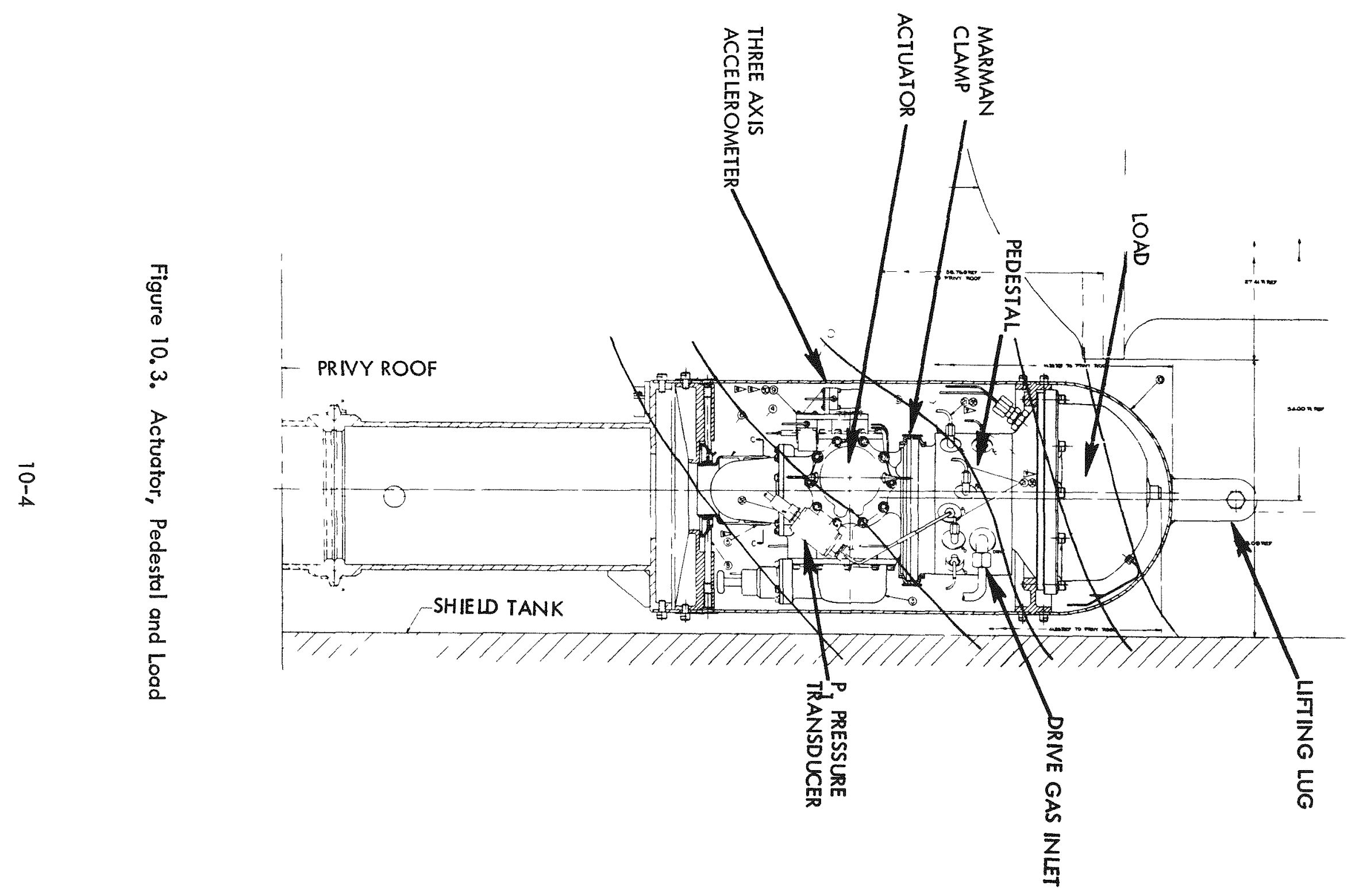

흘을 


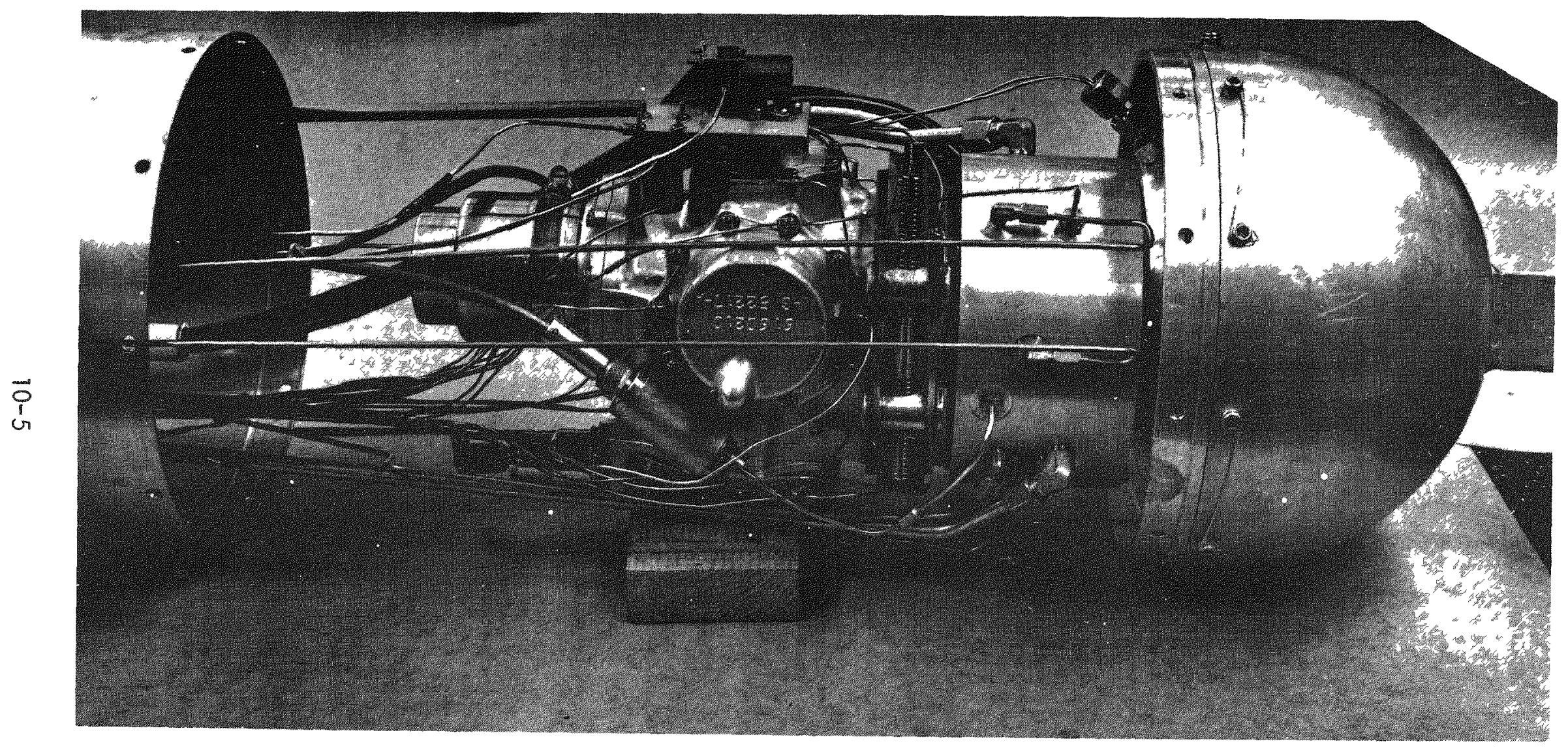

Figure 10,4。 Test Fixture Assembly

(1)

总总 
(QV) Astronuclear

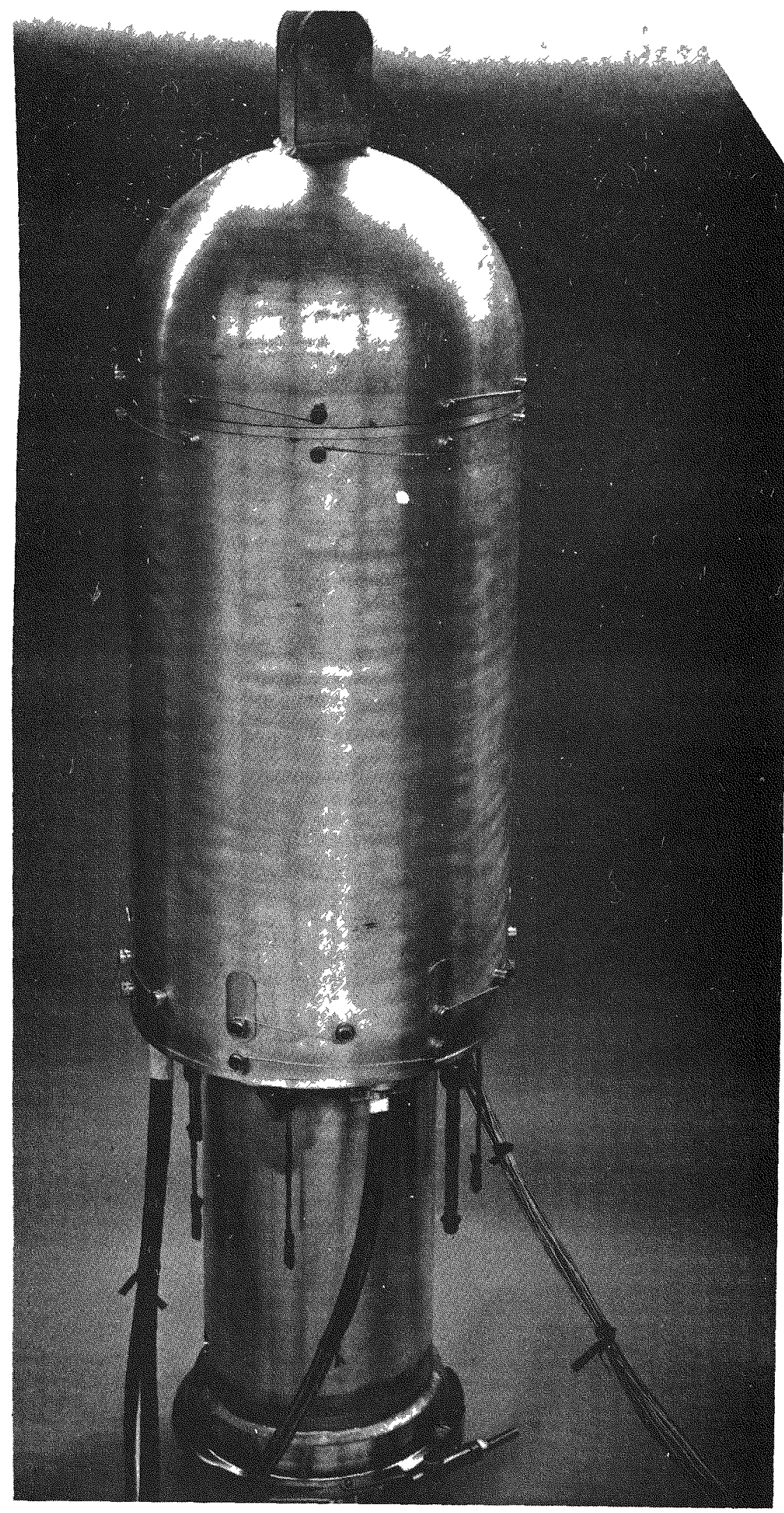

Figure 10.5. NRX-A6 Side-by-Side Actuator Tesf Fixiure 


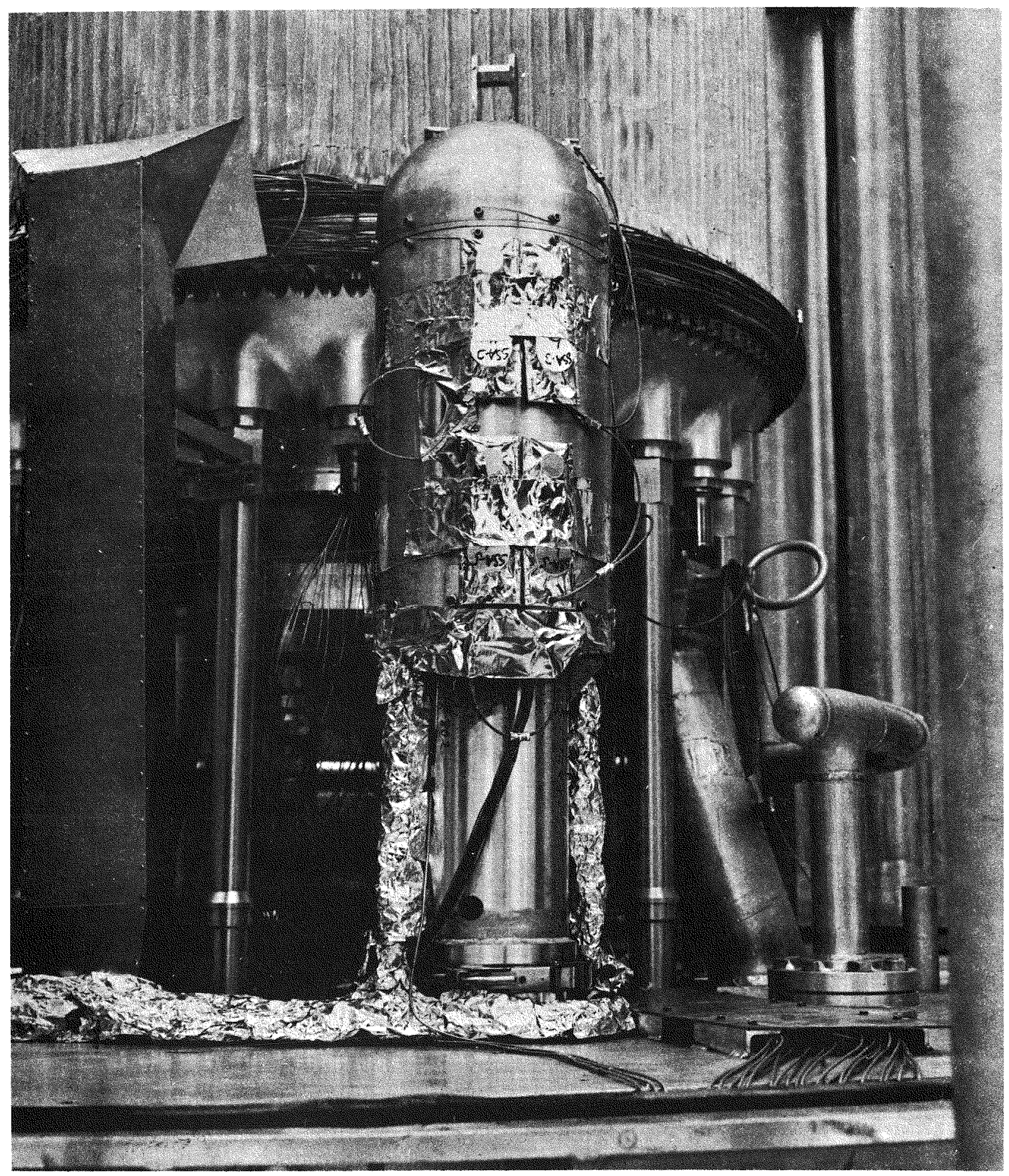

Figure 10.6. Test Fixture Mounted on Test Car 
SSA-3 and SSA-5 can be seen in the photograph while dosimeter packets SSA-2 and SSA-4 are hidden because they are mounted diametrically opposite to SSA-3 and SSA-5. SSA-1 cannot be seen in the photograph because it was located on the top of the test experiment near the lifting handle.

The actuator used for this test was an AG-20 type actuator which is a prototype of the XE series actuators. This actuator was upgraded with XE-1 parts that were sensitive in nature and to make the component as nearly like an XE-1 actuator as possible without actually testing an XE-1. The XE-1 parts installed were:
1) Servovalve
2) Potentiometer
3) Piston Rings
4) Solenoid Shut-Off Valve

The Shut-Off Valve was a new design retrofitted into all the XE-1 actuators. The actuator was lubricated using molybdenum diselenide as used in the XE-1 units. One of the major difficulties experienced with the preparation of this test was to adequately instrument the actuator so that the test would provide useful information. Installing thermocouples for this purpose was difficult. Pressure transducers and impulse lines were installed to measure and provide signals for recording the following pressures.
1) Coolant Pressure
2) Drive Pressure
3) Cylinder No. 1 Pressure
4) Cylinder No. 2 Pressure
5) Exhaust Pressure

Thermocouples were installed to give temperatures of critical components as well as give temperature distribution information across the actuator. Thermocouples were installed to measure the following temperatures.

1) Coolant Temperature

2) Drive Temperature 


\section{3) Potentiometer Temperature \\ 4) Exhaust Temperature \\ 5) Torquemotor Temperature \\ 6) Cylinder No. 1 and No. 2 Temperature \\ 7) Lock Housing Temperature \\ 8) Marmon Clamp Temperature}

In some cases, more than one thermocouple was installed to measure temperatures at different points on a component. For example, four thermocouples were installed at different $\theta$ locations to measure the marmon clamp temperature. Also, temperature at various locations within the load were recorded to assure safe operation. In addition to pressure and temperature measurements, three accelerometers were used to record levels of shock and vibration during testing. Dosimeter packets were mounted on the final assembly. The dosimeters, SSA-1 to SSA-5, were used to measure.

Slow neutron integrated flux $(E<0.4 \mathrm{eV})$

Fast neutron integrated flux $(E>2.9 \mathrm{MeV}$ )

Gamma dose

In addition to pressure, temperature, acceleration, and radiation, the actuator performance parameters measured and recorded were:

Position command signal

Actuator position signal

Torquemotor current

\subsection{DESCRIPTION OF THE TEST}

Prior to operation of the reactor, a closed loop frequency response was performed. A four degree peak to peak input command was given to the actuator at various frequencies and the feedback position was compared to this input. The frequency response was repeated while the reactor was at full power and again after the reactor was shut down. In addition to the frequency response, the following test sequence was initiated approximately 15 minutes prior to reactor startup. 
$3.5 \mathrm{~min}$. Sinusoidal input of $4^{\circ} \mathrm{p}-\mathrm{p}$ at $3 \mathrm{HZ}$ while actuator was positioned at $90^{\circ}$ $0.5 \mathrm{~min}$. Scram, lock and reset

$5.0 \mathrm{~min}$. Sinusoidal input of $40^{\circ} \mathrm{p}-\mathrm{p}$ at $0.5 \mathrm{HZ}$ while actuator was positioned at $90^{\circ}$ 0.5 min. Scram, lock and reset

9. 0 min. Ramp input at $3^{\circ} / \mathrm{sec} ; 20^{\circ}$ to $160^{\circ}$

0.5 min. Scram, lock and reset

5. 0 min. Step between $81^{\circ}$ and $99^{\circ}$ at $0.1 \mathrm{HZ}$

0.5 min. Scram, lock and reset

5.0 min. Dwell at static position of $90^{\circ}$

$0.5 \mathrm{~min}$. Scram, lock and reset

This test sequence was repeated until approximately 15 minutes after reactor shutdown.

\subsection{TEST RESULTS}

The plot in Figure 10.7 shows the three closed loop frequency responses taken before, during, and after the test. Very little change in performance occurred between the pre-run test and the full power test. The test performed after the reactor run exhibits an increased bandwidth which is indicative of reduced piston rings friction.

Although the data were adequate to provide accurate attenuation information, a malfunctioning speed control on the Sanborn recorders made it impossible to separate the adjacent cycles sufficiently to obtain phase shift information. Evaluation of the performance data shows that the actuator can be safely used to drive the control drums on the XE reactors and that the radiation levels experienced were at about the levels predicted for the $R$ and $E$ reactors.

A summary plot of actuator temperatures and coolant pressure during the reactor full power run is shown in Figure 10.8. In general, the coolant pressure was reduced in controlled increments during reactor full power operation to obtain internal temperature distribution as a function of the cooling pressure. One significant difference between this test and $X E$ and $R$ type tests (where the actuators will be mounted on the pressure vessel or extemal shield) is the coolant temperature as it enters the actuators. Coolant temperatures on XE and $R$ tests are 


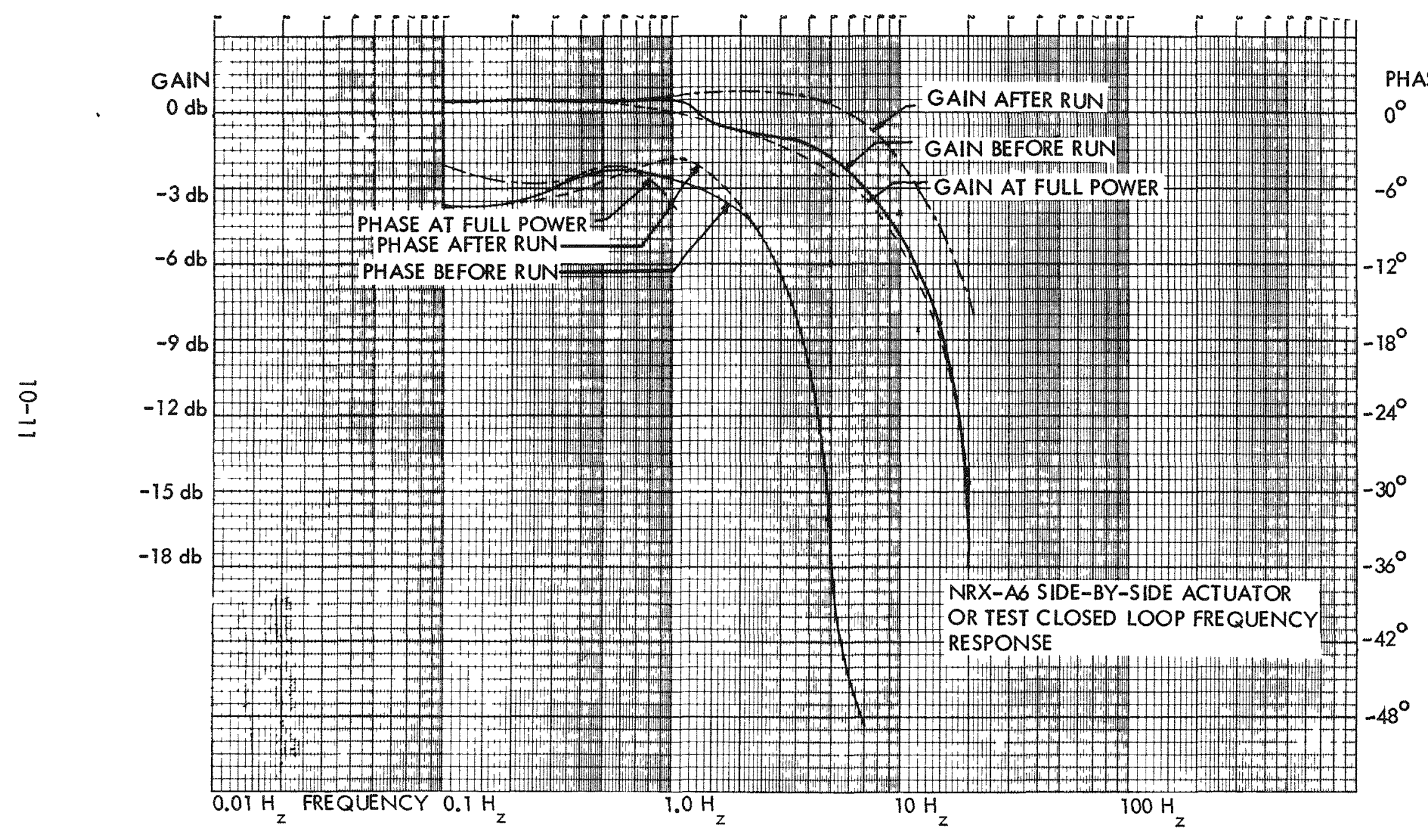

Figure 10.7. NRX-A6 Side-by-Side Actuator Test Closed Loop Frequency Response 


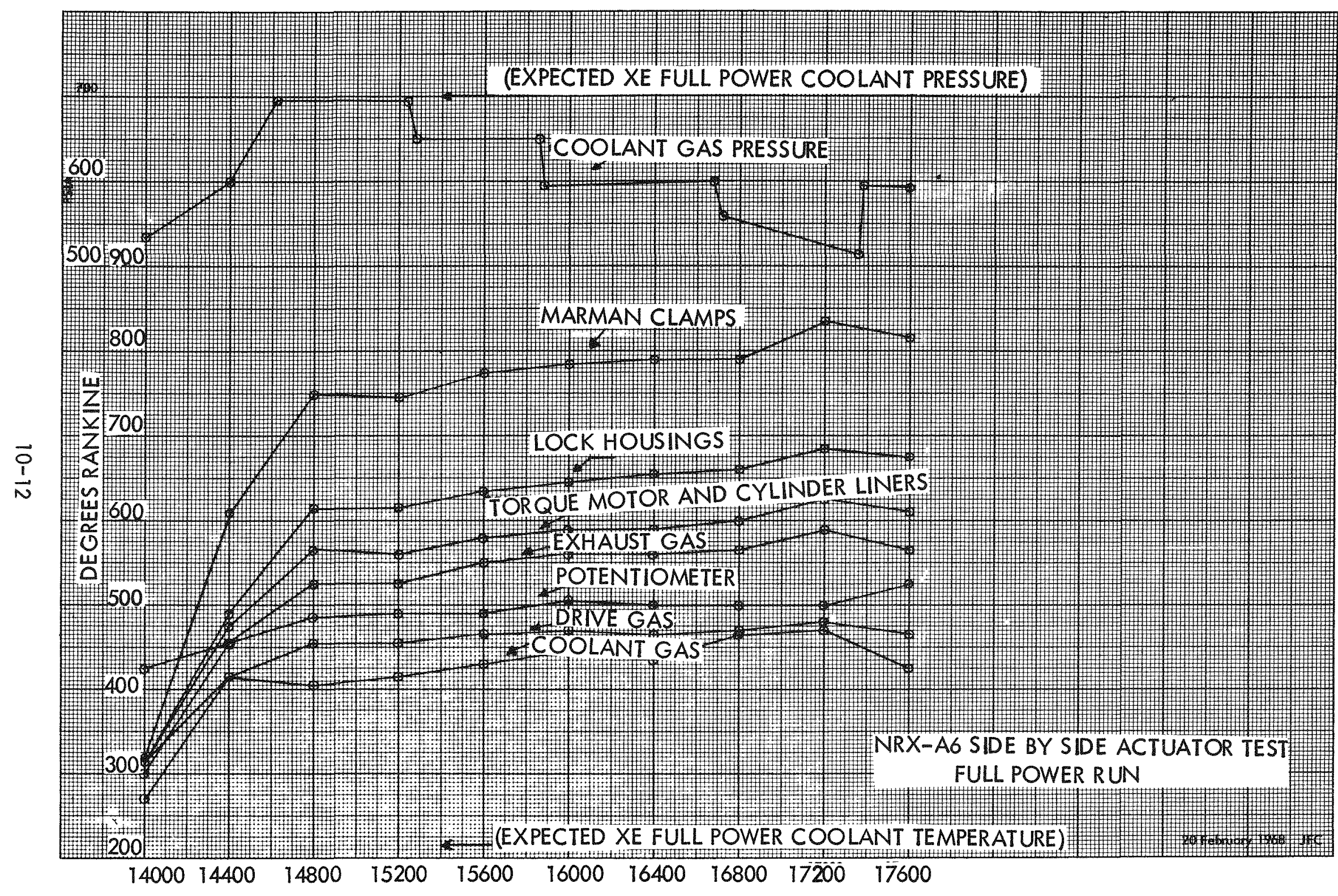

Figure 10.8. NRX-A6 Side-by-Side Actuator Test Full Power Run 
expected to be very near dome temperature or about $212^{\circ} R$ at full power. The actuator sideby-side coolant temperature was about 400 to $450^{\circ} \mathrm{R}$. This warm up of coolant in the side-byside test is due to the relatively long run between the $\mathrm{LN}_{2}$ heat exchanger and the inlet to the actuator. The closely coupled XE and $R$ tests will eliminate this warm-up. Even with the relatively warm coolant gas temperature $\left(450^{\circ} \mathrm{R}\right)$ and the experimentally low coolant pressures (550 psi) none of the component temperatures exceeded allowable limits. This gives strong evidence of the adequacy of the actuator coolant flow.

A plot of the gamma dose received by the side-by-side experiment is shown in Figure 10.9. These curves were plotted using data obtained from the dosimeter pockets mounted directly on the experiment container. From the figure, it can be seen that the actuator experienced a heating rate of about 93 to 116 watts/lb. This exceeds the expected XE gamma dose by a factor of about 250 and is approximately equal to the gamma dose predicted for the $R$ \& E reactors. A plot of the fast neutron flux obtained by using dosimeter data is shown in Figure 10.10. The flux field in the vicinity of the actuator was between 0.1 and $0.2 \times 10^{16}$ $\mathrm{n} / \mathrm{cm}^{2}$ which is about 100 greater than predicted field for the XE actuators located above the shield. A similar plot showing slow neutron flux is presented in Figure 10.11. The slow neutron flux levels were between 3 and $5 \times 10^{16} \mathrm{n} / \mathrm{cm}^{2}$ at the actuator.

Following the test, the side-by-side pneumatic actuator was completely disassembled and photographed in search of any radiation caused damage. No malfunctions were observed during performance and no unusual wear or damage to internal components were detected upon disassembly. Although many photographs were taken, only a few are presented here. The views selected are of those components felt to be of the most critical nature. Figure 10.12 shows the torquemotor, solder joints, lead wire and miscellaneous servovalve components. Figure 10.13 shows the lock indication switches, solder connections, wires and the lock and lock shut off valve in the background. A view of the three deck potentiometer again showing the solder points, wire and insulating sleeves is shown in Figure 10.14. Figure 10.15 shows the $P_{1}$ piston and rack assembly, the $\mathrm{P}_{2}$ piston and all the piston rings. 


\section{(18) \\ 兽商}

墖离

氙美希

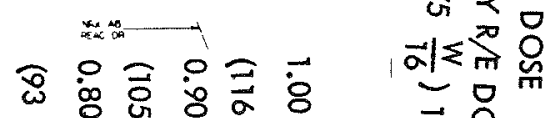

히 $\leqslant x=$

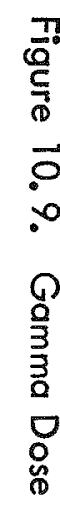

- PRIVYROOF

更

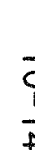

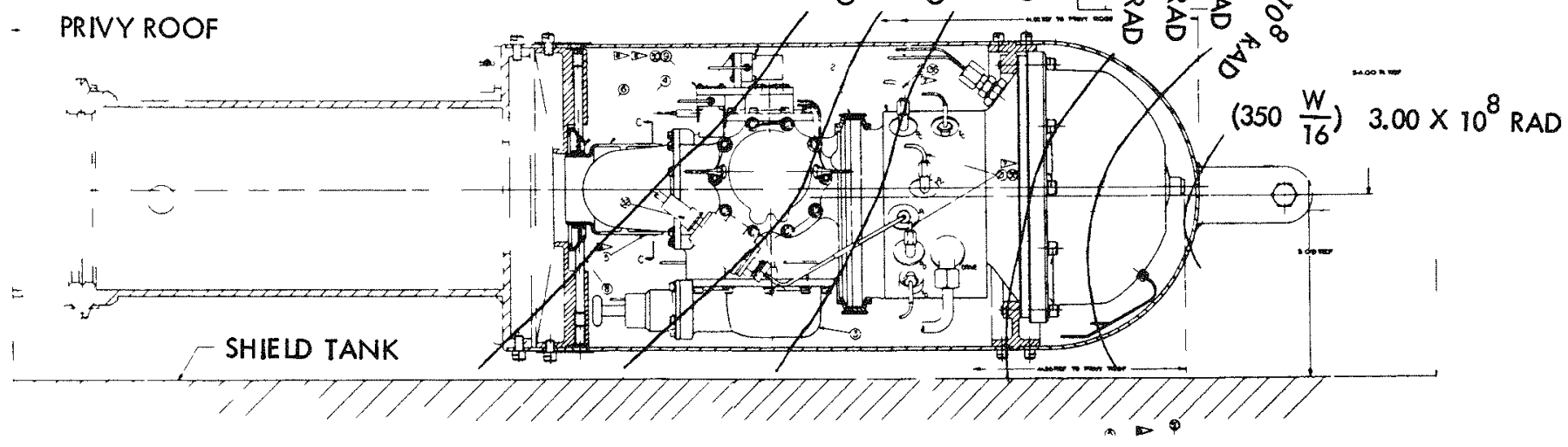




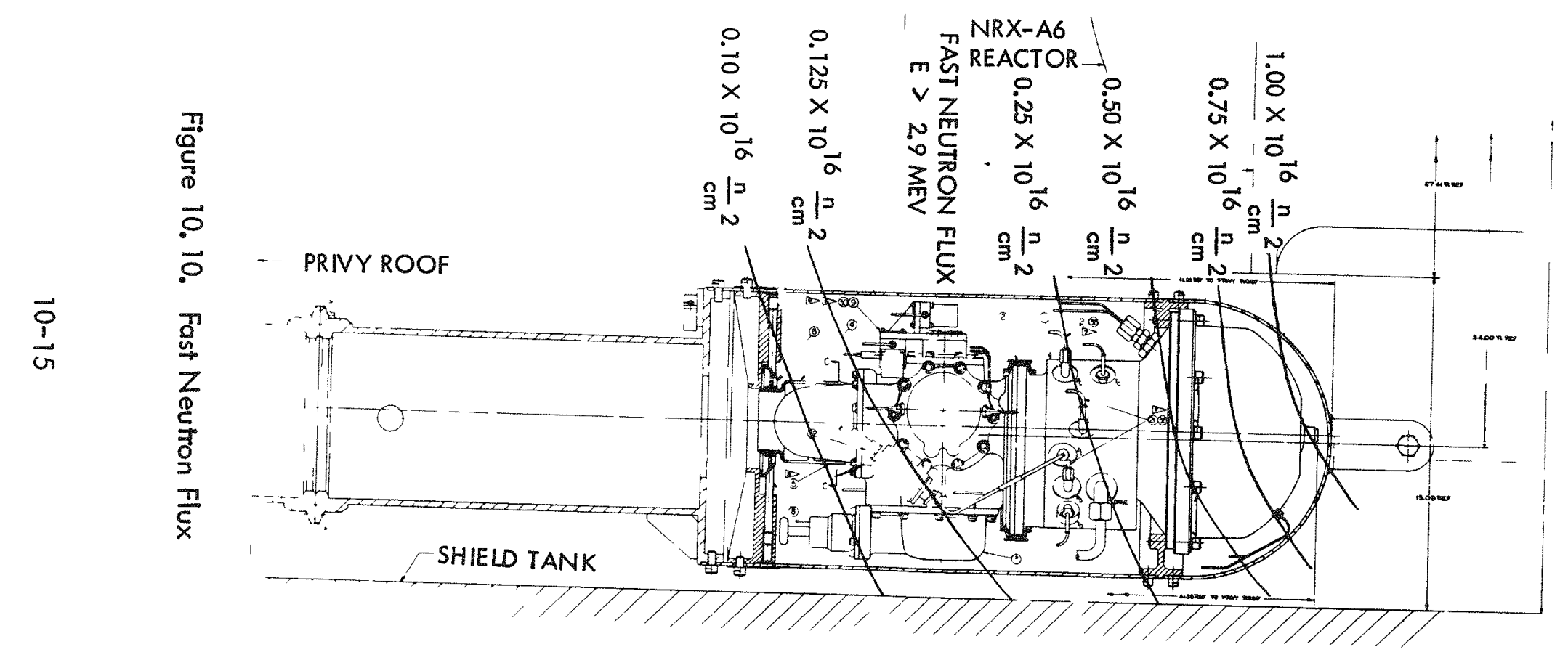

(15)

毵高 


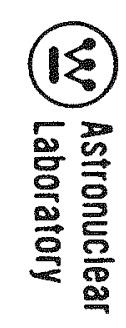

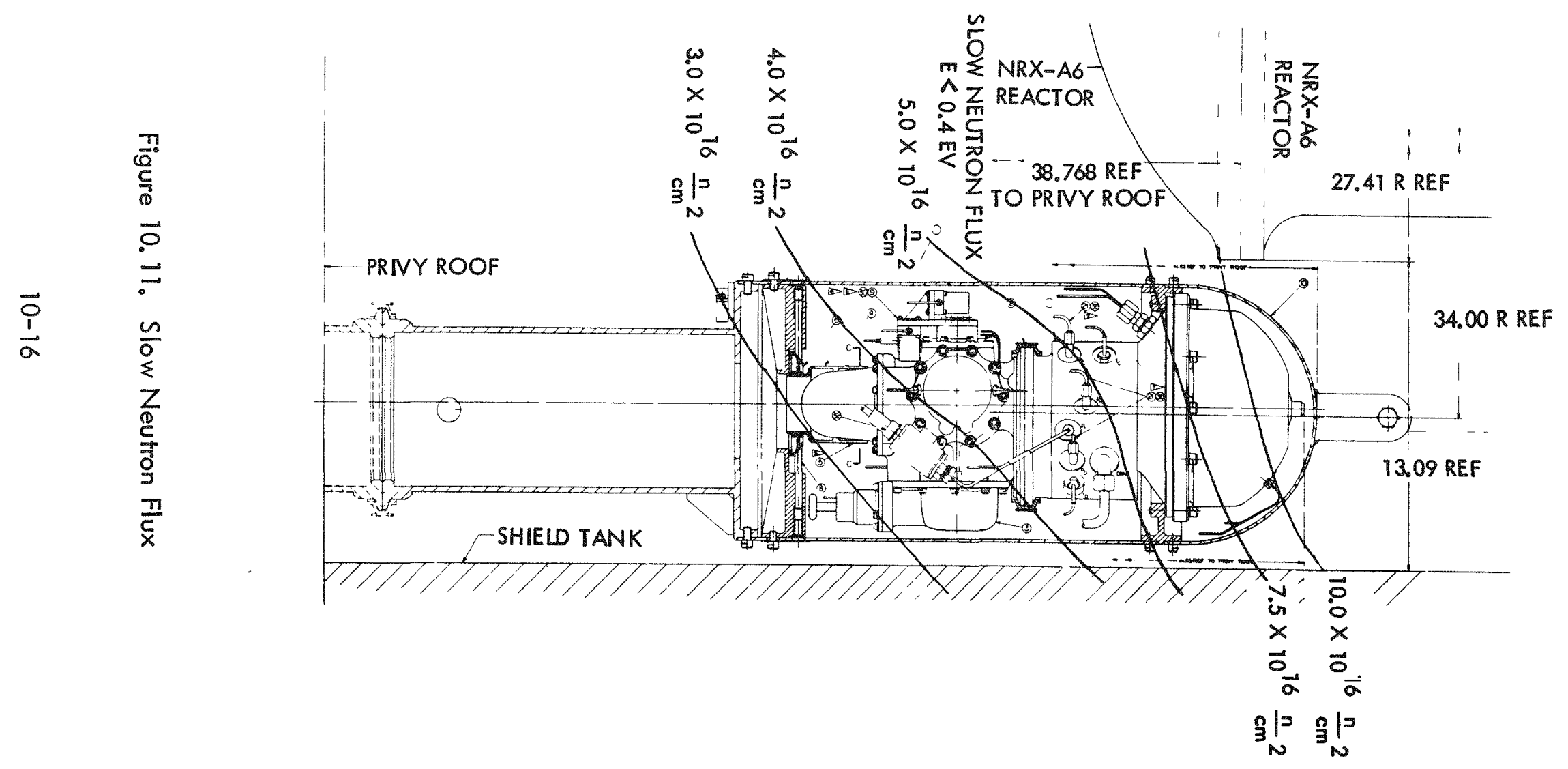




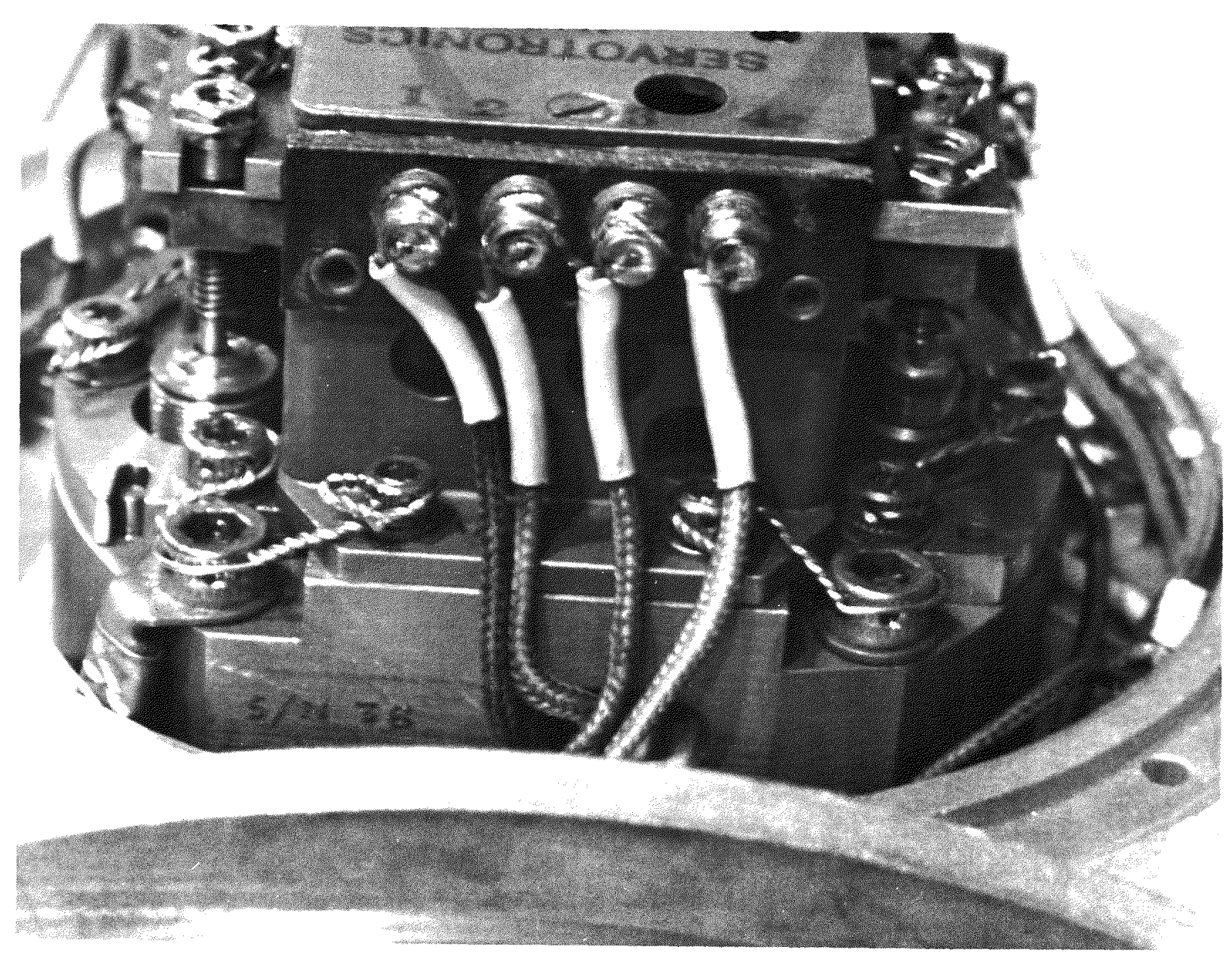

Figure 10.12. Site Photo, Torque Motor 霎

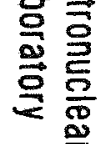




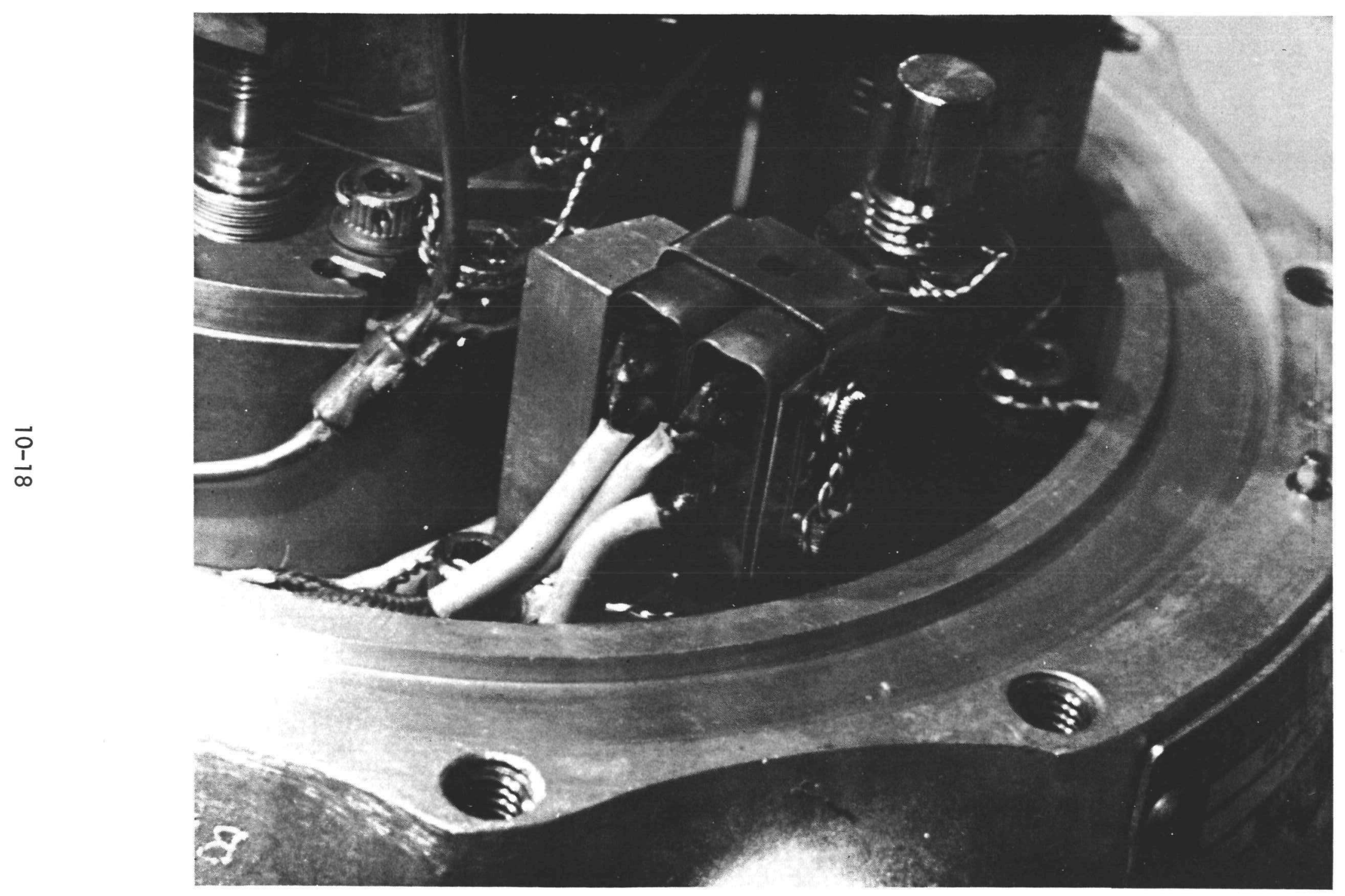

Figure 10.13. Site Photo, Lock Indication Switches 
(W. Astronuclear

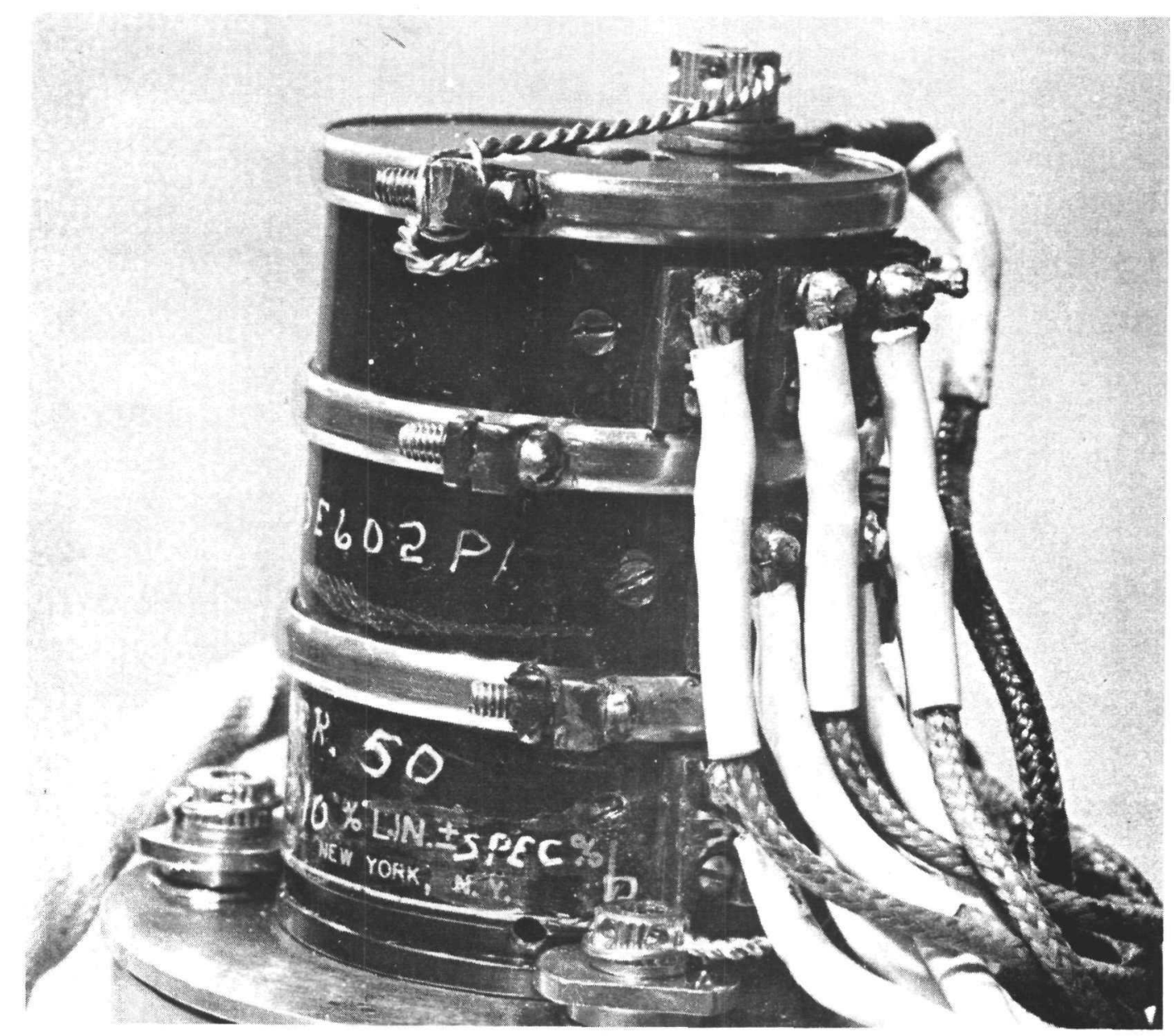

Figure 10.14。 Three Deck Potentiometer 


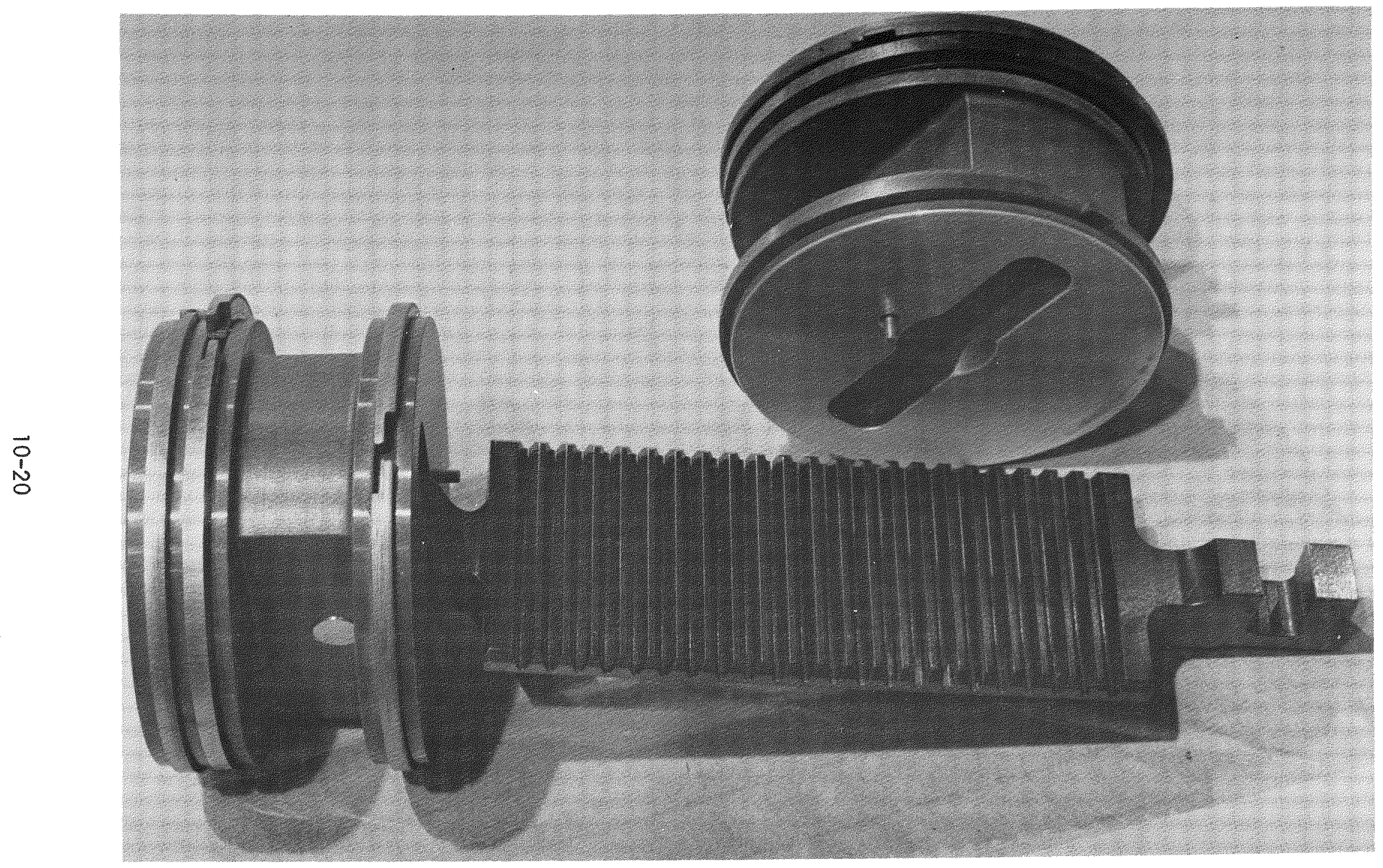

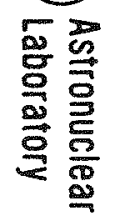

Figure 10.15. Site Photo, Pistons and Rack 


\subsection{CONCLUSIONS}

The pneumatic control drum actuator will perform as designed while under the influence of a radiation field (and after being subjected to an integrated radiation field) well in excess of the XE predicted field and about equivalent to that expected on the $R$ reactor and $E$ engine tests. The coolant flow to the actuator was designed with the NR heating rates of 350 watts/lb as a parameter; these rates are higher than required for heating rates expected on the $X E, R$ and $E$ programs which are predicted to be on the order of 125 watts/lb maximum. Coolant flow could probably be reduced, and as more experience is obtained this modification will be considered. 
APPENDIXA

A-1 


\section{Westinghouse Astronuclear Laboratory}

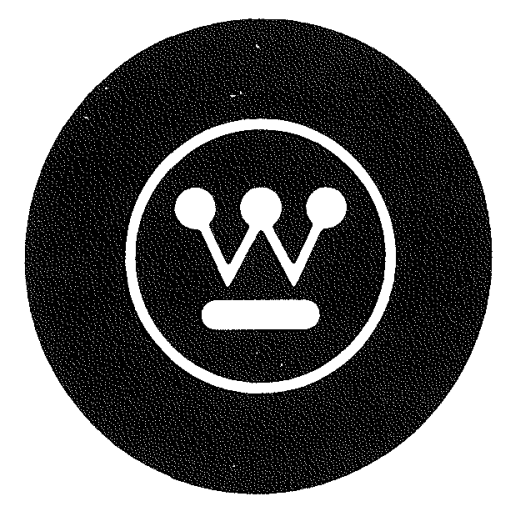

\section{QUALIFICATION SPECIFICATIONS FOR CONTROL DRUM \\ PNEUMATIC ACTUATORS FOR XE-1 APPLICATION}

Prepared By:

John Burke

Actuator Engineering

Approved By:

R.A.Clark,Jr.,Supervisor

G.R. Thomas, Manager

Actuator Engineering

Nuclear Systems Engineering

Control Systems Engineering

G.L.Hohmann, Manager

Control Systems Engineering

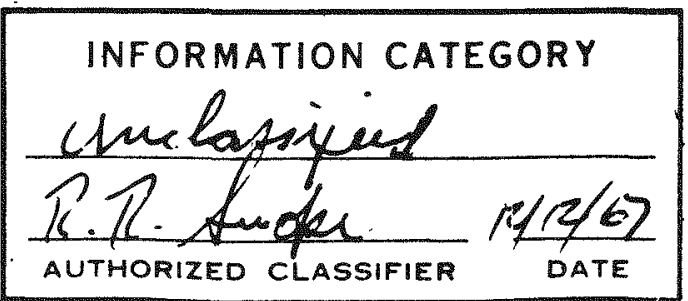




\section{TABLE OF CONTENTS}

Section

INTRODUCTION

Page

VIBRATION QUALIFICATION TESTS FOR CONTROL DRUM PNEUMATIC ACTUATORS

\subsection{Purpose}

2.2 Guiding Specifications

2.3 Procedure

2.4 Performance Requirements for Qualifications

2.5 Post Vibration Inspection

2.6 Report Required

3.1 Purpose

3.2 Guiding Specifications

3.3 Procedure

3.4 Performance Requirements for Qualification

3.5 Post Shock Test Inspection

3.6 Report Required

LOW TEMPERATURE QUALIFICATION SPECIFICATIONS FOR

CONTROL DRUM PNEUMATIC ACTUATORS FOR XE-I APPLICATION

$4-1$

4. 1 Scope

4-1

4.2 Objective

4-1

4.3 Reference Specifications

4-1

4.4 Test Parameters

$4-1$

4.5 Test Plan

$4-3$

4.6 Qualification Requirements 
TABLE OF CONTENTS (CONTINUED)

Section

4.7 Post Mortem Inspection

Page

4. 8 Reports

$4-5$

$4-5$

5 LIFE QUALIFICATION TESTS FOR CONTROL DRUM PNEUMATIC ACTUATORS

5.1 Scope 5-1

5.2 Objective of Test 5-1

5.3 Environmental Conditions 5-1

5.4 Duty Cycle 5-2

5.5 Test Parameters 5-2

5.6 Data 5-3

5.7 Performance Requirements for Qualification 5-4

5.8 Inspection 5-5

5.9 Report Required 5-5

6 RADIATION QUALIFICATION SPECIFICATIONS FOR CONTROL DRUM PNEUMATIC ACTUATORS FOR XE-1 APPLICATION $6-1$

6.1 Scope 6-1

6.2 Objective 6-1

6.3 Environmental Conditions 6-1

6.4 Qualification Requirements 6-2

6.5 Report 6-3 


\section{LIST OF ILLUSTRATIONS}

Figure

2-1

$2-2$

Anticipated Vibration Environment, NERVA XE-1; Ground Firing Test, Longitudinal Plane

Page

Anticipated Vibration Environment, NERVA XE-1; Ground Firing Test; Lateral Plane

\section{LIST OF TABLES}

Number 


\section{INTRODUCTION}

This document specifies the environmental tests and expected performance of the XE-1 Control Drum Pneumatic Actuator. The actuator is to be subjected to the various environments that are expected in the XE Test Series while its performance as a control system component is evaluated. Among the tests to be performed are vibration and shock which shall qualify the actuator for both ground handling and anticipated ground firing conditions. The actuator shall also be tested for operation at low temperatures. The low temperature tests shall consist of both uniform temperature throughout the actuator and localized cooling at various points on the actuator housing. To determine the life expectancy of the actuator, a continuous operation for 150 hours followed by one hour operation at low temperature and under expected ground firing vibration is to be performed. The results of the NRX-AG Sideby-Side Test and the NASA Lewis AG-20 and XE-1 irradiating tests will serve to qualify the actuator for use in a radiation environment. 


\section{VIBRATION QUALIFICATION TESTS FOR CONTROL DRUM PNEUMATIC ACTUATORS}

\subsection{PURPOSE}

The purpose of this test is to determine the acceptability of the pneumatic drum actuator for use in the NERVA X-Engine Test XE-1. This investigation is limited to qualification in a vibration environment consisting of a sinusoidal forcing function varying in frequency at a logarithmic rate.

\subsection{GUIDING SPECIFICATIONS}

The following specifications shall serve as guidelines in completing the requirements of this specification:

1) MIL-STD-810 - "Environment Test Methods for Aerospace and Ground Equipment" (Equipment Class 4, and Equipment Class 6, Mounting Method "a")

2) AGC Report Number RN-DR-0020 - "Preliminary Specification, NERVA XEngine, NERVA Program, Contract SNP-1"

3) WANL Specification E-675560 - "Actuator Mechanisms, Pneumatic - XE Series Control Drum"

\subsection{PROCEDURE}

\subsubsection{Pre-Test Installation and Test}

Prior to the initiation of the vibration test, measure and record the load stand spring gradient and friction. Apply low level vibration to a dummy actuator of dimensions similar to an actual XE-1 actuator to determine the resonances of the load stand.

Mount the actuator on the load stand and tune the amplifier for optimum transient response of the system and establish the 100 degree per second velocity limits.

\subsubsection{Pre-Test Performance Record}

A complete set of performance data shall be recorded with the actuator operated under ambient conditions and no applied vibration. This data shall be used as a reference 
throughout the subsequent test and shall be referred to as the "Base Line Data". The "Base Line Data" shall include:

1) Linearity and resolution check

2) Transient response check

3) Scram turnaround check

4) Frequency response check between frequencies of 0.1 to $20 \mathrm{cps}(\mathrm{Hz})$

The definition and conditions for these tests shall be as outlined in the appropriate paragraphs of WANL Specification E-675560 except as modified herein. The method of obtaining data shall be as outlined in TS 711892-A.

\subsubsection{Vibration Tests}

\subsubsection{Test Plan}

The tests described in the table below shall be conducted to determine the performance of the actuator when subjected to these vibratory environments. TS $711892-A$ outlines the procedure to be followed in performing these tests.

\subsubsection{Planes of Vibration}

The actuator shall be vibrated according to the test schedule of Table 2-1 in each of the following planes:

Vertical: $\quad$ Applied vibration force in a plane parallel to the actuator output shaft.

Horizontal

Number 1:

Applied vibration force in a plane parallel to the direction of piston travel.

Horizontal Number 2:

Applied vibration force in a plane normal to the direction of piston travel. 
TABLE 2-1

TEST SEQUENCE AND SPECIFICATIONS

\begin{tabular}{|c|c|c|c|c|c|c|c|c|c|c|}
\hline \multirow[b]{2}{*}{ Phase } & \multirow[b]{2}{*}{$\begin{array}{l}\text { Actuator } \\
\text { Condition }\end{array}$} & \multirow[b]{2}{*}{$\begin{array}{c}\text { Vibration } \\
\text { Plane }\end{array}$} & \multicolumn{5}{|c|}{ Performance Tests } & \multicolumn{3}{|c|}{ Resonance Dwell } \\
\hline & & & $\begin{array}{l}\text { Test } \\
\text { No. }\end{array}$ & \begin{tabular}{|c|} 
Sweep \\
Frequency \\
$(c p s)$
\end{tabular} & \begin{tabular}{|c|} 
No. \\
of \\
Sweeps
\end{tabular} & $\begin{array}{l}\text { Time/ } \\
\text { Sweep }\end{array}$ & \begin{tabular}{c|} 
Applied \\
Force \\
$(g)$
\end{tabular} & Test & $\begin{array}{l}\text { Dwell } \\
\text { Time at } \\
\text { Resonance }\end{array}$ & $\begin{array}{l}\text { Applied } \\
\text { Force (g) } \\
\text { Vector }\end{array}$ \\
\hline $\begin{array}{l}\text { Low Level } \\
\text { Vibration } \\
\text { Search }\end{array}$ & $\begin{array}{l}\text { Non-Opera- } \\
\text { tional }\end{array}$ & All 3 & 1 & $5-2000-5$ & 2 & $3 \mathrm{~min}$ & 1.0 & -- & - & -- \\
\hline $\begin{array}{l}\text { Shipment } \\
\text { and } \\
\text { Storage }\end{array}$ & $\begin{array}{l}\text { Non-Opera- } \\
\text { tional }\end{array}$ & All 3 & 2 & $10-30-10$ & 3 & $2 \mathrm{~min}$ & 4.0 & 5 & $30 \mathrm{~min}$ & 4.0 \\
\hline $\begin{array}{l}\text { Ground } \\
\text { Firing }\end{array}$ & Operating & Vertical & 3 & $5-2000-5$ & 1 & $30 \mathrm{~min}$ & $\begin{array}{c}\text { See } \\
\text { Figure 21 }\end{array}$ & 6 & $10 \mathrm{~min}$ & \begin{tabular}{|c} 
See \\
Figure 2-1
\end{tabular} \\
\hline $\begin{array}{l}\text { Ground } \\
\text { Firing }\end{array}$ & Operating & Horizontal & 4 & $5-500-5$ & 2 & $15 \mathrm{~min}$ & \begin{tabular}{|c|} 
See \\
Figure 2-2
\end{tabular} & 7 & $10 \mathrm{~min}$ & $\begin{array}{c}\text { See } \\
\text { Figure 2-2 }\end{array}$ \\
\hline
\end{tabular}




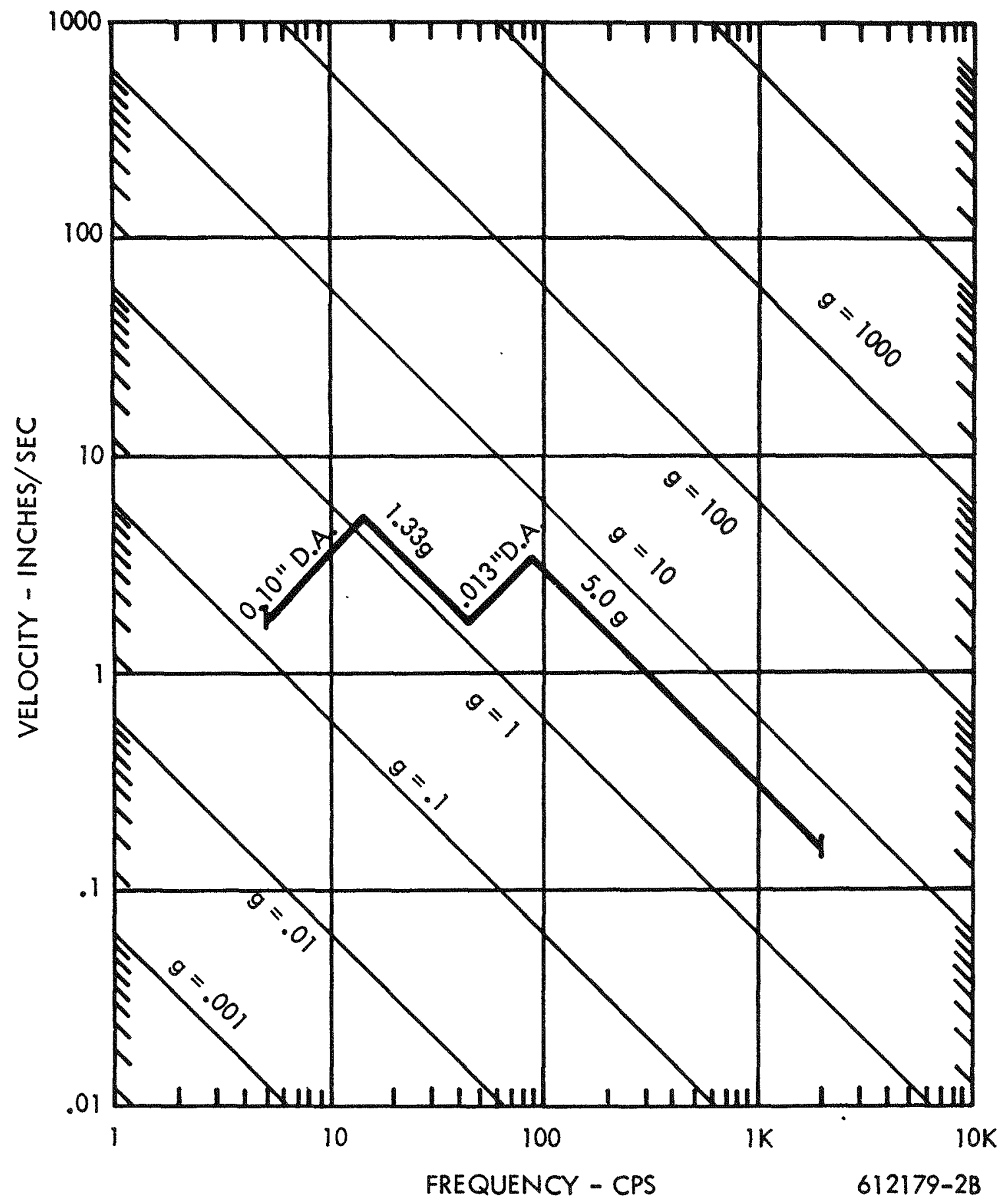

Figure 2-1. Anticipated Vibration Environment, NERVA XE-1; Ground Firing Test, Longitudinal Plane 


\section{(20) Astronuclear}

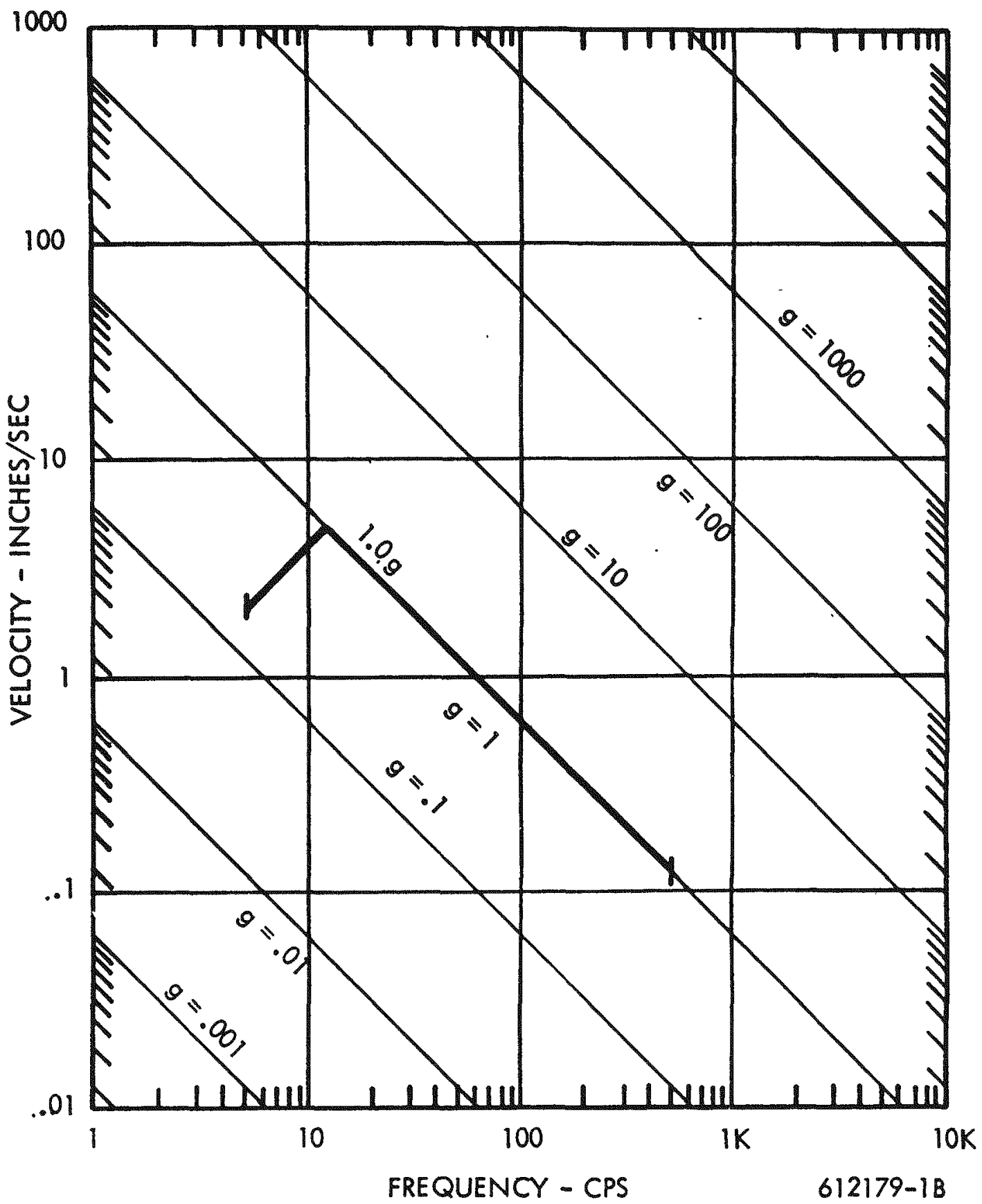

Figure 2-2. Anticipated Vibration Environment, NERVA XE-1; Ground Firing Test; Lateral Plane 


\subsubsection{Test Sequence}

The tests listed in Table 2-1 shall be conducted in the following sequence:

Vertical: $\quad 1,2,3,5,6$

Horizontal

Number 1: $\quad 1,2,4,5,7$

Horizontal

Number 2: $\quad 1,2,4,5,7$

In addition, a dynamic resolution check and a transient response check shall be performed after tests 3 and 4 , whenever they occur in the test sequence, while a complete set of performance data shall be taken after tests 6 and 7 .

\subsubsection{Actuator Conditions}

1) Non-operating

In those tests where the actuator is non-operating, the following conditions shall prevail:

a) The drive and coolant gas supplies to the actuator shall be turned off.

b) The actuator shall be locked at the 15 degree shaft position.

c) The electrical supplies to the torque motor shall be turned off.

2) Operating

In those tests where the actuator is operating, the following conditions shall prevail:

a) Drive gas pressure at $200 \pm 10$ psig.

b) Coolant gas pressure at $675 \pm 25$ psig.

c) Drive and coolant gas temperature at ambient conditions.

d) External friction load shall be as measured.

e) Simulated inertia load at $0.24 \mathrm{inch} /$ pound $/$ second $^{2}$.

f) Actuator velocity limit set at $100 \pm 10$ degrees per second.

g) The actuator set at a nominal drum position of 90 degrees, with various command signals superimposed on the nominal position. 


\subsubsection{Data Requirements}

The following data shall be recorded during the tests:

1) Vibration control accelerometer.

2) Three accelerometers recording motion along the three axes of the actuator.

3) Drive gas pressure and temperature.

4) Coolant gas pressure and temperature.

5) Two cylinder pressures.

6) Actuator shaft position.

7) Actuator command.

8) Torquemotor current.

9) Position error.

\subsection{PERFORMANCE REQUIREMENTS FOR QUALIFICATIONS}

To successfully demonstrate the qualification of the actuator in the XE-1 vibration environment, performance within the deviations specified should be satisfied during and after the vibration tests described in Table 2-1. Isolated departures that vary beyond the allowable limits shall be evaluated individually in light of the control system requirements.

\subsubsection{Scram Operation}

Maximum allowable turnaround time - \pm 10 percent of base line data.

2.4.2 Transient Response to 18 Degree Peak-to-Peak Square Wave

Rise Time $\quad-\quad \pm 10$ percent of base line data

Settling Time $\quad-\quad \pm 10$ percent of base line data

Overshoot $\quad-\quad \pm 10$ percent of base line data

\subsubsection{Frequency Response to 4 Degree Peak-to-Peak Sine Wave}

1) Amplitude ratio shall not exceed $\pm 2 \mathrm{db}$ of base line.

2) Phase lag at $1 \mathrm{cps}(\mathrm{Hz})$ not to exceed \pm 5 degrees of base line data. 
3) Phase lag at $2 \operatorname{cps}(\mathrm{Hz})$ not to exceed \pm 5 degrees of base line data.

4) Phase lag at $6 \mathrm{cps}(\mathrm{Hz})$ not to exceed \pm 7.5 degrees of base line data.

5) Phase lag at $12 \mathrm{cps}(\mathrm{Hz})$ not to exceed \pm 10 degrees of base line data.

2.4.4 Dynamic Resolution to a 3 Degree per Second Ramp Command

Maximum error from base line data shall be \pm 0.5 degree $(0.0055$ volt $)$.

\subsubsection{Static Resolution}

Static position resolution at the output shaft shall not exceed \pm 0.5 degree

$(0.0275$ volt $)$ of base line data.

\subsection{POST VIBRATION INSPECTION}

Upon completion of all the scheduled tests, if there is an unexplainable discrepancy in the performance requirements (detailed in Section 2.4) the actuator shall be disassembled and inspected for physical damage or changes. A careful record shall be maintained of each step in the disassembly process. Pictures shall be taken wherever it is deemed necessary.

\subsection{REPORT REQUIRED}

\subsubsection{Final Report}

A final report covering the entire environmental testing of the XE-1 actuator shall be written which shall include the results of the vibration qualification test. It should include but not be limited to:

1) Introduction

2) Description of Test Setup

3) Description of Test Procedure

4) Presentation of Discussion of Test Data

5) Conclusions and Recommendations 


\section{MECHANICAL SHOCK QUALIFICATION SPECIFICATION FOR DRUM PNEUMATIC ACTUATORS FOR XE-I APPLICATION}

\subsection{PURPOSE}

The purpose of this test is to qualify the pneumatic drum actuators for use in the NERVA $X$-Engine Test XE-1. This investigation will be limited to observing the actuator closed loop performance while it is subjected to mechanical shock loads, which are considered typical of the XE-1 environment.

\subsection{GUIDING SPECIFICATIONS}

The following specifications will serve as guidelines in completing the requirements of this specification:

1) MIL-STD-810 - "Environmental Test Methods for Aerospace and Ground Equipment" (Test Method Number 516, Procedure 1)

2) AGC Report Number RN-DR-0020 (Revised) - "Preliminary Specification, NERVA Program, Contract SNP-1", September 1964

3) WANL Specification E-675560 - "Actuator Mechanisms, Pneumatic - XE Series Control Drum"

\subsection{PROCEDURE}

\subsubsection{Pre-Shock Test Performance Record}

Prior to the initiation of the shock tests, the actuator shall be mounted on the test stand and a complete set of performance data shall be recorded. This data will be used as a reference throughout the subsequent test and will be referred to as "the base line data". The base line data shall include the following items:

1) Linearity and Resolution Check

2) Transient Response Check

3) Scram Turnaround Check

4) Frequency Response Check between 0.5 and $20 \mathrm{cps}(\mathrm{Hz})$ 
The definition and test conditions for these tests shall be as outlined in the appropriate paragraphs of WANL Specification E-675560, except as modified herein.

\subsubsection{Shock Test}

\subsubsection{Test Plan}

The following tests shall be conducted to determine the actuator performance when subjected to shock loads. TS 711892-B outlines the procedure to be followed in performing these tests.

\subsubsection{Direction of Applied Loads}

The shock loads shall be applied in the following planes as described in Table 3-1:

Vertical:

Horizontal Number 1:

Horizontal Number 2:
Applied force parallel to the actuator output shaft.

Applied force parallel to the direction of the piston travel.

Applied force normal to the direction of the piston travel.

\section{TABLE 3-1}

SHOCK SCHEDULE

\begin{tabular}{|l|c|c|c|c|c|}
\hline \multicolumn{1}{|c|}{ Plane } & $\begin{array}{c}\text { Actuator } \\
\text { Condition }\end{array}$ & $\begin{array}{c}\text { Load } \\
\left(\mathrm{g}^{\prime} \mathrm{s}\right)\end{array}$ & $\begin{array}{c}\text { Dwell Time } \\
(\mathrm{sec})\end{array}$ & $\begin{array}{c}\text { Shocks in } \\
\text { Each Direction }\end{array}$ & $\begin{array}{c}\text { Shocks in } \\
\text { Each Plane }\end{array}$ \\
\hline Vertical & Operating & \pm 2.0 & 0.01 & 3 & 6 \\
Horizontal No. 1 & Operating & \pm 1.0 & 0.01 & 3 & 6 \\
Horizontal No. 2 & Operating & \pm 1.0 & 0.01 & 3 & 6 \\
\hline
\end{tabular}




\subsubsection{Actuator Conditions}

During all of the tests described in Table 3-1, the conditions to be imposed on the actuator shall be as follows:

1) Drive gas pressure at $200 \pm 10$ psig

2) Coolant gas pressure at $675 \pm 25$ psig

3) Drive and coolant gas temperatures at ambient conditions

4) Simulated inertia load at $0.24 \mathrm{in} / \mathrm{lb} / \mathrm{sec}^{2}$

5) Actuator velocity limit set at $100 \pm 10$ degrees/second

6) The actuator set at a nominal drum position of 90 degrees and a 3 degree/second triangular wave of 100 degrees peak-to-peak amplitude applied.

\subsubsection{Data Requirements}

The following data shall be recorded during the tests:

1) Applied shock pulse

2) Shock pulse as recorded at two places on the actuator housing

3) Drive gas pressure and temperature

4) Coolant gas pressure and temperature

5) Actuator shaft position

6) Actuator command

7) Torquemotor current

8) Position error

\subsubsection{Post Shock Test Performance Record}

Upon completion of the tests described in Section 3.3.2, a complete set of performance data shall be recorded to compare with the base line data recorded in Section 3.3.1. These data shall include the same requirements as specified in Section 3.3.1. 


\section{(W) Astronuclear

\subsection{PERFORMANCE REQUIREMENTS FOR QUALIFICATION}

To successfully demonstrate qualification of the actuator in the XE-1 environment, the following performance parameters should be satisfied after the shock tests described in Table 3-1. In addition, the physical structure of the actuator should remain intact. There should be no damage to the individual components such that they would be unable to perform their intended functions. Isolated cases that vary beyond the allowable limits shall be evaluated individually in light of the control system requirements.

\subsubsection{Scram Operation}

Maximum allowable turnaround time - \pm 10 percent of base line data.

3.4.2 Transient Response to 18 Degree Peak-to-Peak Square Wave

$\begin{array}{lll}\text { Rise Time } & - & \pm 10 \text { percent of base line data } \\ \text { Settling Time } & - & \pm 10 \text { percent of base line data } \\ \text { Overshoot } & - & \pm 10 \text { percent of base line data }\end{array}$

\subsubsection{Frequency Response to 4 Degree Peak-to-Peak Sine Wave}

1) Amplitude ratio shall not exceed $\pm 2 \mathrm{db}$ of base line data

2) Phase lag at $1 \mathrm{cps}(\mathrm{Hz})$ not to exceed \pm 5 degrees of base line data

3) Phase lag below $2 \mathrm{cps}(\mathrm{Hz})$ not to exceed \pm 5 degrees of base line data

4) Phase lag at $6 \mathrm{cps}(\mathrm{Hz})$ not to exceed \pm 2.5 degrees of base line data

5) Phase lag at $12 \mathrm{cps}(\mathrm{Hz})$ not to exceed \pm 10 degrees of base line data

3.4.4 Dynamic Resolution to a 3 Degree per Second Ramp Command

Maximum error from base line data shall be \pm 0.1 degree $(0.0055$ volt $)$

\subsubsection{Static Resolution}

Static position resolution at the output shaft shall not exceed \pm 0.1 degree $(0.005$ volt $)$ of the base line data. 


\subsection{POST SHOCK TEST INSPECTION}

Upon completion of all scheduled tests, if there is an unexplainable discrepancy in the performance requirements (detailed in Section 3.4), the actuator shall be disassembled and visually inspected for physical damage or changes. A careful record shall be maintained of each step in the disassembly process. In the event that any part(s) shows evidence of material failure or excessive wear, a dimensional check with suitable photographs of the failure will be made.

\subsection{REPORT REQUIRED}

\subsubsection{Final Report}

A final report covering the entire environmental testing of the XE-1 actuator shall be written which shall include the results of the mechanical shock qualification rest. It should include but not be limited to:

1) Introduction

2) Description of Test Setup

3) Description of Test Procedure

4) Presentation and Discussion of the Test Data

5) Conclusions and Recommendations 


\section{LOW TEMPERATURE QUALIFICATION SPECIFICATIONS FOR CONTROL DRUM PNEUMATIC ACTUATORS FOR XE-I APPLICATION}

\subsection{SCOPE}

The XE-Engine control drum pneumatic actuators, herein called actuators, must be capable of operating satisfactorily when using low temperature gas as supplied by the XEEngine. Specific operating requirements and conditions required to qualify actuators for $X E-1$ Engine use are defined and specified by this document.

\subsection{OBJECTIVE}

It is the primary objective of this document to demonstrate by tests that the actuators are qualified for XE-1 during low temperature operation. This qualification will be considered for both mechanical integrity of the actuator and components as well as functional operation of the actuator sub-system.

\subsection{REFERENCE SPECIFICATIONS}

The following sources shall serve as specification guidelines in interpretation of the actuator requirements for low temperature qualification:

AGC Report RN-DR-0020

WANL Specification E-675560
"Preliminary Specification, NERVA X-Engine, NERVA Program Contract SNP-T", Section 5 (Seprember 1964)

"Actuator Mechanisms, Pneumatic - XE Series Control Drum"

\subsection{TEST PARAMETERS}

Test parameters, as specified herein, must be controlled and recorded during all phases of test qualifications. The only exception being the inertia load value which should be constant, but need not be measured. 


\section{W Astronuclear}

\subsubsection{Actuator Drive Gas Parameters}

Fluid $\quad$ He or $\mathrm{H}_{2}$

Pressure $\quad 200 \pm 10$ psig

Temperature $\quad 150 \pm 25^{\circ} \mathrm{R}$ and $50+25^{\circ} \mathrm{R}\left(\mathrm{H}_{2}\right.$ only $)$

\subsubsection{Actuator Coolant Gas Parameters}

Fluid He or $\mathrm{H}_{2}$

Pressure $\quad 675 \pm 25$ psig

Temperature $\quad 150 \pm 25^{\circ} \mathrm{R}$ and $50+25^{\circ} \mathrm{R}\left(\mathrm{H}_{2}\right.$ only $)$

4.4.3 Actuator Return Gas Parameters

Fluid Mixture of coolant and drive

Pressure $\quad$ Back pressure of vent (not to exceed 35 psig)

Temperature Result of mixture

\subsubsection{Friction Load}

Friction Value 0 to $32 \mathrm{in} / \mathrm{lb}$ (not controlled)

4.4.5 Actuator Temperature

Metal Temperature - regulated by gas temperature

4.4.6 Inertia Load

Inertia Value $\quad-0.24 \mathrm{in} / \mathrm{lb} / \mathrm{sec}^{2}$

4.4.7 Test Duration

Number of Cycles - 4 at each specified temperature

Length of Cycles - 300 seconds minimum with steady state actuator temperatures

4.4.8 Actuator Subsystem Gain Controls

Gain control values shall remain constant for the entire test. Actual settings will be adjusted prior to testing. 


\section{5 TEST PLAN}

\subsubsection{Test Description}

It will be required to provide all of the test parameters as specified above for each test cycle. A test cycle will be performed to attain the gas temperatures specified. for a minimum of 300 seconds. The actuator should be allowed to "warm up" to room temperature after each cycle prior to beginning another cycle. During each cycle the actuator must be operated in such a manner as to demonstrate the actuator qualification requirements as outlined in Section 4.6 of this document. TS 711892-C outlines the procedures to be followed in performing these tests.

\subsubsection{Data Required}

The following data shall be measured and recorded.

\subsubsection{Pressures}

a) Drive gas

b) Coolant gas

c) Cylinder gas $\left(P_{1}\right.$ and $\left.P_{2}\right)$

4.5.2.2 Temperatures

a) Drive gas

b) Coolant gas

c) Actuator Housing

4.5.2.3 Actuator Data

a) Shaft position

b) Position command

C) Position error

d) Torquemotor current 


\subsection{QUALIFICATION REQUIREMENTS}

Prior to low temperature operation, an ambient "base Line" operation shall be accomplished and the values of the following "Qualification Performance Requirements" shall be measured and recorded. These values shall be referred to as "Base Line Data" for evaluation of actuator performance at low temperature.

\subsubsection{Scram Operation}

Maximum allowable turnaround time - $t 10$ percent of base line data

\subsubsection{Transient Response to 18 Degree Peak-to-Peak Square Wave}

Rise Time

Settling Time

Overshoot
- $\quad \pm 10$ percent of base line data

- $\quad \pm 10$ percent of base line data

- $\quad \pm 10$ percent of base line data

\subsubsection{Frequency Response to 4 Degree Peak-to-Peak Sine Wave}

1) Amplitude ratio shall not exceed $\pm 2 \mathrm{db}$ of base line data.

2) Phase lag at $1 \mathrm{cps}(\mathrm{Hz})$ not to exceed \pm 5 degrees of base line data.

3) Phase lag at $2 \mathrm{cps}(\mathrm{Hz})$ not to exceed \pm 5 degrees of base line data.

4) Phase lag at $6 \mathrm{cps}(\mathrm{Hz})$ not to exceed \pm 7.5 degrees of base line data.

5) Phase lag at $12 \mathrm{cps}(\mathrm{Hz})$ not to exceed \pm 10 degrees of base line data.

\subsubsection{Dynamic Resolution to a 3 Degree per Second Ramp Command}

Maximum error from base line data shall be \pm 0.1 degree $(0.0055$ volt $)$.

\subsubsection{Static Resolution}

Static resolution at the output shaft shall not exceed \pm 0.1 degree $(0.0055$ volt $)$ of base line data. 


\subsection{POST MORTEM INSPECTION}

Upon completion of low temperature testing, if there is an unexplainable discrepancy in the performance requirement (detailed in Section 4.6), the actuators shall be disassembled and a visual inspection performed on all parts. In the event that any part(s) shows evidence of material failure or excessive wear, a dimensional check with suitable photographs of the failure shall be made.

\subsection{REPORTS}

A final report covering the entire environment testing of the XE-1 actuator shall be written which shall include the results of the low temperature. The report shall include all performance data and an evaluation of the results of the test. 


\section{LIFE QUALIFICATION TESTS FOR CONTROL DRUM PNEUMATIC ACTUATORS}

\subsection{SCOPE}

This memorandum defines the life test requirements for the XE-1 Engine Control Drum Actuators. The test conditions as specified herein represent the design life requirements as specified in WANL-Specification E-675560 but modified to what is currently known of the XE-1 Engine test environment. TS-711892-D outlines the procedure to be followed in performing these tests.

\subsection{OBJECTIVE OF TEST}

The objective of the life test defined herein is to qualify the control drum actuators for the XE-1 Engine Test by demonstrating satisfactory performance over an extended operating period.

The life test shall consist of a 150 hour room temperature test followed by a one hour combined low temperature and vibration test.

\subsection{ENVIRONMENTAL CONDITIONS}

\subsubsection{Room Temperature Test}

The room temperature test shall consist of 150 hours of operation in accordance with the duty cycle specified in paragraph 5.4.1. Helium shall be used as the drive gas whenever data are to be taken, but to conserve helium, the actuator shall be operated on nitrogen drive gas for the remaining time. The coolant shall be nitrogen gas. The test shall be conducted continuously in so far as possible with any necessary shutdowns held to a minimum. Any breakdowns shall be repaired and the test continued to completion.

\subsubsection{Combined Low Temperature and Vibration Test}

The combined low temperature and vibration test shall consist of one hour of operation in accordance with the duty cycle defined in paragraph 5.4.2 while subjected to the vibratory conditions defined by Figure 2-1. Vibration shall be in the vertical plane, i.e., along the 
the axis of the output shaft. The drive gas, coolant gas and the actuator housing temperature shall be maintained at $140 \pm 25^{\circ} \mathrm{R}$. Sufficient time shall be allowed prior to running the one hour test to allow the housing temperature to stabilize.

\subsection{DUTY CYCLE}

The actuator shall be subjected to the following duty cycle during the test. During the room temperature test the cycling sequence shall be such that the actuator will be cycled through each of the six steps at least once per hour.

\subsubsection{Room Temperature Test}

1) Sinusoidally at $6 \mathrm{cps}$ and 4 degrees peak-to-peak amplitude 12.5 hours

2) Sinusoidally at $0.5 \mathrm{cps}$ and 40 degrees peak-to-peak amplitude 20.0 hours

3) Ramp at 3 degrees per second over full stroke 45.0 hours

4) Scram, lock, and reset

22.5 hours

5) Step at $0.1 \mathrm{cps}(\mathrm{Hz})$ between 81 degrees and 99 degrees 25.0 hours

6) Dwell at static position of 90 degrees 25.0 hours

TOTAL $\quad 150.0$ hours

\subsubsection{Combined Low Temperature and Vibration Test}

1) Ramp at 3 degrees per second over full stroke

15.0 minutes

2) Step at $0.1 \mathrm{cps}(\mathrm{Hz})$ between 81 degrees and 99 degrees

15.0 minutes

3) Dwell at static position of 90 degrees

15.0 minutes

4) Sinusoidally at $6 \operatorname{cps}(\mathrm{Hz})$ and 4 degrees peak-to-peak amplitude

15.0 minutes

TOTAL $\quad 60.0$ minutes

\section{5 TEST PARAMETERS}

The various test parameters shall be controlled as specified in the following table. 


\subsubsection{Pressures}

Parameter

a) drive gas

b) coolant gas

c) exhaust
Room Temperature Test

$200 \pm 10$ psig

$675 \pm 25$ psig

not regulated
Combined Environment Test

$200 \pm 10$ psig

$675 \pm 25$ poig

not regulated

\subsubsection{Temperatures}
a) drive gas
530 to $540^{\circ} \mathrm{R}$
$140 \pm 25^{\circ} R$
b) coolant gas
530 to $540^{\circ} \mathrm{R}$
$140 \pm 25^{\circ} \mathrm{R}$
c) actuator housing
530 to $540^{\circ} \mathrm{R}$
$140 \pm 25^{\circ} R$

\section{5 .3 Load}
a) inertia
0.24 in $/ 1 \mathrm{~b} / \mathrm{sec}^{2}$
$0.24 \mathrm{in} / \mathrm{lb} / \mathrm{sec}^{2}$
b) friction
0 to $32 \mathrm{in} / 1 \mathrm{~b}$
0 to 32 in $/ 16$

\subsection{DATA}

Prior to the start of the test, a complete set of data, as defined in paragraph 5.7, shall be taken and shall be referred to as the base line data. A complete set of data shall also be taken at the completion of the 150 hour room temperature test and upon completion of the one hour combined low temperature and vibration test.

During the room temperature test, a frequency response test shall be made every 25 hours.

The following data shall be recorded continuously (except gas flow) throughout the test except during the dwell period defined in paragraph 5.4.1, item (6).

\subsubsection{Temperatures}

1) Drive gas

2) Coolant gas

3) Structural temperature (to be taken only during cold test of paragraph 5.3.2). 


\section{(W. Astronuclear}

5.6.2 Pressures

1) Drive gas

2) Coolant gas

3) Piston chamber, $P_{1}$

4) Piston chamber, $P_{2}$

\subsubsection{Electrical Measurements}

1) Manual Command

2) Dynamic Command

3) Actuator position

4) Torquemotor current

5) Error

5.6.4 Gas Flow

The drive gas and coolant flow shall be read during the dwell period of paragraph

5.4.1, item (6), approximately every 8 hours.

\subsubsection{Test Time}

A running time meter shall be used to record the actual operating time. The time meter shall be operated when the actuator is unlocked.

\subsection{PERFORMANCE REQUIREMENTS FOR QUALIFICATION}

The actuator shall be considered to have passed the life qualification test provided the following performance requirements are met. Isolated cases that vary beyond the allowable limits shall be evaluated individually in light of the control system requirements.

\subsubsection{Scram Operation}

Maximum allowable turnaround time - \pm 10 percent of base line data. 


\subsubsection{Transient Response to 18 Degree Peak-to-Peak Square Wave}
1) Rise time
- $\quad \pm 10$ percent of base line data
2) Settling time
- $\quad \pm 10$ percent of base line data
3) Overshoot
$-\quad \pm 10$ percent of base line data

\subsubsection{Frequency Response to 4 Degree Peak-to-Peak Sine Wave}

1) Amplitude ratio shall not exceed $\pm 2 \mathrm{db}$ of base line data.

2) Phase lag at $1 \mathrm{cps}(\mathrm{Hz})$ shall not exceed \pm 5 degrees of base line data.

3) Phase lag at $2 \mathrm{cps}(\mathrm{Hz})$ shall not exceed \pm 5 degrees of base line data.

4) Phase lag at $6 \mathrm{cps}(\mathrm{Hz})$ shall not exceed \pm 7.5 degrees of base line data.

5) Phase lag at $12 \mathrm{cps}(\mathrm{Hz})$ shall not exceed \pm 10 degrees of base line data.

\subsubsection{Dynamic Resolution to a 3 Degree per Second Ramp Command}

Maximum error from base line data shall be \pm 0.5 degree $(0.0275$ volt $)$.

\subsubsection{Static Resolution}

Maximum static position resolution at the output shaft shall not exceed \pm 0.5 degree $(0.0275$ volt) of base line data.

\subsection{INSPECTION}

Upon completion of the test if there is an unexplainable discrepancy in the performance requirements (detailed in Section 5.7), the actuator shall be disassembled and a visual inspection made of all parts. A dimensional inspection shall be made and photographs taken of any parts exhibiting significant wear.

\subsection{REPORT REQUIRED}

A final report covering the entire environmental testing of the XE-1 actuator will be written which will include the results of the life qualification test. The report should include the performance data and an evaluation of the results of the test. 


\section{RADIATION QUALIFICATION SPECIFICATIONS FOR CONTROL DRUM PNEUMATIC ACTUATORS FOR XE-1 APPLICATION}

\subsection{SCOPE}

The installation requirements imposed by XE-1 place the Control Drum Pneumatic Actuators above the external shield in the vicinity of Station 130.0. At this location estimates have been made of the radiation level expected in the fully shielded condition. The dose rates are defined by Aerojet Letter 7425:009, dated July 28, 1964. The integrated dose and environmental conditions are based on information contained in the NERVA X-Engine Specification RN-DR-0020 dated September 1964. It is expected that the results of the NRXA6 side-by-side test, and the Lewis AG-20 and XE- 1 irradiation tests will serve to qualify the actuators for use in a radiation environment.

\subsection{OBJECTIVE}

The purpose of this specification is to define the necessary conditions for qualification of the Control Drum Pneumatic Actuator in the XE-1 radiation environment.

\subsection{ENVIRONMENTAL CONDITIONS}

Since the functional operation of the pneumatic actuator is dependent upon the material properties of the components, it is necessary that the materials be qualified under the most severe conditions expected. The combined environments of radiation and low temperature represent the most severe environmental condition because the low temperature tends to accelerate or intensify the material degradations due to radiation.

\subsubsection{Radiation Field}

The radiation field in and near the pneumatic actuator in the XE-1 shielded condition can be characterized by the following values:

\begin{tabular}{|c|c|}
\hline Item & Dose Rate \\
\hline Gamma & $2.8 \times 10^{5} \mathrm{rad} / \mathrm{hr}$ \\
\hline Fast Neutron (E I Mev) & $\times 10^{10} \mathrm{~N} / \mathrm{cm}^{2} / \mathrm{sec}$ \\
\hline Thermal Neutron (E $0.48 \mathrm{ev}$ ) & Not reported \\
\hline
\end{tabular}


Neglecting the heating effect due to neutrons, the heating value due to $X$ rays is calculated at 0.35 watt $/ \mathrm{lb}$.

\subsubsection{Temperature Field}

Accurate information is not presently available with regard to the temperature distribution within the actuator mechanism. It is sufficient to consider the lowest value expected, and the temperature is based on the actuator coolant flow obtained from the reactor plenum volume. The estimated value for the actuator mechanism on XE-1 is 50 to $60^{\circ} \mathrm{R}$.

\subsection{QUALIFICATION REQUIREMENTS}

\subsubsection{Unconditional Qualification}

In this sense the entire actuator mechanism must be tested under the conditions of Section 6.3 with the following results:

1) The actuator mechanism must retain its mechanical and electrical integrity.

2) The actuator mechanism must perform satisfactorily when operated in the subsystem. Satisfactory performance exists when the requirements of WANL Specification E-675378, Section 6.5 are met.

\subsubsection{Conditional Qualification (XE-1 Application)}

In this context, the actuator mechanism components (as opposed to the actuator mechanism) must be tested under conditions of Section 6.3 with equivalent input/output characteristics, including loading, yielding the following results:

1) The components must retain their mechanical and electrical integrity.

2) The components must perform satisfactorily when operated under the sub-system conditions encountered in the closed loop; i.e., a dynamically similar and equivalent test.

\subsubsection{Exceptions}

Minor departures from the required performance may occur in either case (Sections 6.4.1 or 6.4.2). These will be analyzed with regard to the control system requirements, 


\section{(29) Astronuclear}

and if no adverse effects result, they will become a part of the final XE-1 qualification conditions.

\subsubsection{Equivalence}

Either Section 6.4.1 or 6.4.2 is sufficient to show qualification for XE-1.

\subsection{REPORT}

A summary report will be issued indicating the actuator qualification for the $X E-1$ radiation environment. The report must include:
1) Abstract
2) Description of Test(s)
3) Results
4) Conclusions and Recommendations 
(W) Astronuclear

- Laboratory

APPENDIX B 
T-711892 A, B, C \& D

QUALIFICATION TEST, ENVIRONMENTAL

XE-1 CONTROL DRUM ACTUATOR

PREPARED BY:

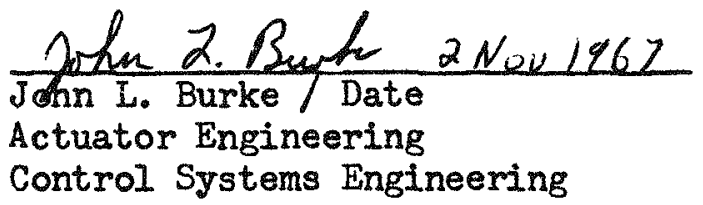

APPROVED BY:

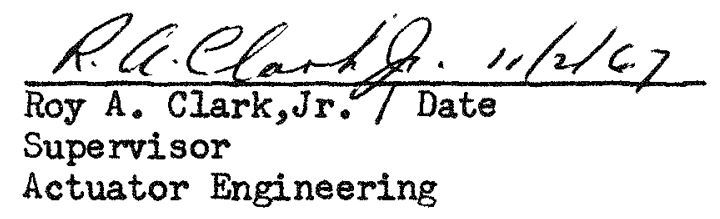




\section{QUALIFICATION TEST, VIBRATION}

\section{TS-711892-A}

\subsection{Introduction}

In this procedure the methods for testing the XE-I Pneumatic Control Drum Actuator in a controlled vibration environment shall be outlined. Prior to vibrating the actuator a series of tests shall be run to determine the performance of the actuator. The results of these tests shall establish the "Base line Data" for the actuator under test.

The actuator shall then be vibrated to simulate the shipment, storage, and ground firing conditions which are expected to be placed on the actuator. Both during and after the vibrations the actuator's performances shall be tested. The results of these tests shall be compared with the Base Line Data and any change shall be noted. Though small changes are to be expected, any gross or critical deviation not logically explained in the actuator's performance shall necessitate the complete disassembly of the actuator to determine the cause of the deviation.

\subsection{Material and Equipment Requirements}

2.1 Vibration Test Ioad Stand

2.2 Vibration Driver and Control System

2.3 Actuator Amplifier XE-1

2.4 Visicorder Honeywell, Model 1508

2.5 Frequency Response Analyzer, IMC, Model 101

2.6 Function Generator, Hewlett Packard, Model 202

2.7 D.C. Power Supply, $+10 \mathrm{~V}, \pm 15 \mathrm{~V}, \pm 24 \mathrm{~V},+28 \mathrm{~V}$ Trygon Model PS32-2.5 
$2.8 \mathrm{X}, \mathrm{Y}, \mathrm{Y}$ ' Recorder, Honeywell Model 480

2.9 Pressure Transducers, C.E.C., Model 4-354

2.10 Gage Balance Unit, Honeywell

2.11 Accelerometers, Endevco

2.12 Data Amplifiers, C.E.C., Type 155

2.13 Digital Voltmeter, Honeywell Model 6305

2.14 Helium Drive Gas (ambient temperature, $200 \pm 5$ psig)

2.15 Nitrogen Coolant Gas (ambient temperature, $650 \pm 25$ psig)

\subsection{Parameters}

3.1 The parameters to be measured in this test are:

3.1.1 ac - control acceleration

3.1.2 $P_{C} \quad-\quad$ coolant gas pressure

3.1.3 $\mathrm{Pd}_{\mathrm{C}}$ - drive gas pressure

3.1.4 $\mathrm{Pe} \quad-\quad$ exhaust gas pressure

3.1.5 $\mathrm{P}_{1}$ - pressure in cylinder \#1

3.1.6 $\quad \mathrm{P}_{2} \quad$ - pressure in cylinder \#2

3.1.7 $\triangle P$ - pressure differential $\left(P_{1}-P_{2}\right)$

3.1.8 $\ominus \mathrm{d}-\mathrm{d} . \mathrm{c}$. demand voltage (angle)

3.1.9 $\Delta \theta_{\mathrm{d}}-$ a.c. demand voltage (angle)

3.1.10 $\theta_{0}$ - actuator position voltage (angle)

3.1.11 $\Delta \theta_{0}-$ a.c. value of actuator position centered about $\theta_{0}\left(\theta_{0}-\theta_{d}\right)$

$3.1 .12 \theta_{e}-$ error voltage (angle) $\left(\theta_{0}-\theta_{d}-\Delta \theta_{d}\right)$

3.1 .13 II - torque motor current

3.1.14 ax - acceleration perpendicular to piston travel

$3.1 .15 \mathrm{a}_{2}$ - acceleration parallel to piston travel

3.1.16 az - acceleration parallel to output shaft 


\subsection{Load Stand Friction and Spring Gradient Test}

4.1 Place torque wrench in Load Stand Spline and measure:

4.1.1 Breakaway torque of increasing angle at spring rest position. Breakaway torque of increasing angle at $15^{\circ}$. Breakaway torque of increasing angle at $90^{\circ}$.

4.1.2 Relaxation torque of decreasing angle at $90^{\circ}$. Relaxation torque of decreasing angle at $15^{\circ}$. Relaxation torque of decreasing angle at spring rest position.

\subsection{Transient Response Cor Amplifjer Tuninr}

5.1 Place actuator ir. vihration load stand and secure marman clamn.

5.2 Turn on drive ras, coolant ras, and actuator amnlifier.

5.3 Move actuator to $90^{\circ}$ ( -5 volt) drum position and annly a $100^{\circ}$ $\left(5.55\right.$ volt) $p-0$ square wave to $\Delta \theta_{d}$.

5.4 Adjust velocity limits to $100 \% \mathrm{sec} \pm 20 \% \mathrm{sec}$ as measured by the out nut voltane of the amnlifier rate stage ( 1 volt \pm 0.2 volts).

5.5 Usin an $18^{\circ}$ ( 1.0 volt) $p-n$ square wave set the rain and lead controls to five ontimum nerformance with an overshnot of less $\operatorname{than} 5^{\circ}$

5.6) 'e-check velocity limits and reneat procedure if velocity limits neer to he chanred.

5.7 Record "ain and lear settin" and velocity.

\subsection{Determination of Base Line Data}

6.1 Linearity and Static Resolution Check

6.1.1 Apply a $90^{\circ}\left(-5 \pm .001\right.$ volt) command $\left(\theta_{d}\right)$ and adjust amplifier offset pot for a position $\left(\theta_{0}\right)$ of $90^{\circ}$ ( $-5 \pm .001$ volt). 
6.1.2 Record comand (Od) on X-axis of plotter ( 1 volt/in) and static error $\left(\theta_{e}\right)$ on $Y$-axis $(.01 \mathrm{rolt} / \mathrm{in})$.

6.1.3 Move actuator command $\left(\theta_{d}\right)$ in $9^{\circ}(0.5$ volt $)$ increments from $9^{\circ}$ to $171^{\circ}(0.5$ rolt to 9.5 volt $)$ and record points when actuator assumes its rest position.

6.2 Dynamic Resolution Check

6.2 .1 Return to $90^{\circ}$ ( -5 volt) position and apply a $3 \% / \mathrm{sec}(7.8 \mathrm{volt}$ $p-p$ (0.01 $0.0 Z$ ) ramp to the dynamic command $(\Delta \theta d)$ input.

6.2.2 Record $\Delta$ od on X-axis of plotter (1.0 volt/in) and error voltage $\left(\theta_{e}\right)$ on $\mathrm{Y}$-axis $(.01 \mathrm{rolt} / \mathrm{in})$.

6.3 Transient Response Check

6.3.1 Return to $90^{\circ}$ position ( -5 volt) and apply an $18^{\circ}$ ( 1 volt $p-p)$ square wave to $\Delta \theta_{d}$.

6.3.2. Record $\Delta \theta_{\mathrm{d}}$ and $\Delta \theta_{0}$ on the visicorder.

6.4 Scram Turnaround Check

6.4.1 Return to $90^{\circ}$ ( -5 volt) position and set auto-scram control to scram the actuator when $\theta_{0} \geq 120^{\circ}(-6.666 \mathrm{volt})$ and apply a $100^{\circ}(5.55$ volt $)$ square wave to $\Delta \theta_{d}$.

6.4.2 Allow actuator to scram and record $\theta_{0}, I_{1}, P_{1}, P_{2}, \triangle P$, lock light, and unlock light on visicorder.

\subsection{Frequency Response Check}

6.5.1 Turn off auto-scram and reset scram relay.

6.5.2 Return actuator to $90^{\circ}$ ( -5 volt) position.

6.5.3 Apply the IMC Osc. output to $\Delta \theta_{\mathrm{d}}$ and set for $4^{\circ}$ (.222 volt) $p-p$ sine wave. 
6.5.4 Connect $\Delta \theta_{d}$ to the input of the $I M C$ and $\Delta \theta_{0}$ to the $e_{2}$ input to the IMC.

6.5.5 Record frequency on the X-axis of the plotter, amplitude on the Y-axis, and phase on the Y'axis.

6.5.6 Run the frequency from $0.1 \mathrm{HZ}$ to $20 \mathrm{HZ}$ and obtain the closed loop frequency response of the actuator.

\subsection{Vibration Schedule}

Vertical Direction (actuator mounted on vibration stand so that the direction of acceleration $\left(A_{z}\right)$ is parallel to the actuator drive shaft).

7.1 Test No. 1

7.1.1 Mount actuator and secure marman clamp.

7.1.2 Make two (2) sweeps from $5 \mathrm{HZ}$ to $2000 \mathrm{HZ}$ to $5 \mathrm{HZ}$ at $1.0 \mathrm{~g}$ acceleration.

7.1.3 Each sweep shall be 3 minutes in duration.

7.1.4 Record all accelerometer voltages and frequency of vibration on the visicorder.

7.2 Test No. 2

7.2.1 With drive gas, coolant gas, and actuator amplifier still off make three (3) sweeps from $10 \mathrm{HZ}$ to $30 \mathrm{HZ}$ to $10 \mathrm{HZ}$.

7.2.2 Each sweep shall be 2 minutes in duration at $4.0 \mathrm{~g}$ acceleration.

7.2.3 Record all accelerometer voltages and frequency of vibration on the visicorder.

\subsection{Test No. 3}

7.3.1 Turn on drive gas, coolant gas, and actuator amplifier.

7.3.2 Move actuator to the $90^{\circ}$ ( -5 volt) position. 
7.3.3 Make one (1) sweep of 30 minute duration using the frequency and acceleration shown on Curve 1.

7.3.4 While sweep is in progress repeat Section 6.2.

7.3.5 After the sweep is finished, turn off vibration and repeat Sections 6.2 and 6.3

7.4 Test No. 5

7.4.I Turn off drive gas, coolant gas, and actuator amplifier.

7.4.2 Vibrate actuator at the resonant frequency or frequencies for 30 minutes each at $4.0 \mathrm{~g}$ acceleration.

7.5 Test No. 6

7.5.1 Turn on drive gas, coolant gas, and actuator amplifier.

7.5.2 Move actuator to $90^{\circ}$ ( -5 volt) position.

7.5.3 Vibrate actuator at its resonant frequency or frequencies for 10 minutes at the acceleration shown in Curve 1.

7.5.4 While vibrating the actuator repeat Section 6.2.

7.5.5 After vibrating the actuator repat Section 6.0 .

7.5.6 Turn off drive gas, coolant gas, and actuator amplifier.

8.0 Horizontal \#1 Direction (actuator mounted on vibration stand so that the direction of acceleration $\left(A_{y}\right)$ is parallel to the direction of piston travel).

8.1 Test No. 1

8.1.1 Mount actuator and secure marman clamp.

8.1.2 Make two (2) sweeps from $5 \mathrm{HZ}$ to $2000 \mathrm{HZ}$ to $5 \mathrm{HZ}$ at $1.0 \mathrm{~g}$ acceleration.

8.1.3 Each sweep shall be 3 minutes in duration. 
8.1.4 Record all acceleroneter voltages and frequency of vibration on the visicorder.

8.2 Test No. 2

8.2.1 With drive gas, coolant gas, and actuator amplifier still off make three (3) sweeps from $10 \mathrm{HZ}$ to $30 \mathrm{HZ}$ to $10 \mathrm{HZ}$.

8.2.2 Each sweep shall be 2 minutes in duration at $4.0 \mathrm{~g}$ acceleration.

8.2.3 Record all accelerometer voltages and frequency of vibration on the visicorder.

8.3 Test No. 4

8.3.1 Turn on drive gas, coolant gas, and actuator amplifier.

8.3.2 Move actuator to the $90^{\circ}$ ( -5 volt) position.

8.3.3 Make two (2) sweeps of 15 minute duration using the frequency and acceleration shown on Curve 2.

8.3.4 While sweep is in progress repeat Section 6.2.

8.3.5 After the sweep is finished turn off vibration and repeat Section 6.2 and 6.3 .

8.4 Test No. 5

8.4.1 Tum off drive gas, coolant gas, and actuator amplifier.

8.4.2 Vibrate the actuator at the resonant frequency or frequencies for 30 minutes at $4.0 \mathrm{~g}$ acceleration.

8.5 Test No. ?

8.5.1 Turn on drive gas, coolant gas, and actuator amplifier.

8.5.2 Move actuator to $90^{\circ}$ ( -5 volt ) position. 
8.5.3 Vibrate actuator at its resonant frequency or frequencies for 10 minutes at the acceleration shown in Curve 2.

8.5.4 While vibrating the actuator repeat section 6.2 .

8.5.5 After vibrating the actuator repeat section 6.0 .

8.5.6 Turn off drive gas, coolant gas, and actuator amplifier.

9.0 Horizontal \#2 Direction (actuator mounted on vibration stand so that the direction of acceleration $\left(A_{X}\right)$ is perpendicular to the direction of piston travel).

9.1 Test No. 1

9.1.1 Mount actuator and secure marman clamp.

9.1.2 Make two (2) sweeps from $5 \mathrm{HZ}$ to $2000 \mathrm{HZ}$ to $5 \mathrm{HZ}$ at $1.0 \mathrm{~g}$ acceleration.

9.1.3 Each sweep shall be 3 mimutes in duration.

9.1.4 Record all accelerometer voltages and frequency of vibration on the visicorder.

9.2 Test No. 2

9.2.1 With drive gas, coolant gas, and actuator ampliffer still off make three (3) sweeps from $10 \mathrm{HZ}$ to $30 \mathrm{HZ}$ to $10 \mathrm{HZ}$.

9.2.2 Each sweep shall be 2 minutes in duration and at $4.0 \mathrm{~g}$ acceleration.

9.2.3 Record all accelerometer voltages and frequency of vibration on the visicorder.

\subsection{Test No. 4}

9.3.1 Turn on drive gas, coolant gas, and actuator ampliffer. 
9.3.2 Move actuator to the $90^{\circ}$ ( -5 volt) position.

9.3.3 Make two (2) sweeps of 15 minutes duration using the frequency and acceleration shown on Curve 2.

9.3.4 While sweep is in progress repeat Section 6.2

9.3.5 After the sweep is finished turn off vibration and repeat Sections 6.2 and 6.3 .

\subsection{Test No. 5}

9.4.1 Turn off drive gas, coolant gas, and actuator amplifier.

9.4.2 Vibrate the actuator at the resonant frequency or frequencies for 30 minutes at $4.0 \mathrm{~g}$ acceleration.

\subsection{Test No. 7}

9.5.1 Turn on drive gas, coolant gas, and actuator amplifier.

9.5.2 Move actuator to $90^{\circ}$ ( -5 volt) position.

9.5.3 Vibrate actuator at its resonant frequency or frequencies for 10 mimutes at the acceleration shown in Curve 2.

9.5.4 While vibrating the actuator repeat Section 6.2 .

9.5.5 After vibrating the actuator repeat Section 6.0 .

9.5.6 Turn off drive gas, coolant gas, and actuator amplifier. 


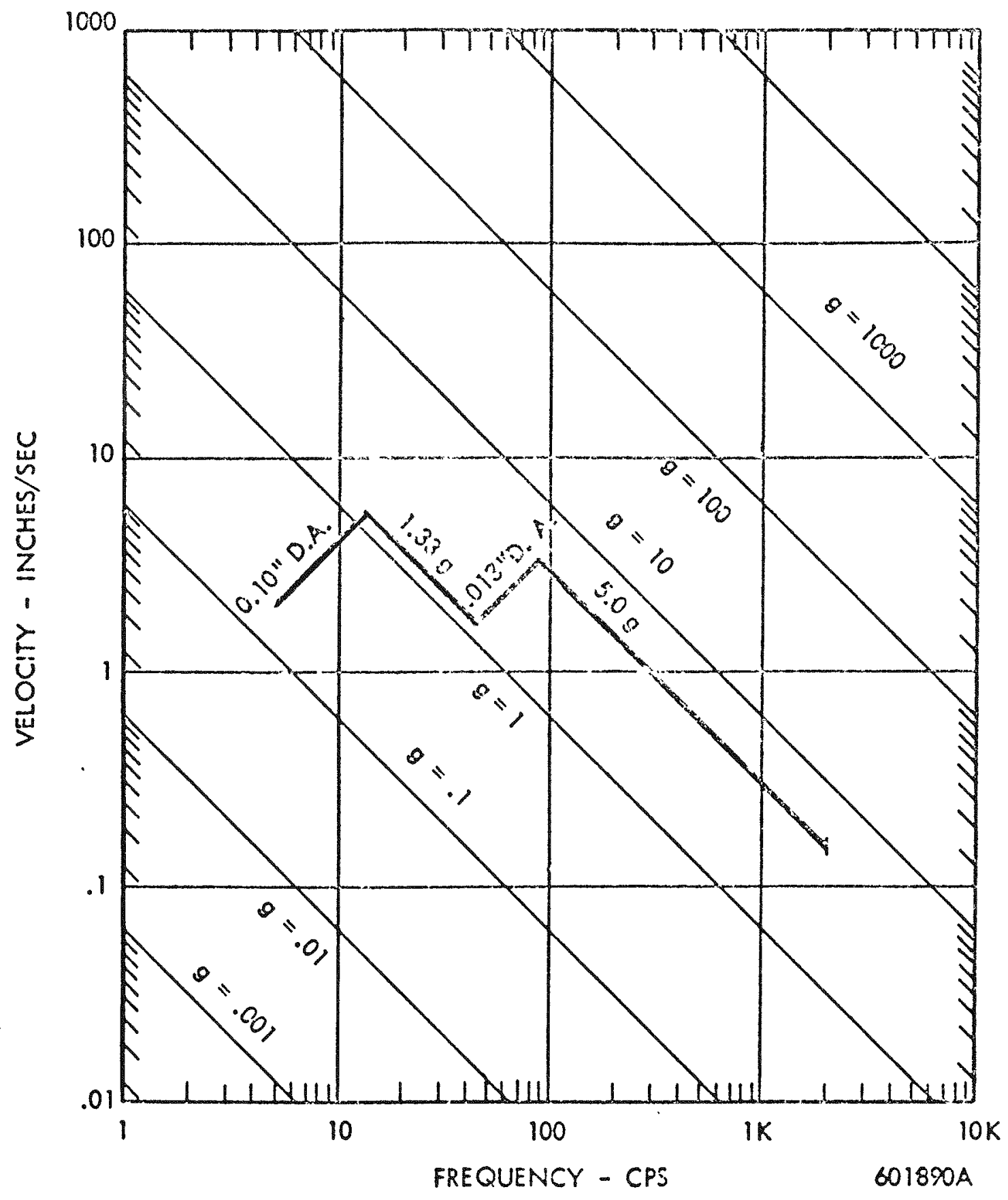

CURVE NO. I ANTICIPATED VIERATION ENVIRONMENT, NERVA XE-1; GROUND FIRING TEST, LONGITUDINAL PLANE.

NOTE: D. $A_{0}=$ DOUBLE AMFLITUDE 


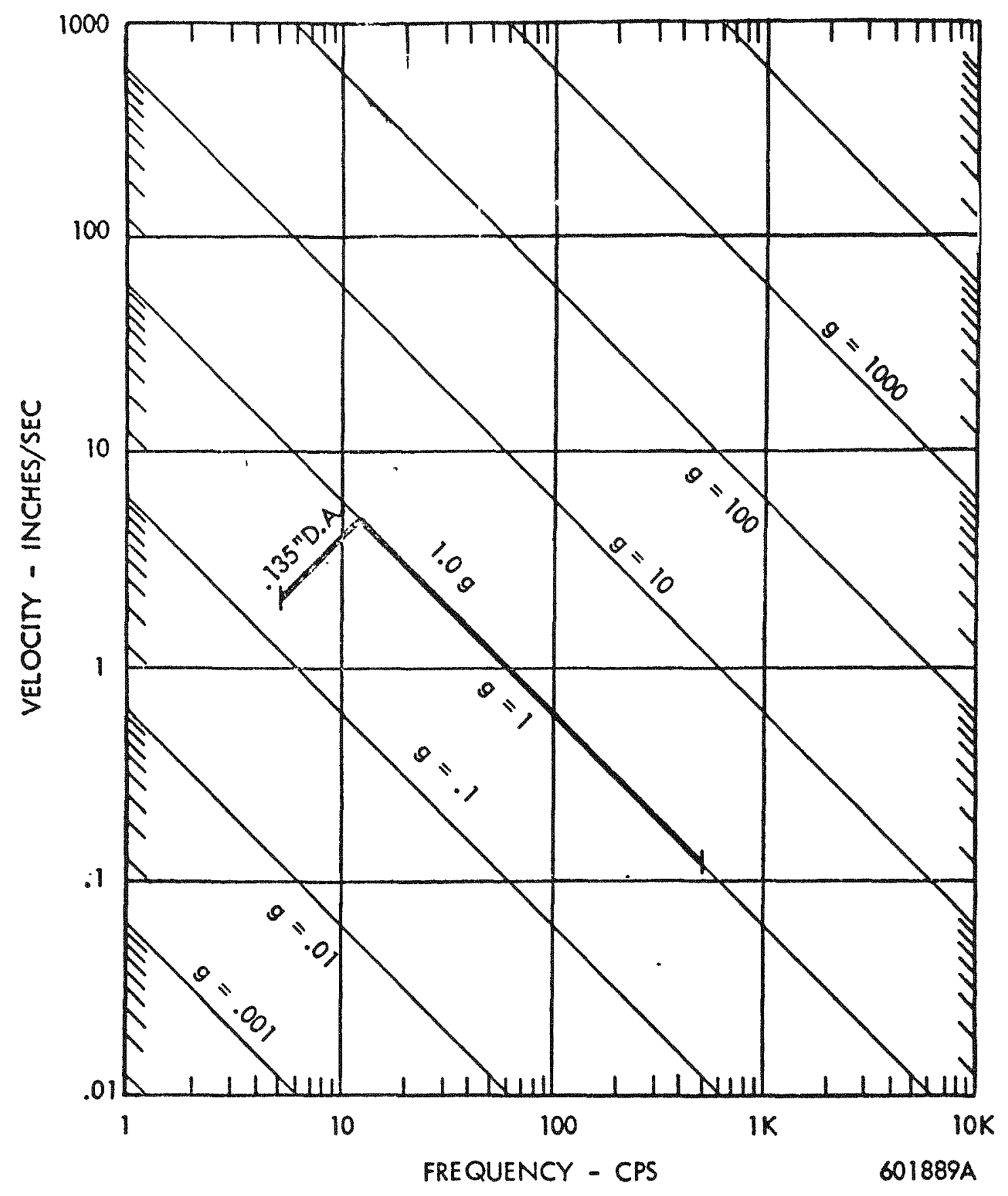

ANTICIPATED VIBRATION ENVIRONMENT NERVA XE-1;

GROUND FIRING TEST; LATERAL PLANE

Note: D.A. = Double Amplitude 


\section{QUALIFICATION TEST, MECHANICAL SHOCK}

TS-711892-B

\subsection{Introduction}

In this procedure the XE-1 Pneumatic Control Drum Actuator shall be tested to determine its qualification for mechanical shock as specifled in WANI-TME1040, Rev. A.

Before the application of any mechanical shock, the actuator shall be given a series of tests to establish the original perfomance of the actuator. The results of these tests shall be called the "Base Line Data".

The actuator shall then be given controlled shocks. After the shocks the actuator shall again be tested. The results of these tests shall be compared with the Base Line Data. If any gross deviation occurs between the pre-shock and the post-shock tests, the actuator shall be completely disassembled to determine the cause of the deviation.

\subsection{Material and Equipment Requirements}

2.1 Shock Test Load Stand

2.2 Shock Driver and Control System

2.3 Actuator Amplifier, XE-1

2.4 Visicorder, Honeywe11, Model 1508

2.5 Frequency Response Analyzer, I.M.C., Model 101

2.6 Function Generator, Hewlett Packard, Model 202

2.7 D.C. Power Supply, $+10 \mathrm{~V}, \pm 15 \mathrm{~V}, \pm 24 \mathrm{~V},+28 \mathrm{~V}$, Trygon, Model PS32-2.5

$2.8 X, Y, Y$, Recorder, Honeywell, Model $4-354$

2.9 Gage Balance Unit, Honeywell 
2.10 Accelerometers, Enderco

2.11 Data Amplifier, CEC, Type 155

2.12 Digital Voltmeter, Honeywell, Model 6305

2.13 Helium Drive Gas (ambient temperature, $200 \pm 5$ psig)

2.14 Nitrogen Coolant Gas (ambient temperature, $650 \pm 25$ psig)

\subsection{Parameters}

3.1 The parameters to be measured in this test are:

3.1.1 $P_{C}-$ coolant pressure

3.1.2 $P_{d}-$ drive pressure

3.1.3 $\mathrm{Pe}_{\mathrm{e}}-$ exhaust pressure

3.1.4 $\mathrm{P}_{1}$ - pressure in cylinder \#1

3.1.5 $\mathrm{P}_{2}$ - pressure in cylinder \#2

3.1.6 $\Delta P$ - differential pressure $\left(P_{1}-P_{2}\right)$

3.1.7 Q - d.c. demand voltage (angle)

3.1.8 $\Delta \theta_{\mathrm{d}}-$ a.c. demand voltage (angle)

3.1.9 $\theta_{0}-$ d.c. actuator drum position voltage (angle)

3.1.10 $\Delta \theta_{0}-$ a.c. actuator drum position voltage (angle)

3.1.11 $\theta_{e}-$ error voltage

3.1.12 $I_{1}$ - torque motor current

$3.1 .13 a_{c}-$ applied shock pulse

3.1.14 $a_{x}$ - acceleration perpendicular to piston travel

$3.1 .15 a_{y}$ - acceleration parallel to piston travel

$3.1 .16 \mathrm{a}_{\mathrm{z}}$ - acceleration parallel to output shaft 


\subsection{Transient Response for Amplifier Tuning}

4.1 Place actuator on shock load stand and secure marman clamp.

4.2 Turn on drive gas, coolant gas, and actuator amplifier.

4.3 Move actuator to $90^{\circ}$ ( -5 volt) position and apply a $100^{\circ}$ ( 5.55 volt p-p) square wave to the a.c. command $\left(\Delta Q_{d}\right)$.

4.4 Adjust the velocity limits if necessary to $100 \% / \mathrm{sec}$ ( \pm I volt at the rate output test point).

4.5 Change cormand input $\left(\Delta \Delta_{t}\right)$ to an $18^{\circ}(1.0$ volt p-p) square wave. 4.6 Adjust gain and lead controls if required to give a rise time of less than $.055 \mathrm{sec}$, a settling time of less than $0.15 \mathrm{sec}$, and an overshoot of less than $6^{\circ}$ (.333 volts).

4.7 Recheck velocity limits and repeat procedure if velocity limits must be changed.

4.8 Record gain and lead settings and relocity.

\subsection{Determination of Base Line Data}

5.1 Linearity and Static Resolution Check

5.1.1 Apply a $90^{\circ}(-5 \pm .001$ volt $)$ command $\left(\theta_{d}\right)$ and adjust amplifier offset pot for a position $\left(\theta_{0}\right)$ at $90^{\circ}(-5 \pm .001$ volt $)$.

5.1.2 Record command $\left(\theta_{d}\right)$ on X-axis of plotter ( 1 volt/in) and static error $\left(\theta_{\theta}\right)$ on $I$-axis (.0I rolt/in).

5.1.3 Move actuator cormand $\left(\theta_{d}\right)$ in $9^{\circ}(0.50$ volt $)$ increments from $9^{\circ}$ to $171^{\circ}$ ( 0.50 volt to 9.50 volt $)$ and record points when actuator assumes its rest position.

\subsection{Dynamic Resolution Check}

5.2.1 Return to $90^{\circ}$ position and apply a $3 \%$ sec ramp $(7.8$ volt at $0.01 \mathrm{HZ})$ to the dynamic command $\left(\Delta \theta_{\mathrm{d}}\right)$ input. 
5.2.2 Record $\Delta \theta_{\mathrm{d}}$ on $X$-axis of plotter $(1.0$ volt/in) and error $\left(\theta_{0}\right)$ on $Y^{\prime}$-axis $(.01$ rolt/inch $)$.

5.3 Transient Response Check

5.3.1 Return to $90^{\circ}$ position and apply an $18^{\circ}$ ( 1 volt $\left.p-p\right)$ square wave to $\theta_{d}$.

5.3.2 Record $\Delta \theta_{\mathrm{d}}$ and $\Delta \theta_{0}$ on the visicorder.

5.4 Scram Turnaround Check

5.4.1 Return to $90^{\circ}$ position and set the auto-scram control to scram the actuator when $\theta_{0} \geq 120^{\circ}(-6.66$ volt $)$ and apply

a $100^{\circ}(5.55$ volt $)$ square wave to $\Delta \theta_{\mathrm{d}}$.

5.4.2 Allow actuator to scram and record $\theta_{0}, I, P_{1}, P_{2}, \triangle P$, lock light, and unlock light on the visicorder

\subsection{Frequency Response Check}

5.5.1 Turn off auto-scram and reset scram relay.

5.5.2 Return actuator to $90^{\circ}$ position.

5.5.3 Apply the I.M.C. oscillator output to $\Delta \theta_{\mathrm{d}}$ and set for $4^{\circ}$ (.222 volt) $p-p$ sine wave.

5.5.4 Connect $\Delta \theta_{\mathrm{d}}$ to the eI input of the I.M.C. and $\Delta \theta_{0}$ to the $e_{2}$ input of the I.M.C.

5.5.5 Record frequency on the X-axis of the plotter, amplitude on the $Y-a x i s$, and phase on the $Y^{\prime}$ axis.

5.5.6 Run the frequency from $0.1 \mathrm{HZ}$ to $20 \mathrm{HZ}$ and obtain a plot of the closed loop frequency response of the actuator. 


\subsection{Shock Schedule}

6.1 Vertical direction (actuator mounted so that the direction of shock is parallel to the actuator drive shaft).

6.1.1 Mount actuator on load stand and secure marman clamp.

6.1.2 Turn on drive gas, coolant gas, and actuator amplifier.

6.1.3 Move actuator to $90^{\circ}$ drum position.

6.1.4 Apply 2 3\%/sec ramp (7.8 rolt p-p @ 0.01 HZ) to the dynamic comand $\left(\Delta \theta_{\mathrm{d}}\right)$.

6.1.5 Apply 3 shocks at $+2.0 \mathrm{~g}$ with a 0.01 sec shock duration.

6.1.6 Apply 3 shocks at $-2.0 \mathrm{~g}$ with a 0.01 sec shock duration.

6.1.7 During a.11 6 shocks record $\Delta 0_{\mathrm{d}}, \Delta \theta_{0}, \mathrm{II}, \mathrm{P}_{1}, \mathrm{P}, \Delta \mathrm{P}$, applied shock, pulse, $a_{x}, a_{y}$, and $a_{z}$.

6.1.8 Remove 3\% sec ramp and repeat Section 5.0. (Determination of Base Line Data).

6.1.9 Turn off drive gas, coolant gas, and actuator amplifier.

6.2 Horizontal \#1 Direction (actuator mounted so that the direction of shock is parallel to the direction of piston travel.

6.2.1 Mount actuator on load stand and secure the marman clamp.

6.2.2 Turn on drive gas, coolant gas, and actuator amplifier.

6.2.3 Move actuator to $90^{\circ}$ drun position.

6.2 .4 Apply a $3 \%$ sec ramp (7.8 volt $p-p @ 0.01 \mathrm{HZ})$ to the dymamic conmand $\left(\Delta \theta_{\mathrm{d}}\right)$.

6.2.5 Apply 3 shocks at +1.0 with a 0.01 sec shock duration.

6.2.6 Apply 3 shocks at $-1.0 \mathrm{~g}$ with a 0.01 sec shock duration.

6.2.7 During all 6 shocks record $\Delta \theta_{d}, \Delta \theta_{0}, I, P, P 2, \Delta P$, applied shock, pulse, $a_{x}, a_{y}$, and $a_{z}$. 
6.2.8 Remore 3\% sec ramp and repeat Section 5.0 (Determiration of Base Line Data).

6.2.9 Turn off drive gas, coolant gas, and actuator amplifier.

6.3 Horizontal \#2 Direction (actuator mounted so that the direction of shock is perpendicular to the direction of piston travel.

6.3.1 Mount actuator on load stand and secure the marman clamp.

6.3.2 Turn on drive gas, coolant gas, and actuator amplifier.

6.3.3 Move actuator to $90^{\circ}$ drum position.

6.3.4 Apply a $3 \%$ sec ramp $(7.8$ volt p-p @ $0.01 \mathrm{HZ})$ to the dynamic command $\left(\Delta \theta_{\mathrm{d}}\right)$.

6.3.5 Apply 3 shocks at +1.08 with a 0.01 sec shock duration.

6.3.6 Apply 3 shocks at $-1.0 \mathrm{~g}$ with a 0.01 sec shock duration.

6.3.7 During al1 6 shocks record $\Delta \theta_{\mathrm{d}}, \Delta \theta_{0}, I_{1}, P_{1}, P_{2}, \Delta P_{1}$ applied shock pulse, $a_{x}, a_{z}$, and $a_{y}$

6.3.8 Remove $3 \%$ sec ramp and repeat Section 5.0 (Determination of Base Line Data).

6.3.9 Turn off drive gas, coolant gas, and actuator amplifier. 


\section{QUALIFICATION TEST, THERMAL}

\section{TS-711892-C}

\subsection{Introduction}

In this procedure the methods for testing the XE-1 Pneumatic Control Drum Actuator in a controlled thermal environment shall be outlined. The actuator, with its amplifier shall sirst be tuned at ambient temperatures. A series of tests shall then be run to determine the performance of the actuator. The results of these tests shall determine the Base line Data for the actuator under test.

The actuator shall then be cooled to the specified temperatures using cold drive and coolant gas and the tests shall be repeated. By comparing the results of the cold tests with the Base Iine Data the qualification shall be determined as specified in WANL-TME-1040, Rev. A.

Should the actuator fail to qualify in any way which grossly affects its performance the actuator shall be disassembled to determine the cause of the fallure.

2.0 Material and Equipment Requirements

2.I Actuator Amplifier, XE-I

2.2 Visicorder, Honeywell, Model 1508

2.3 Frequency Response Analyzer, I.M.C., Model 101

2.4 Function Generator, Hewlett Packard, Model 202

2.5 D.C. Power Supply ( $+10 \mathrm{~V}, \pm 15 \mathrm{~V}, \pm 24 \mathrm{~V},+28 \mathrm{~V})$, Trygon Model PS $32-2.5$

2.6 X,Y,I' Recorder, Honegwell, Model 480

2.7 Pressure Transducers, C.E.C., Model $4-354$ 
2.8 Gage Balance Unit, Honegwell

2.9 Data Amplifiers, C.E.C., Type 155

2.10 Digital Voltmeter, Honeywell, Model 6305

2.11 Thermocouples, Copper/Constantan

2.12 Thermocouple Reference Junction, Pace Model BRJ14-18TP-1182

2.13 Helium Drive Gas (200 \pm 5 psig, controlled temperature)

2.14 Hydrogen Drive Gas (200 \pm 5 psig, controlled temperature)

2.15 Hydrogen Coolant Gas (650 \pm 25 psig, controlled temperature)

2.16 Nitrogen Coolant Gas (650 \pm 25 psig, controlled temperature)

2.17 Heat Exchangers

\subsection{Parameters}

3.1 The parameters to be measured in this test are:

3.1.1 $P_{c}-$ coolant pressure

3.1.2 $P_{d}-$ drive pressure

3.1.3 $\mathrm{Pe}_{e}-$ exhaust pressure

3.1.4 $P_{1}$ - cylinder \#I pressure

3.1.5 $\mathrm{P}_{2}$ - cylinder \#2 pressure

3.1.6 $\Delta P$ - differential pressure $\left(P_{1}-P_{2}\right)$

3.1.7 $\mathrm{T}_{\mathrm{C}}$ - coolant temperature

3.1.8 $\mathrm{T}_{\mathrm{d}}$ - drive temperature

3.1.9 $\mathrm{Te}$ - exhaust temperature

3.1.10 $\mathrm{T}_{1}$ - potentiometer case temperature

3.1.11 $\mathrm{T}_{2}$ - actuator housing temperature

$3.1 .12 \theta_{d}-d . c$. demand voltage (angle)

3.1.13 $\Delta \theta_{\mathrm{d}}-$ a.c. demand voltage (angle) 
$3.1 .14 \theta_{\mathrm{d}}$ - actuator position roltage (angle)

3.1.15 $\Delta \theta_{0}-$ a.c. actuator position centered about $\theta_{0}\left(\theta_{0}-\theta_{d}\right)$

$3.1 .16 \theta_{e}$ - error voltage (angle) $\left(\theta_{0}-\theta_{d}-\theta_{d}\right)$

3.1.17 $I_{1}$ - torque motor current

$3.1 .18 V_{r}$ - rate stage output

3.1.19 Lock Light Voltage

3.1.20 Unlock Light Voltage

4.0 Determination of Base Line Data

4.I Linearity and Static Resolution Check

4.1.1 Apply a $90^{\circ}(-5 \pm .001$ volt $)$ command $\left(\theta_{d}\right)$ and adjust the amplifier of fset pot for a position $\left(\theta_{0}\right)$ of $90^{\circ}(-5 \pm .001$ volt $)$.

4.1.2 Record command $\left(\theta_{d}\right)$ on $X$-axis of plotter ( 1 rolt/in) and static error $\left(\theta_{\theta}\right)$ on I-axis (.I rolt/in).

4.1.3 Move actuator command $\left(\theta_{d}\right)$ in $90 n(.5$ volt $)$ increments from $9^{\circ}$ to $171^{\circ}$ (.5 rolt to 9.5 rolt) and record points when actuator assumes its rest position.

4.2 Dynamic Resolution Check

4.2.1 Return to $90^{\circ}$ position and apply a $3 \% / \mathrm{sec}$ ramp $(7.8$ volt (3) .01 HZ) to the dynamic comand $\left(\Delta \theta_{d}\right)$ input.

4.2.2. Record $\Delta \theta_{\mathrm{d}}$ on $\mathrm{X}$-axds of plotter $(1.0$ volt $/ \mathrm{in})$ and error $\left(\theta_{e}\right)$ on $Y^{\prime}$-axis (.01 volt/in).

\subsection{Transient Response Check}

4.3.I Return to $90^{\circ}$ position and apply an $18^{\circ}$ ( 1 volt $p-p$ ) square wave to $\Delta \theta_{\mathrm{d}}$. 
4.3.2 Record $\Delta \theta_{\mathrm{d}}$ and $\Delta \theta_{0}$ on the visicorder.

4.4 Scram Turnaround Check

4.4.I Return to $90^{\circ}$ position and set the auto-scram control to scram the actuator when $\theta_{0} \geq 120^{\circ}(-6.66$ volt $)$ and apply a $100^{\circ}$ $\left(5.55\right.$ volt) square wave to $\Delta \theta_{d}$.

4.4.2 Allow actuator to scram and record $\theta_{0}, I, P_{1}, P_{2}, \Delta P$, lock light, and unlock light on the visicorder.

\subsection{Frequency Response Check}

4.5.1 Turn off auto scram and reset scram relay.

4.5.2 Return actuator to $90^{\circ}$ position.

4.5.3 Apply the I.M.C. oscillator output to dynamic comand $\left(\Delta \theta_{d}\right)$ and set for $4^{\circ}(.222$ volt $) \mathrm{p}-\mathrm{p}$ sine wave.

4.5.4 Connect $\Delta \theta_{\mathrm{d}}$ to the e $\mathrm{I}$ input of the I.M.C. and $\Delta \theta_{0}$ to the e2 input of the I.M.C.

4.5.5 Record frequdncy on the $X$-axis, amplitude on the $Y$-axis, and phase on the $\mathrm{Y}^{1}$-axis of the plotter.

4.5.6 Run the frequency from $0.1 \mathrm{HZ}$ to $20 \mathrm{HZ}$ and obtain a plot at the closed loop frequency response of the actuator.

\subsection{Thermal Cycle Schedule}

5.1 Run \#I $\left(150^{\circ} \mathrm{R}\right)$

5.1.1 Supply the actuator with ambient drive and coolant gas.

5.1.2 Unlock the drum and set manual command $\left(\theta_{\mathrm{d}}\right)$ to $-5 \pm .001$ volt $\left(90^{\circ}\right)$

5.1.3 Adjust the amplifier trim to obtain $-5 \pm .001$ volt on position $\left(\theta_{0}\right)$ buffer amplifier. 
5.1.4 Set velocity limits to $100 \% / \mathrm{sec}$ ( \pm I volt on output of rate stage) with a $100^{\circ}$ step comand on $\Delta \theta_{\mathrm{d}}$.

5.1.5 Set gain and lead controls for optimum step response.

5.1.6 Perform Section 4.0 to determine the Base Line Data

5.1.7 Start thermal cycles

5.1.7.1 For the first and third cycle the actuator shall be operated with a $100^{\circ}$ ramp input $\left(\Delta \theta_{d}\right)$ during cooldown.

5.1.7.2 Allow drive and coolant gas to cool to $150 \pm 25^{\circ} \mathrm{R}$.

5.1.7.3 Record temperatures and pressures on visicorder and perform Section 4.2 during cooldown.

5.1.7.4 When actuator temperatures have stabilized perform Section 4.0 .

5.1.7.5 After completion of Section 4.0 warm drive and coolant gas to ambient and record warm up wile performing Section 4.2.

5.1.7.6 For the second the fourth cycle the actuator shall be locked at the $15^{\circ}$ position with the amplifier turned off.

5.1.7.7 Allow drive and coolant gas to cool to $150 \pm 25^{\circ} \mathrm{R}$.

5.1.7.8 Record temperatures and pressures on visicorder.

5.1.7.9 When actuator temperatures have stablizized perform Section 4.0 .

5.1.7.10 After completion of Section 4.0 warm drive and coolant gas to ambient and record warm up with actuator locked at $15^{\circ}$ position. 
5.1.7.11 Four cycles will be completed by performing all of Section 5.1.7 twice.

\subsection{Run \#2 $\left(50^{\circ} \mathrm{R}\right)$}

5.2.1 Supply the actuator with ambient drive and coolant gas.

5.2.2 Unlock the drum and set mamual command $\left(\theta_{\mathrm{d}}\right)$ to -5

\pm .001 volt $\left(90^{\circ}\right)$

5.2.3 Adjust the amplifier trim to obtain $-5 \pm .001$ volt on position $\left(\theta_{0}\right)$ buffer amplifier.

5.2 .4 Set velocity limits to $100 \% / \mathrm{sec}$ ( $\pm I$ volt on output of rate stage) with a $100^{\circ}$ step command on $\Delta \theta_{d}$.

5.2.5 Set gain and lead controls for optimum step response.

5.2.6 Perform Section 4.0 to determine the Base Line Data.

5.2.7 Start thermal cycles.

5.2.7.1 For the first and third cycle the actuator shall be operated with a $100^{\circ}$ ramp input $\left(\Delta \theta_{\mathrm{d}}\right)$ during cooldown.

5.2.7.2 Allow drive and coolant gas to cool to $50 \pm 25^{\circ} \mathrm{R}$.

5.2.7.3 Record temperatures and pressures on visicorder and perform Section 4.2 during cooldown.

5.2.7.4 When actuator temperatures have stabilized perform Section 4.0

5.2.7.5 After completion of Section 4.0 warm drive and coolant gas to ambient and record warm up while performing Section 4.2 .

5.2.7.6 For the second and fourth cycle the actuator shall be locked at the $15^{\circ}$ position with the amplifier turned off. 
5.2.7.7 Allow drive and coolant gas to cool to $50 \pm 25^{\circ} \mathrm{R}$. 5.2.7.8 Record temperatures and pressures on visicorder.

5.2.7.9 When actuator temperatures have stabilized perform Section 4.0 .

5.2.7.10 After completion of Section 4.0 warm drive and coolant gas to amblent and record warm up with actuator locked at $15^{\circ}$ position.

5.2.7.11 Four cycles will be completed by performing all of Section 5.2 .7 twice. 


\section{QUALIFICATION TEST, LIFE}

$\underline{\text { TS-711892-D }}$

\subsection{Introduction}

This procedure outlines the methods to be used to test the XE-I Pnewmatic Control Drum Actuator for its life qualification as specified in WANI-TME-1040, Rev. A. The actuator shall be mounted on its laad stand and a set of "Base line Data" shall be recorded to determine the performance of the actuator. The actuator shall then be cycled with various input signals for 150 hours contimuous. After 150 hours of operation the actuator shall again be tested for performance and the results compared with the "Base Line Data" to determine its qualification.

In the second phase of the test the actuator shall be operated at a low temperature, vibrated in the vertical plane, and given various inputs for one hour. After this test the performance of the actuator shall again be tested to determine its qualification.

\subsection{Material and Equipment Requirements}

2.1 Actuator Amplifier, XE-1

2.2 Visicorder, Honeywell, Model 1508

2.3 Frequency Response Analyzer, I.M.C., Model 101

2.4 Function Generator, Hewlett Packard, Model 202

2.5 D.C. Power Supply ( $+10 \mathrm{~V}, \pm 15 \mathrm{~V}, \pm 24 \mathrm{~V},+28 \mathrm{~V})$, Trygon Model PS32-2.5

$2.6 X, Y, Y^{\prime}$ Recorder, Honeywell Model 480

2.7 Pressure Transducers, C.E.C. Model 4-354

2.8 Gage Balance Unit, Honeywell

2.9 Data Amplifiers, C.E.C. 155

2.10 Digital Voltmeter, Honeywell, Model 6305 
2.11 Thermocouples, Copper/Constantan

2.12 Thermocoupel Reference Junction, Pace Model BRJ14-18TP-1182

2.13 Drive Gas, Helium, $200 \pm 5$ psig, controlled temperature

2.14 Coolant Gas, Nitrogen, 650 - 25 psig, controlled temperature

2.15 Vibration Controller and Driver

2.16 Accelerometers, Endevco

2.17 Heat Exchangers

2.18 Elapsed Time Meter

\subsection{Parameters}

3.1 The parameters to be measured in this test are:

3.1.1 $\quad P_{C} \quad-\quad$ coolant pressure

3.1.2 $P_{d} \quad-$ drive pressure

3.1.3 $\mathrm{P}_{\mathrm{e}} \quad-\quad$ exhaust pressure

3.1.4 $P_{1}$ - cylinder \#1 pressure

3.1.5 $\quad \mathrm{P}_{2} \quad-\quad$ cylinder \#2 pressure

3.1.6 $\triangle P$ - differential pressure $\left(P_{1}-P_{2}\right)$

3.1.7 $T_{c} \quad-$ coolant temperature

3.1.8 $\mathrm{T}_{\mathrm{d}}-$ drive temperature

3.1.9 $\mathrm{T}_{\mathrm{e}} \quad-$ exhaust temperature

3.1.10 $T_{1}$ - potentiometer case temperature

3.1.11 $\quad \mathrm{T}_{2} \quad$ - actuator housing temperature

$3.1 .12 \theta_{\mathrm{d}}-\mathrm{d} . c$. demand voltage (angle)

3.1.13 $\Delta \theta_{\mathrm{d}}-$ a.c. demand voltage (angle)

3.1.14 $\theta_{\mathrm{d}}-$ actuator position voltage (angle)

3.1.15 $\Delta \theta_{0}-$ a.c. actuator position centered about $\theta_{0}\left(\theta_{0}-\theta_{d}\right)$ 
$3.1 .16 \theta_{c}-$ error roltage (angle) $\left(\theta_{0}-\theta_{d}-\Delta \theta_{d}\right)$

3.1.17 $I_{1}$ - torque motor current

3.1.18 $\nabla_{R}$ - rate stage output

3.1.19 Lock light voltage

3.1.20 Unlock light voltage

3.1.21 Elapsed TIme

\subsection{Determination of Base Line Data}

4.1 Linearity and Static Resolution Check

4.1.1 Apply a $90^{\circ}(-5 \pm .001$ volt $)$ command $\left(\theta_{d}\right)$ and adjust the amplifier offset pot for a position $\left(\theta_{0}\right)$ of $90^{\circ}$ $(-5 \pm .001$ volt $)$.

4.1.2 Rocord command $\left(\theta_{d}\right)$ on X-axds of plotter ( $I$ volt $/ 1$ nch) and static error $\left(\theta_{e}\right)$ on I-ards (.01 rolt/inch).

4.1.3 Move actuator command $\left(\theta_{d}\right)$ in $9^{\circ}(0.5$ volt) increments from $9^{\circ}$ to $171^{\circ}$ (.5 volt to 9.5 volt $)$ and rocord points when actuator assumes its rest position.

4.2 Dynamic Resolution Check

4.2.1 Return to $90^{\circ}$ position and apply a $3 \% / \mathrm{sec}$ ramp (7.8 rolt p-p at .01 $\mathrm{HZ})$ to the dynamic comand $\left(\Delta \theta_{\mathrm{d}}\right)$ input.

4.2.2 Record $\Delta \theta_{d}$ on $X$-axis of plotter ( $1.0 \mathrm{rolt} / \mathrm{inch}$ ) and error $\left(\theta_{e}\right)$ on $Y$-axis (.0l rolt/inch).

4.3 Transient Response Check

4.3.1 Return to $90^{\circ}$ position and apply an $18^{\circ}$ ( 1 rolt p-p) square wave to $\Delta \theta_{d}$. 
4.3.2 Record $\Delta \theta_{\mathrm{d}}$ and $\Delta \theta_{0}$ on the visicorder.

4.4. Scran Turnaround Check

4.4.1 Return to $90^{\circ}$ position and set the auto-scram control to scram the actuator when $\theta_{0} \geq 120^{\circ}(-6.66$ volt $)$ and apply a $100^{\circ}$ ( 5.55 volt) square wre to $\Delta \theta_{\mathrm{d}}$.

4.4.2 Allow actuator to scram and record $\theta_{0}, I_{1}, P_{1}, P_{2}, \Delta P$, lock light, and unlock light on the visicorder.

4.5 Frequency Response Check

4.5.1 Turn off auto-scram and reset scram relay.

4.5.2 Apply the I.M.C. oscillator output to dynamic command $\left(\Delta \theta_{\mathrm{d}}\right)$ and set for $4^{\circ}$ (.222 rolt) peak to peak sine wave.

4.5.3 Connect $\Delta \theta_{\mathrm{d}}$ to the e input of the I.M.C. and $\Delta \theta_{0}$ to the e input of the I.M.C.

4.5.4 Record frequency on the X-axis, amplitude on the I-axis, and phase on the $Y^{I}$-axis of the plotter.

4.5.5 Run the frequency from $0.1 \mathrm{HZ}$ to $20 \mathrm{HZ}$ and obtain a plot of the closed loop frequency response of the actuator.

\subsection{Iife Test Schedule}

5.1 Mount actuator on load stand and secure marman clamp.

5.2 Tum on helium drive and nitrogen coolant gas and the actuator amplifier.

5.3 Position the actuator at $90^{\circ}(-5 \pm .001$ volt $)$ and set velocity limits to $100 \%$ second using a $100^{\circ}(5.55$ rolt $)$ step input.

5.4 Set gain and lead dials of amplifier for best transient response to an $18^{\circ}$ ( 1 volt) step input. 
5.5 Perform Section 4.0 to obtain the "Base Itine Data".

5.6 Change helium drive gas to nitrogen and operate the actuator with the following inputs for the time perlod glven.

5.6 .1 Sine War $-6 \mathrm{~Hz}-4^{\circ} \mathrm{p}-\mathrm{p}(.222 \mathrm{rolt})-5 \mathrm{~min}$.

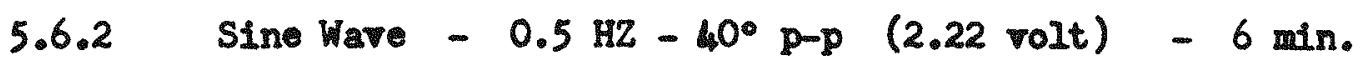
5.6 .3 Ramp $-0.01 \mathrm{HZ}-3 \%$ sac $(7.80$ volt $\mathrm{p}-\mathrm{p})-20 \mathrm{~min}$. $5.6 .4 \quad$ step $\quad-0.1 \mathrm{HZ}-18^{\circ} \mathrm{pmp}(1.00$ rolt ) $-10 \mathrm{~min}$. 5.6 .5 Dwell at $90^{\circ} \quad 10 \mathrm{~min}$. 5.6.6 After the each of the five periods (5.6.1 to 5.6.5) mentioned above scram, lock, and reset the actuator to the $90^{\circ}$ position.

5.7 After ach 25 hour period change the drive gas from nitrogen to helium and obtain a frequency response as detailed in Section 4.5. 5.8 After 150 hours repeat Section 4.0 to determine the performance of the actuator.

\subsection{Combined Low Tamperature and Vibration Test Schedule}

6.1 Mount actustor on load stand and secure marman clamp.

6.2 Turn on ambient drive and coolant gas and the actuator amplifier.

6.3 Position the actuator to $90^{\circ}$ and set velocity 1 imits to $100 \% / \mathrm{sec}$ using $\& 100^{\circ}(5.55$ rolt $)$ stop input.

6.4 Set gain and lead dials of amplifier for best transient responso to an $18^{\circ}$ ( 1 volt) step input.

6.5 Perform Section 4.0 to obtain tee "Base Line Data".

6.6 Lower temperature of drive and coolant gas to $140^{\circ} \mathrm{R} \pm 10^{\circ} \mathrm{R}$ and allow the actuator housing to stabilize. 
6.7 After a constant temperature is achieved start the vibration of the actuator as detalled in Curve I.

6.8 A complete cycle, both up and down in frequency shall la st fifteen minutes.

6.9 During each successive cycle the actuator input shall be: 6.9.1 Ramp, .01 HZ, $3 \%$ sec $(7.8$ volt) for first vibration cycle. 6.9.2 Step, .I HZ, $18^{\circ} \mathrm{p}-\mathrm{p}$ ( 1 rolt) for second vibration cycle. 6.9.3 Dwell at $90^{\circ}$ position for third vibration cycle. 6.9.4 Sine wave, $6 \mathrm{HZ}, 4^{\circ} \mathrm{p}-\mathrm{p}(.222$ rolt $)$ for fourth vibration cycle.

6.10 After vibration and while the actuator is still at $395^{\circ} \pm 10^{\circ} \mathrm{R}$ repeat Section 4.0 to determine the performance of the actuator. 


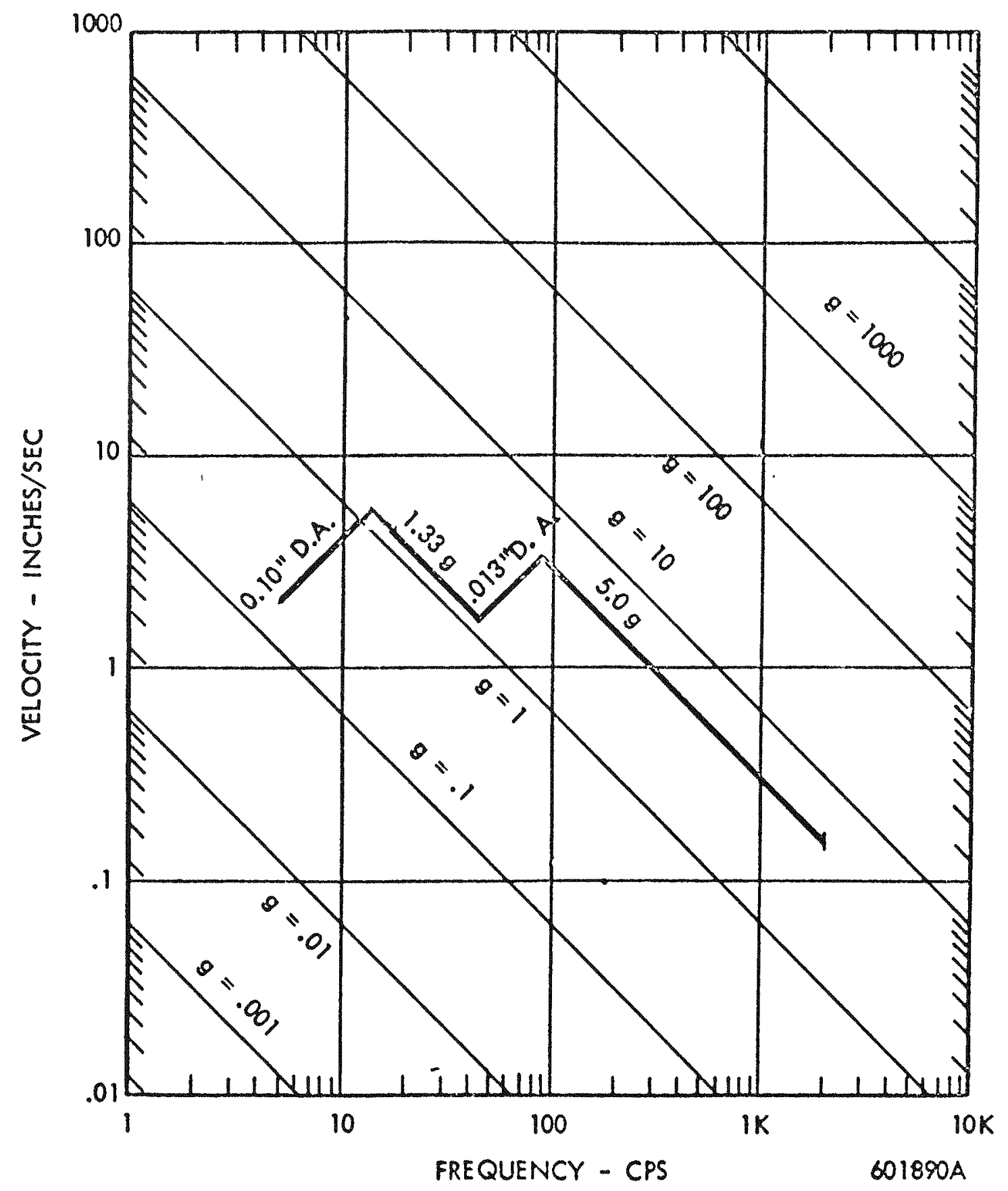

CURVE NO. I ANTICIPATED VIDRATION ENVIRONMENT, NERVA XE-1; GROUND FIRING TEST, LONGITUDINAL PLANE.

NOTE: D. A. = DOUBLE AMPLITUDE 